\title{
Unravelling molecular and biochemical dysfunction by Shiga toxin: implication for thrombotic microangiopathy in Hemolytic Uremic Syndrome
}

Citation for published version (APA):

Morigi, M. (2006). Unravelling molecular and biochemical dysfunction by Shiga toxin: implication for thrombotic microangiopathy in Hemolytic Uremic Syndrome. [Doctoral Thesis, Maastricht University]. Universiteit Maastricht. https://doi.org/10.26481/dis.20060316mm

Document status and date:

Published: 01/01/2006

DOI:

10.26481/dis.20060316mm

Document Version:

Publisher's PDF, also known as Version of record

Please check the document version of this publication:

- A submitted manuscript is the version of the article upon submission and before peer-review. There can be important differences between the submitted version and the official published version of record.

People interested in the research are advised to contact the author for the final version of the publication, or visit the DOI to the publisher's website.

- The final author version and the galley proof are versions of the publication after peer review.

- The final published version features the final layout of the paper including the volume, issue and page numbers.

Link to publication

\footnotetext{
General rights rights.

- You may freely distribute the URL identifying the publication in the public portal. please follow below link for the End User Agreement:

www.umlib.nl/taverne-license

Take down policy

If you believe that this document breaches copyright please contact us at:

repository@maastrichtuniversity.nl

providing details and we will investigate your claim.
}

Copyright and moral rights for the publications made accessible in the public portal are retained by the authors and/or other copyright owners and it is a condition of accessing publications that users recognise and abide by the legal requirements associated with these

- Users may download and print one copy of any publication from the public portal for the purpose of private study or research.

- You may not further distribute the material or use it for any profit-making activity or commercial gain

If the publication is distributed under the terms of Article 25fa of the Dutch Copyright Act, indicated by the "Taverne" license above, 


\section{Unravelling molecular and biochemical dysfunction by Shiga toxin: implication for thrombotic microangiopathy in Hemolytic Uremic Syndrome}


Unravelling molecular and biochemical dysfunction by Shiga toxin: implication for thrombotic microangiopathy in Hemolytic Uremic Syndrome

\author{
PROEFSCHRIFT \\ ter verkrijging van de graad van doctor \\ aan de Universiteit Maastricht, \\ op gezag van de Rector Magnificus, \\ Prof. mr. G.P.M.F. Mols, \\ volgens het besluit van het College van Decanen, \\ in het openbaar te verdedigen \\ op donderdag 16 Maart 2006 om 14.00 uur
}

door

\title{
Marina Morigi
}

geboren op 30 Augustus 1961 te Ravenna, Italie 


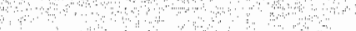


Supervisors

Prof.dr. G. Remuzzi, Bergamo

Jrof.dr. K.M.L. Leunissen

Beoordelingscommissie

Prof.dr. J.Rosing, (voorzitter)

Prof.dr. R. Donckerwolcke

Dr. K. Hamulyak

Prof.dr. L. Monnens, UMC St. Radboud

Prof.dr. G. J. Navis, UCM Groningen 

To: Arturo, Francesco, and Matteo 



\section{CONTENTS}

Chapter 1: Introduction and objectives of the thesis

Chapter 2: The role of the endothelium in Hemolytic Uremic Syndrome. J Nephrol 2001; 14: S58-62

Chapter 3: Verotoxin-1 promotes leukocyte adhesion to cultured endothelial cells under physialogic flow conditions.

Blood 1995; 86: 4553-4558

Chapter 4: Shiga toxin-2 triggers endothelial leukocyte adhesion and transmigration via NF-kB dependent up-regulation of IL-8 and MCP-1.

Kidney Int 2002; 62: 846-856

Chapter 5: Verotoxin-1 - induced up-regulation of adhesive molecules renders microvascular endothelial cells thrombogenic at high shear stress.

Blood 2001; 98:1828-1835

Chapter 6: In response to protein load podocytes reorganize cytoskeleton and modulate ET-1 gene: implication for permselective dysfunction of chronic nephropathies.

Am J Pathol 2005; 166: 1309-1320

Chapter 7: Shiga toxin-2 up-regulates endothelin-1 gene in glomerular podocytes and promotes cytoskeletal dysfunction: implications for glomerular ischemia and hemodynamic changes of HUS. Am J Pathol 2006; manuscript in submission

Chapter 8: General Discussion

Chapter 9: Summary

Curriculum vitae 
CHAPTER 1

\section{INTRODUCTION}

In part published in :The role of the endothelium in Hemolytic Uremic Sindrome.

C. Zoja, M. Morigi, G. Remuzzi.

J Nephrol 2001: 14: S58-S62. 


\section{INTRODUCTION}

Hemolytic uremic syndrome (HUS) is a disease of non-immune microangiopathic hemolytic anemia, thrombocytopenia and acute renal failure that mainly affects infants and small children. The characteristic lesion, thrombotic microangiopathy, is unique to this syndrome and consists of vessel wall thickening, with swelling and detachment of endothelial cells from the basement membrane, accumulation of fluffy material in the subendothelium and platelet thrombi in the microcirculation of the kidney and other organs [1-3]. In its typical presentation, HUS manifests as an acute disease; with gastrointestinal or respiratory tract prodromes, that recovers without sequelae in 80 to $90 \%$ of cases, either spontaneously (as in most cases of childhood HUS) or following plasma infusion or exchange (as in adult or severe forms of HUS). Typical HUS is triggered by environmental factors, drugs or infective agents such as Shiga toxin-producing E.coli; systemic immune disorders or cancer may also cause the disease [1, 2]. These forms of HUS may subside when the underlying condition has been treated or removed. However, there are rare forms, often occurring in families, which frequently relapse even after complete recovery of the presenting episode, with death or permanent neurological or renal sequelae being the final outcome in the large majority of cases. These atypical forms are considered to be supported by a genetic background which predispose to microvascular thrombosis. Both autosomal recessive and autosomal dominant mode of inheritance have been recognized, with precipitating events such as pregnancy, virus-like disease or sepsis being identified in some but not in all series.

\section{Shiga toxin as fosterer of HUS}

In $90 \%$ of cases of typical diarrhea-associated $\left(D^{+}\right)$HUS in children, infection with E.coli producing a verotoxin (VT) also termed Shiga toxin (Stx) has been strongly implicated as the most common causative agent of this disease $[1,4-6]$. More than $100 \mathrm{E}$. coli serotypes have been found to produce Stx, but only few of them have been involved in human disease. The serotype 0157:H7 is the most common pathogen in the United States and 
Europe, but other strains, particularly the 0111:H-serotype, are frequently reported in other areas of the world [7]. Infection by Stx-producing Shighella dysenferia serotype 1 has been commonly linked to Stx-HUS in developing countries of Asia [8] and Africa [9], but rarely in industrialized countries [10]. Of note, E. coli 0157: H7 strains that are isolated from patients with HUS, usually produced both $S t x-1$ and 2 . It is estimated that following exposition to E.coli $\mathrm{O} 157: \mathrm{H} 7,38 \%$ to $61 \%$ of persons develop hemorrhagic colitis, and $2 \%$ to $7 \%$ of these patients progress to overt HUS. The reservoir of E. coli $0157: H 7$ is the gastrointestinal tract of the domestic animals. The microorganism is transmitted to person by ingestion of contaminated food or water/water-borne, directly from person to person $[7$. $11,12]$ and also through occupational exposure. Undercooked ground beef, meat patties, roastbeef, ham, turkey, cheese, fruits and vegetables, radish sprouts and sausages, unpastorized milk and apple juice have all been implicated in the transmission of $E$. coli [7]. After ingestion of contaminated food or water, E.coli $0157: \mathrm{H} 7$ reaches the gut and closely binds to the epithelial cells of the gastrointestinal mucosa. Adhesion by a $97 \mathrm{kD}$ outer membrane protein intimin, encoded by the eae gene, produces characteristic "attaching and effacing" lesions aimed at preventing the expulsion of the microorganisms [13]. The intimin receptor named Tir (translocated intimin receptor), is produced in the bacteria and translocated via a secretory pathway into the eucariotic cell, where it is phosphorylated and interacts with the host cell cytoskeleton [14]. The consequent disruption of the brush border per se is sufficient to produce non-bloody diarrhea. E.coli 0157:H7 (as well as E.coll 0111, non motille 026:H11, or 0103:H2) may produce large amount of Stx, that traverses polarized gastrointestinal epithelial cells, probably via transcellular pathways [14] and gains access to the systemic circulation.

Recent studies have contributed to clarify how StxNT once has reached the circulation is transferred to the kidney [15]. It has been shown that VT-1 when incubated in whole blood in vitro, bound rapidly and completely to human polymorphonuclear leukocytes (PMN). Binding studies with ${ }^{125}$ I-VT-1 showed a single class of binding sites on freshly isolated, non stimulated human PMN. Interestingly, the $\mathrm{Kd}$ of the high affinity receptor for $\mathrm{VT}$ on PMN was 100-fold less than that found for the functional receptor Gb3, on glomerular 
microvascular endothelial cells (GMVEC). As a consequence, incubation of PMN that had bound fluorescent VT, with GMVEC resulted in passing of the toxin to GMVEC and subsequent inhibition of protein synthesis and cell death [15]: Stimulating the GMVEC with inflammatory mediators, such as TNF $\alpha$ or lipopolysaccharide (LPS), upregulated the $V T$ receptor Gb3 on cell surface and favored transfer of Stx from PMN. These in vitro data were further supported by the detection of VT-2 in the circulation of 9 out of 10 patients with the epidemic form of HUS, bound exclusively to PMN [16]. The detection of VT-2 bound to PMN was associated with the presence of diarrhea at the time the blood samples were obtained. It has been demonstrated that in vitro purified human monocytes bound VT significantly after activation by LPS through a different receptor, globotetraosyl-ceramide (Gb4). After toxin challenge, monocyte release of cytokines like IL-1 and TNF, preceded by the nuciear translocation of the transcriptional activator NF-kB and Ap-1, remarkably potentiated the sensitivity of vascular endothelial cells to $V T$ by upregulating endothelial Gb3 receptors [17, 18]. Endothelial cells are not the only targets for Stx in the kidney and other cells as mesangial, glomerular visceral epithelial cells, proximal and distal tubular cells express the receptor for Stx and are damaged by the toxin.

\section{Shiga toxin and the specific receptors}

Several members of Shiga toxin Nerotoxin family $(69 \mathrm{kDa})$ produced by $E_{\text {. }}$ coll have been characterized, Stx-1, Stx-2, Stx-2c, and Stx2e. Stx-1 is almost identical to Stx from Shighella dysenteriae type 1 differing by a single aminoacid, and is $50 \%$ homologous with Stx-2 [19].

Stx consists of a biologically active $A$ subunit $(35 \mathrm{kD})$ and five $B$ subunits $(7-8 \mathrm{kD})$ that allow binding of the toxin to specific glycosphingolipid receptors located on the plasma membrane of target cells. The binding is followed by internalization via endocytosis [20] of the A subunit, an RNA N-glycosidase that inhibits protein translation by removing specific adenine residue from ribosomal RNA and causes cell death [17] or apoptosis [21].

The neutral glycolipid globotriaosylceramide Gb3 also known as Gal $\alpha 1-4 \mathrm{Gal} \beta 1-4 \mathrm{Gic}$ ceramide binds all Stx members, except Stx-e, which preferentially binds to Gal NAc $\beta 1$ - 
3Gal $\alpha 1-4$ Gal $31-4 \mathrm{Gcl}$ ceramide (Gb4), the $P$ antigen on human erytrocytes. The Gb3 receptor is the Pk antigen of the P blood group system [22] and it has been suggested that Stx might bind to blood red cells as a function of their $\mathrm{P}$ blood group phenotype. Evidence are available showing that individuals with high expression of $\mathrm{P}$ blood group glycolipids containing the disaccharide Gal $\propto(1-4)$ Gal structure necessary for toxin binding, are at reduced risk of HUS after Stx-producing $E$. coli infection, because the red cells act as a sink to mop up systemic toxin and prevent access to the more critical renal endothelial cells. Gb3 (CD77) is also a marker for germinal center $B$ lymphocytes [23] and is the Burkitt lymphoma antigen [24].

The Gb3 fatty acid chain length and the degree of unsaturation markedly affect the ability of the toxin to bind [25]. These latter effects can only be demonstrated within a lipid matrix and show that there is a lower limit (14 carbons) on the fatty acid chain length that allows effective toxin recognition. Increasing chain length increases receptor activity for Stx-1 to a maximum at 20-22 carbons; above a chain length of 22 carbons, binding declines. In contrast, Stx-2c which has $90 \%$ similarity with Stx-2, preferentially binds to Gb3 containing C18 fatty acids. For both Stx-1 and Stx-2c incorporation of unsaturated fatty acids increases Gb3 receptor activity [25], suggesting that lateral mobility within the phospholipid bilayer may be involved in glycolipid receptor activity. There is also evidence that Gb3 receptor containing shorter fatty acid species directs the toxin to the endoplasmic reticulum rather than to the Golgi apparatus, and increases Stx cytotoxicity [26]. Genetic differences in Gb3 fatty acid composition might therefore account for different individual susceptibility to the effect of Stx [26].

In human renal tissue Stx-1 binds primarily to collecting ducts and distal convoluted tubules, expecially those adjacent to glomerull. The toxin also binds to the glomeruli of infants but not of adults [27], implying that Gb3 is expressed in the renal glomeruli of children and that it is a developmentally regulated expression and decreased during ontogenesis. This is in concordance with the finding of HUS being more prevalent in young children than adults. Of interest, a recent study in baboons [28] that share with humans a similar distribution of gastrointestinal and renal tubular Gb3 receptors, demonstrated that 
Stx injection induced direct cell injury to the endothelial and epithelial cells of the gastrointestinal apparatus and of the renal microcirculation [28].

The degree of upregulation of Gb3 synthesis at the time of illness could be important in determining toxicity. Cytokines known to increase cell expression of the Gb3 receptor include IL-1 and TNF. TNF acts mainly via its 55kDa receptor, TNFR-p55, present on endothelial cells $[17,29]$. It is possible that cytokines induce breakdown of sphingomyelin, by the activation of sphingomyelinase, to ceramide which favors Gb3 synthesis [30].

\section{Shiga toxin and endothelial cell injury}

Endothelial injury predominantly of glomerular capillaries, has been recognized as the inciting event in the development of microangiopathic process of HUS. It is generally assumed that Stx is cytopathic for endothelial cells. In vitro studies have indicated that priming of endothelial cells by cytokines as IL-1 and TNF is required for Stx cytotoxicity. These mediators remarkably potentiate the sensitivity of vascular endothelial cells to Stx by upregulating endothelial Gb3 receptor expression [20]. This finding is closely related to the observation that Stx induced apoptosis in human glomerular endothelial cells only when cells were pre-exposed to TNF $\alpha$ [21].

Increasing evidences suggests that Shiga toxins by favoring interaction of endothelial cells with leukocytes serve to amplify and extend the injury at renal level. First, the number of neutrophils is elevated in HUS, and it was suggested that it is a predictive factor for the outcome of the disease [31]. In addition, Fitzpatrick et al. [32] described that neutrophils of HUS patients were activated as indicated by the fact that plasma concentrations of $\alpha 1$ antitrypsin -complexed elastase and the chemokine interleukin-8 (IL-8) - a potent activator of neutrophils- were remarkably higher in the acute phase of the disease. Neutrophils from children with acute phase of HUS adhered to endothelial cells in vitro more than normal neutrophils and induced endothelial injury by degrading endothelial cell fibronectin, possibly depending on the release of neutrophil-specific proteases [33]. A preliminary report showed that glomerular endothelial cells exposed to Stx became more susceptible to neutrophil-mediated oxidant injury [34] . 
Histological examination of kidney specimens from HUS children with evidence of Stxproducing E.coli infection, revealed a conspicuous infiltration of mononuclear and polymorphonuclear cells within the glomeruli, along with microvascular injury $[35,36]$. In those patients urinary levels of $\mathrm{LL}-8$ and monocyte chemoattractant protein-1 (MCP-1), potent attractants of neutrophils, and monocytes/macrophages and T-lymphocytes, respectively, were elevated during the acute phase of the disease, and gradually declined until recovery, indicating an involvement these chemokines in the attraction of inflammatory cells at renal level $[36,37]$. A recent study in cultured endothelial cells showed that subtoxic concentrations of Stx-1 and 2, exerting minimal influence on protein synthesis, were able to strongly upregulate inflammatory cytokines, chemokines, and adhesive molecules -IL-6, IL-8, ICAM-1 gene expression and GRO-1 and MCP-1 proteinpossibly implicated in the recruitment and adhesion of circulating leukocytes to the endothelium [38].

Among the inflammatory mediators that are released from adherent neutrophils, reactive oxygen species have been shown to exert a direct cytotoxic effect on vascular endothelium. Neutrophils from patients with HUS produced excessive superoxide anion $\left(\mathrm{O}_{2}\right)^{2}$, which argued in favor of oxygen radicals as candidates for neutrophil-induced endothelial damage in these patients [39]. Injured endothelium changes its normal thromboresistant phenotype and becomes thrombogenic initiating microvascular thrombus formation.

In HUS structural damage of microvessels associated with narrowing of the lumina determines major changes in fluid shear stress, which would favor persistent endothelial damage, platelet activation and progression of microvascular thrombosis [40]. Changes in shear stress, the tractive force produced by blood flowing over the endothelial surface, have a profound influence on von Willebrand factor (WWF) handling, by promoting its endothelial secretion and enhancing its susceptibility to proteolytic cleavage [41]. WWF under condition of high shear stress undergoes conformational changes and serves to bridge subendothelial matrix to glycoprotein (GP) lb expressed on platelet membrane [42]. The engagement of this receptor promotes activation of platelet $\alpha_{11 b}-\beta_{3}$ (GPIIb/llla) 
complex that binds to the RGD sequence of WWF leading to thrombus formation [42]. WWF via the RGD sequence may also bind vitronectin receptor $\left(\alpha_{4} \beta_{3}\right)$, the major integrin expressed on endothelial cells [43] that promotes endothelial cell adhesion to the vascular matrix [44]. GPlb is also expressed on endothelial cells; however ${ }_{3}$ controversial results about its function have been reported so far [45]. Relevant to the role of WWF in the pathogenesis of D+ HUS is also the evidence that in Stx-mediated primate model of HUS, VWF expression increased in glomeruli and peritubular capillaries [46].

Several distinct endothelial cell molecules have been reported to be involved in the binding of platelets to endothelial cells. P-selectin, which is stored in intracellular granules of platelets and endotheliall cells together with VWF, and rapidly mobilizes to the cell surface upon stimulation [47], is required for platelet rolling and adhesion on activated endothelium [48]. Increased plasma levels of P-selectin have been measured in patients with HUS, possibly reflecting activation/damage of platelets and endothelial cells [49].

\section{Shiga toxin and renal cells}

HUS is commonly viewed as a disease of the vascular endothelium. However evidence is emerging that renal injury in D+HUS is not limited to glomerular vessels but also affects other compartment as mesangial, glomerular epithelial cells (GEC), proximal and distal tubular cells (PTEC). Mesangial cell injury in HUS ranges from mild cellular edema to severe mesangiolysis and eventual glomerulosclerosis. In vitro experiments documented that mesangial cells are direct targets of Stx-1 that exerts diverse biological effects on these cells ranging from activation of a chemokine gene as MCP-1 to a lethal toxic injury [50]. Inflammatory cytokines potentiate the effects of the toxin in these cells.

Recent study have indicated that in vivo glomerular epithelial cells, also called podocytes, are susceptible to the toxic effects of Stx because they express high levels of Gb3 and bind the toxin as described either in cultured podocytes [51] or in human renal biopsies [52]. In baboon model of HUS, swelling of podocytes with osmophilic inclusions was found together with the typical glomerular endothelial lesions after intravenous infusion of Stx [28]. In vitro, Stx-1 besides its cytotoxic effect on cell viability and protein synthesis, 
activated podocytes to release inflammatory cytokines like IL-1 and TNF, an effect potentiated by lipopolysaccaride co-incubation [53]. Stx-1 also increased arachidonate release from human podocytes in association with the production of both TXA2 and PGI2 [54]. Finding that Stx modulates mesangial and GEC function could clearly have a significant impact on glomerular function through alteration of glomerular capillary surface area and filtration rate, thus contributing to glomerular ischemic changes and hemodynamic derangement in HUS.

Renal tubular epithelial cells also express high levels of $\mathrm{Gb} 3$ and bind to the toxin [27]. Studies on renal biopsy samples from children with D+HUS in the early stages revealed histologically apparent proximal tubular damage [3]. Apoptotic cell death of renal tubules was also observed [55]. Moreover, increased urine concentrations of $\mathbb{N}$-acetyl glucosaminidase and $\beta 2$ microglobulin, specific markers of tubular function, were found in these patients providing the evidence of impaired renal tubular function during the acute phase of the disease [56]. Hughes et al have found that PTEC in culture are exquisitely sensitive to the ribotoxic effects of Stx, thus indicating that the toxin directly injured these cells [57]. Treatment of $\mathrm{ACHN}$ cells (derived from renal tubular epithelial carcinoma) with Stx-2 induced prompt growth inhibition and fragmentation of the genomic DNA, typical of apoptosis, an effect which was potentiated by TNF [58]. 


\section{OBJECTIVES OF THE THESIS}

In this thesis further investigations were performed to identify the mediators and intracellular signalling underlying renal toxicity of Shiga toxin (Stx)-1 and 2, also called Verotoxin- (VT) 1 and 2 , the offending agents for typical childhood D+HUS.

Evidence on the role of endothelium in HUS have been reported and discussed in a review. Endothelial damage has been recognized as the trigger event in the development of microangiopathic lesion. Recent findings suggest that leukocytes as well as platelet activation participate in the development of endothelial injury. Intrinsic abnormalities of the complement system may also play a role in HUS (Chapter 2).

Endothelial injury and leukocyte activation are instrumental to the development of microangiopathic lesions in HUS. First, we studied whether VT-1 directly modulated leukocyte adhesion to vascular endothelium exposed to flow conditions that mimic postcapillary venule circulation. Experiments were planned to address the molecular determinants expressed by endothelium in response to $V T-1$ involved in the adhesive phenomena. Given that TNF $\alpha$, appears a crucial molecule in the sequence of events that lead to endothelial damage, we also investigated the possible role of TNF $\alpha$ in amplifying VT-1 induced leukocyte adhesion on endothelial cells (Chapter 3 ).

To obtain more insight into the mechanisms favouring endothelium-leukocyte interaction, we studied the effect of Stx-2 on leukocyte adhesion and transmigration through human umbilical vein endothelial cells (HUVEC) and glomerular endothelial cells under flow conditions. Since in patients with HUS, kidney speciments reveald conspicuous infiltration of neutrophils and mononuclear cells, and urinary levels of the chemoattractants IL-8 and MCP-1 were elevated during the acute phase of the disease, we assessed the effect of Stx-2 on endothelial gene expression of IL-8 and MCP-1 and their functional role in the adhesive phenomena. 
Based on the evidence that these chemokines are transcriptionally regulated by NF-kB, we verified whether Stx-2 induced the activation of this transcription factor and whether transfection of endothelium with recombinant adenovirus coding for $1 \mathrm{kB} \alpha$, the natural inhibitor of NF-kB, resulted in the suppression of chemokine upregulation, and leukocyte adhesion and transmigration induced by the toxin (Chapter 4 ).

Thrombocytopenia and deposition of platelet thrombi that occlude the microcirculation of the kidney and other organs, are characteristic of VT-associated HUS. Why thrombi form only on arterioles and capillaries is not known. The present study was designed to investigate whether VT-1 affected endothelial anti-thrombogenic properties promoting platelet deposition and thrombus formation on endothelial cells under high shear stress. We also evaluated whether microvascular endothelium had a higher susceptibility to VT-1induced thrombus formation in respect to endothelial cells derived from large vessels. Moreover, we wanted to identify platelet and endothelial adhesive proteins involved in the thrombotic process promoted by VT-1 (Chapter 5).

The kidney is the privileged target of Stx, with glomerular ischemic changes preceding microvascular thrombosis. Retraction and collapse of the capillary tuft in the glomerulus are also prominent and tipically occur in association with fusion of foot processes and swelling of glomerular visceral epithelial cells, termed podocytes. Since podocytes possess Stx receptor, are highly sensitive to Stx-2 cytotoxicity and represent an important source of vasoactive molecules, we studied whether Stx-2 modulates the production of the vasoconstrictor peptide ET-1, taken as candidate mediator of podocyte dysfunction, and the intracellular signals involved (Chapter 7 ).

Propedeutic to this work was a previous paper focused on the study of mechanisms and mediators underlyng phenotypic changes in podocytes induced by protein overload, that reproduced the condition of exaggerated protein traffic through the glomerular capillary barrier during proteinuric condition. Given that effacement of podocyte foot processes 
occurring in many proteinuric nephropathies is accompanied by rearrangement of actin cytoskeleton, we tested the hypothesis that protein overload alters the F-actin-based contractile podocyte apparatus resulting in modulation of ET-1 gene expression and production of the vasoactive peptide. We also identified the possible relevant intracellular signals evocated by cytoskeletal changes ultimately leading to ET-1 gene expression (Chapter 6). 


\section{REFERENCES}

1. Remuzzi $G$, Ruggenenti $P$ : The hemolytic uremic syndrome. Kidney Int 47:2-19, 1995

2. Ruggenenti $P$, Noris $M$, Remuzzi $G$ : Thrombotic microangiopathy, hemolytic uremic syndrome, and thrombotic thrombocytopenic purpura. Kidney int 60:831-846, 2001

3. Remuzzi $G$, Ruggenenti $P$, Bertani $T$ : Thrombotic microangiopathy, in Renal Pathology With Clinical and Functional Correlations, edited by Tisher $\mathrm{CC}$, Brenner BM, 2 ed, Philadelphia, J.B. Lippincott Company 1994, pp 1154-1184

4. Karmali MA, Petric M, Lim C, Fleming PC, Arbus GS, Lior M: The association between idiopathic hemolytic uremic syndrome and infection by verotoxin-producing Escherichia Coli. J Infect Dis 151:775-782, 1985

5. Arbus GS: Association of verotoxin-producing $E$. coli and verotoxin with hemolytic uremic syndrome. Kidney Int Supp/ 58:\$91-96, 1997

6. Andreoli SP: The pathophysiology of the hemolytic uremic syndrome. Curr Opin Nephrol Hypertens 8:459-464, 1999

7. Mead PS, Griffin PM: Escherichia coli 0157:H7. Lancet 352:1207-1212, 1998

8. Srivastava RN, Moudgil A, Bagga A, Vasudev AS: Hemolytic uremic syndrome in children in northern India. Pediatr Nephrol 5:284-288, 1991

9. Guerin PJ, Brasher C, Baron E, Mic D, Grimont F, Ryan M, Aavitsland P, Legros D: Shigella dysenteriae serotype 1 in west Africa: intervention strategy for an outbreak in Sierra Leone. Lancet 362:705-706, 2003

10. Houdouin $V$, Doit $C$, Mariani $P$, Brahimi $N$, Loirat $C$, Bourrillon $A$, Bingen $E: A$ pediatric cluster of Shigella dysenteriae serotype 1 diarrhea with hemolytic uremic syndrome in 2 families from France. Clin Infect Dis 38:e96-99, 2004

11. Carter AO, Borczyk AA, Carlson JA, Harvey B, Hockin JC, Karmali MA, Krishnan C, Korn DA, Lior H: A severe outbreak of Escherichia coli 0157:H7-associated hemorrhagic colitis in a nursing home. N Engl J Med 317:1496-1500, 1987 
12. Pavia AT, Nichols CR, Green DP, Tauxe RV, Mottice $S$, Greene KD, Wells JG, Siegler RL, Brewer ED, Hannon $D_{\text {; }}$ et al.: Hemolytic-uremic syndrome during an outbreak of Escherichia coli 0157:H7 infections in institutions for mentally retarded persons: clinical and epidemiologic observations. J Pediatr 116:544-551, 1990

13. Donnenberg MS, Tzipori S, McKee ML, O'Brien AD, Alroy J, Kaper JB: The role of the eae gene of enterohemorrhagic Escherichia coli in intimate attachment in vitro and in a porcine model. J Clin Invest 92:1418-1424, 1993

14. Acheson DW, Moore R, De Breucker $S$, Lincicome $L$, Jacewicz $M$, Skutelsky $E$, Keusch GT: Translocation of Shiga toxin across polarized intestinal cells in tissue culture. Infect Immun 64:3294-3300, 1996

15. te Loo DM, Monnens LA, van Der Velden TJ, Vermeer MA, Preyers F, Demacker PN, van Den Heuvel LP, van Hinsbergh WW: Binding and transfer of verocytotoxin by polymorphonuclear leukocytes in hemolytic uremic syndrome. Blood 95:33963402,2000

16. Te Loo DM, van Hinsbergh WW, van den Heuvel LP, Monnens LA: Detection of verocytotoxin bound to circulating polymorphonuclear leukocytes of patients with hemolytic uremic syndrome. J Am Soc Nephrol 12:800-806, 2001

17. van de Kar NCAJ, Monnens $\mathrm{LAH}_{\text {v }}$ Karmali MA, van Hinsbergh WWM: Tumor necrosis factor and interleukin-1 induce expression of the verocytotoxin receptor globotriaosylceramide on human endothelial cells: implications for the pathogenesis of the hemolytic uremic syndrome. Blood 80:2755-2764, 1992

18. van Setten PA, Monnens LA, Verstraten RG, van den Heuvel LP, van Hinsbergh WW: Effects of verocytotoxin-1 on nonadherent human monocytes: binding characteristics, protein synthesis, and induction of cytokine release. Blood 88:174183, 1996

19. Tesh VL, Burris JA, Owens JW, Gordon VM, Wadolkowski EA, O'Brien AD, Samuel JE: Comparison of the relative toxicities of Shiga-like toxins type I and type II for mice. Infect Immun 61:3392-3402, 1993 
20. van Setten $P A_{i}$ van Hinsbergh $W W$, van der Velden $T J$, van de $\operatorname{Kar} N C$, Vermeer $M$, Mahan JD, Assmann KJ, van den Heuvel LP, Monnens LA: Effects of TNF alpha on verocytotoxin cytotoxicity in purified human glomerular microvascular endothelial cells. Kidney Int 51:1245-1256, 1997

21. Pijpers $A H$, van Setten $P A$, van den Heuvel $L P$, Assmann $K J$, Dijkman $H B$, Pennings AH, Monnens $L A$, van Hinsbergh $\mathrm{WW}$ : Verocytotoxin-induced apoptosis of human microvascular endothelial cells. J Am Soc Nephrol 12:767-778, 2001

22. Lingwood CA: Role of verotoxin receptors in pathogenesis. Trends Microbiol 4:147153,1996

23. Maloney MD, Lingwood $\mathrm{CA}: \mathrm{CD} 19$ has a potential $\mathrm{CD} 77$ (globotriaosyl ceramide)binding site with sequence similarity to verotoxin B-subunits: implications of molecular mimicry for $\mathrm{B}$ cell adhesion and enterohemorrhagic Escherichia coli pathogenesis. J Exp Med 180:191-201, 1994

24. Nudelman E, Kannagi R, Hakomori $S$, Parsons $M$, Lipinski $M$, Wiels J, Fellous $M_{*}$ Tursz T: A glycolipid antigen associated with Burkitt lymphoma defined by a monoclonal antibody. Science 220:509-511, 1983

25. Kiarash $A$, Boyd $B$, Lingwood $C A$ : Glycosphingolipid receptor function is modified by fatty acid content. Verotoxin 1 and verotoxin $2 c$ preferentially recognize different globotriaosyl ceramide fatty acid homologues. J Biol Chem 269:11138-11146, 1994

26. Arab $S$, Lingwood $C A$ : Intracellular targeting of the endoplasmic reticulum/nuclear envelope by retrograde transport may determine cell hypersensitivity to verotoxin via globotriaosyl ceramide fatty acid isoform traffic. J Cell Physiol 177:646-660, 1998

27. Lingwood CA: Verotoxin-binding in human renal sections. Nephron 66:21-28, 1994

28. Taylor FB, Jr., Tesh VL, DeBault L, Li A, Chang AC, Kosanke SD, Pysher TJ, Siegler RL: Characterization of the baboon responses to Shiga-like toxin: descriptive study of a new primate model of toxic responses to Stx-1. Am J Pathol $154: 1285-1299,1999$ 
29. van de Kar NCAJ, Kooistra $T$, Vermeer $M_{\text {, Lesslauer }} W_{\text {, Monnens LAH, van }}$ Hinsbergh WWM: Tumor necrosis factor induces endothelial galactosyl transferase activity and verocytotoxin receptors. Role of specific tumor necrosis factor receptors and protein kinase C. Blood 85:734-743, 1995

30. Kaye SA, Louise CB, Boyd $B$, Lingwood CA, Obrig TG: Shiga toxin-associated hemolytic uremic syndrome: interleukin-1 beta enhancement of Shiga toxin cytotoxicity toward human vascular endothelial cells in vitro. Infect Immun 61:3886 3891,1993

31. Milford DV, Staten J, MacGreggor I, Dawes J, Taylor CM, Hill FG: Prognostic markers in diarrhoea-associated haemolytic-uraemic syndrome: initial neutrophil count, human neutrophil elastase and von Willebrand factor antigen. Nephrol Dial Transplant 6:232-237, 1991

32. Fitzpatrick MM, Shah V, Trompeter RS, Dillon MJ, Barratt TM: Interleukin-8 and polymorphoneutrophil leucocyte activation in hemolytic uremic syndrome of childhood. Kidney int 42:951-956, 1992

33. Forsyth KD, Simpson AC, Fitzpatrick MM, Barratt TM, Levinsky RJ: Neutrophilmediated endothelial injury in haemolytic uraemic syndrome. Lancet II:411-414, 1989

34. Andreoli SP, Green DF: Verotoxin promotes nitric oxide generation in glomerular endothelial cells (GEC) and accelerates PMN mediated GEC injury. J Am Soc Nephrol 8:582, 1997 (Abstract)

35. Inward CD, Howie Ad, Fitzpatrick MM, Rafaat F, Milford DV, Taylor CM: Renal histopathology in fatal cases of diarrhoea-associated haemolytic uraemic syndrome. British Association for Paediatric Nephrology. Pediatr Nephrol 11:556559,1997

36. van Setten $P A_{x}$ van Hinsbergh $W W$, van den Heuvel LP, Preyers F, Dijkman HB, Assmann KJ, van der Velden TJ, Monnens LA: Monocyte chemoattractant protein-1 and interleukin-8 levels in urine and serum of patents with hemolytic uremic syndrome. Pediatr Res 43:759-767, 1998 
37. Inward $C D$, Varagunam $M$, Adu $D$, Milford DV, Taylor CM: Cytokines in haemolytic uraemic syndrome associated with verocytotoxin-producing Escherichia coli infection. Arch Dis Child 77:145-147, 1997

38. Matussek $A_{n}$ Lauber $J_{1}$, Bergau $A_{*}$ Hansen $W$, Rohde $M$, Dittmar KE, Gunzer $M$, Mengel $M_{s}$ Gatzlaff $P$, Hartmann $M$, Buer J, Gunzer F: Molecular and functional analysis of Shiga toxin-induced response patterns in human vascular endothelial cells. Blood 102:1323-1332, 2003

39. Noris $M$, Ruggenenti $P$, Todeschini $M$, Figliuzzi $M$, Macconi $D$, Zoja $C$, Paris $S$, Gaspari $F$, Remuzzi $G$ : Increased nitric oxide formation in recurrent thrombotic microangiopathies: a possible mediator of microvascular injury. Am J Kidney Dis $27: 790-796,1996$

40. Remuzzi G, Galbusera M, Salvadori M, Rizzoni G, Paris S, Ruggenenti P: Bilateral nephrectomy stopped disease progression in plasma-resistant hemolytic uremic syndrome with neurological signs and coma. Kidney Int 49:282-286, 1996

41. Tsai HM, Sussman, II, Nagel RL: Shear stress enhances the proteolysis of von Willebrand factor in normal plasma. Blood 83:2171-2179, 1994

42. Ruggeri ZM: von Willebrand factor. I Clin Invest 99:559-564, 1997

43. Byzova TV, Rabbani R, D'Souza SE, Plow EF: Role of integrin alpha(v)beta3 in vascular biology. Thromb Haemost 80:726-734, 1998

44. Cheresh DA: Human endothelial cells synthesize and express an Arg-Gly-Aspdirected adhesion receptor involved in attachment to fibrinogen and von Willebrand factor. Proc Natl Acad Sci U S A 84:6471-6475, 1987

45. Perrault $C$, Lankhof $H_{1}$ Pidard D, Kerbiriou-Nabias D, Sixma JJ, Meyer D, Baruch D: Relative importance of the glycoprotein Ib-binding domain and the RGD sequence of von Willebrand factor for its interaction with endothelial cells. Blood 90:23352344, 1997

46. Pysher TJ, Siegler RL, Tesh VL, Taylor FB, Jr.: von Willebrand Factor expression in a Shiga toxin-mediated primate model of hemolytic uremic syndrome. Pediatr Dev Pathol 5:472-479, 2002 
47. Wagner DD: P-selectin chases a butterfly. J Clin Invest 95:1955-1956, 1995

48. Frenette $P S$, Johnson RC, Hynes RO, Wagner DD: Platelets roll on stimulated endothelium in vivo: an interaction mediated by endothelial P-selectin. Proc Natl Acad SciU S A 92:7450-7454, 1995

49. Chong BH, Murray B, Berndt MC, Dunlop LC, Brighton T, Chesterman CN: Plasma P-selectin is increased in thrombotic consumptive platelet disorders. Blood 83:1535-1541, 1994

50. Simon M, Cleary TG, Hernandez JD, Abboud HE: Shiga toxin 1 elicits diverse biologic responses in mesangial cells. Kidney int 54:1117-1127, 1998

51. Hughes AK, Stricklett PK, Schmid D, Kohan DE: Cytotoxic effect of Shiga toxin-1 on human glomerular epithelial cells. Kidney Int 57:2350-2359, 2000

52. Ergonul $Z$, Clayton $F$, Fogo $A B$, Kohan $D E$ : Shigatoxin-1 binding and receptor expression in human kidneys do not change with age. Pediatr Nephrol 18:246-253, 2003

53. Hughes AK, Stricklett PK, Kohan DE: Shiga toxin-1 regulation of cytokine production by human glomerular epithelial cells. Nephron 88:14-23, 2001

54. Schmid DI, Kohan DE: Effect of shigatoxin-1 on arachidonic acid release by human glomerular epithelial cells. Kidney Int 60:1026-1036, 2001

55. Kaneko K, Kiyokawa N, Ohtomo Y, Nagaoka R, Yamashiro Y, Taguchi T, Mori T, Fujimoto J, Takeda $\mathrm{T}$ : Apoptosis of renal tubular cells in Shiga-toxin-mediated hemolytic uremic syndrome. Nephron 87:182-185, 2001

56. Takeda T, Dohi S, Igarashi T, Yamanaka T, Yoshiya K, Kobayashi N: Impairment by verotoxin of tubular function contributes to the renal damage seen in haemolytic uraemic syndrome. J Infect 27:339-341, 1993

57. Hughes AK, Stricklett PK, Kohan DE: Cytotoxic effect of Shiga toxin-1 on human proximal tubule cells. Kidney int 54:426-437, 1998

58. Taguchi T, Uchida H, Kiyokawa N, Mori T, Sato N, Horie H, Takeda T, Fujimoto J: Verotoxins induce apoptosis in human renal tubular epithelium derived cells. Kidney Int 53:1681-1688, 1998 

CHAPTER 2

THE ROLE OF THE ENDOTHELIUM IN HEMOLYTIC UREMIC SYNDROME

C. Zoja, M. Morigi, G. Remuzzi

J Nephrol 2001; 14: S58-62 



\title{
The role of the endothelium in hemolytic uremic syndrome
}

\author{
Carla Zoja', Marina Morigi', Giluseppe Remuzzi", \\ ' Mario Negri Institute for Pharmacological Research, Bergamo - Itally \\ z Unit of Nephrology and Dialysis, Bergamo Hospital, Bergamo - Italy
}

\begin{abstract}
Hemolytic uremic syndrome (HUS), which is the most common cause of acute renil failure in children, is caused by Shiga toxin-producing Escherichic coli infection. This infection leads to renal and other organ microvascular thrombosis. Endothelial injury has been recognized as the trigger event in the development of microingiopathic process. Evidence suggests that leukocyte as well as platelet activation participate in endothelial damage. Intrinsic abnormalities of the complement system may also play a role in HUS.
\end{abstract}

Key words: Verotoxin, Endothelium, Platelets, Leukocytes, Complement

\section{INTRODUCTION}

Hemolytic uremic syndrome (HUS) is a disease comprising non-immune hemolytic anemia, thrombocytopenia and renal failure due to platelet thrombi in the microcirculation of the kidney and other organs $(1,2)$. The characteristic lesion, thrombotic microangiopathy, is unique to this syndrome. It consists of vessel wall thickening, with swelling and detachment of endothelial cells from the basement membrane and accumulation of fluffy material in the subendothelium (3). In its typical presentation, HUS manifests as an acute disease, with gastrointestinal or respiratory tract prodromes. Recovery without sequelae occurs in 80 to $90 \%$ of cases, either spontaneously (as in most cases of childhood HUS) or following plasma infusion or exchange (as in adult or severe forms of HUS). Typical HUS is triggered by environmental factors, drugs. or infective agents such as verotoxin or Shiga-toxinproducing $E$. coli; systemic immune disorders or cancer may also cause the disease $(1,2)$. These forms of HUS may subside when the underlying condition has. been treated or removed. However, there are rare forms, often occurring in families, which frequently relapse even after complete recowery of the presenting episode, with death or permanent neurological or renal sequelae being the final outcome in the large majority of cases. These atypical forms are considered to be supported by a genetic background of predisposi- tion to microvascular thrombosis. Both autosomal recessive and autosomal dominant mode of inheritance have been recognized, with precipitating events such as pregnancy, virus-like disease or sepsis being identified in some butnot in all series.

\section{SHIGA TOXIN AS FOSTERER OF HUS}

In $90 \%$ of cases of typical diarrhea-associated $(\mathrm{D}+)$ HUS in children, infection with $E$. coli producing at verotoxin (VT) also termed Shiga toxin (Stx), especially serotype $0157: H 7$, has been strongly implicated as the most common causative agent of this disease ( 1 , 4-6). Undercooked meat, unpasteurized milk, apple juice, radish sprouts and sausages have all been implicated in the transmission of E. coli. (7). Water-born as well as person to person transmission in either sporadic cases or outbreaks have also been reported. It is estimated that following exposition to E. coli O157\% $38 \%$ to $61 \%$ of persons develop hemorrhagic colitis, and $2 \%$ to $7 \%$ of these patients progress to overt HUS. Endothelial injury has been recognized as the trigger event in the development of microangiopathic process of HUS and evidence points to Shiga toxins as critical determinantis for the development of vascular lesions $(1,2,5,8,9)$. Stx-1 and Stx-2 or (VT-1 and VT2) consist of a biologically active subunit $A$ and five $B$ subunits that allow binding of the toxin to a specific 
glycosphingolipid globotriaosyl ceramide (Gb3) receptors on the endothelial cell surface. The binding is foillowed by internalization in the cytosol of the A subunit, which inhibits protein synthesis by inactivating ribosomal subunits and causes cell death (10) or apoptosis (11). After the ingestion of contaminated food or

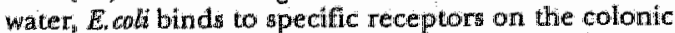
mucosa, multiplies and causes cell death. This normally leads to diarthera, but strains that produce Stx daniage the wasculature of the mucosa, causing hemorrhagic colitis. Microwascular damage develops at target organs when the toxin gains access to the systemic circulation. Recent studies have contributed to clarify how Stx/VT, once it has reached the circulation, is transferred to the kidney (12). It has been shown that when VI-1 is incubated in wholle blood in witro it binds rapidly and comple tely to human polymorphonuelear leukacytes (PMN). Binding studies with "st-VT-1 showed a single class of binding sites on freshly isolat$\mathrm{ed}_{i}$ non stimulated human PMN. Interestingly, the Kd of the high affinity receptor for VT on PMN was 100fold less than that found for the functional receptor for $\mathrm{VT} \mathrm{Cb}^{3}$, on glomerular microvascular endothelial cellls (GMVEC), which facilitated transfer of the toxin from PMN to GMVEC. Indeed, incubation of PMN, that had bound fluoresceinated VT with GMVEC resulted in passing of VT to CMVEC and subsequent inhibition of protein synthesis and cell death. Stimulating the GMVEC with inflammatory mediators, such as TNF $\alpha$ or LPS, upregulated the VT receptor Gb3 on cell surface and favored transfer of VT-1 from PMN. These in vitro data were further supported by the detection of VT-2 in the circulation of 9 out of 10 patients with the epidemic form of HUS, bound exclusively to PMN (13). The detection of VT-2 bound to PMN was associated with diarrhea at the time the blood samples were obtained.

It has been demonstrated that in witro purified human monocytes bound VT significantly after activation by L.PS, and that after toxin clallenge the monocytes released cytokines like IL-1 and TNF that remarkably potentiated sensitivity of vascular endothelial cells to VT by upregulating endothelial $\mathrm{Cb} 3$ receptors $(10,14)$.

\section{SHIGA TOXUN AND ENDOTHELIAL, CELL INJURYY THROUGH LEUKOCYTE ACTIVATION}

The interaction between leukocytes and endothelial cellis is instrumental to the development of microvas. cular injury in Stx-associated HUS as documented by experimental and clinical evidence. First, the number of neutrophils is elevated in HUS, and it was suggested that it is a predictive factor for the outcome of the disease (15). In addition, Fitzpatrick et al (16) described that neutrophils of HUS patients were activated as in- dicated by the fact that plasma concentrations of allantitrypsin-complexed elastase and the chemokine interleukin-8 (IL-8) - a potent activator of neutrophilswere remarkably higher in the acute phase of the disease. Neurrophils from children with acute phase of HUS adhered to endothelial cells in vitto more than normal neutrophlls and induced endothelial injury by degradirng endothelial cell fibronectin, possibly depending on the release of neutrophil-specific proteas es (17). A preliminary report showed that glomerular endothelial cells exposed to So became more susceptible to neutrophil-mediated oxidant injury (18). Some years ago we demonstrated for the first time that Stx-1 promoted a massive leukacyte adhesion to cultured human umbilical vein endothelial cells (HUVEC) under flow conditions, by upregulating endothellial expression of the adhesive proteins E-selectin, ICAM-1 and VCAM-1 (19). The adhesion of leukocytes was enhancedd by pre-exposure of endothelial cells to TNFa. Sx-1 was able to inhibit the process of rolling that normally precedes adhesion of cells to the endothelium.

Histological examination of kidney specimens from HUS children with evidence of Stx-producing $E$ coli isfection, revealed a conspicuous infiltration of mononuclear and polymorphonuclear cells within the glomeruli, along with microvascular injury $(20,21)$. In those patients urinary levels of IL-8 and monocyte chemoattractant protein-1 (MCP-1), potent attractants of neutrophils, and monocytes/macrophages and T-lymphocytes, respectivelly, were elevated during the acute phase of the disease, and gradually declined until recovery. This implied a role for these chemokines in the recruitment of inflammatory cells at glomerular level $(21,22)$. Recently, we showed that Stx-induced leukocyte adhesion was followed by transmigration of leukocytes across the endothelium, under flow conditions, and that IL-8 and MCP-I were inplicated in the adhesive phenomena (23). The expression of IL-8 and MCP-1 mRNAs were upregulated after exposure of endothelial cells to subtoxic concentrations of Stx-2. Increased levels of chemokine transcripts were preceded by activation of the transcription factor NF-kB as revealed by electrophoretic mobility shift assay. Blocking of endothelial IL-8 and MCP-1 with corresponding antibodies significantly inhibited Stx-induced leukocyte adhesion and transmigration.

Among the inflammatory mediators that are released from adherent neutrophils, reactive oxygen species thave been shown to exert a direct cytotoxic effect on vascular endotheliurn. Neutrophils from patients with HUS produced excessive superoxide anion $\left(\mathrm{O}_{2}{ }^{-}\right)$, which suggested that oxygen radicals caused neutrophil-induced endothelial damage in these patients (24). Injured endothelium changes its normal throm- 
boresistant phenotype and becomes thrombogenic initiating microvascular thrombus formation.

\section{SHIGA TOXEN AND ENDOTHELAL CEIL DNUKY THEROUGH PLATELIET ACTTVATION}

We have recendy demonstrated that Stx is a potent promoter of platelet adhesion and thrombus formation on cultured endothellal cells perfused with whole blood in a now chamber system under high shear stress levels that mimic the ones encountered in the microcirculation (25). The effect of Sx was superior to that of other known thrombogenilc agonists such as thrombin and cytokines. Microvascular endothelial cells of dermal origin demonstrated a remarkably greater sensitivity to the thrombogenic effect of Stx than endothelium derived from large vessels ( $H U$ VEC), possibly due to the higher expression of Sox receptors (20-folld more). In the attempt to identify the adhesive proteins involwed in platelet-endothelial cell interactions elicited by $S t x$, which resulted in thrombus formation on microvascular endothelial cells, we first focused on the von Willebrand factor (wWF), Which is the indispensable adhesive substrate to promote platelet thrombus formation in high shear stress environments (26). Changes in shear stress, the tractive force produced by blood flowing over the endothelial surface, have a profound influence on wWF handling by enhancing its susceptibility to proteolytic cleavage $(27)$. WWF under conditions of high shear stress undergoes conformational changes and serves as a bridge between subendothelial matrix and glycoprotein (GP) Ib expressed on platelet membrane (26). The engagement of this receptor promotes activation of platelet $\alpha_{\mathrm{Hb}} \phi_{3}$ (GPIb/MIa) complex that binds to the RGD sequence of wWF leading to thrombus formation. We found that polymeric aurin tricar boxylic acid (ATA), an inhibitor of WWF-platelet GPIb interation, completely prevented the deposition of thrombi (25). Furthermore, blockade of $\mathrm{a}_{\mathrm{IT}} \mathrm{n}_{\mathrm{g}}$ on ac* tivated platelets by chimeric $7 \mathrm{E} 3 \mathrm{~F}$ ab also abrogated platelet adhesion and thrombus formation, suggesting the involvement of $v W F-p$ latelet interaction at high shear stress in this phenomenon. Other experiments showed that functional blockade of endochelial $\beta_{3}$ integrin subunit, vitronectin receptor, $P$-selectin and PECAM-1 with specific antibodies was associated with a significant decrease of the endothelial area coyered by thrombi (25). In addition, confocal microscopy studies revealed that $S x$ increased the expression of vitronectin receptor and P-selectin, and redistributed PECAM-1 away from cell-cell border of endothelial cells, thus indicating that the above endothelial adhesion molecules are directly involved and possibly determine the effect of Six of enhancing plarelet adbesion and thrombus formation in microvascular endothelium. In conclusion, these results might be relevant to understanding why thrombi in HUS localize in microvessels rather man in larger ones. They may also provide insights on the molecular events involved in the process of microvasciular thrombosis associated with $\mathrm{D}+\mathrm{HUS}$.

\section{COMPLLARENT AND HUS}

Apart from Stx other agents potentially toxic to the vascular endothelium - such as certain viruses, bacteria, immunecomplexes and cycotoxic drugs - have been proposed as possible triggers of microvascular thrombosis of HUS. Independently from its causative agent, local thrombosis amplifies the inflammatory injury by promoting complement deposition within tapillary vessels through formation of the C $36 B \mathrm{Bb}$ convertase of the alternative pathway of complement activation. Evidence implicating the complement system, and in particular the alternative pathway, exists for all forms of HUS. Low CS levels were first described in D+HUS in the early 1970 s and it thas also been report ed that persistently low levels are predictive of a poor prognosis (28). Hypocomplementemia was also found in sporadic and familial forms of HUS (29). Cranular C3 deposits in glomeruli and arterioles of HUS patients and evidence of $C 3$ breakdown products in HUS sera document that low C3 concentrations probably reflect complement consumption in the microvasculature. At variance with typical and sporadic forms in which hypocomplementemia subsides with remission of the disease, in recurrent and familial cases serum C3 levels are often consistently and remarkably depressed even during remission. This was initially attributed to an inherited defect in C9 synthesk, but much more corvincing data are now avallable indicating that low CS in HUS derives from ether lack or ath

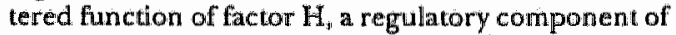
the alternative pathway of the complement system (30). By multivariated analysis on 35 castex of familial HUS from 10 families, we showed that decreased $C S$ levels correlated with history of disease and were associated with a 16.6-fold increased relative risk of developing HUS within the families (29). In this series low Cu levels also correlated with factor $\mathrm{H}$ deficiency. In addition, a recent report documented that an area on chromosome $1 q$, where factor $\mathbb{H}$ is mapped, segregates with HUS; in one family a mutation in factor $\mathrm{H}$ gene was found, consisting in a $\mathrm{C}$ to $\mathrm{G}$ transwersion causing an arginine to glycine change in Short Consensus Repeat 20 (SCR20) (31). The same authors also described a nonsense mutation, located in SCRL of factor $\mathrm{H}$, in a sporadic case with late onset (31). In a large series of patients with farnilial history of HUS, we 
found four new heterozygous mutations in factor $\mathrm{H}$ gene (32). Three of the mutations were obserwed in families with dominant transmission, the fourth was found in a single case of a patient who experienced disease recurrence on the renal allograft. Another study reported an apparent mutation in factor $\mathrm{H}$ (a C to $T$ transition in SCR 20 ) in a family with HUS with a recessive mode of inheritance and severely depressed factor H levels (33). However, two independent groups subsequently documented that the apparent mutation was an arufact caused by coamplification of a factor H-related gene. They demonistrated that the real mutation in this family is an $A$ to $T$ transwersion and a 24 bp deletion that was present in homozygosity in affected member patients and in heterozygosity in the healthy carriers $(34,35)$. Altogether, these data provide compelling molecular evidence that genetic alterations in factor $\mathrm{H}$ are involved in both autosomal dominant and recessive HUS. Data showing that folLowing exposure to Stx producing $E$. coli, only 2 to $7 \%$ of patients progress to overt HUS suggest that a genetic predisposition may have a role allso in typical D+ forms. Polymorphisms in the promoter and in the coding regions of factor $H$ gene have been recently described. It is intriguing to speculate that some of these polymorphic variants confer a genetic predisposition to SE-induced HUS.

Correspondence to:

Giusope Remuari, M.D.

"Wario Negn" Institule for Pharmacological Resentch

Via Gaunzumi, 11

24125 Bergamo, Haly

gremurzi marionegri, it

\section{REFERUENCES}

1. Remuzzi $G$, Ruggenenti P. The hemolytic uremic syndrome, Kidney Int 1995; 47: 2-19.

2. Ruggenemti $P$, Noris $M$, Remuzzi: $G$. Thrombotic microangiopathy, herrolytic uremic syndrome, and thrombotic thrombocytopenic purpura. Ridney Int 2001; 60:891-46.

5. Remuzzi $G$, Ruggenenti $P$, Bertani $T$. Thrombotic microanm giopathies. In Tisher, CC. Brenner BM Eds. Renal Pathology. With Cilinical and Fumctional Correlations. Philadelphia: J. B, Lippincott Company 1994; 1154-84.

4. Karmali MA, Petric M, Lim C, Fleming PC Arbus CS, Lim M, The association between idlopathic hemolytic uremic syn. drome and infection by werotoxin-producing Escherichia coll. J linfect Dis 1985; 151: 775-82;

B. Arbus Cis. Assactation of verotoxin-producing colí and verotoxin with bemolytic uremic syndrome, Kidney Int 1997; 51 : 5-91-6.

6. Andreoll SP. "The paithophysiology of the hemolytic uremic Syndrome, Curr Opin Nephrol Hypertens 1999; 8: 459-6.4.

7. Mead PS. Griffin PM. Exeherichia rolf 0157\%7. Lancet 1998; 352: $1207+12$.

8. Zoja C, Remuzzi C. The piwonal role of the endothelial cell in the pathogenesis of HUS. In Kaplan BS, Trompeter RS, Moake JIL Eds. Hemolytic uremic syndrome and thrombotic thrombogyopenic purpura. New York: Marcel Dekker 1992; 389.

9. Obrig TG. Pathogenesis of shiga toxin (verotoxin)-induced endothellal cell injury. In Kaplan BS, Trompeter RS, Moake JL. Eds. Hemolytic uremic syndrome and thrombotic them. bocytopenic purpura. New Yorki Marcel Dekker 1992; 405.

10. van de Kar NCAj, Monnens LAH, Karmali MA, van Hinsbengh VWM. Tumor necrosis factor and interleukin-1 induce expression of the verocytotoxin receptor globotriasylceramide on human endothelial cells: impllications for the prathogenesis of the hemolytic uremic syndrome. Bllood 1992; 80: $2755-64$.
11. Pijpers AHH, van Setten PA, Van den Heuvel LP. Verocytoloxilninduced apoptosis of human microvascular endothelial cells. J Am Soc Nephrol 2001; 12: 767-78.

12. Te Loo DM, Monnens LA, wan der Velden T]. Binding and transfer of verocytotoxim by polymorphonuclear leukocytes in hemolytic uremic syrudrome. Blood 2000; 95: 3996-402.

13. Te Loo DM, Van Hinsbergh VW, Van den Heuwel $L P_{n}$ Moninens LA. Detection of verototoxin bound to circulating polymorphonuclear leukocytes of patients with hemolytic uremic synidrome. J Am Soc Nephrial 2001; 12:800-6.

14. van Setten PA, Monnens LAH, Verstraten RGG, van den Heuwel LPW], wan Hinsbergh VWM. Effects of verocytotoxin1 on nonadherent human monocyles: binding characteristics, protein synthesis, and induction of cytokine release. Bbood 1996; 88: 174-83.

15. Milford DV, Staten J, MacGreggor 1, Dawes: J, Taylor CM, Hill FC. Prognostic markers in diarrhoea-associated haemolyticuremic syndrome: initial neutrophil count, human neutrophil elastase and won Willebrand factor antigen. Nephrol Dial Transplarit 1991; 6: 232-7.

16. Ficzatrick MM, Shah V, Trompeter RS, Dillon M], Barratt TM. Interleukin-s and polymorphoneutrophil leukocple activation in hemolytic uremic syndrome of childhood. Kidney Int 1992; 42; 951-6.

17. Forsyth $\mathrm{KD}$, Simpson $\mathrm{AC}$, Fitupatrick MM, Barratt TM, Levinsky RJ. Neutrophil-medliated endothelial injury in thaemolytic uremic syndrome. Lancet $1989 ; 2: 411-4$.

18. Andreoli SP, Green DF, Verotoxin 1 promover nitric oxide (NO) generation in glonerular endothelital cells (GEC) and accelerates PMN mediated GEC injury. J Am Soc Nephrol 1997; 8: 582A-5820.(Abstract)

19. Morigi M, Micheletti G, Figliuzzi M. Verotoxin-1 promotes leukocye adhesion to cultured endothelial cells under physiologic flow conditions. Blood 1995; 86: 455.3-8.

20. Inward CD. Howie AJ, Fitzpatrick MM. Renal histopathology in fatal cases of diarrhoea-8ssociated haennolytic uremic syndrome. Pediatr Nephrol 1997; $11: 556-9$. 
21. van Setten PA, Han Hinsbergh WWM, van den Hewe! LPWI? Monocyte chemoatractant protein-1 and interleukin-8 lewels in urine and serum of patients with hemolytic uremic Eyrodrome. Pediaur Res 1998; 48: 759-67.

22. Inward $C D$, Varagunam $M$, Adu $D$, Milford DV, Taylor CM. Cptokines in haemolytic uremic syndrome associated with verocytotoxin-producing Eseherichta woli infection. Arch Dis Child 1997; 77 : $145-7$.

23. Zoja C, Morigi M, Donadelli R. Verotoxin-2 induces subendotheliall leukocyce transmigration via upregulation of MCP-1 and IL-8. J Am Soc Nephrol 1999; 10: 595A. (Abstract)

24. Noris $M$, Ruggenenti $P$, Todeschini $M$. Increased nitric axide formarion in recurrent thrombotic microangiopathies' a possible mediator of microvascular injury. Am J Kidney Disi 1996; 27: 790-6.

25. Morigi M, Galbusera M, Binda E. Verotoxin-1 linduced upregulation of adbesive molecules reniders microvascular en. dothelial cells thrombogenic at high shear stress. Blood 2001 ; 98: 1828-95.

26. Ruggeri ZM, Perspectives series: Cell adhesion in vascular biology, von Willebrand Factor. J Clin Inwest 1997; 99: 559-64.

27. Tsail H-M, Sussman II Nagel RL. Shear stress enhances the proteolysis of von Willebrand factor in normal plasma. Blood 1994; 89: $2171-9$.

28. Seuhlinger W, Kourilsky $O$, Kanfer $A_{n}$ Sraer JD. Hemolytic-uremic syndrome: evidence for intravascular $C 9$ activation. Lancet 1974; 2: 788-9.

29: Noris $M_{*}$ Ruggenenti P, Perna $A_{n}$ et al. Hypocomplementemia disclosies genetic predisposition to hemolytic uremic syn- drome and thrombotic thrombogpopenic purpura: role of factor H abnormalities, Itatian Registry of Familial and Re current Hemolytic Unemic Syndrome/Thrombetic Thronn* bocycopentic Pturpura. I Am Sac Nephrol 1999; 10:281.99.

30. Zipfel P.F. Hemolytic uremic syndromes how do faetor H mu tants mediate endothelial damige? Tremels lmmund 2001; 22: 345-8.

31. Warwicker $\mathrm{P}$, Goodship TH, Donne RL. Cenetic studies into intrerited and sporadie heimolytic uremic syndrome. Kidney Int $1998 ; 3.9: 89644$

32. Caprioll J Bettinaglio P 2 piel PF. The molecular basis of famillal hemolytic uremic syadrome mutation analystis of factor $\mathrm{H}$ gene reveals a hot spoc in short consensus repeat 20 . J Am Soc Nephrol 2001; 12:297.307.

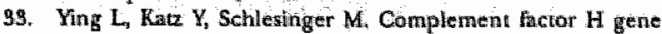
mutation associaced with antosomal recessive atypical hemolytic uremic syndrome. Am J Hum Otnet 1999, 65: 11588 . 46.

34. Buddles MR, Donne RL, Richards $A_{a}$ Goodship J, Goodship TH. Complement factor $\mathbb{H}$ gene mutation assochated with au. tosomal recessive atypical hemolytic aremic syndrome. An J Hum Genet 2000 66 : 1721.2.

35. Caprioli J, Bettinaglio P, Vasile B. Factor $H$ (HF) gene mutation in tamilial hernolyte aremic syondrome (HUS). J Am Soc Nephrol 2000; $11: 404$ A (Abstract).

C Societ Italiana di Nefrologia 

CHAPTER 3

VEROTOXIN-1 PROMOTES LEUKOCYTE ADHESION TO CULTURED ENDOTHELIAL CELLS UNDER PHYSIOLOGIC FLOW CONDITIONS

M. Morigi, G. Micheletti, M. Figliuzzi, B.Imberti, M.A. Karmali, A. Remuzzi, G. Remuzzi, and C. Zoja

Blood 1995; 86: 4553-4558 


\section{Verotoxin-1 Promotes Leukocyte Adhesion to Cultured Endothelial Cells Under Physiologic Flow Conditions}

By Marina Morig:; Gianluca Michetetti, Marina Figlifuzi, Barbara lmbenti, Mohamed A. Karmall, Andraa Remuzi, Giuseppe Remuzzl, and Carla Zoja

Hemalytic uremic syndrome (HUS), which the most common cause of acute renal fallure in infants and small children. is caused by werotoxin (NT)-producing Escherichis coll infection Endothefial injury determines microwascular thrombosils and evidence is avallable from recent studiles that suggests that leukocyte sctivation participates in endothelial damage. We studied here the effect of VT-1 on leukocyte adhesion to vaspular endothelium under physiologic flow canditions. Human umbitical veln endothellal cells (HUVECs) were incubatod for 24 hours with VT. 1 10.3, 1, and 10 pmol/ 4 and then exposed to a total leukocyte suspension in a parallel plate flow chamber under laminar flow conditions (1.5 dymes $\left(\mathrm{cm}^{2}\right)$. Adtherent lis were coutnted by digittal image processing. Results showed that VT-1 dose-dopendently increased the number of achering leukacytest to HUVECs as compared with unstimulated cells. The adhesive response ellicited by VT-1 was comparable to that of interleukin-1B

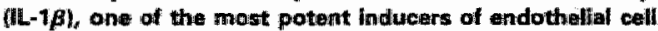
adhesiveness. Exposure of HUVECs to VT-1 did not affect

$\mathbf{R}$ ESEARCH IN THE last few years has established a link between enteric infection with verotoxin (VT)producing Escherichia coli (VTEC) and benolytic uremic sindrome (HUS), ${ }_{2}{ }^{1-3}$ a disorder of thrombocytopenia, microangiopathic hemolytic amemia, and acute renal failure that mainly affects infants and small children."

VT (or Shiga-like toxins, a family of $E$ coli-derived toxins) bind to a specific receptor identified as the glycosphingotipid globotriaosylceramide $\left(\mathrm{Gb}_{j}\right)^{\text {bi }}$ on leukocytes and endothelial cells af target organs, and cell susceptibility to VT damage is a function of $\mathrm{Gb}_{3}$ expression on cell membranes. ${ }^{.35}$ In North America and Western Europe, 90\% of children with epidemic diarrhea-associabed HUS have evidence of VTEC infection. ${ }^{3.10}$ It is now clear that vascular endothelial cell injury is central to the full development of microangiopatic lessions, "but the complex mechanism('s) underlying endothelial perturbation and darnage in this disease is far from being defined. The toxicity of VT.1 on wiscultar endothelial cells in culture is remarkably potentiated by leukocyte-derived tumor necrosis factor $\alpha$ (TNF $\alpha$ ), which also contributes to upregulate $\mathrm{Cb}_{3}$ receptors on endothelial cells. ${ }^{912}$ TNF $\alpha$-induced upregulation of VT-1. receptors on endothelial cells depends on galactosyl transferase induction ${ }^{13}$ by a mecham nism independent of protein kinase $\mathrm{C}$ activation. Endothelial surface expression of VT-1 receptor then orients subsequent localization of microvascular damage, as documented by animal experiments. ${ }^{14}$ Thus, TNFa appears a crucial molecule in the sequence of events leading to endathelial damage in VTEC-associated forms of childhood. HUS. Finding that circulating inflammatory cells including macrophages (the main source of TNF $\alpha$ in humans) constitutively express VTI receptors and release TNF $\alpha$ in vitro upon VT-1 binding to its specific receptors' ${ }^{15}$ led investigators to consider the possibility that, in HUS, interaction between activated leukcocytes and endothelial cells is indeed instrumental to the development of microvascular injury. Preliminary data have suggested that endothelial damage might eritically depend the number of rolling leckoeytes, which was simllar to that of control volues. To examine the role of athesion motecules in VT-1-induced leukooyte adhesion, HUNECs ward incurbated with mouse monoclonal antibodies against E-selectin. intercellular adhesion molecule-1 (NCAM-1), and vescular cell adhesion molecule-1 (MCAM-1) before adhesion assey. Funetional blociking of E-selectin, ICAM-1, and VCAM-1 on ondothelial cells significantly intibited WT-1-indueed inereaso in leukocyte adhesion. In some expeniments, before VT-1 incu bation, HUVECs wore pretreaked for 24 hours with tumor necrosis factor a (TNFa; $100 \mathrm{U} / \mathrm{mLl}$, whileh is known to in crease VT racepter expression on HUVECs. The number of athering leukocytes on HUVECs exposed to TNFer and VT-1 significantly Incrased as compared with HUVECs incubated with VT-1 and TNFa allone. These results suggest that $V T-1$ modulates leukacyte-endathelium lnteraction, thus increasIng leukocyte adhesion and upregullating adhesive protelins on endotheliall surface mombrano.

1995 by The Americian Sodety of Hematology.

on neutrophil-specific proteases, particularly elastases, neleased by activated hyperadherent leukocytes. ${ }^{16}$ Consistent with this possibility are findings that levels of plasma leukocyte elastase were remarkably higher than normal in children with diarnea-associated HUS, which presumably reflected leukocyte activation in vivo."

The present study was designed to clarify whether VT-11 directly modulated leukocyte adhesion to endothelial cells. Experiments were planned to address (1) the effect of VT1 on leukocyte adhesion to cultured endothelial cells exposed to flow conditions that mimic postcapillary venule circulation; (2) the molecular determinants of VT-1-induced leukocyte adhesion; and (3) the possible role of TNF $\alpha$ of amplifying VT-1-induced leukocyte adhesion to endothelial cells.

\section{MATERIIALS AND METHODS}

Endotheliad cell culture. Esidothelial celly were obtibitid from human umbilical veins (HUVECs) by collagennse digestion ace

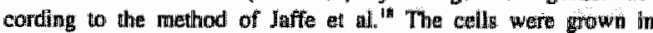
Medium 199 (CLBCO, Grand Laland, NY) supplemented with IO newborn ealf serum (GIECO), 10\% human serum, and antibiotics.

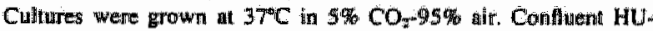

From the Mario Negri Institure for Pharmacolonical Research Bergamo, Italy. the Division of Nephrology and Dialysis, Ospedill Rituniti di Bergamo, Bergano. Italy: and the Department of Aticrob:ology, The Hospital for Sick Children, Torronio, Oritario, Conada.

Submilted June 12, 1995; accepted Augkst 7, J995.

Address reprint requests to Marina Morigi, Biol SciD, Mario Negri Instütute for Pharmacological Research, Via Gavazizeni $I I$. 24125 Bergama, Ntaly.

The publication icosts of this article were defrayed in parn by page charge payment. This article must therefors be hereby marked

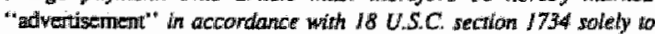
indicate this fact.

- 1995 by The Aumerican Sociery of Hematology.

$0006-4971 / 95 / 8612-0005 \$ 3.0010$ 


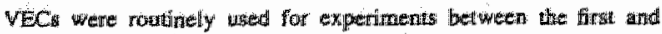

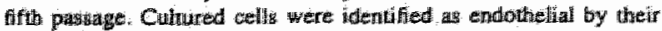
cobbletione morphology and the presence of von Willebrand facm.

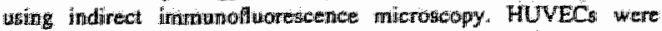
piated on 60 - $x$ 20-min platic cowersl pe (Thermanox" Wunc Naper-

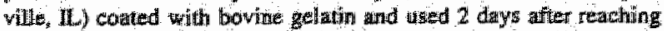
confluence, HUWEC were inewbatad for 24 hours whth control me-

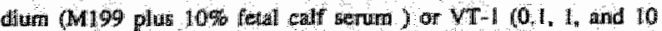

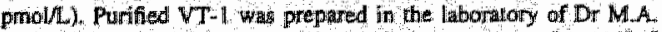

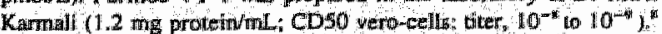

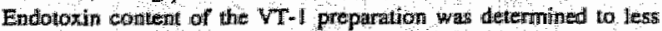

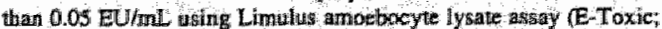

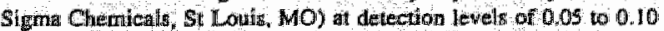

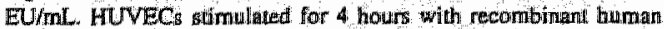
interledun-10 $1 \mathrm{~L}, 1,100 \mathrm{U} / \mathrm{mL} ; 5 \times 10^{7} \mathrm{U} / \mathrm{mg}$ proteh; Boteninger Mannhem, Wanthelm, Germany were tsed as positive controt.

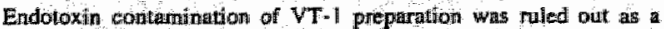
caise of WT-1-induod levkocyle adhesion by experiments in which HUVRCs were inculbated for 24 hours with endotoxin (Buato Lipow

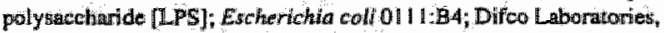
Detirof, MII) al a comcentration that approximated that present in 10 pmol/L VT - I. In some experiments, after VT-1 incubation, HUVEC were trested with mowse monoclonal antibolly (MoAb)-dudherion bilockade anti - Eselectin (BBIG-EA; British Bio-Technology Produnts Lud, Abimgdon, Oxon, UK), ant-intercellular adhestion molecule-1 (ICAM-1) (BBIC-11) or anti-vaseular cell suthesion mole-

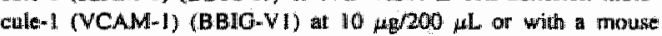

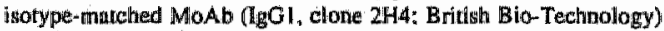
for 20 minutes before the adhesion asmy. At the cond of incubation. cells were exposed to humian totall leukacytes in a parallei-plate fiow thamber for adthesion lassay. In additional experiments HUVECS were pretreated for 24 tiours with haman recombinant "TNE 1100 or $300 \mathrm{U} / \mathrm{mL} ; 6.1 \times 10^{7} \mathrm{U} / \mathrm{mg}$ protein; gifi from $\$$ ASF KNOLL. Lodwighthafert, Germany) before incubarion for 24 hours with VT1 ( 10 pmoln $/$ ).

Parallel-piote flow chamber. For adlinesion experiments, wee used (2) paraillel-plate how chamber as previously described ${ }^{|4-2|}$ Briefly. the chambar is composed of two parallell surfaces, a coversilip coated with HUVECs at conflumes and a flat surface machined from polymethylmethacryllate, separated by a 250 - $\mathrm{km}$ thick silicon nbber gatsket, leawing a rectangular surface ( $30 \times 13 \mathrm{~mm}$ ) exposed to flow. Am inles and an outler channel distribute the fluid uniformtly along the entrance side of the adhesion sunface. After assembling with the

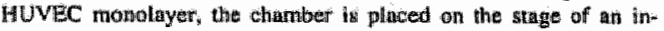

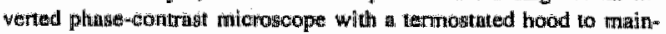

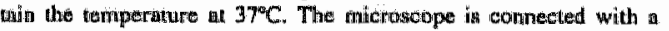

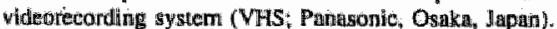

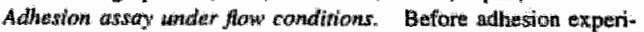
ments, letukocyle suspenzion was prepared trom fresh venowis blood

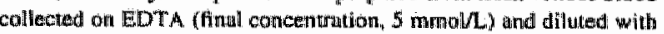
an equal volume of cold saline : is lution. The blood samples were centirituged at $200 \mathrm{~g}$ for 10 minutes at $4^{\circ} \mathrm{C}$, the cell pellel was resuspended in 4 vol of Enagel (Behringwerke $\mathrm{AO}_{1}$ Marburg, Germany), and erythrocytes were sedimented $4^{\circ} \mathrm{C}$ for 40 minutes. Supernatani was rimoved and centrifuged at $500 \mathrm{~g}$ for 7 mimuses at $4 \% \mathrm{C}$. and the pellet wasted twice by centrithigation with saltine. Remaining rythrocytes were removed by ammonitum chloride lysis al th and centrifugation. After this procedure, the cell viablilicy, neasured by uypan blue exclusion, was greater than 95 g. Cells were then resuspended, in culture medium at a fral concentrition of $10^{*} \mathrm{cellis} / \mathrm{mL}$.

Leukocyte sitspension was pumped through the chamber on $\mathrm{HL}$ $\mathrm{WEC}$ monolay ets, at contralled flow rates, using syringe pump (hiarviand Apparatus Inc. South Natick, MiA). After an initial perfusion of the fow chamber $0.6 \mathrm{dynes} \mathrm{cm}^{*}$ for 2 minutes for equilibration, the total leuknoyte suspension was perfused through the chamm

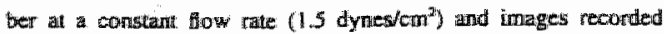
Hsing a video recording system. Anter 10 winutes of pertusion, the flow rate of the cell suspension was fincreased so that with sherar

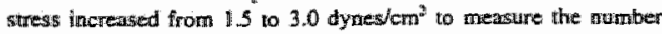

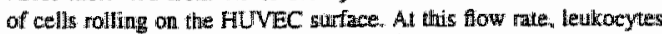
rolling on the adluesion surface are easily distimginishable from cells

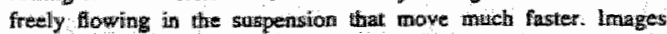
of adhering lewkocytes on the HUVEC surfoce were digtized and processed on a panonal computer using general purpose image processing softwiare (NITH Image, v. 1.43, Bethesda, MD). The number of rolling cells on HUVEC surtace ar 3.0 dynes/ $\mathrm{cm}^{2}$ was determitmed on a series of 16 consecutve images digitized dining a 10 wecond interval. Adherent levkocytes were dertified and counted at the end of 13 minutes of perfusion. ${ }^{202}$. All images were then superimposed by digitat processing so that moving cells could be distinguisherd from their walce.

Stantitical andysiss. Rescults are expressed as the mean $\pm \mathrm{SE}$. Statistical analysis was performed alsing andysis of variance and the Tukey-Ciccheti lest for multiple group comparisons. as appor prialce" Statistical significance was defined as $P<.05$.

\section{RESULTS}

Effect of VT.J an lewkocyte adhesion to HUVECs under physiologic flow conditions. We have studied the adhesion of peripheral total leukocynes to control. VT-1-treated $(0.1$. 1. and $10 \mathrm{pmol} / \mathrm{L})$ and $\Pi \mathrm{L}-1 \beta$-treated (100 U/mL) HUVECs under flow comditions. We used VT-1 at concentrations (chosen according to previous studjes ${ }^{\mathrm{k} g}$ ) that did not affect cell morphology (Fig 1 ) and cell count after 24 hours of incubation (VT-1 at $10 \mathrm{pmol} / \mathrm{L}: 69.4 \pm 2.0 \times 10^{4}$ cells $v$ control: $65.5 \pm 2.5 \times 10^{4}$ cells). As shown in Fig 2, exposure of HUVECs for 24 hours to increasing concentrations of VT1 dose-dependently increased the number of leukocytes adhering to HUVECs after 13 minutes of perfiusion, as compared with unstimulated control cells. On awerage $62 \pm 7$ leukocytes/mm adhered to unstirnulated HUVECs. Exposure of HUVECs to $0.1 \mathrm{pmol} / \mathrm{L}$ VT-1 did not modify the number of adherent leukocytes, which averaged $62 \pm 4$ leukocytes/mm ${ }^{2}$. VT-1 at 1 pmoll concentration significantly $(P<.01)$ increased the number of adhering leukocytes as compared with control cells; on average, $181=30$ leukocytes/mm adhered on the HUVEC surface. A similar adhesive response was observed after incubation with $10 \mathrm{pmol}$ L VT-1, with the number of adherent cells averaging $186=$ 20 lewkocytes/ $\mathrm{mm}^{2}$ ( $P<.01 \nu$ control) On $[L-1 \beta-$ stimulated HUVECs, the mean number of frrmly attacthed cells reached $226 \pm 29$ leukocytes $/ \mathrm{mm}^{2}$.

The possibility that VT-1-induced leukacyte adhesion could be due to endotoxin contamination of $V T-1$ preparations was ruled out by experiments showing that the number of leukocytes adhering to HUVECs exposed for 24 hours to LPS was similar to that of control HUVECs $(66 \pm 9$ y 58 \# 9 leukocytes $/ \mathrm{mm}^{2}$ ). Figure 3 depicts digitized inages from a representative experiment at the end of 13 minutes of leukocyne perfusion. A limited number of leukocytes firmly adhered to control HUVECs. A more than threefold increase in leukocyte adhesion was observed on HUVEC monolayers exposed for 24 hours to VT-1 (10 pmol/L). A similar response was elicited by IL-1 $\beta$, which is one of the most potent inducers of endothelial cell athesive properties.

The number of leukocytes rolling at 3 dynes $\mathrm{cm}^{2}$ are re- 

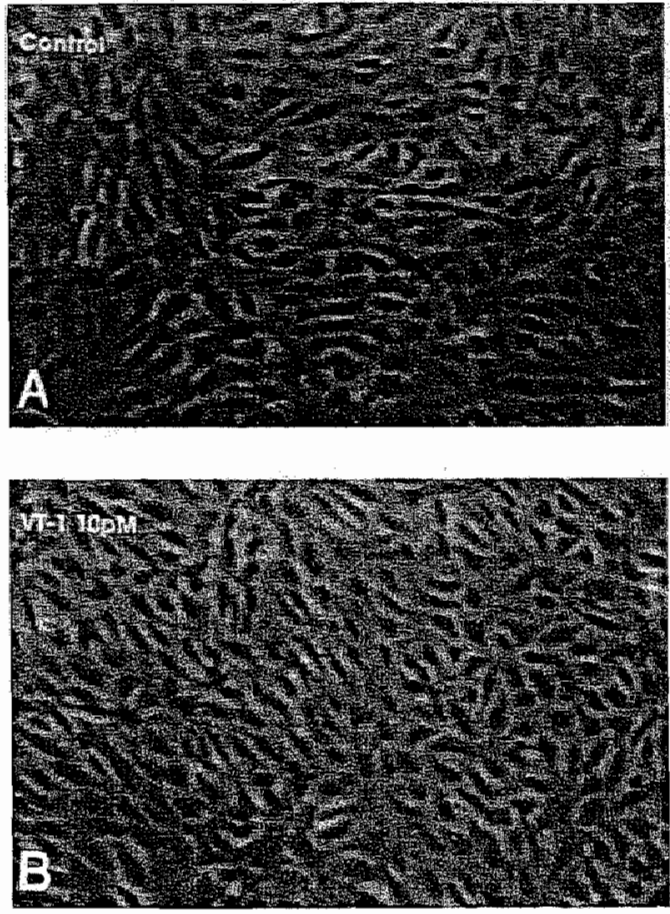

Fig 11. Effect of VT-1 on ondothellat oell morphology. HUVEC were incubated for 24 hours whth medium alone (erantroli) or in the prosence of VT-1 110 pmol/L).

ported in Fig 4. On unstimulated static HUVECs, fev rolling cells were delected averaging $2.3 \pm 0.5$ leukocytes $/ \mathrm{mm}^{2}$. Trentment of HUVECs for 24 hours with 1 or $10 \mathrm{pmol} / \mathrm{L}$ VT- $\|$ did not affect the number of rolling leukocytes, which averaged $5.3 \pm 2.1$ and $3.4 \pm 0.7$ leukocytes/mm" respectively. However, on IL- $1 \beta$-stimulated cells. the number of leskocytes nolting on endothelial surface significuntly $(P<$ 01) increased compared with that rolling on control and $\mathrm{VT}$ $1-$ treated HUVECs $(58 \pm 6$ leukocyles/mm²).

Cefl surface proteins involved in teuthocye adherton to VT-1-stimulafed HUVECi. To explore the mollecular basis of VT-1-induced leukocyte adhesion 10 endorthelinl cells under filow, HUVECs exposed for 24 hours to VT.1 (10 pmollL) were incubated for 20 minutes witl MoAb antiE-selectin, ant-ICAM-1, and ant-VCAM-1 immediately before performing leukocyte adhesion experiments. As shown in Fig $S$, at the end of the perfusion assay the number of adherent leukocytes on HUVECs treated with VT-1 was singnificantly higher as compared with leukocytes adhering on contral untreated HUWECs $191 \pm 28$ y $196 \pm 6$ leukocyles $/ \mathrm{mm}^{2}$. $P<011$. MoAb anti-E-selectin singifficantly inhibited VT-1 induced increase in leukocyte adhesion $(73$ $\pm 17,191 \pm 28$ lewkocytes $m^{2}, P<01 \%$. MoAb antiICAM-I and anti-VCAM-I also significantly reduced leukocyte adhesion to VT.1-treated HUVECs $1100 \pm 26$ and

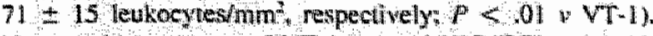
Noteworthy expasane of TT 1 -neated HUVECS to MoA ant-E-seleetin and ant - YCAM-1 lowered the number of adhering lewkocytes to contro values $150 \pm 6$ leukocyles $\mathrm{mm}^{2}$ ). Treatmen with welewan MoAb did not uffert leukocyle adhesion on VT-1-woted HUVECs $(207 \pm 63$ \% 187 \pm 56 leukocytes/mat

The number of folling letukocytes on VT-I-treated 10 pmoLL HUVECs ncubaled with MoAb against Eselectin. $1 C A M-1$ and VCAM-I was simita to that observed on endothelial cells treated with VT, 1 alone $(3.4 \pm 1.5 ; 4.8 \pm$ $0.8: 3.1 \pm 0.6 v 3.4 \pm 0.7$ leukacytes $/ \mathrm{mm}^{2}$ ).

Effect of TNF on VT-1-indinced lewaroy adhesion to HUNECs under physiologie flow condirions in some experiments, before $\mathrm{VT}-1(10 \mathrm{pmol} / \mathrm{L})$ Incubation, HUVEC were pre-exposed for 24 hours to TNF $\alpha$ ar the concentration of $100 \mathrm{CH} \mathrm{mL}$, which was previtousty show to increwse VT-I receptor expression on HUVEC: (Fig) 6 ) $\mathrm{VT}-1$ significamtly enhanced leukocyne adhesion on HUVEC as compared with comtrol cells $\left(146=15\right.$ N45 $=5$ leukocytes/mm $\left.{ }^{2} P<.01\right)$ The number of leukogytes adhering to HUVECs pre-exposod to TNFa before challenge with VT-1 were sirgnilicantly bigher than that of HUVEC exposed to VT') alone (300) $13 \vee 146 \pm 15$ leukooytes/mm,$P<01)$. The number of leukocytes adhering on HUVECs exposed to TNFo (100 U) $\mathrm{mL})$ alone averaged $201=29$ leukocytes/mm $(P<.01$ TNF $\alpha$ + VT 1 )

With additional experiments we established thal leukocyte adhesion on HUVECs reached alatenu at a TNFa concentration of $300 \mathrm{w} / \mathrm{mL}$ (control. $71.2 \pm 6.8 ; 100 \mathrm{U} / \mathrm{mL}$ TNFar, $162.4 \pm 13.5 ; 300 \mathrm{U} / \mathrm{mL}$ TNFa, $286.2 \pm 13.6 ; 500 \mathrm{U} / \mathrm{mL}$ TNF $\alpha, 268.0 \pm 10.7$ leukocyles $\left./ \mathrm{mm}^{2}\right)$. When HUVECs pretreated with $300 \mathrm{U} / \mathrm{mL}$. TNFar were exposed to VT-1 10

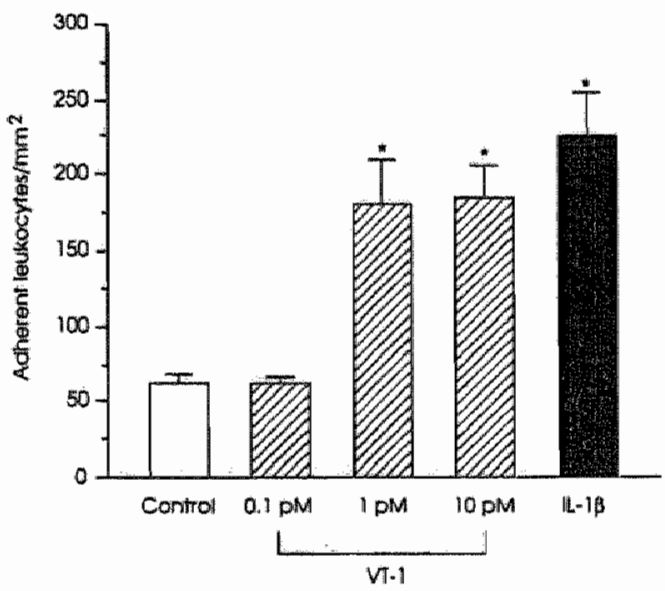

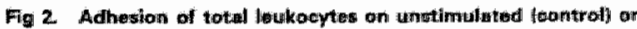
VT-1-stimntizted: HUVECs tunder conditions of flow, HUWECs ware

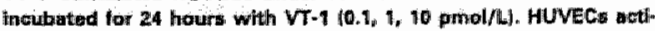

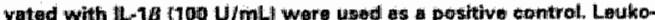
oyte adthesson was miensured at the ond of 13 minutes of perfution.

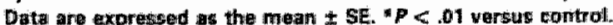



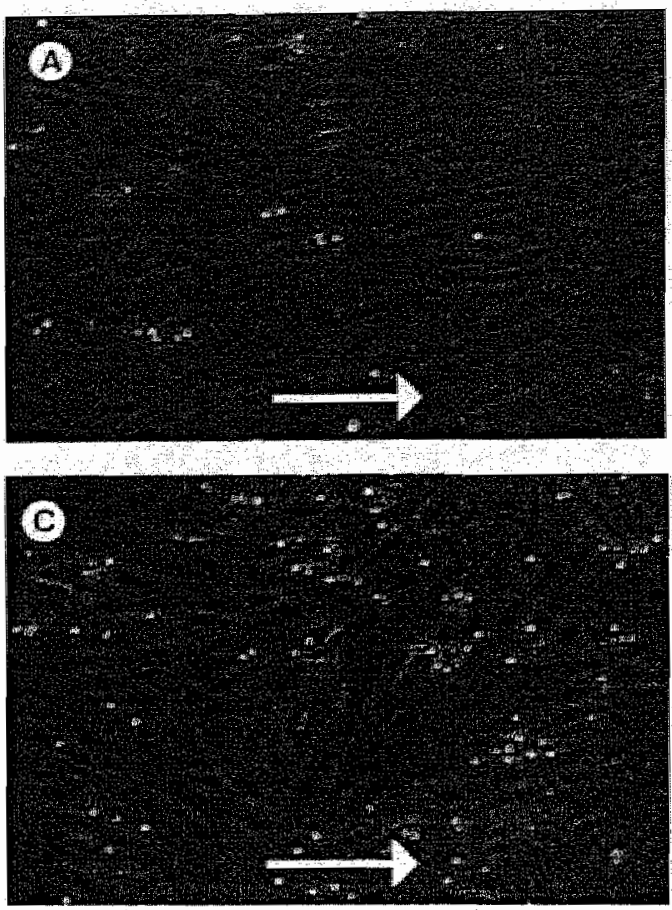

(pmol/L), an additive effect of VT-I on leukocyte adhesion was observed in only 4 of 8 experiments with a perceniage increase of $60.7 \% \pm 8.3 \%$ over TNFa alone.

\section{DISCUSSION}

The presen results show that VT-1 dose-dependently induced leukracyte adhesion to endothelial cells under fow

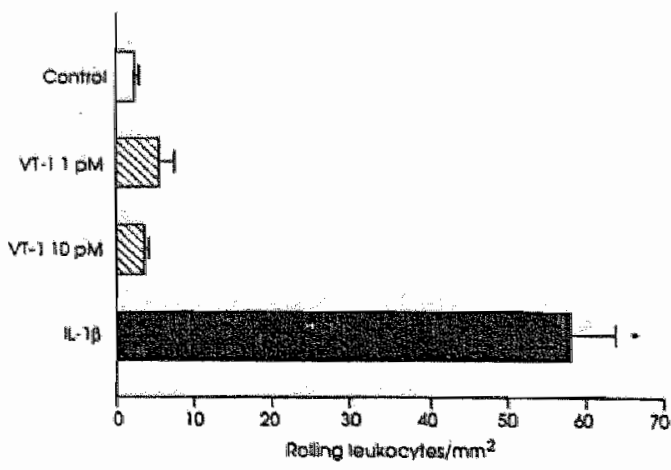

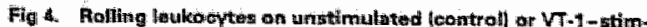

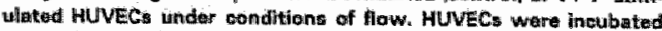

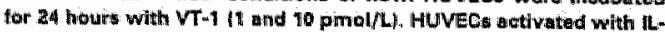
1 (5 1 $100 \mathrm{~W} / \mathrm{mLL}$ were used as a positive controd. Leukocyte rolling was

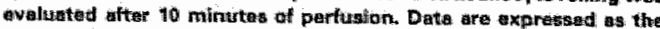

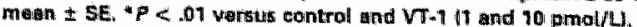

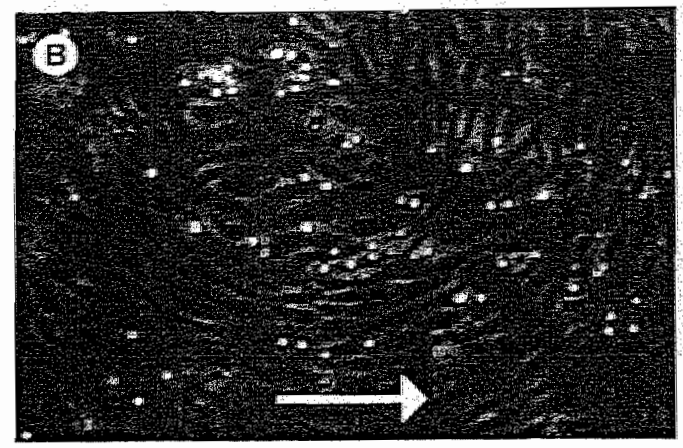

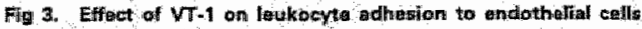

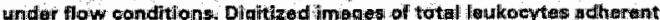
an HUVECs afrer 13 minutes of parfixsion in a pratrallel-plat flow chambar. HUVECs wero inculatated with modium alone (A) in the

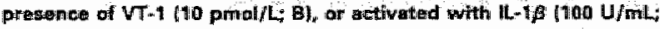
c).

conditions. The adhesive response elicited by VT-I was quite comparable to that of $\mathrm{IL}-1 \beta$, one of the most potent inducers of leukocyte-endothelial cell adhesion. Becuse leukocyte atrachment consistenly induces granule content reledse," the present sudy helps to ciurify mechanism(s) by which VT-I damages the endothelium. These results are in harmony with data that in vitro HUS neutrophils adhere 10 endothelium more than nomal neutrophils. ${ }^{16}$ Neutrophil-derived products (particularly elastase) that are released locally on nevtrophil adhesion to endothelium degrade extracellutar matrix, which would favor endothelital cell detachment from basement membrante, aypical feature of HUS. " Formal evidence that this may occur in HUS derives from data that enhaneed adhesion of neutrophils from HUS patients to endothelium in vitro is followed try degradatian of endothellial cell fibronectin.

Events that regulate recruitment of leukocytes and subse. quent migration are critically dependent on adbesive molecules consitutively expressed on the surface of the endothelium and letukocytes or induced by cytokines or flow condition. ${ }^{2+21}$ Early molecules invalved in this process belong to the selectin tumily ${ }^{24}$ and are expressed on endothelial cells upon cytokine activation. Subsequent firm athesion of leukocytes implies the interactions of leukocyte $\beta 2$ and $\beta 1$ integrin receptors with specific endothelial ligand, ie, ICAM- 1 and VCAM-1, constitutively expressed on endothelial surface, whose level is further increased by oytokine

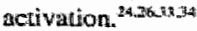

With the present study we have established that functional 
Fig 5. Effoct of MaAb anti-E-salectin, anti-ICAM1, or anti-VCAM-1 on VT-1-inducad leulkocyte adhesion on endotheltil cellis. Before the adhesion asserer. VT-1-treated (40 pmol/L) HUVEC ware incubated for 20 minutes with MoAb anti-E-salactin, entiICAM-1, or anxi-VCAM-1. Data are expressed as the merin \pm SE. " $p<$. 01 warsus controb $* p<.01$ versus VT-1..

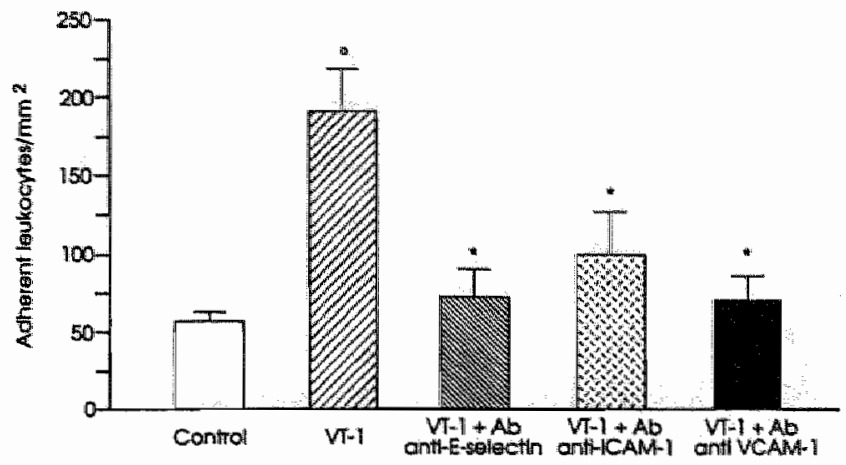

blocking of E-selectin, ICAM-1, and VCAM-1 with respective antibodies significantly reduced VT-1-mediated leukocyte adhesion to endothelial cells exposed to flow. An additional finding of the present study was that VT-1 inhibited the process of rolling that normally precedes adhesion of cells to the endothelium. We observed a similar phenomenon in tumor cell adhesion to the endothelium under flow ${ }^{20}$ It was established that certain lines (ie, A375M and A2058. melanomas and the MG-63 osteosarcoma) fimly adhered on activated endothelial cells before any rolling could be seen whereas other lines (HT-29M colon carcinoma and OVCAR3 avarian carcinoma) were capable of usual rolling before they adhered. It is tempting to speculate that VT-1 causes sudden expression of ICAM- $\|$ and VCAM-I at very high density on endothelial cell surface, which would promote immediate leukocyte adbesion not preceded by rolling. The last observation of the present study was that pre-exposure of HUNECs to TNF $\alpha$ before challenge with VT-1 significantly increased the number of adherent leukocytes under flow. This observation is consistent with several recent findings

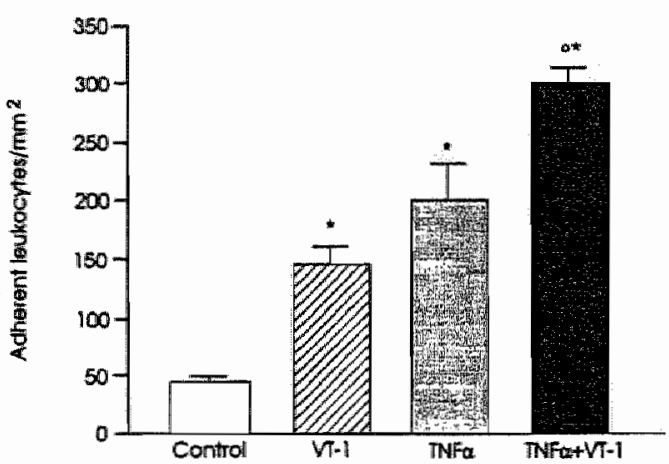

Fig 6. Effect of TifFa on VT-1-induced laskocyte adhesion on endothelial cells undier flow conditions. HUVECS were intubated with medfium atone, VT-1 $110 \mathrm{pmol} / \mathrm{L}\}$, or TNF $(100 \mathrm{U} / \mathrm{mL})$ before exposure to VT-1 (10 pmot/h). Data are expressed as the mean \pm SE. "P $<.01$ varsis comtrol: ${ }^{*} P<.01$ versus $V T-1$ and TNF $\alpha$. that TNFo does promote upregulation of endothellial VT$\mathrm{Cb}_{3}$ receptor and supports VT-11 binding

That TNF $\alpha$ plays a major role in VT-1-induced microvascular injury is documented by findings that mice genetically defective in TNF $\alpha$ production were less sensitive to the lethal effects of VT-1. ${ }^{35}$ These mice consistently had a longer mean time to death than did mice who were nominally responsive. The molecular basis for the interaction between VT- 1 and TNF $\alpha$ in determing extent and localization of microvascular lesions were recently addressed in an elegant experiment of mice bearing a chloroamphenicol acetyll-transferase (CAT) reporter gene that indicates TNF $\alpha$ synthesis. ${ }^{36}$ Upon VT-1 injection to the above-mentioned mice, CAT activity was selectively induced in the kidney but not in other organs. indicating a distinct potential of VT-1 of upregulating TNF $\alpha$ gene expression not equally distributed within all organs, which fits well with the unique sensitivity of the kidney to microvascular damage in HUS.

In conclusion, our results indicate that (1) VT-1 is a potemt promoter of leukocyte adhesion to endothelial cells ander fow conditions; (2) VT-1-induced leukocyte-endothelial interaction depends on upregulation of adthesion molecules that include E-selectin, ICAM-1, and VCAM-1, as documented by inhibition studies with respective specific anitibodies; and (3) VT-1-induced leukocyte adthesion is enthanced by TNFa.

Despite the potential limuthtions of these in vitro studies ass far as their theoretical implicution in vivo, the presert fincings might be relevant to understand the nature of microvascular lesions in children with VTEC-associzted HUS and open exciting new perspectives for treatment.

\section{ACKNOWVEDGMENT}

This work is dedicated to Prof Alfrecio Leonardi. We thank Dry Aldo Gambarini and Papll Rosaschino (Division of Obsietries and Gynecology, Ospedale Bolognini, Seriate, Bergatno, (tally) for invaluable help in collecting unibilical samples.

\section{REFERENCES}

1. Karmali MA, Petrie M, Lim C, Fleming PC, Arbuis QS, Lior $M$ : The association between idiopathic hemolytic uremic symdrome and infection by verotoxin-producing Estherlchia coll. IInfect Dis 151:775 1988 
2. Karmall MA: The sesteciation of verocytotoxins and the classteal hemolytic aremic syndrome, fon Kaplass BS Tromipeter RS

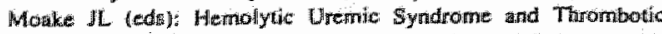
Thrombocylopenic Purpumia New York, MY, Marcel De:ker. 1992. pi 199

3. Remuzzi $O_{1}$ Rugenenti P: The hemolytic uremic syndirome. Kituney Int 472,1995

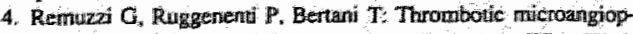
withy, in Twsher CC. Brenner BM (eds): Rendil Pathology With Clinical and Functionall Contelations. Philadelphia, Lippincott, 1994, p $\| 1154$

5. O'Rrien $A D_{1}$ Holmes RK: Shiga and shiga-like toxins. Mierobiol Rev $\$ 1,206,1987$

6. Lirigwood CA, Law H, Richardson S, Petric M, Brunton $\mathrm{JL}$ De Orandis \$. Kamili MA: Glycolipid binding of punfied and recombitiant Escherichila coll produced verotoxin in vitro. I Biol Chem 262.8834, 1987

7. Lindberg AA, Brown JE, Stronberg $N$, Westling-Ryd $M$, Schultz JE, Karllsion K-A. Identificiation of the earbohydrate receptor for Shiga toxin produced by Shigella dysenteriae type 1. I Biol Chern 262:1779, 1987

8. Obrig TG, Lovilse CB, Lingwood CA, Boyd B, Barley-Maloney $\mathrm{L}_{\mathrm{L}}$ Dariel To: Endothelial beterogeneity in Stiga "Toxin receptors and respontses. I Bial Chem 268:15484, 1993

9. vain de Kar NCAl, Monnens LA.H, Karmali MA, van Hinsbergh VWM: Tumor necrosis factor and interleukin-1 induce expression of the verocytotoxin receptor globotriaosylceramide on human endothelial cells: Implications for the pathogenesis of the bemolytic uremic syndrome. Blood 80:2755, 1992

10. Kavi J, Wise R: Causes of the haemolytic uraemic syoudrome: I might the verociytotoxin produced by Escherichio coll. Br Med I $298: 65.1989$

11. Zoja C. Remuzzi G: The pivotal role of the endothelial cell in the pathogenesis of HUS, in Kaplan BS, Trompeter RS, Moake JL. (edis): Hemolytic Uremic Syndrome and Thrombotic Thrombocytopenic Purpura. New York, NY, Marcel Dekker, 1992, p 389

12. Louise CB, Obrig TO: Shign toxin-asscciated hemolytic-uremic syndrome: Combined cytotoxic effects of shiga toxin, interlewkin-1 $\beta$, and tumor neerosís factor ulpha on humat vascular endothelial cells in vitro. Infect Immunity 59:4173, 1991

13. wan de Kar NCAJ, Kooistra T. Vemneer M. Lesslauer W, Monnens $\mathrm{LAH}_{1}$ van Hinsbergh VWM: Tumor necrosis factor a indiwess endlothelial galactosyl transferase acti wity and verocytotonin recepiors. Role of appexiffic thmor necrosis factor receptors anil protein kinatse C. Blowd 85:734, 1995

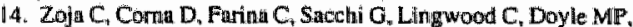

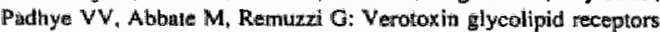
determine the locialization of microungiopathte process in rabbits given wetoxinn 1 . I Lub Clin Ned 120:229, 1992

15. wan Setten PA, wan de Heuvel LPWJ, Monnens LAH Effects of werocytotoxin-I on butman monocytes. Binding chatacteristics and induction of cytokine relense. J Am Soc Nephrol 4:639, 1993 (abstr)

16. Forsyth KD. Sirmpson AC. Fitzpatrick MM, Barran TM, Le. winkly R: Neutrophill-imediated endothellial injury in haemolytic uraemic syndrorne. Lancet 2:411, 1989

17. Fitzpaurick MM, Shah V. Trompeter RS. Dillon MU, Barratt TM: Interleukin-8 and polymorphoneutrophil lencocyte sctivation in hemolytic uremic syadrome of childhood. Kidmey int $4295 \%$. 1992

18. Jaffe E Machman R Becker C. Minick C' Cuthure of fuman endothelfial cells derived from umbilical veins: Aentification by morphologic and immunologice criteria. J Clin Inwest 52:2745, 1973

19. Lawrence MB, McIntire LV, Eskin SG: Effect thew on polymorphonuclear leakocytedendothelial cell adhesion. Biood 70.1284. 1998

20. Giasazzi $R$, Foppolo M, Dossi $R$, Remuzz A: Rolling and adheaion of human twmor cells on vaseular endothelium vinder physiological flow condituons. J Clin Invest 92:3038, 1993

21. Morigi M. Zoja C, Fyglinzza $M_{8}$ Foppolo $M_{n}$ Micheleti $G$. Bontempilf $M$, Saronni M, Remwezi Ci, Remuzzi A: Filuid shicar stress modulates surface expression of adhesion molecules by endothellial cells. Blood 85:1696, 1995

22. Wallenstein $\mathrm{S}, \mathrm{Zueke \pi} C \mathrm{CL}$. Fierss $1 \mathrm{LL}$ - Some statistical methots useful in circulation research. Circ Res 47:1, 1980

23. Nathan CF: Neutrophil activation on biological surfaces. Massive secretion of hydrogen peroxide in response to products of macrophages and |lymphocytex. 1 Clin Invest 80,1550, 1987

24 Brady HR: Leukocyte adhesion molecules and kidney diseases. Kïdney Ins 45:1288, 1994

25. Cronstein $B N$, weissman $G$ : The adhesion molecules of inflammation. Arthritis Rheurn 36:147, 1993

26. Osborn L: Leukocyte adhesion to endothelium in inflammation. Cell $62 \% 3,1990$

27. Nagel T, Resnick N. Adkinson WJ, Dewey CF Jr, Gimbrone MA. Jr. Shear suress selectively apregulates intercellular adhesion molecule-i expression in cultured human wascular endothelial cellis. $J$ Clin Inwest 94:885, 1994

28. Ohtsuka $A_{n}$ Ando J, Korenaga $R_{n}$ Kamiya $A_{*}$ Toyama-Sorimachi Mi Miyasaka $M$ : The effect of flow on the expression of vascular adhesion moleculle-1 by cuthred mouse endotieliall cells. Biochem Biophys Res Commun 193:303, 1993

29. Alon R, Rossiter H, Wang X, Springer TA, Kupper TS: Dishtinct cell surface ligands mediate $T$ lymphocyte attachment and nolling on $P$ and $E$ selectin under physiological flow. J Cell Biol $127: 1485_{\mathrm{u}} 1994$

30. Ley $K$, Bullard DC, Arbones ML, Bosse R, Vestueber $D$, Tedder TF, Beaudet AL: Sequential contribution of $L$ - and P-selectin to leukocyte rolling in wivo. J Exp Med 181:6.59, 1995

31. Lawrence MB, Springer TA: Neutrophills roll on E-selectin. J Immunol 151:6338, 1993

32. Abbassi $O$ Kishimoto TK, Meintire LV, Anderson DC, Smith CW: E-selectin suppots neutrophil rolling in vitro under conditions of How. J Clin invesh 92:2719, 1993

33. Wuthrich RP: Intercellular adkesion molecules and vascular cell adhesion molecule-1 and the kidiney. J Am Soc Nephrol 3:1201. 1992

34. Jones DA, Mclntire LW, Smich CW, Picker LS: A momstep adivesion cascade for $T$ celbrandathelial cell interactions under flow conditions. I Clin Inverst 94:2443, 1994

35. Barrent TI, Poter ME, Strockbine N.A: Evidence for participation of the macrophage in Shiga like toxin-Il induced lethility in mice. Microb Pathog 9:95, 1990

36. Harel Y, Silva M. Giroir B, Weinberg A, Cleary TE, Beutler B: A reporter tranggene indicates renal-specific induction of amor necrosis factor (TNF) by Shiga-like toxin. If Clin Invest $92: 2110$ 1993 
CHAPTER 4

SHIGA TOXIN-2 TRIGGERS ENDOTHELIAL LEUKOCYTE ADHESION AND TRANSMIGRATION VIA NF-KB DEPENDENT UP REGULATION OF IL-8 AND MCP-1.

C. Zoja, S. Angioletti, R. Donadelli, C. Zanchi, S. Tomasoni, E. Binda, B. Imberti, $M$. te Loo, L. Monnens, G. Remuzzi and M. Morigi

Kidney Int 2002; 62: 846-856 



\title{
Shiga toxin-2 triggers endothelial leukocyte adhesion and transmigration via NF- $\mathrm{B}$ dependent up-regulation of IL-8 and MCP- $1^{1}$
}

\author{
Carla Zoja, Stefania Angrolett, Roberta Donadell, Cristena Zanch, \\ Susanna Tomason, Elena Binda, Barbara Imberm, Maroeska te Loo, \\ Leo Monnens, Gruseppe Remuzzi, and Marna Morigr
}

Mario Negri Instinte for Phanmacolagical Research, and Unit of Nephrology amd Dialysis, Artuenda Ospedaliera, Ospedali Rinuiti di Bergano, Bergano, Italy; and Department of Pediatrios, University Hospiral Numegen, Nijmegen, The Netherlands

\begin{abstract}
Shiga toxin-2 triggers endothelial leakocyte adthesion and transmugration via $\mathrm{NF}-\mathrm{k} B$ dependent ap-regulation of $\mathrm{L}-8$ and MCP-1.

Background Shiga toxin (Stx)-producing $E$. coll is a causative agent of the epidemic form of hemolytic uremic syndrome (HUS), the most common cause of acute renal failure in chil. drea. Endothelial injury and leukocyte activation are insirumental to the development of microangiopathic lesions. To obrain more insight in to the mechanisms favoring endotheliumlevtrocyte interaction, we studied $(l)$ the effect of $S+x-2$ on lenkocyte adhesion and ransmigration in human ondothelial cells under flow; (2) the effect of Stx-2 on endothelial expression of monocyte chemoattractant protein-1 (MCP-1) and interleukin-8 $(\mathbb{L}-8)$ and their functional role in the adhesive phenomene; and $(3)$ the role of nuclear factor-kB $(N \sqrt{F-\kappa B})$ in endothellial chemoline expression.

Methods. For adhesion experiments, human umbilical vein endo thellial cells (HUVEC) and human glomerular endothelial cells (GEC) were incubated for 24 hours with $5+2$ ( 25 pmollL), with or without anti-IL-8 or MCP-1 amtibodies, and then expased to leukocyte suspuension under fow (1.5 dynes/cm $\left.{ }^{2}\right)$. IL-8 and MCP-1 expression was evaluated in Stx-2 treated endothelial cells ( 6 hours) by Northem blot. NF-KB activity was assessed by electrophoretic mobility shift assay. The role of NF.kB in Stx-induced chemokines was evaluated by transfect. ing HUVEC with an adenovirus coding for $I_{k} B \alpha$.

Resulss. Stx-2 signitteantly enhanced the number of leukocytes that adhered and then migrated across the entothelium. $5 t x-2$ increased the expression of $I L-8$ and MCP-1, which was preceded by $N F-k \mathbb{B}$ activation. Blocking of endotbelial IL-8 and MCP-1 with corresponding antibodies signifeantly imhibited $S$ sinduced leukocyte adhesion and migration wither in HUWEC or GEC. Adenovirus-mediated gene transfer of $1 \times B \alpha$
\end{abstract}

"See Editorial by Silegler and Pysther, p. 1088.

Key wordss benolytic uremic syndrome, chemolines, glomerular enciothelial cells, gene transfer, flow thrombocytopenia, acute renal failure.

Recelved for publication December 27, 2001

and in revised form March 22, 2002

Accepled for publication March 27, 2002

2002 by the Internationall Society of Nephrology down-regulated II-8 and MCP.1 mRNA and also inhibited the adhesion and tramsingration of leukocytes in Stx-trated HUVEC.

Conclusions. Stx -2 wia a transcriptional activation mecha. nism specifically mediated by $N F-k B$ up-regulates exdothelial. MCP- 1 and $\Pi-8$. Both chemokines are important modulators of leukocyte adbesion and transmigration under liow. These findings might be relevant to anderstand the tature of mictovascular lesions in HUS and open future perspectives for better treatment of microvascular thrombosis.

Sporadic hemolytic uremic syndrome (HUS) is a disease of thrombocytopenia, microangiopathic hemolytic anemia and acute renal failure that mainly affects infants and small children [1,2]. Infection with Shiga toxin (Stx)producing Escherichia coli has been strongly implicated as the most common causative agent [3-6]. E. coll $0157:$ H7 strains that are isolated from patients with HUS produce $S t x-1$ and $S t x-2$, and epidemiological data indicate that Stx-2 producing $E$. coli are more likely to cause HUS than the strains that produce only $S t x-1[5,6]$.

After the ingestion of contaminated food or water [7], Shiga toxins gain access to the systemic circulation and rapidly and completely bind to specific receptors expressed on circulating cells, mainly polymorphonuclear leukocytes, which transport them to the kidney or other target organs $[8,9]$. Endothelial damage is crucial to the subsequent development of microangiopathic lesions, and evidence is available that the interaction between leukocytes and endothelial cells serves to magnify the ex. tent of endothelial injury $[5,6,10,11]$. Shiga toxins can directly damage endothelial cells after binding to a specific glycosphingolipid globotriaosyl ceramide (Gb3) receptor expressed on the cell surtace [11,12]. The binding is followed by internalization in the cytosol of the toxin that exerts its cytotoxic effect via ithibition of protein 
sydthesis $[4,13,14]$ and apoptosis [15]. Cytokines like interleukin-1 (NL1) and tumor necrosis factor (TNF) released by monocytes/macrophages in response to Stxs [16] remarkably enhanced vascullar sensitivity to the toxins by up-regulating the endothelial Gb3 receptor [13].

We have demonstrated that $S t x-1$ induced a massive leukocyte adhesion to culnured human endothelial cells under flow conditions, by up-regulating the adhesive proteins E-selectin, intracellular adhesion molecule-1 (ICAM-1), and wascular cell adhesion molecule-1 (VCAM-1) [17]. The adhesion of leukocytes was enhanced by pre-exposure of the endotbelial cells to TNF- $\alpha$. More over, nevtrophills from children with the acute phase of HUS adhered to endothelial cells in witro more than normal neutrophils and induced endothelial injury by local release of proteases [18]. Indeed, plasma concentrations of $\alpha 1$-antitrypsin-complexed elastase and the chemolkine IL-8-a potent activator of neutrophils-were remarkably higher in the acute phase of the disease, which presumably reflected nentrophil activation and degranulation in vivo [19].

Kidney specimens from HUS children with evidence of Stx-producing $E$. coli infection revealed a conspicuous infiltration of polymorphonviclear and mononuclear cells within the glomeruli, along with microvascular injury $[20,21]$. In those patients urinary levels of $L L-8$ and monocyte chemoattractant protein-1 (MCP-1), potent attractants of neutrophils, and monocytes/macrophages and T-lymphocytes, respectively, were elevated during the acute phase of the disease, and gradually declined until recovery, implying a role for these chemokines in the recruitment of inflammatory cells at the glomerular level $[21,22]$.

Evidence is available that IL-8 and MCP-1 can be released by endothelial cells stimulated by proinflammatory mediators, such as cytokines and lipopolysaccharide [23], depending on the activity of the transcription

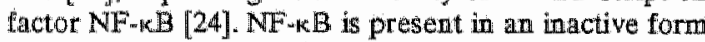
in the cell cytoplasm and is activated upon proteolytic degradation of the inhibitory protein $1 \mathrm{kB}$ [25].

The present study investigated: (1) the effects of $5 t x-2$ on leukocyte adhesion and transmigration through human endothelium tuman umbilical vein endothelial cells (HUVEC) and human glomerular endothelial cells (GEC)under flow conditions; (2) the ability of Stx-2 to modulate the endothelial expression of the chemoattractant proteins $1 L-8$ and MCP.1 and their functional role in the adhesive phenomena. Moreover, since IL-8 and MCP-1 are regulated by the transcription factor $N \mathrm{NF}_{-} \mathrm{kB}$, we also studfed (3) whether $S t x-2$ induced the activation of $N E-k B$ in endothelial cells and (4) whether transfection of endothelium with recombinant adenovirus coding for $I_{k} B \alpha$, the natural in mibitor of $N F-k B$, resulted in successful inhibition of chemokine up-regulation, and leukocyte adbesion and transmigration induced by $\mathrm{Stx}-2$.

\section{METHODS}

\section{Endothelial cell culture and incubation}

Human umbilical vein endothelial cells (HUVEC were obtained by collagenase digestion according to th method of Jaffe et al [26]. The cells were grown in Me dium 199 (Gibco BRL, Gaithersburg, MD, USA) svp plemented with $10 \%$ newborn calf serum (Gibco) and $10 \%$ human serum, $5 \mathrm{mmol} / \mathrm{L} \mathrm{N}$-2-hydroxyethylpipera zine-N-2-ethanesulfonic acid (HEPES; Sigma Chemical St. Louis, MO, USA), $100 \mathrm{U} / \mathrm{mL}$ penicillin, $100 \mu \mathrm{g} / \mathrm{ml}$ streptomycio. $2.5 \mu \mathrm{g} / \mathrm{mL}$ fungizone, $2 \mathrm{mmol} / \mathrm{L}$ glutaming (Gibco), $15 \mathrm{U} / \mathrm{mL}$ heparin (Parke-Davis, Milan, Italy) and $50 \mu \mathrm{g} / \mathrm{mL}$ endothelial cell growth factor. Cultured cells were identified as endothelial by their cobblestone morphology and the presence of won Willebrand factor using indirect immunofluorescence microscopy. Confil ent cells were routinely used between the first and fifth passages. For adhesion experiments, HUVEC were plated on $60 \times 20 \mathrm{~mm}$ plastic coverslips (Thermanox, Nunc inc; Naperville, IL, USA) coated with bovine gelatin ( $0.2 \%$ Sigma) and used two days after reaching confluence.

Human glomerular endothelial cells (GEC) were iso* lated from kidneys that were not suitable for transplanta: tion because of anatomical anomalies or technical rea. sons, by collagenase digestion as previously described [27]. The cells were grown in Medium 199 supplemented with $10 \%$ newbora calf serum (Gibco) and $10 \%$ buman serum, 2. mmolL glutamine, $100 \mathrm{U} / \mathrm{mL}$ penicillin, $100 \mu \mathrm{g} / \mathrm{mL}$ streptomycin, $5 \mathrm{U} / \mathrm{mL}$ heparin and $150 \mu \mathrm{g} / \mathrm{mL}$ endothelial cell growth factor. Cells were characterized by indirect immunofluotescence with a panel of endothelial cell-specific antibodies, namely von Willebrand factor, platelet. endothelial cell adhesion molecule-1 (PECAM-1) and visceral epithelial (VE)-cadherin. To exclude contamination with epithelial and mesangial cells, indirect immumofluorescence with antibodies against anti-cytokeratin 20 and anti-o-smootil muscle actin were performed [27]. No immunoreactivity was observed in cells used for the experiments, indicating that pure GEC were used. Two different donors of $\mathrm{GEC}$ were used to perform experi. ments.

For adhesion experiments GEC were plated on $60 \times$ 20-mm plastic coverslips (Thermanox) coated with porcine gelatin ( $1 \%$ : Fluka BioChemika, Buchs, Switzerland) and used two days after reaching confluence.

To investigate the effect of $S \mathrm{Lx}-2$ on leukocyte adhesion and transmigration, confluent HUVEC were incubated for 24 hours with medium alone (M-199 plus $10 \%$ fetal calf serum; Gibco), with Stx-2 at a subtoxic concentration (25 pmol/L; Toxin Technology Inc., Sarasota, FL, USA) or with TNF- $\alpha$ (100 U/mL; Knoll AG, Ludwigshafen, Germany), then endothelial cells were perfused at $1.5 \mathrm{dynes} / \mathrm{cm}^{2}$ in a parallel plate flow chamber with total leukocyte suspension. Selected adhesion experi. 
ments $(N=3)$ under How were performed in GEC exposed for 24 hours to $S \mathrm{Lx}-2$ (25 pmoll ).

To elucidate whether Stx-2 modulated endothelial $\mathrm{ex}$ pression of IL-8 and MCP-1, HUVEC were exposed for six hours to different concentrations of $\mathrm{Stx}-2(25 \mathrm{pmol} / \mathrm{L}$, $50 \mathrm{pmol} / \mathrm{L}$ and $1 \mathrm{nmol} / \mathrm{L}$ ), and then cells were processed for Northern blot analysis of IL-8 and MCP-1 mRNA.

The role of these chemokines in Stx-induced leukocyte adhesion and transmigration was evaluated by incubating HUVEC or GEC pre-treated 24 hours with 25 pmoll Stx-2- with functional blocking rabbit polyclonal anti-buman IL-8 antibody (10 $\mu \mathrm{g} / 200 \mu \mathrm{L}$; Endogen, Woburn, MA, USA) or mouse monoclonal anti-human MCP-1 antibody $(20 \mu \mathrm{g} / 200 \mu \mathrm{L}$; a kind gift by G. Peri, Mario Negri Institute, Milan, Italy) [28] or with rabbit or mouse isotype-matched IgG $(10 \mu \mathrm{g} / 200 \mu \mathrm{L}$, Endogen; and $20 \mu g / 200 \mu, \mathrm{L}$, Camfolio, Becton Dickinson, San Jose, CA, respectively) as control, for 20 minutes at room temperature, before the adhesion assay.

To identify the leukocyte populations that adhered on Stx-treated endothelial cells in the presence or absence of anti-IL-8 and MCP- 1 antibodies, HUVEC at the end of leukocyte perfusion under flow were staimed by MayGrunwald/Giemsa. Cells were fixed in methyl alcohol for three minutes at room temperature and stained with $1: 2$ dilution of May-Grunwald solution in phosphatebuffered saline (PBS) for one minute. After two washings with distilled water, cells were incubated for five minutes with $1: 3$ dilution of Giemsa solution in PBS. Coverslips were washed twice and examined by microscope. Polymorphonuclear cells and mononuclear cells were identified and counted in several fields $(N=10)$ for each coverslip ( $N=4$ experiments).

The ability of Stx-2 to activate the tramscription factor NF- $\kappa B$ was evaluated by electrophoretic mobility shift analysis (EMSA) of nuclear extracts from HUVEC exposed for one hour to $S \mathrm{tx}-2(25 \mathrm{pmol} / \mathrm{L}, 50 \mathrm{pmol} / \mathrm{L}$ and $1 \mathrm{nmol} / \mathrm{L})$.

Finally, to assess the involvement of $\mathrm{NF}-\mathrm{KB}$ in $\mathrm{Stx}-$ induced IL-8 and MCP-1 mRNA up-regulation and levkocyte adhesion and transmigration, HUVEC were transfected (for $3 \mathrm{~h}$ ) with recombinant adenovirus coding for $I_{\kappa} B \alpha$, the natural inhibitor of NF-KB [29]. After transfection cells were maintained for 24 hours in growth medium and then exposed $(6 \mathrm{~h})$ to $50 \mathrm{pmol} / \mathrm{L}$ Stx-2 for Northern blot experiments or to $25 \mathrm{pmol} / \mathrm{L}$ StX-2 (24 h) for adhesion experiments.

\section{Shiga toxin-2 preparation}

Shiga toxin-2 was prepared by the manufacturer as follows: $E$ coli strain PMJ-100 was grown overnight in Brain Heart Infusion Broth, then centrifuged to collect the cells. The cells were extracted by freezing and then treating with lysing agent (B-PER; Pierce, Rockford, IL, USA). The extract was dialyzed and purified chromato- graphically (DEAE-anion exchange, Sephacryl-gel filtration). Purity was assessed using sodium dodecyl salinepolyacrylamide gel ellectrophoresis (SDS-PAGE) and activity was determined by a Vero cells-cytotoxicity assay.

\section{Leukocyte isolation}

Leulocyte suspension was prepared from human fresh venous blood collected from bealthy volunteers on ethylenediaminetetracetic acid (EDTA; final concentration $5 \mathrm{mmol} / \mathrm{L}$ ) and diluted with an equal volume of cold saline solution as previously described [17]. The blood samples were centrifuged at $200 \times \mathrm{g}$ for 10 minutes at $4^{\circ} \mathrm{C}$, the cell pellet was resuspended in 4 volumes of Emagel (Behringwerke $\mathrm{AG}_{\mathrm{v}}$ Marburg, Germany) and erythrocytes were allowed to sediment at $4^{\circ} \mathrm{C}$ for 40 minutes. Supernatant was removed, centrifuged at $500 \times$ $g$ for 10 minutes at $4^{\circ} \mathrm{C}$ and the pellet washed twice by centrifugation with saline. The remaining erytbrocytes were temoved by ammonium chloride lysis at $4^{\circ} \mathrm{C}$ and centrifugation. After this procedure the cell viability, measured by trypan blue exclusion, was greater than $95 \%$. Cells were then resuspended in culture medium at a final concentration of $10^{\circ}$ cells/mL.

\section{Adhesian assay under flow conditions}

For adhesion experiments we used a parallel-plate flow chamber and a perfusion system as previously described $[30,31]$. Briefly, the chamber is composed of two parallel surfaces, a coverslip coated with HUVEC at confluence and a flat surface machined from polymethylmethacrylate. The two surfaces are separated by a $250 \mathrm{\mu m}$ thick silicon rubber gasket, leaving a rectangular surface of $30 \times 13 \mathrm{~mm}$ exposed to flow. An inlet and outlet channel distributed the fluid uniformly along the entrance side of the adhesion surface. Shear stress levels as a function of medium flow rate was calculated assuming fully developed laminar flow between the two parallel plates. After assembling with the HUVEC monolayer, the chamber is placed on the stage of an inverted plasecontrast microscope with a thermostated hood to main. tain the temperature at $37^{\circ} \mathrm{C}$. The microscope is connected with a video recording system (Panasonic, Osaka, Japan). Leukocyte suspension was pumped through the chamber, at controlled fow rates, using a syringe pump (Harvard Apparatus Inc., South Natick, MA, USA). After initial perfusion with cell free thedium plus $0.5 \%$ bovine serum albumin at $0.6 \mathrm{dynes} / \mathrm{cm}^{2}$ for two minutes for equilibration, the leukocyte suspension was perfused through the chamber at $1.5 \mathrm{dynes} / \mathrm{cm}^{2}$ and images recorded thereafter. After 10 minutes, cell free medium was perfused at a llow rate of $3.0 \mathrm{dlynes} / \mathrm{cm}^{2}$ for evaluation of the number of leukacytes rolling on the HUVEC surface. At this fow rate the rolling leukocytes are easily distinguishable from cells freely flowing in the suspension that move much faster. After three minutes of perfu- 
sion at 30 dynes/cm $/ \mathrm{cm}^{2}$ everall fields $(>10)$ were observed for exaluation of the number of firmly adherent cells. Images acquired during the perfusion experiments were digitized and processed on a personal computer using general purpose image processing software (NIH Image, v. 1.59; NiH, Bethesda, MD, USA). Adherent leukocytes were identified and counted at the end of the 13 minute perfusion, as previously described in details [31]. The number of cells transmigrated across the HUVEC monolayer during the perfusion experiments was quantifed by visual inspection of the videotape, since adherent cells that transmigrate under the endothelium change their color from white to black [32].

The shear stress of $1.5 \mathrm{dynes} / \mathrm{cm}^{2}$, used to study leukocyte-endothelium interaction, mimics post-capillary venule circulation [30], but this same value of wall shear siress may be present also within the glomerullar microcirculation. In a three-dimensionall model of glomerular capillary [33], we estimated that a large fraction of glomerullar capillary segments are exposed to wall shear stress values $<5$ dynes $/ \mathrm{cm}^{2}$.

\section{Northern blot analysis}

Total RNA was isolated from HUVEC by the guanidium isothiocyanate/cesium chloride procedure, as previously described [34]. "Ten micrograms of total RNA were then fractionated on $1.6 \%$ agarose gel and blotted onto synthetic membranes (Zeta-probe; Bio-Rad, Richmond, CA, USA). IL- \& and MCP-1 CDNA probes were kindly provided by Dr. K. Matsushima (Laboratory of Molecular Immunoregulation, National Cancer Institute, Bethesda, MD, USA). IL-8 mRNA was detected by using a 300 base pair (bp) fragment of human IL-8 CDNA. For MCP-1 a 345 bp fragment of human MCP-1 CDNA was used to detect the MCP-1 mRNA transcript. The probes were labeled with $\alpha{ }^{32} \mathrm{P}$ dCTP by randomprimed method as previously described [35]. Hybridization was performed overnight at $60^{\circ} \mathrm{C}$ in $0.5 \mathrm{~mol} / \mathrm{L}$ $\mathrm{Na}_{2} \mathrm{HPO}_{4}, \mathrm{pH} 7.2,7 \%$ SDS. Filters were washed twice for 30 minutes with $40 \mathrm{mmol} / \mathrm{L} \mathrm{Na} \mathrm{HPO}_{4}, \mathrm{pH} 7.2,5 \%$ SDS and two times for 10 minutes with 40 mmoll $L$ $\mathrm{Na}_{2} \mathrm{HPO}_{4}, \mathrm{pH} 7.2,1 \%$ SDS at $65^{\circ} \mathrm{C}$, Membranes were subsequenty probed with a glyceraldehyde-3-phosphate dehydrogenase (GAPDH) cDNA, taken as internal standard of equal loading of the samples on the membrane. IL-8 and MCP.1 mRNA optical density was normalized to that of the constituently released GAPDH gene expression.

\section{Preparation of nuclear extracts}

Nuclear extracts were prepared from HUVEC using the NE-PER Nuclear and Cytoplasmic Extraction Reagents Kit (Pierce/Celbio, Pero, Italy) according to the manufacturer's instructions. To minimize proteolysis, all buffers contained protease inhibitor cocktail (Protease inhibitor cocktall tablets; Boehringer Manaheim, Maniheim, Germany). The protein concentration was determined by the Bradford assay using the Bilo-Rad protein assay reagent.

Electrophoretic mobility shifi and supershifit assays. Electrophoretic mobility shift assays (EMSAs) were performed as previously described [36] using the $\mathrm{kB}$ DNA sequence of the immunoglobulin gene (5'-GGGACT TTCC). Nuclear extracts $(2 \mu \mathrm{g})$ were incubated with $50 \mathrm{kcpm}$ of ${ }^{3 \mathrm{P}}$ labeled NF- $\mathrm{KB}$ oligonucleotide in a binding reaction mixture [10 mmol/L Tris-HCl, $\mathrm{pH} 75,80$ mmol/L NaCl, immol/L EDTA, $1 \mathrm{mmol} / \mathrm{L}$ dithiothreito] (DTT), $5 \%$ glycerol, $1.5 \mu \mathrm{g}$ of poly(dI-dC) $]$ for $30 \mathrm{~min}$ utes on ice. To assay the specificity of the binding reaction, a 100 -fold molar excess of unlabeled $N F-k B$ probe or an unlabeled nonspecific oligonucleotide (tissue plasminogen activator regulatory element, TRE) was added to the binding reaction mixture as indicated, prior to the addition of the labeled $\mathrm{kB}$ probe. For supershift assays" the reaction mixture minus the probe was incubated for one hour on ice with $1 \mu \mathrm{L}$ of affinity-purified rabbit poly. clonal antisera specific for p65 (sc-109), p50 (sc-114), RelB (sc-226), cRel (sc-71) and p52 (sc-298; Santa Cruz Biotechnology, Santa Cruz, CA, USA). The labeled NF-kB oligonucleotide was then added, and the incubation was continued at room temperature for 20 minutes.

Overexpression of adenovirally encoded $I K B \alpha$ in HUVEC. Subcomfluent HUVEC were incubated with recombinant adenovirus coding for $1 \mathrm{kBa}$ (a kind gift from Dr. R. de Martin, Department of Vascular Biology and Thrombosis Research, University of Vienna, Vienna, Austria) [29] or with a control adenovirus (Ad null control) at a multiplicity of infection (MOI) of 300 in M-199 without serum for three hours at $37^{\circ} \mathrm{C}$. The adenovirus was washed off and cells were maintained in fresh growth medium for 24 hours. Then HUVEC were exposed to $\mathrm{Stx}-2$ ( 25 or $50 \mathrm{pmol} / \mathrm{L}$ ) for additional 24 hours and processed for IL 8 and MCP-1 mRNA expression (Northern blot) or leukocyte adhesion and transmigration experiments.

\section{Statistical analysis}

Results are expressed as mean \pm SE. Data were analyzed by analysis of variance (ANOVA) followed by Tukey's test for multiple comparisons or by the nonparametric Kruskal-Wallis test for multiple comparisons. Statistical significance level was defined as $P<0.05$.

\section{RESULTS}

\section{Stx-2 promotes leukocyte adhesion and transmigration via up-regulation of $\mathrm{IL-8}$ and MCP-1 mRNA in HUVEC}

We previously showed that 5 tx-1 induced lenkocyte adhesion to HUVEC under flow conditions [17]. Here, 

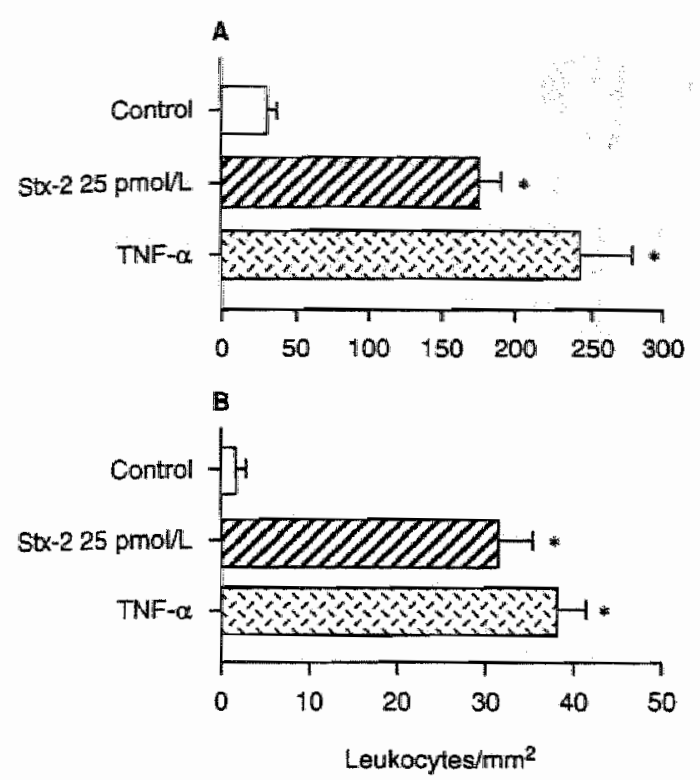

Fig. 1. Lankocyte adhesion (A) and transmigration (B) in human umblical endothellal veln cells (FUVEC) treated with Shiga toxin-2 (Stx-2) under fow condition (15 dynes/ $\left.\mathrm{cm}^{2}\right)$. Endothelial cells were exposed to controt medium, $5 \mathrm{tx}-2$ (25 pmoll, 24 howrs) or tamor necros is factor-a (TNI- $\infty, 100 \mathrm{U} / \mathrm{m}$ ", 24 hours) as positive control. Alt the end of perfusion, the number of adherent and transmigrated leukocytes were quantiLied by digital analysis of videotapes of each experiment $(N=4$ experiments). Data are expressed as mesin $\pm \mathrm{SE}$. ${ }^{*} P<0.01$ vs. contro!

we investigated the effect of Stx-2 on subendothelial lenkocyte transmigration and the role of IL-8 and MCP-1 expressed by the endothelium in these adhesive events. Consistent with our prior study [17], Stx-2 at a subtoxic concentration $(25 \mathrm{pmol} / \mathrm{L}, 24 \mathrm{~h})$ significantly $(P<0.01)$ increased the number of leukocytes that adhered on HUVEC with respect to unstimulated cells ( $175 \pm 14$ ys. $32 \pm 6$ leukocytes $/ \mathrm{mm}^{2}$, Fig. 1). This response was similar to that elicited by TNF- $\alpha$, one of the most potent inducers of endothelial cell adhesive properties, used as positive control ( $244 \pm 34$ leukocytes $/ \mathrm{mm}^{2}$ ). As shown in Figure 1 a massive transringration of leukocytes across the endothelium was elicited by $\mathrm{Stx}-2(\mathrm{Stx}-2,33 \pm 3 \mathrm{vs}$. control, $2 \pm 1$ leukocytes/mm ${ }^{2}, P<0.01$ ), which was as intease as that observed after cell activation, with TNF $-\alpha$ $\left(39 \pm 2\right.$ leukocytes/ $\left.\mathrm{mm}^{2}\right)$.

Scanning electron micrographs of $\mathrm{Stx}-2$ treated HUVEC illustrate adberent and transmigrated leukocytes at different stages of activation in a sequence that resembles the multistep model of in vivo leukacyte-endothelial cell recognition and extravasation (Fig. 2) $[23,37]$. As the initial step, some leukocytes attach to the endothelium through their membrane projections, others become activated and change shape (Fig. 2A) before transmigrating through the subendothelium (Fig. 2B):

The ability of $S \mathrm{Stx}-2$ to modula te the endothelial expression of IL 8 and MCP-1 was assessed by Northern blot experiments. The expression of IL- $8 \mathrm{mRNA}$ in. creased over control after 6 hour exposure of HUVEC to different concentrations of $5 \mathrm{tx}-2$ (Fig. 3A). Actually, $\mathrm{Stx}-2$ at $25 \mathrm{pmol} /$, the same concentration used in the adhesion experiments, promoted a twofold increase in IL-8 transcript levels as compared to control cells ( $P<$ $0.01)$, which was further enhanced by 50 pmollt and maintained elevated by the highest concentration of 1 mol/L (2.6- and 2.4-fold increase, $P<0.01$ ). As shown in Figure 3B, up-regulation of MCP-1 mRNA also was induced by Stx-2 at all the concentrations studied $(P<$ 0.01 vs, control).

To study the functional role of these chemokines in Stx.2-induced leukocyte adhesion and transmigration, HUVEC exposed for 24 hours to 25 pmol/L Stx-2 were treated with anti-IL-8 and anti-MCP-1 antibodies before performing the adhesion assay. Functional blocking of IL-\& significantly reduced the number of adhering lenkocytes on Stx-2 treated HUVEC under fow conditions (Stx-2, $164 \pm 12$ vs. Stx-2 + anti-IL-8 Ab, $40 \pm 2$ leukocyles $/ \mathrm{mm}^{2}, P<0.01$; Fig. 4). A remarkable inhibilory effect also was obtained by treating HUVEC with the anti-MCP-1 Ab (Stx-2 + anti-MCP-1 Ab, $80 \pm 7$ leukocytes $/ \mathrm{mm}^{2}, P<0.01 ; \mathrm{Fig}$. 4). As a consequence of the reduced leukocyte adhesion, the number of transmigrated cells through the endothelial monolayer was significantly lessened by both anti-IL-8 and anti-MCP-1 antibodies $(S \mathrm{Lx}-2,29 \pm 1$ ws. Stx- $2+$ anti-IL-8 Ab, $3 \pm 1$ and Stx-2 + anti-MCP-1 Ab, $6 \pm 1$ leukocytes $/ \mathrm{mm}^{2}, P<$ 0.01 ; Fig. 4). Treatment with the corresponding irtelevant antibodies did not affect leukocyte adhesion (irrelevant rabbit $\mathrm{IgG}, 154 \pm 6$ and irrelevant mouse $\mathrm{lgG}$, $157 \pm 13$ leukocytes/min ${ }^{2}$ for anti-IL 8 and MCP-1 Abs, respectively) and transmigration induced by $\mathrm{Stx}-2$ (irrelevant rabbit $\operatorname{IgG}, 30 \pm 3$ and irrelevant mouse $\operatorname{Ig} G$, $33 \pm 4$ leukocytes $/ \mathrm{mm}^{2}$ for anti- IL-8 and MCP-1 Abs, respectively).

By analyzing the leukocyte populations that adhered to the Str-treated endothelial cells after flow exposure, we identified polymorphonuclear cells as the major sub. sets of adherent leukocytes $(80.2 \pm 4.2 \%)$. Mononuclear cells $(19.3 \pm 4.2 \%)$ also were present. Anti-IL 8 antibody reduced by $81.8 \pm 2.8 \%$ and $69.5 \pm 5.5 \%$ the adhesion of polymorphonuclear and mononuclear cells, tespectively. As expected, a more pronounced inhibitory effect on adherent mononuclear cells was observed after treatment with arti-MCP-1 antibody (\% inhibition, mononuclear cells, $90.2 \pm 1.5$ and polymorphonuclear cells, $27 \pm$ $3.4 \%)$. 
A
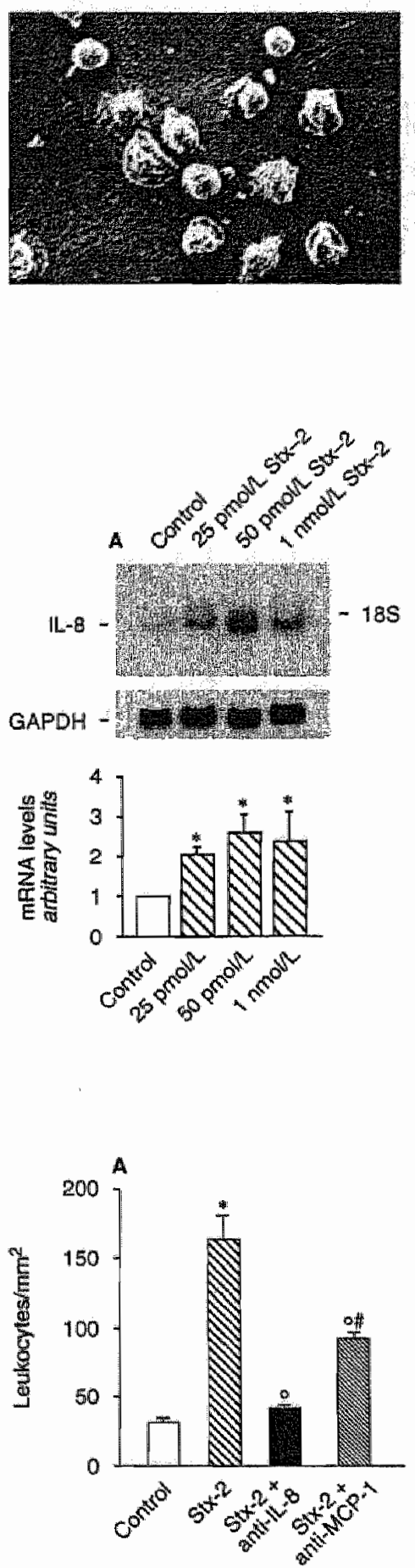

E.
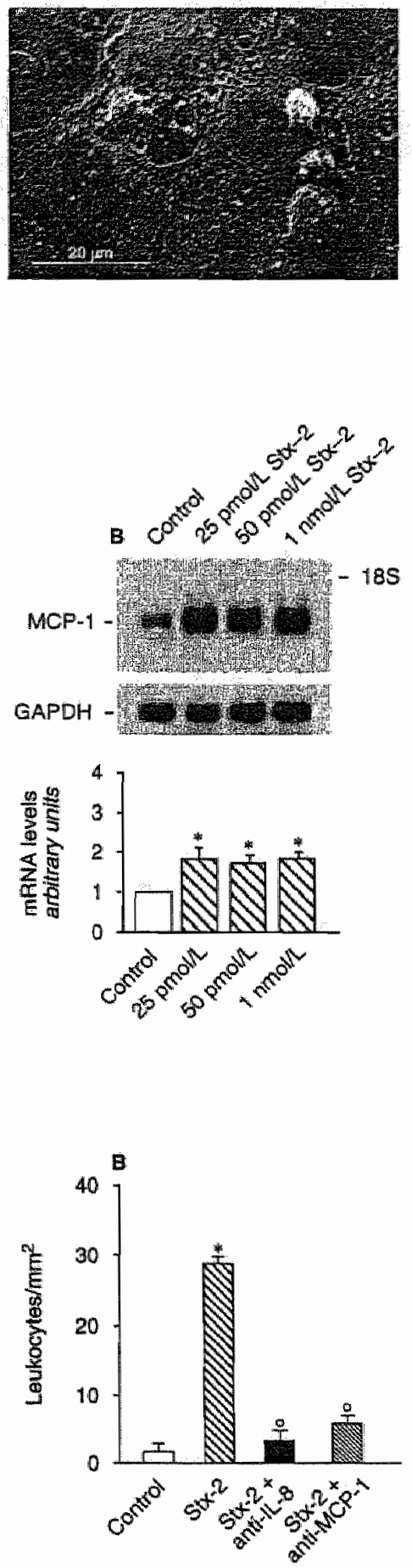

Fig. 2. Scamning electron miterograpth of adherent and transulgated leukocytes in HUVEC ellallenged with S11.2. Micrographs show ad herent (A) and transmigrated (B) lewkocytes at different stages of activation HUVEC treated with Six:2 (25 prollL, 24 h).

Fig. 3. Expresgion of intertenkin-8 (TL $8 ; A)$ and monocyte chemonttractant protein-1 (MCP-1; B) mRNA in HUVEC exposed io Str-2 (Top) Norther blot experiments were performed using totall RNA isolated after a 6-hour period of culture with medium alone (control) or $5 \mathrm{tx}-2$ (25 pmoll/ $50 \mathrm{pmol} / \mathrm{L}$ and $1 \mathrm{nmolL}$ ). Data shown are representative of $N=5$ experiments. (Bottom) Densitometric analysis of autoradiographic signals for $1 \mathrm{~L}-8$ and MCP-1. The oputical densily of the autoradiographic signals was quantified and calculated as the ratio of IL-8 or MCP-1 to GAPDH mRNA Results (mean $\pm \mathrm{SE}$ ) are expressed as the fold increase over tontrol (considered as 1) in denstitometric arbitrary units. $P<$ $0.01 \mathrm{vg}$ acontrol.

Fig. 4. Effect of anti-Hic or anti-MCP-1 antibodies on Str-2 induced leukocyte adhession and tranumigration moder flow. Before the adhestion assay, HUVEC treated for 24 hours with Stx-2 (25 pnoLL) were exposed for 20 minutes to anti-IL-8 of anti-MCP-I antibodies. At the end of perfusion, the number of adherent and transmigrated leuliocytes were quantified. Data are mean $\pm S E(N=7$ expariments). $P<0.01$ vs, control ${ }^{\circ} P<0,01 \mathrm{ws}$. Stx-2, $H P<0.05$ ks. Stx-2 +anti IL-8 antibody. 


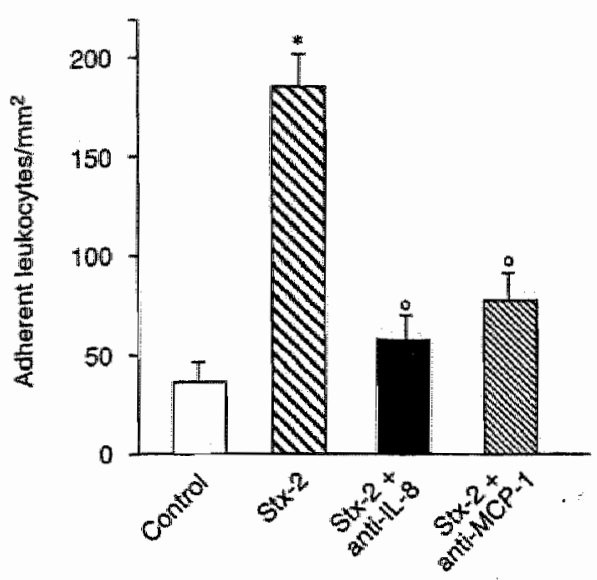

Fig. 5. Stx-2 miluce lenkocyle andhesion on glomerular endothelist cells (GEC) vader fow. Effect of anti-lL or anti-MCP-1 antibodies. GEC were treated for 24 hours with control medium or StX-ż $(25$ pmol L ), and then cells were exposed or not to anti-IL-8 or anti-MCP-1 antibodies for 20 minutes. At the end of perfusion. tine number of adherent leukacyles were quantified. Data are mean \pm SE $(N=3$ experiments). ${ }^{*} P<0.01$ ws. control, ${ }^{\circ} P<0.01$ ws. $S \mathrm{tx}-2$

\section{Stx-2 enhances leukocyte adhesion and}

transmigration in glomerular endothelial cells through an IL-8 and MCP-1 dependent pathway

In selected experiments performed in human glomerular endothelial cells, $5 \mathrm{tx}-2$ (25 pmol/L, $24 \mathrm{~h})$ promoted a massive adhesion of leukocytes on the endothelium under How, at a comparable extent than HUVEC. As shown in Figure 5 , on average $185 \pm 16$ leukocytes $/ \mathrm{mm}^{2}$ adhered to Stx-2 treated GEC compared with $36 \pm 10$ leukocytes $/ \mathrm{mm}^{2}$ to unstimulated cells $(P<0.01)$. AntiIL- 8 and anti-MCP-1 antibodies significanty limited the number of adherent leukocytes (Stx-2 + anti-IL-8 Ab, $57 \pm 12 ; \mathrm{SLx}-2+$ anti-MCP-1 Ab, $77 \pm 14$ leukocytes/ $\mathrm{mm}^{2} ; P<0.01$ vs. $S \mathrm{tx}-2$ ). Similar to what was obserwed in HUVEC leukocyte adbesion induced by $S+2$ on GEC was followed by transendothelial migration, which was reduced by the functional blockade of IL-8 and MCP-1.

\section{Stx-2 activates the transcription factor NF-kB}

Based on the evidence that both the IL- 8 and MCP-1 genes have a consensus sequence in their promoter for the transcription factor $\mathrm{NF}_{-\mathrm{K}} \mathrm{B}[38,39]$, we studied the effect of $5 \mathrm{x}-2$ on NF-kB activation. As shown in Figure 6, the nuclear extracts from control cells displayed two constitutive bands: an upper complex (complex I) and a faster migrating lower complex (complex II). Treatment of HUVEC for one hour with increasing concentrations of Stx-2 elicited a substantial rise in $N F-k B$ binding activity that was already evident at $25 \mathrm{pmol} / \mathrm{L}$ (Fig. 6A). The specificity of the binding reaction was confirmed in competition experiments by the ability of excess unlabeled (cold) NF-kB oligonucleotide to inhibit binding. Moreover when excess unlabeled TRE oligonucleotide was used as irrelevint probe, it did not affed the binding of the specific $\mathrm{k}$ probe to nuclear proteins.

Since $\mathrm{NF}-\mathrm{KB}$ complexes may constitute a variety of different homo- and heterodimers, the subunit compositions of the Stx-induced DNA complexes were analyzed by supershift assay (Fig. 6B). Rabbit polyclonal antisera specific for p65, p50, cRell, RelB, and $\mathrm{p} 52$ were added to nuclear extracts of Stx-treated HUVEC. The upper band, complex I consisted of p65/p50 heterodimer, since pre-incubation of the cells with anti-p50 antibody consistently reduced the intensity of the complex, while antip65 antibody abolished it. Both antibodies catased further gel retardation (supershift). Complex II was inhibited by anti-p 50 antibody, suggesting that the complex II represented p50/p50 homodimer.

\section{Ademoviral overexpression of $I_{k} \mathbf{B} \alpha$ inhibits Stx-induced L-\& and MCP-1 mRNA and leukocyte adhesion and transmigration}

We explored the possibility that up-regulation of endothelial IL-8 and MCP-1 mRNA in response to Str-2 was dependent on $N F-k B$. Since $N F-k B$ activity is regulated by $I \kappa B$ inhibitor proteins, which sequester $N F-k B$ into cytoplasm and avoid its translocation to the nucleus, overexpression of $I_{k} B \alpha$ was achieved through infection of HUVEC with a replication-deficient recombinant adenovirus encoding I $\mathrm{B} \alpha$. In non-stimulated cells, complex formation with $I_{\kappa} \mathrm{Bi}$ inhibited constitutive expression of IL-8 and MCP.1. Moreover, delivery of IKB $\alpha$ resulted in a remarkable reduction of Stx-induced IL-8 and MCP-1 mRNA transcript levels (Fig. 7), thus indicating that activated NF-KB is responsible for chemokine up-regulation.

The consequence of inhibiting $\mathrm{NF}-\mathrm{kB}$ by adenovirusmediated gene iransfer of $I \mathrm{kB}$ o was investigated further in the adhesion assay. As shown in Figure 8, lenkocyte adhesion induced by $5+x-2$ was reduced by $60 \%$ on HUVEC overexpressing I $B$ B $\alpha$ versus noninfected cells $(P<0.05)$. A similar inhibition $(70 \% ; P<0.05)$ was observed in leuk ocyte transmigration. No difference was. observed in unstimulated cells infected with the control adenovirus (Ad null control) with respect to unstimulated cells transfected with rAd IKBa.

\section{DISCUSSION}

Endothelial dysfunction is crucial to the developmeat of microvascular lesions in HUS $[5,6]$, and increasing evidence suggests that Shiga toxins, by favoring interac. tion of endothelial cells with leukocytes $[17,18]$ and platelets [40], serve to amplify and extend the injury at renal level. As a follow-up of previous studies [17], here 


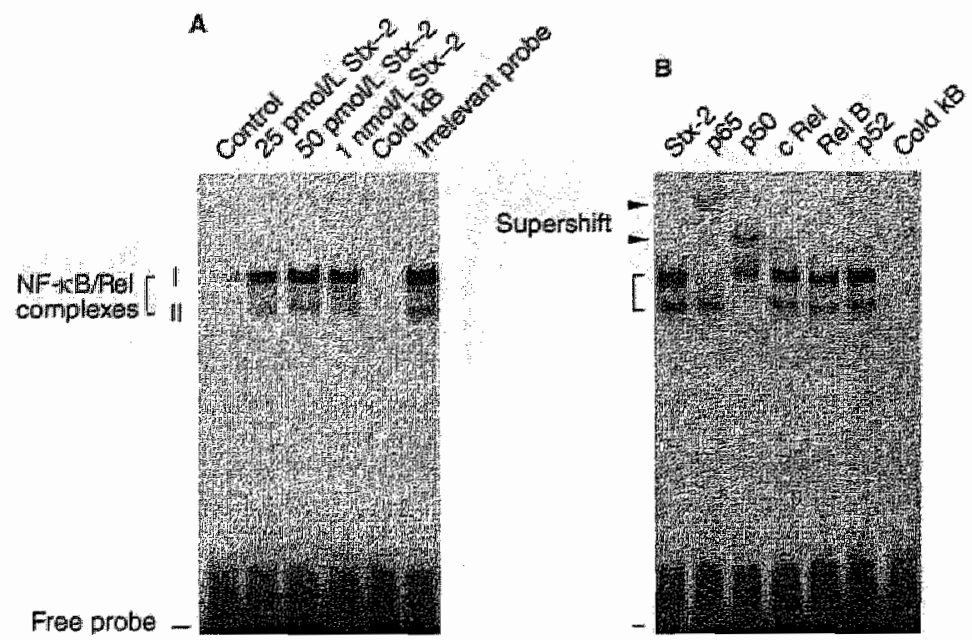

Frove probe
A

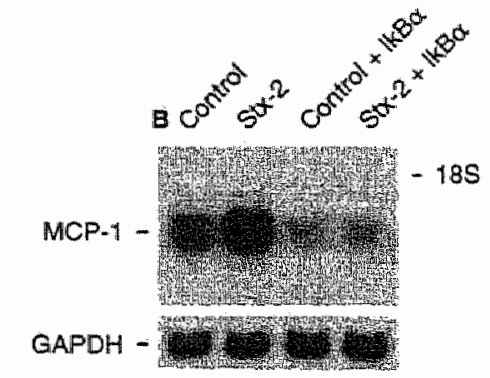

$-185$

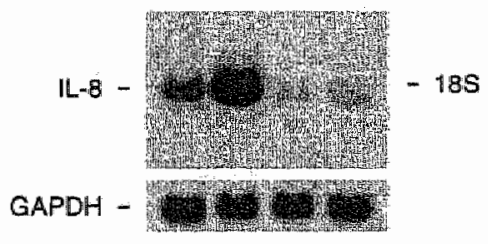

GAPDH -
Fig. 6. Str-2 activat the trancription factor NT-kiB. (A) EMSA lor NF-kiB activity was performed in Duclear exdacts from HUVEC

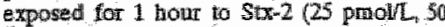
provol, and 1 amol/L). Complexe I and II de note the inducible $\mathrm{kB}$ specific DNA-protein complexes. A 100-fold molar excess unilabeled (cold) or an unlabeled nonspecific oligonacleotide (irrelevant probloy was added to nuclear extracts from HUVEC treated with Str.2 150 pmollL). The results shown are representalive of three independent experiments employing different nuclear extracts. (B) Subunit compostion of NF-KB activated by StK-2 Nucleas extracts from HUNEC treated with $5 \mathrm{t}-2$ - 150 pmol/L, 1 hour) were incubiated with antibod. fes against p55, p 50, cRel, RelB and p52 sub. units. Anthbody supershifts produced by binding of the antibody to the DNA.protein complex are indicated.

Fig. 7. Expression of $\mathrm{IL}-8$ and MCP.1 mRNA induced by Str. 2 is inhibated by wedeno rirus-medliated gene transfier of IkBa. Endo thelial cells were left untreated or infected with IAd.lkB a for 3 hours, then cells were exposed to medium alone or to $5 t x-2$ (50 pmol/L 6 bours). Results shown are representative of $N=3$ Northerm blot experiments.

Fig. 8. Lenkocyte adhesiton and transmiluretoon induced by Str-2 are regulated by endo

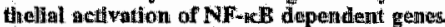
Endothetlin cells were left untreated or infected with IAd.IKBar for 3 bours, then cells were exposed to medium alone (control: $\square$ ) or to $\operatorname{stx}-2$ ( $25 \mathrm{pmol} / \mathrm{L}, 24 \mathrm{~b}$; Stx-2; $)$. At the end of incubation, HUVEC were perfused with total leuk:ocyte suspension and the num. ber of leukocytes that adhered and transmi. grated were quantilied. Data are expressed as mean $=S E\left(N=3\right.$ experiments). ${ }^{\circ} P<0.00$ ws. control: $\$ p<0.05$ ws. non infected $S t x-2$ 
W characterized the adbesive phenomena triggered by $\$ x^{-2}$, studying the adhesion and transmigration of leu* kocytes in buman endothelial cells exposed to $5 \mathrm{tx} \cdot 2$, under flow conditions. We found that sub-toxic concentrations of Stx-2 [17, 40] induced a significant increase in the number of leukocytes adhering to HUVEC, followed by a massive transmigration through the endothelial monolayer. The adhesion elicited by $S t x-2$, that is, sixfold increase over control, was comparable to that of TNF- $\alpha$ (8-fold increase), one of the most potent inducers of leukocyte-endothelial cel] adhesiveness known to date. The major subset of leukocytes that adhered on Stxtreated endothelial cells consisted of polymorphonuclear cells $(80 \%)$ while mononuclear cells represented $20 \%$.

A relevant finding was that exposure to $5 \mathrm{tx}-2$ under How induced massive adhesion and transmigration of leukocytes in glomerular endothelial cells, to a similar extent as that for HUVEC. Thus, both types of endothelial cells at confluence stowed a similar sensitivity to a $S \times x-2$ concentration that did not affect cell viability, but stimulated intracellular pathways resulting in the enhanced adhesive phenomena.

Contrasting data are available in the literature regarding the differential sensitivity of HUVEC and renal microvascular endothelial cells to Stxs. Confluent HUVEC were little susceptible to the cytotoxic effect of Stx- 1 , unless they were pretreated with cytokines that up-regulate Gb3 receptors [13]. Renal microvascular endothelial cells had greater sensitivity to the toxic effects of Stx-1 than HUVEC, because they constitutively expressed 50 times more Stx receptor [41]. At variance, purified glomerular endothelial cells, such as those used in our study, similarly to HUVEC, responded to Stx and underwent cell death and inhibition of protein synthesis only when they were sub-confluent. At confluence, they instead required pre-exposure to cytokines [15].

The concept that leukocytes are crucial to the patbogenesis of microvascular lesions in Stx-associated HUS is based on evidence that the number of polymorphonuclear cells is elevated and may be a predictive factor for the outcome of the disease [42]. Ultrastructural studies showed polymorphonuclear and mononuclear cell infiltrates in the glomeruli of patients with sporadic HUS $[20,21]$. In addition, during the acute phase of the disease neutropbils are activated [19], become more adhesive than normal, and damage the endothelium by producing elastase [18] and superoxide [43]. More recently, in vitro and in vivo studies pointed to an additional role of neutrophils as the cells responsible for binding and transfer of Stx from intestine to the kidney endothelium $[8,9]$.

In the present study we sought to understand cellular and inclecular mechanisms responsible for the recruitment of leukocytes into the kidney of HUS, which have never been clarified.

Interleukin-8 and MCP-1 were significantly increased in the urine of HUS patients during the acutie phase of the disease and returned to normal in remission $[21,22]$. Here we found that IL-8 and MCP-1 mRNA expression was increased after a six hour exposure of endothelial cells to $\mathrm{St}$-2. That both chemokines can actually have a functional role in the adhesive process triggered by $S t x-2$ rests on the evidence that specific antibodies against IL-8 and MCP-1 limited to a remarkable extent the leukocyte adhesion and subendothelial transmigration in HUVEC as well as glomerular endothelial cells treated with $S \mathrm{Wx}-2$. Of note, anti-IL-8 antibody had a more pronounced inhibitory effect as compared to anti-MCP-1 antibody. Actwally, anti-IL-8 antibody markedly decreased both adherent polymorphonuclear and mononiclear cells ( $82 \%$ and $70 \%$ in hibition, respectively). This finding is consistent with recent data that IL-8, thought to act predominantly on neutrophils, instead had the ability to promote the adhesion of monocytes to vascular endothelium under flow [44]. Anti-MCP-1 antibody almost completely abolished mononuclear cell adhesion to Stx-treated endothelium (90\% inhibition) and decreased polymorphonuclear cells by $27 \%$.

Chemokines trigger adhesion and migration of distinct leukocyte subsets either as soluble chemoattractants or as immobilized molecules bound to heparan sulfate proteoglycans of the endothelial surface of post-capillary venules and small veins $[23,37,45]$. In an in vitro flowbased adhesion assay and video microscopy, exposure of endothelial cells to hypoxia and re-oxygenation resulted in mettrophil attachment and migration due to the action of TL- 8 expressed on the endothelium as docu- $^{-}$ mented by the inhibitory effect of an anti-IL-8 antibody [46]. In a model of monocytes rolling on adenovirally E-selectin transduced endothelial cells under fow, MCP-1 and IL-8 caused firm adhesion of monocytes to the endothelium through the activation of leukocyte integrins [44].

Since IL-8 and MCP-1 genes have in their promoter a consensus sequence for the transcription factor $\mathrm{NN}^{-1} \mathrm{kB}$ $[38,39]_{\text {a }}$ we veriffed whether $N F_{-K} B$ activation could be a candidate pathway of $\mathrm{Stx}-2$-induced chemokine expression in endothelial cells. NF-KB belongs to Rel family comprising different members, including Rel.A ( $p 65$ ), cRel, RelB, p50 and p 52 , which form homo- or heterodimers with different affinities for variants of a decameric consensus binding site $[25,47]$. NF- $\mathrm{kB}$ exists in an inactive form in the cytoplasm of cells bound to the inhibitory I $K B$ subunit and upon activation by different stimulit $N F-K B$ translocates into the nucleus for binding to DNA motis in gene promoters [25]. Here we found that exposure of endothelial cells to Stx-2 increased $\mathrm{NT}^{2}-\mathrm{K}$ B-DNA binding activity and that the protein subunits involved were p65/p50 heterodimer and p50/p50 homodimer. These results are in line with a previous study showing that treatment of cultured human monocytes with Stx-1 
induced nuclear transiocation of $\mathrm{NF}-\mathrm{kB}$ complexes and lKB degradation [48].

Ass a proof of the concept that Stx-induced IL-8 and MCP-1 genes are regulated by NF- $\mathrm{B}$, we inhibited endothelial response to $S t x-2$ by inducing overexpression of an NF $+k B$ specific inhibitor, $I_{k} B \alpha_{k}$. Delivery of $I_{k} B \alpha$ to HUVEC followed by Stx-2 stimulation fully suppressed IL-8 and MCP-1 mRNA up-regulation. As expected, Stx-2 induced leukocyte adhesion and transmigration were strongly reduced in I KB transfected HUVEC, suggesing. that such adhesive processes are selectively modulated by activation of $N F-k B$ dependent genes. Our findings are consistent with the receat observation that adenoviral transfer of I.kB $\alpha$ suppressed the endothelial expression of adhesive molecules required for the adhesion and transmigration of monocytes on endothelium activated by TNF- $\alpha$ under flow [49].

In conclusion, the results of the present study documented that $(1)$ under flow Stx-2 induces a massive adhesion and transmigration of leukocytes on HUVEC and glomerular endothelial cells through the up-regulation of IL-8 and MCP-1; (2) this phenomenon involves the activation of $N F-K B$, to the extent that endothelial cell overexpression of a specific inhibitor $I_{k} B \alpha$, using a recombinant adenovirus, fully prevents levkocyte adhesion and transmigration.

Despite the potential limitations in extrapolating results from in vitro studies, our findings might be relevant to understand the role of chemokines in promoting leukacyte-endothelium interaction which favors microvascular lesions in Stx-associated HUS, and could help to find innovative treatments.

\section{ACKNOWLEDGMENTS}

Part of this work was presented at the 32nd Arnual Meeting of the American Sociery of Nopharology (Mami Beach, Plorida November

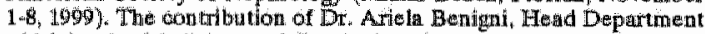

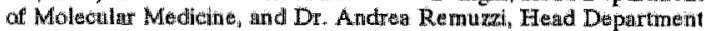

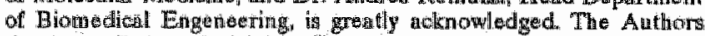

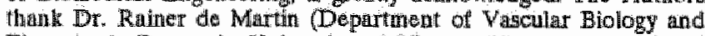

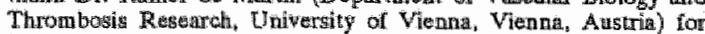

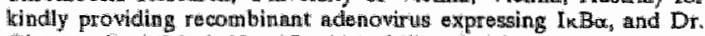

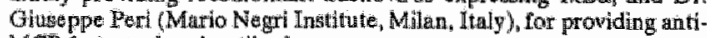
MCP-1 monoclonal antibody.

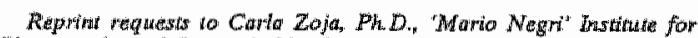

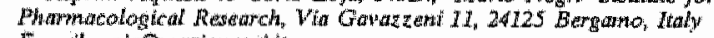

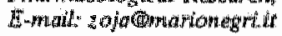

\section{REFER ENCES}

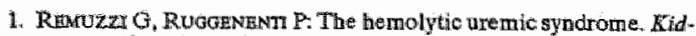
Nity Irut $472-19,1995$

2. SRGLE $\mathrm{RL}$. Hemolytio uremic syndrome in children. Curr Opin Peallatio 7:1:59-163, 1995

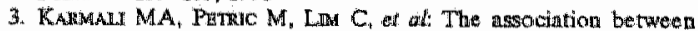
didopathic themolytic uremic syndrome and untetion by verotoxinproduding Eschenchin coll $J$ infert $D$ is $151 \times 775$ 782, 1985

4. AdRus OS: Association of verotoxin-producing E coli and verom

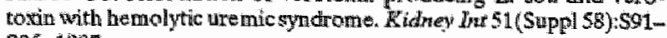
Sols, 107
5. A wDERCL SP: The pathoptwiology of the hemolytic wrempe sydrome. Cur Opin Nephrol IYpertew 849-464, 1999

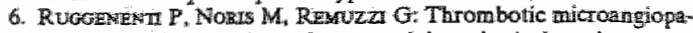
thy, bemolytic uramic sydrome, and thrombotic thrombocytogene purpura. Kudney bat 60,831-846, 2001

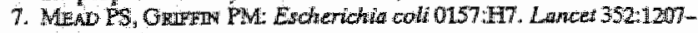
1212, 1998

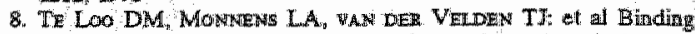

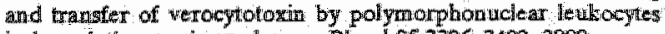
in homolotic uremic spnotrome. Blood $953396-3402_{4}, 2000$

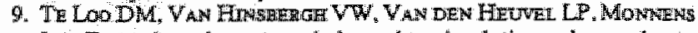
LA: Detection af werototoxin bound to circalating polymorphonilaclewi leukocytes of patieng with fimolytic uremic symdrome. I Am Soc Nephrol $12800-806,2001$

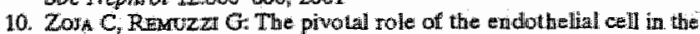
pathogenesis of HUS, in Fiemolytic Umearic Syndrame and Threw botic Thrombocylopenic Purpura, edited by KAPLAN BS. TRosWrain RS, MoAkE JL, New Yokk, Marcel Dekker, 1992, p 389

11. Onkr TG: Pathagemesis of striga toxin (verotoxin)-jaduced endothellal cell injury, in Hemolytic Uremie Symdrome and Thrombatic

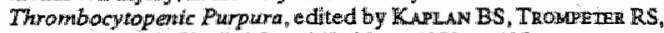
MoAme JL, Meny York, Marcel Dekker, 1992, p 405

12. LinWwood CA: Role of veroloxin recoptors in pathogenesis. Tirewd Microbiol 4:147-153, 1995

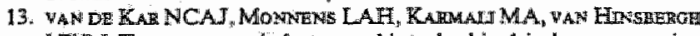
WhM: Tumor mecrosis factor and interleukin -1 induce expression: of the werocytotowin receptor globotriaosylceramide on buman eadothelial cells implications for the pathogemesis of the hemolytic Hemic syndrome. Blood $8022755-2764,1992$

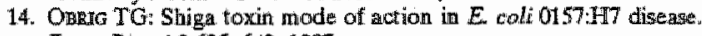
Frant Btonci $2.635-642,1997$

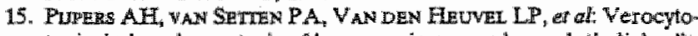
toxin-induced apoptosis of human microvastrilat endothelial cetis. I. An Soc Nephrol 12:767-778, 2001

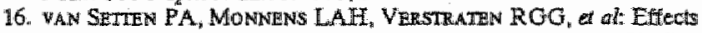
of verocytotoxin 1 on nonadherent human monocytes: Buding characteristios, prote in sya thesis, and induction of cytokine release. BLood 8s:74-183,1996

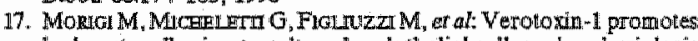
leukocyte adhesion to cultured endothellal alls under physiologic flow conditionsi. Blood 86:4553-4558, 1905

18. Forsyra KD, Simpson AC. FrrzPatrick MM, al Nevtrophilmediated endothe lial injury in baenolytic uraemic syndrome. Lan. cet it:411-414, 19:8?

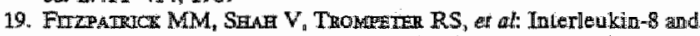
polymorphoneutrophil leukocy te activation in hemolytic uremic syadrome of childhood Kidruey Ims 42:951-056, 1992

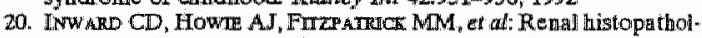

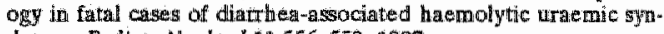
drome. Pediair Nephrol 11 $1+556-559,1997$

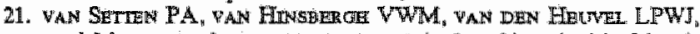

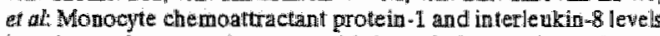
in arime and serum of patents wilh hemolytic uremic symanome. Pediatr Res 43:759-767, 1998 .

22. INWARD CD, VARAOUN MM ADU D, et al: Cytokines in haemolytiti urg emio syndtome assoliated with werocytotoxin-producing Fscherichia coli infection. Arch Dis Chald $77,145-147,1997$

23. LUSHEn AD: Chemokines-chemolactic cytakines that mediate in fiammation. $N$ Engl J Med $328 \times 436-445,1998$

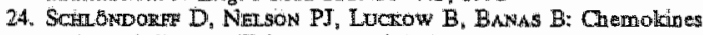
and renal disease Kidmey Wu 51:610-621, 1997

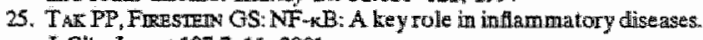
ICHit Dow 107:7-11, 2001

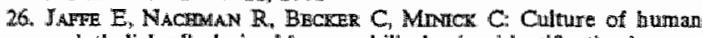
endothelial cells derived from ambilical weins identification by morphologie and immunologic oriteria. J CLin Inver 52:2745-2756, 1973

27. WAN SETHEN PA, WAN HINISTERGE, VTM, VAN DER VELDEN TYAN,

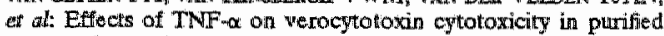
humia glomerular microvascilar endotbelial cells. Kidmey 1 m. 51 : $1245-1256,1997$

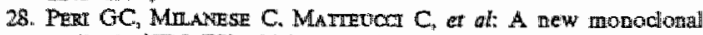
antibody (5D3-F7) which recogrizes human monocyte-chermotastic protein-1 but not related chemokines. Development of a sand- 
with ELISA and in sita detection of producing cells. $I$ Immunol Meth 1742,49-25, 1994

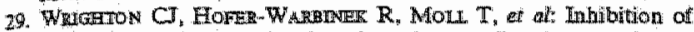
endothelinal cell activation by adenowirus-mediated expression of $I_{k} B \alpha_{1}$ an inhibitor of the transcription factor NF*kB. I Exp Med 187:1013-1022, 1996

30. LAARENCE MB, MCINTERE LV, ESKTn SG: Enfect of how on polymorphonuclear leukocytelendothelial cell adhesion. Blood 70:284 1290,1987

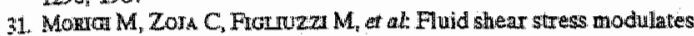
surface expression of adbesion molecules by endothelial cellis. Blood of:1696-1703, 1995

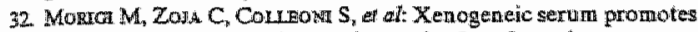
lewkocyte-endothe lium interaction under liow through two tempovally distinct pathways: Role of complement and nuclear factor- $\mathrm{k}$. $J$ Aim Soc Nephrol 10:2197-2207, 1999

33. REMUZZI A, BREKNER BM, PATA V, et al: Three-dimensional reconstructed glomerular capillary metwork: blood flow distribution and local filtration. Am I Physial 23-F562-F572, 1992

34. RAME ALD A, YOUNG DC, GRJFIn JD: Expression of the M-CSF (CSF-1) gene by human monocytes. Blood 69:1409-1413, 1987

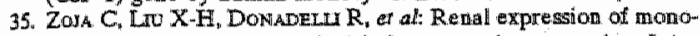
cyte chemoattractant protein-1 in lupus autoimmune mice. I Am Soc Nephrol 8:720-729. 1997

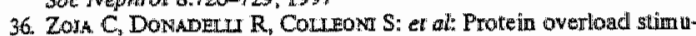
lates RANTES production by proximal tubular oells depending on NF-KB activation. Fidney Int 53:1608-1615, 1998

37. RovaN BH, PrAN LT: Chemotactic factors and renal inflammation. Aun I Kiduey Dis 31:1065-1084, 1998

38. Kunscr C, ROSEN CA: NF-Kappa B subunit-specific regulation of the interieukin-8 pramoter. Mfol Cell Biol 10:6137 -6146, 1993

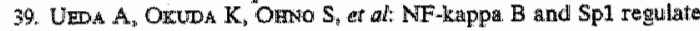

tramscription of the human anowote chemoahtratant protem 1 gene. $I$ fromitum $153: 052-2063$, 199

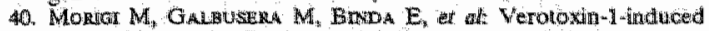
brtegulation of adhesive molecules renders microviascular endothelial cells thrombogenic at high thear stress. Blood 98:18281835,2001

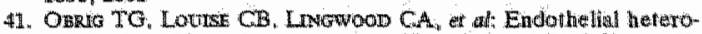
genetly in shigh tosin receptors and responses: I biol Cherw 268: $15484-15438,1903$

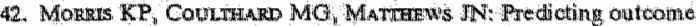
affer chilldiond hemolytic uremic syndrome Clin Neplanol 36:263264,1991

43. KING AT, StNDARUM \$, CENDORoGro M, al Shiga toxin induces superoxide prodtuction in polynorphontelear cells with subsequent impairment of phagochtosis and responsiveness to phorbol esters. 1 Infect Dis $170 \times 502-507,1999$

44. GHRSTISN RE, GARCI-ZEPEDA EA, LM YC or at MCP il and IL 8 trigger firm adhesion of monocytes to vagetilar endethelium under flow condifioms. Nature 398718-723, 1999

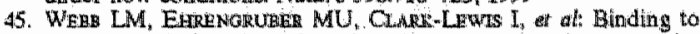
heparan sulfate ar heparin enhanes netutrophil responses to interievikin 8. Proc Nati Acat Sal US.490:7158-7162, 1993

46. RADGed GE, Fisider AC, NASTH GB: Endothelinimorne platele t activation factor and interleukin \& rapidly inmobilize rolling nevtrophils. Am J Phystiol 272H114-H122, 1997

47. BALDwIN AS: The transeription factor NF-m IClin Invest 107:3-6, 2001

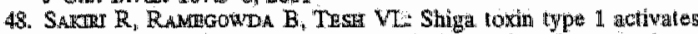
tumor necrosis factor $\alpha$ gene transcription and nuclear translociation of the transcription activators nuclear factor $-\mathrm{k} B$ and activator protein-1. Blood $92.558-566,1998$

49. WEBER KS, DRADDE G, ERI W, af Monocyte arrest and trangmgration on inflamed endothelium in shear flow is inhibited by adenowirus-mediated geve transfer of 1 B B-a. Blood 93:3685-3693, 1999 

CHAPTER 5

VEROTOXIN-1-INDUCED UP-REGULATION OF ADHESIVE MOLECULES RENDERS MICROVASCULAR ENDOTHELIAL CELLS THROMBOGENIC AT HIGH SHEAR STRESS

M. Morigi, M. Galbusera, E. Binda, B. Imberti, S. Gastaldi, A. Remuzzi, C. Zoja, and G. Remuzzi

Blood 2001; 98:1828-1835 



\title{
Verotoxin-1-induced up-regulation of adhesive molecules renders microvascular endothelial cells thrombogenic at high shear stress
}

\author{
Marina Morig, Miriam Galbusera, Elena Binda, Barbara imberti, Sara Gastoldi, Andrea Remuzzi, Catha Zoja, and Giuseppo Remuzzi
}

\begin{abstract}
Verotoxin-1 (NT-1)-producing Escherichla coll is the causative agent of postdliartheal hemolytic uremic syndrome (D+HUS) of children, which leads to renal and other organ microvascular thrombosis. Why thrombl form only on arterioles and capillaries is not known. Thlls study investigated whether VT-1 directly affected endiathelial antithrombogenic properties promoting platelet deposition and thrombus formation on human microvascular endothellal cell line (HMEC-1) under high shealu stress. Human umbillical vein endiothellal colls (HUNECS) were used for comparison as a large-vessel endothellum. HMEC-1 and HUVECS were pre-exposed for 24 thours to increasing concentrations. of VT-1 (2-50 pM) and then perfused at 60 dynes/ $\mathrm{cm}^{2}$ with heparinized human blood: prelabeled with mepacrine. Results. showed that VT-1 signifficantly increased platelet adhesion and thrombus formation on HMEC-1 in comprarison with unstimulatod control colls. An increase in
\end{abstract}

thrombus formation was also observed on HUVECS exposed to VT-1, but to a remarkablly lower extent. The greater sensittivity of HMEC 1 to the toxin In compartson with HUVECs was at least in part dite to a higher expression of VT-1 receptor (20-fold more) as documented by FACS analysis. The HMEC-1 lino had a comparable susceptibility to the thrombogenilc effect of VT-1 as primary human milcrovasscular cells of the same dermal origin (HDMECs). The adhestive molecules involved in VT-induced thrombus formation were also studied. Blocking the binding of von Willebrand factor to platelet glycoprotein lb by aurintricarboxylic acld (ATA) or inthlbition of platelet of A $_{3}$-integrin by chimaric $7 E 3$ Fab resulted in significant reduction of VT-1-finduced thrombus formation, suggesting the involwement of von Willebrand factor-platelet interaction at high sinear stress in this phenomenon. Functional blockadie of endothellal $B_{3}$. Integrin subunit, viltronectin receptor,
P-Selecttn, and PECAM-1 whith spoelfic antibodles was associated with in signiffcant decroase of the ondothellal area coverad by thrombl. Contocal mileroscopy studies reveralled that VT-1 increased the expression of vitronectin reseptor and Puselectin and redistributod PECAMI-1 away from the cell-cell bordtor of HMEC-1, as woll as of HDMECS, thus indicating that the above ond othelial ad. hersion molecules are directly involtwed and posslbly determine the effoct of VT-1 on enhancing platelet adheslon and thrombus formation in microwascular en= dothellum: These results might help to explain why thrombi in HUS locallze in microvessells rather than im larger ones and provide insights on the molesular events lnwolwed in the process of mlerovascular thrombosis associated with DHHUS. (Blood. 2001;98:1828-1835)

Q 2001 by The American Society of Hamatelogy

\section{Intraduction}

Verotoxin (VT)-producing Escherichia colt infection has been strongly implicated as the causative agent for most eases of postdiantheal hemolytic uremic syndrome (D+FUS), a disorder of microangiopathic bemolytic anemia, thrombocytopenia, and acute rentil failure that mainly affects infamis and small children ${ }^{1-3} \mathrm{Tbe}$ characteristic lesion, thrombotic mictoangiopalhy, consists of swelling and detachinen of endotbelinel cells from the basenent membrane and deposition of platelet thrombi that occlude the wherocirculation of the kintneys and other organas. Why thrombi form only in arterioles and capillaries is not known.

It is now clear that endothelial dysfunction plays a crucial role in the sequence of events leading to the microangiopathic procerses, and evidence poimts to VT-1 and VT-2 as critical delerminants for the development of vascular lesions, Verotoxins (also called Shiga foxins) ane formed by a biologieally actre A submit and a number of B subwits by which the toxin binds to a spesifio glycosphingolipid dobotriaosyl cenamide (Gb3) receptor on the endothelial surface. ${ }^{25}$ After binding, the towin penetrates the cytosol by endocytosis and exerts tus cytotoxic effect by inhibiting protein synthesis and causing well death. 60 Monocytes/macrophages in response to VT release cytokines such as interteukin-1 (TL-1) and tumor necrosis factor (TNF) that remarkably potentiate

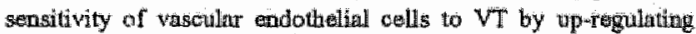
endotheljal GB3 receptor." Evidence also shows that rewil undovascular endothelial cells have a higher sensitivity to the cytotoxic effect of VT as conapared to endothelial cells derived from large vessels. 7.8

The interaction between leakoeytes and endotheilial cells its instumental in the developiment of microvascular injury in VT. associated HUS. Thus, exidence suggests that neatropinis isolated from children in the acute phase of D + HUS adhered to endothelial cells in culture more than normal beutrophils and induced endiouthehial injury by local release of proterases. 10 We have demonstrated in. vitro that VI-1 directly induced a massive leukocyte athesion to

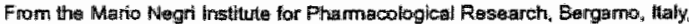
and the Diwision of Nephrology and Ciallysis, Aziendia Orpedatiera, Ospedall

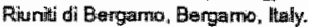

Stubmitted May 2, 2000; accepted May 15, 2001.

E.B. is a recipient of a felloweship from "Foppolo alubla I bambint."

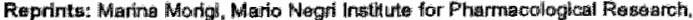

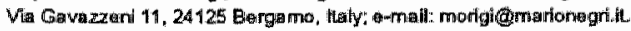

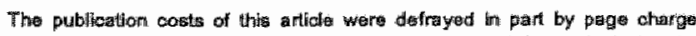

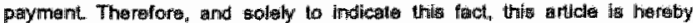

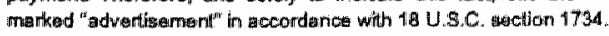

2001 by The American Society of Homatology 


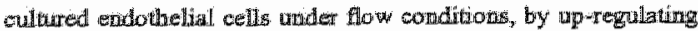

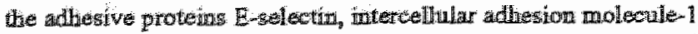
(CAM 1), and vascular cell afthesion molecule-1 (VCAM-I): Furtiemore. prelimintry report bas show that glomerular endothefial esllis expoged to VT becane mote susceptible to treutrophilmediatted oxillant injury." Taken together these studies indictite that UT canseg cell ingry by altering cell adbesive

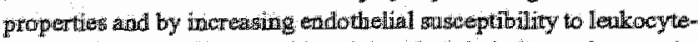
mediated indury. The resulung injured endothelium changes its nomal thromboresistani phenotype and becomes thrombogenic, mitiating miscrovasicular thrombes formation.

lin HUS, stmuetural damage of microvessels associated with natrotwing of the lunina detemines major changes in thid shear stressi, which would favor persistent endothelial darnage, platelei wivation, and progression of microvasciular thrombosis ${ }^{13}$ Changes in shear suress, the tractive force produced by blood flowing over the entothelisil surfate, have profoud influence on won Willebrand flactor (wWF) handling by enhancing its stusceptibility to proteolytic cleawage. 14 Under conditions of baigh shear stress, vWF undergoes conformationall changes and serves to bridge the subendothelial mintrix to glycoprotein (GP) Ib expressed on platelet membrines. ${ }^{15}$ The engagement of this receptor promotes activa-

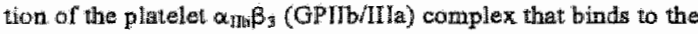
RGD (Arg-Gly-Asp) sequence of vWF leading to thrombus formition. ${ }^{\text {is }} \mathrm{Via}$ the $R O D$ sequence, $\mathrm{WWF}$ ma also bind vitronetin receptor $\left(\alpha_{4} \beta_{3}\right)$, the major integrin expressed on eadothelial cells ${ }^{16}$ that promotes endothelial cell adhesion to the vascular matrix. ${ }^{17}$ GPIb is also expressed on endothelial cells; however, controversial results about its function have been reported so far. ${ }^{18,15}$

Several distinct endothelial coll molecules have been reported to be imolved in the binding of platelets to ondothelial cells. P-selectin, which is stared in intracellular granules of platelets and endothelial cells logetber with WWF and which rapidly mobilizes to the cell surface on stimulation, 30 is required for platslet rolling and aclhesion on activated endotheliwm. ${ }^{2}$ Increased plasma levels of P -selectin have ben mensured in patients with HUS, possibly reflecting activation/damage of platelets and endothelial cells." ${ }^{\text {.2 }}$ Evidence also indicates that platelent-endothelial cell adhesion

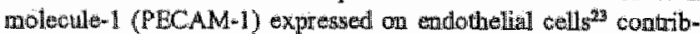
utws to platelet achesion and aggregation at sites of injured endothelium, as documented by the finding that anti-PECAM-1 antibody imetion delayed thrombus formation in laser-induced inicrowes injury of mouse brain.

In the present sthdy, wo sought to (1) assess whether VT-1 diretly affected the antititrombogenic properties of the endothelium wher high shear stress; (2) waluathe whether microvascular endothelizum bad a bighar sensitivity to VT-I-induoed hrombus formation as compared to ancothelium derived from large vessels; and (3) identify platelat and endothelial cell adbesive proteins involwed in the thrombotic process promoted by VT-1.

\section{Materials and methods}

\section{Endothellial cell culture and incubation}

The hurnan microwaseular endothelial cell line of dermal onigin (FMEC- - $)^{\text {t5 }}$ was a kind gafl from Dr Franciseo J. Cundel (Centers for Disease Control and Prevencion, Allamta, G.A). The grow th medium consisted of MCDB 131 (Gibeo, Girand Island, NY) snpplemented with $10 \%$ feral bovine serum (Gibeo), $1 \mu \mathrm{g} / \mathrm{mL}$ hydrocodtisone, $100 \mathrm{U} / \mathrm{mL}$ penicill in, $100 \mu \mathrm{g} / \mathrm{mL}$

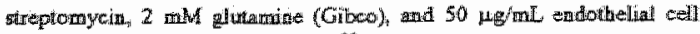
grow it factor prepared as described.

Humain unbilical ven endothellat cellis (TVVEC a) were obtained by

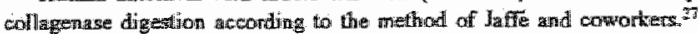
The cells were prown in Mextiur 199 (Gibco) supplemented wiflo $16 \%$

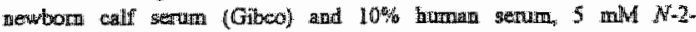
hydroxyethylpiperazine-N-2-etbatiesulfionic acid (HEPES; Sygma Chemi-

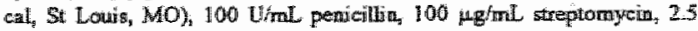

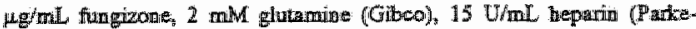

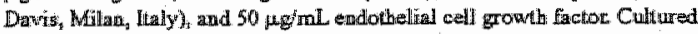
cells vitere identitited as endothelial by their cohblextone morphology and the presence of $\mathrm{VWF}$, wisigg indiret immunofluorescence microscopy. Confluent HUVECs were used for expeninents beiween the first and fifth parsage.

Primang buman microvascular andothellial cells of derrnall origin

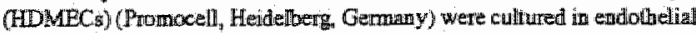
cell growth medium MV plus SupplementMix (Ponocell). HDMECs were used between the second and sixth passiage.

For the experiments, endothelial cells were plated on of $\times 20$-nmm plastic ewverslips (Thermanox Nunc Naperville, IL) and used 1 day after reachiog contiluence.

To study the ffoct of VT-1 in inducing platelet adhesion and thrombis formation, HMEC-1 and HUVEC were pre-exposed for 24 hours in static eondition to 2, 10, and 50 pM VI-I (kindly provided by Dr M. A. Karmali, Hospital for Sick Children, Toronto, ON, Canada; endotoxin content <0.05 EU/mL usiag Limulus amobocyte lysaie assay) in medium plus $2 \% 6$ fetal calf serum (Fyclone Laboratories, Logan, UT): then cells wore perfused at $60 \mathrm{dymes} / \mathrm{cmi}^{2}$ in a parallel plate flow chamber with human blood. Blood was drawn. from an antecubital wein through a 19 -gange needle (infusion set) dinectly into a polypropyleme tube and prelabeled for 5 minutes with fluoregoent dye mepacrine (10 $\mu_{\mathrm{n}}$ quinimerine dihydrochloride BP; Sigma Chemical). Blood was then tramsferred (5-mL alliquots) to lest tabes and a ot disturthed until assay. The percentage of the sutface occupped by thrombi was calcalated by analysis of fluoreseent thrombus images aciguired by confacal microstcopy.

The concentrations of VT-1 used for the athesion experiments did not affect cell colut after 24 hours of incubation either in HMEC-1 $10 \mathrm{pM}$ : $75 \pm 0.5 \times 10^{4}, 50 \mathrm{pM}: 75 \pm 5 \times 10^{4}$ warsus control: $70 \pm 5 \times 10^{4}$ cells) or in HUVECs $\left(10 \mathrm{pM}: 38.2 \pm 1.1 \times 10^{4}, 50 \mathrm{pM}: 37.4 \pm 0.7 \times 10^{4}\right.$ wersus control: $36.5 \pm 0.5 \times 10^{4}$ cells).

To waluate exdothelial isfegrity, HIMEC-1 pre-exposed for 24 hours to VT-1 (10 pM) were perfused with blood without mepacribe and then fixed with $0.5 \%$ glutanaldebyde (Fluka, Milan, Italy), dehydrated with methyl alcohol, snd strined with May-Grumald Giemat technique (Carto Etba Reageats, Milan, itasly).

By belected exponiments we verifed whether the HMEC-I cell lim axdibitted a similar sensitivity to VT-1-as for the VT effect to induce thrombus formation-compared with primary HDMEC. For this pumpose HMEC-1 and HDMECs were exposed to VT-1 (10 pMD) for 24 hours. HUVEC were sudied in parallel.

To compare the effect of VT-1 with respect to other thrombogenic stimuli, FMEC-1 and HUVECs were exposed to throm this (2 U/mi $\mathbb{L}_{\|} 10$ minutes; Biosciences, La Jolls, CA), TNF KNOLL, Ludwightafen, Germany), KL-1/ (100 U/mL, 4 bours" Becton Dickinson, Milan, Italy), or VTm $(10 \mathrm{pM}, 24$ hours) and parfused with blood al 60 dynessieri ${ }^{2}$.

To identify platelet receptors involved in VT-induced thrombus formstion, FMEC-1 treated for 24 hours with WT-1 ( 10 pM) were perfused with human biood preincubated with imbibitors of GPIb and $\alpha_{916} \beta_{3}$ receptor binding. We used polymeric aurin trimatboxylic atide (ATA; ATA trisodium salt, Aldrich Chemical, Milwaukes, WI) that interacis with wWF and inhilyts its binding to platelet receptor GPIt Because the most effective inhibitors of WWF are AIA polymers of molecular waight greater than $2500 \mathrm{~d}^{3}$ the higher molecular weigh polymers of ATA were separated from the lower molecular weight ones by a 30 -ked curoff digl ysis membrane concentrators (Centrican 30 , Amicon. Beverly, MA). For experiments

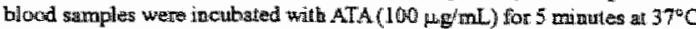
before perfusion on VT-Lreated FMEC-I. The platelet raceptor $\alpha_{15 h} \beta_{3}$ was blocked by incubating blood samples with chimeric $7 \mathrm{E} 3$ Fab anti-nime 


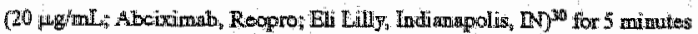
ail $37^{\circ} \mathrm{C}$ before blood perfiusion.

To determine be endothelial athesive proteins involved in VT-induced thrombuls formution, HMEC-1 preitented with VT-1 (10 pM) for 24 hours were iacubated with chimeric $7 \mathrm{E3}$ Fab $(20 \mu \mathrm{g} / \mathrm{ml})$ for 20 minites, mouse monoclonal antibody (mAb) antinuman witronectin receptor LM609 (10

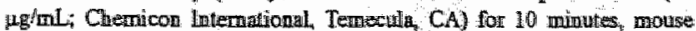

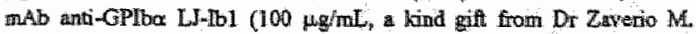
Ruggen, The Scripps Research Institute, Lal Jolla CA)-a competidive

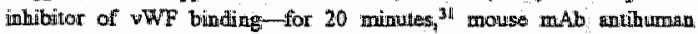
P-selectstn (50 $\mu \mathrm{g} / \mathrm{mL}$; Endogen, Wolbum, MA) for 20 minules, or mouse

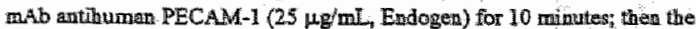
adilusion assay unas performed. Appropriate concentration and ficuibation time for each antibody prere identified by preliminary experiments. Lrelewant antibody of mouse IgGI (CAMrolia, Becton Dickinson) at concentrations of 10,25 , and $50 \mu \mathrm{g} / \mathrm{mL}$ were used

The inwolvernen of P-selectin and PECAM-1 in VT-1-induced thrombus formation on HDMECs was also assessed, using the same expeninental condition described alhove for HMEC-1.

\section{Adthesion assay under flow conditions and fluorescence confocal milcroscopy}

Platelet athesion assay was performed with whole blood perfused ig a chamber using a syringe pump. A flow chamber reguliated at $37^{\circ} \mathrm{C}$ was used in which one surfice of the perfusion channel has a coverslip (Thermanox"

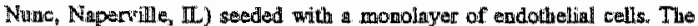
chamber dirnensions $(30 \times 1 \mathrm{~mm}$ and 1.50 H obtain a wide range of shenr rates using low flow rates of bloow. The flow conditionis are well characterized for this geomatry and are predicted to be hainar with very low Rejoolds aumber $(<10)$; precise estimation of shear stress canclitions on the adhesion surface was glso performed wsing the compentational thuid dynamic analysis (CFD packege FDAP Fluid Dynanic International, Evanston, Ll) to verify the inlet and outlet effect an flow velocity profilles. The system was filled with $10 \mathrm{ml}$ phosplatebuffered saline (PBS) at pH 7.3 ; then the slide seeded with the endothelial monolayer was mounted in the flow chamber, Heparinized wholle blood was incubsted with the fluorescent dye mepacrine $(10 \mu \mathrm{M})$. Mepacrine concen. trates in the dense granules of platelets and in the granules of leukocytes. At this concentration it has no effect on nomral platelet function. ${ }^{32}$ Any fluorescence within the erythrocytes is quenched by hemoglobin. Blood presincubated for 5 winutes a $37^{\circ} \mathrm{C}$ was then perfused into the chamber at

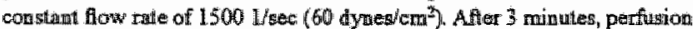
wirss stopped and the slide with the endothelial cell monolinyor was delesydrated and fixed in acetone for 20 minutes.

\#mang of platelet thrombi on endothelial call surface mere acquired by a conffocal inverted laser microwcope (InSight plus: Meridian lastrumedis s; Okenios, MI). An argon laser emission fitter al $488 \mathrm{~nm}$ was used to excite specimens. Fifteen fields, systemstically digitized along the wherion surfice wene acquired wsing a computer-based imange andlysis system. The area occupsied by thrombi was evaluated by automatic etge detection using built-in specific functions of the software Image 1.61 (National Institutes of

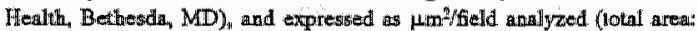
$474473 \mu \mathrm{m}^{2} /$ field $)$.

\section{Scanining olectron microsciopy}

For scaming elestrom microscopy analysis HMEC-1 grown on coversilips were trealled with VT-1 (10 pM, 24 hours), perfused with blood, and then fuxed opernight at $4^{\circ} \mathrm{C}$ with $2.5 \%$ gluthraldebyde in $0.1 \mathrm{M}$ sodium crecodylate besffer, $\mathrm{pH}$ 7.4. The slides raere rinsed in $0.1 \mathrm{M}$ sodivin cacodylate buffer, ofmicated for 1 hour, and then debydrated in an ascending servies of ethanal. The dehydration series concluded with $2 \times 15$-minute exchanges in $100 \%$ othatol. After drying, the slides were conted whith poid and examined in a seanning electron microseope (Stereoscan 200, Cambriuge Instrumentr, Cambridge, MA).

\section{Flow cytometry anallysis}

The serthe expression of VT-1 regentor on HMC-1 and HUVECs was

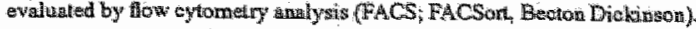

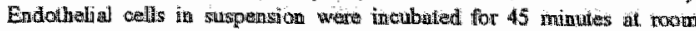

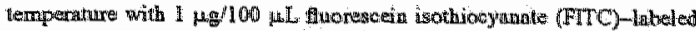

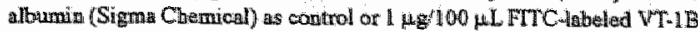
subsunit (a kind gifl from DF C. A Lingwod, The Hospital for Sick

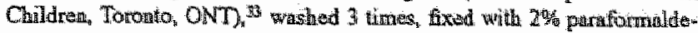
hyde, and assayed within 1 hour.

\section{Fluorescence confocal microscopy}

The HMEC-1 line and MDMECs gnown on cowemsilps ware incubared with medrum alone or VT-1 (10 pM) for 2 s hours and then fixed in $39 \%$ paraformaldebjode plus $2 \%$ sucrose in PBS, pH. 7.4, for 15 minutes at room temperature. After 3 washings (5 vainutis) with PRS plus $3 \%$ boving serum to prevent nonspecife antibody binding cells prese tranted with aniti-P. galactin antibody $(50 \mu \mathrm{g} / \mathrm{mL}$ ) or antivitronection receptor antibody LMOOS (10 $\mathrm{kg} / \mathrm{mL})$. For PECAM-1 assessmen, cells pertuesbillized win Tilion X-100 (0.1\% in PBS; Sigma Chomical) for 4 minutes before incubation with anti-PECAM-1 antibody $(10 \mu \mathrm{g} / \mathrm{mL})$. Then collow were incubated with FITC-conjugated $\mathrm{F}\left(\mathrm{ab}^{*}\right)$ n goat antimowise $\mathrm{Fg}$ (Jackson Immunoresearch Laboratories, West Growe, PA).

Nagetive control experiments with PITC-conjugened antibody allone were parformed Coversips were washed, mounted in $1 \%$ N-propyl-ngallate

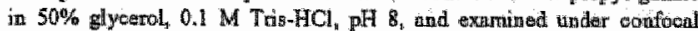
inverted laser microscopy. Representative fields were digtized with millions of colors and printed.

\section{Statistical analysis}

Results are expressed as mean I SE. Statisticall andysis was porfourmed using ANOVA followed by the Tukey test for miltiple compurisons, as approprinte. ${ }^{34}$ Statistical significance way defined as $P$ lessi thun 05 .

\section{Results}

\section{WT-4 promotes platelet adhesion and thrombus formation on endothellial cells}

We studied the effect of VT-II on platelet athesion and thrombus formation under lamiratir how at bigh shour rate on MMrC-1. HUVECs were used for comparison as large-vesed endothelium Heparinzzed blood was prelabeled with mepering and perfused at 60 dynes $\mathrm{cm}^{2}$ ower resting or VT-1-ixeated endotholial owls; then thrombus formation was quantifed by amalyzing inages acquired by confocial microscopy. On resting HMEC 1 only limited platelet depositio were observed, nswally less than $0.3 \%$ of the wotal perfuad ares, corresponding to about $1200 \mathrm{jm}^{2} /$ field andilyzed. Exposure of HMEC-1 to VT-1 for 24 bours led to significaut $(P<.01)$ increase in platelet adhesion and thrombus formation in comapari:son to control cells, with a maximum affect at $10 \mathrm{pM}(2 \mathrm{pM}$ : $7754 \pm 1592 ; 10 \mathrm{pM}: 10090 \pm 2246 ; 50 \mathrm{pM}: 8244 \pm 2874$ wersins

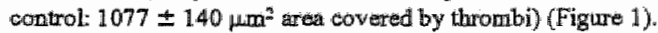

in these experimental condition the endothelial cell integrity was preserved as indicated by stainitg with May Grumwald Giemsa of HMEC-1 treated with VT-1 (10 pM) and then perfised with blood.

As shown in Figure 1, VT-1 also promoted platelet adhesion and thrombus formation on HUVECs but to a remarkably low or exten that on HMEC-1 (2 pM: $3406 \pm 297$ : $10 \mathrm{pM}: 3849 \pm 540,50 \mathrm{pM}$ :

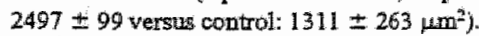

Figure 2 depicts digitized imaiges from a represeatative oxperiment acquired by confocal fworescent micrascopy showing an 


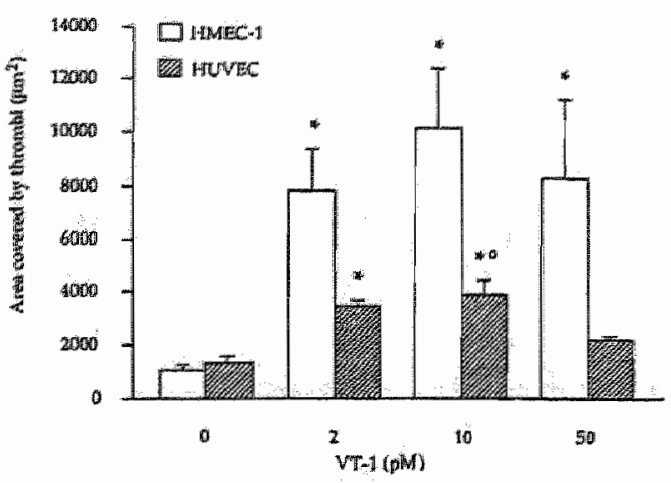

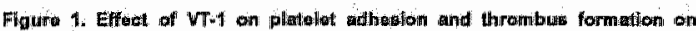

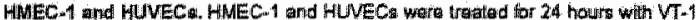

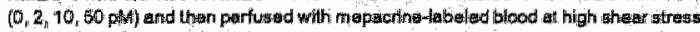

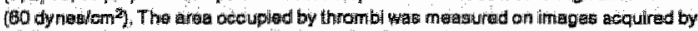

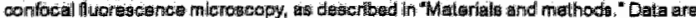

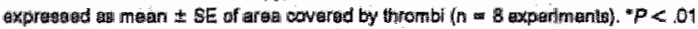

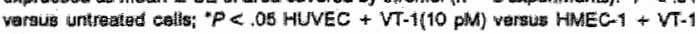
(10 plus).

increase in the number of mepacrine-labeled thrombi on HMEC-1 exposed to VT-1 im comparison to HUVECs.

Swanning electron microscopy evaluation of VT-treated HMEC-1 illustrates the attachment of platelets to the endothelial cell monolayer to form orgamized thrombi in which lenkocytes at diffierent stages of activation are entrapped (Figure 3).

In selected experiments, the beliavior of the HMBC-1 cell line in response to the thrombageriic effect of VT-1 was compared with that of primary microvascillar endothelial cells of similar dermal origim. VT-1 (10 pM) induced thrombus formation on the HMEC-1 line and primary HDMEC to a similar extent (HMEC-1: $11831 \pm 1303$; HDMEC. $9226 \pm 1979 \mu \mathrm{m}^{2}$ area covered by thrombi). HUVECs used in these settings for comparison were significantlly less susceptible to the effects of VT-1 (4061 \pm 553 $\mu \mathrm{m}^{2}{ }^{2} P<.01$ versus, HMEC- 1 and $P<.05$ versus $\mathrm{HDMECs}$ ).

\section{VT.4 Is more thrombogenilc than thrombin and cytokimess}

We eormpared the capribility of WT-11 to induce thrombus formation on $\mathrm{HMEC}-1$ and HUVBCs with other thrombogenie agonists like thrombin, TNF-at, and IL-13. As athorin in Figure 4, thrombin and cytokines were less effective in promoting plntelet deposition than VT-1 in both endotheliel cell types. The superior thrombogenic effect of VT-1 tramslatid in larger thrombus size with respect to

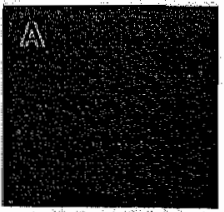

Figure 2. Thrombl formed aftur tromathant with VT-1.

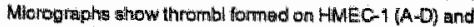

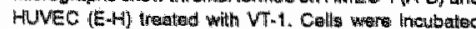
with achtrol medium (A, or with W W DN $(C, 6), 00 \mathrm{pM}(\mathrm{O}, \mathrm{H})$ for 24 hours, perfused with biond at 60 dyngeglem? arte examined lby canfocal mierosocoy. ougtized ropresentative fieleds are showm.

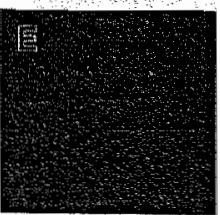

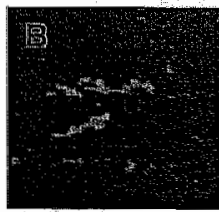
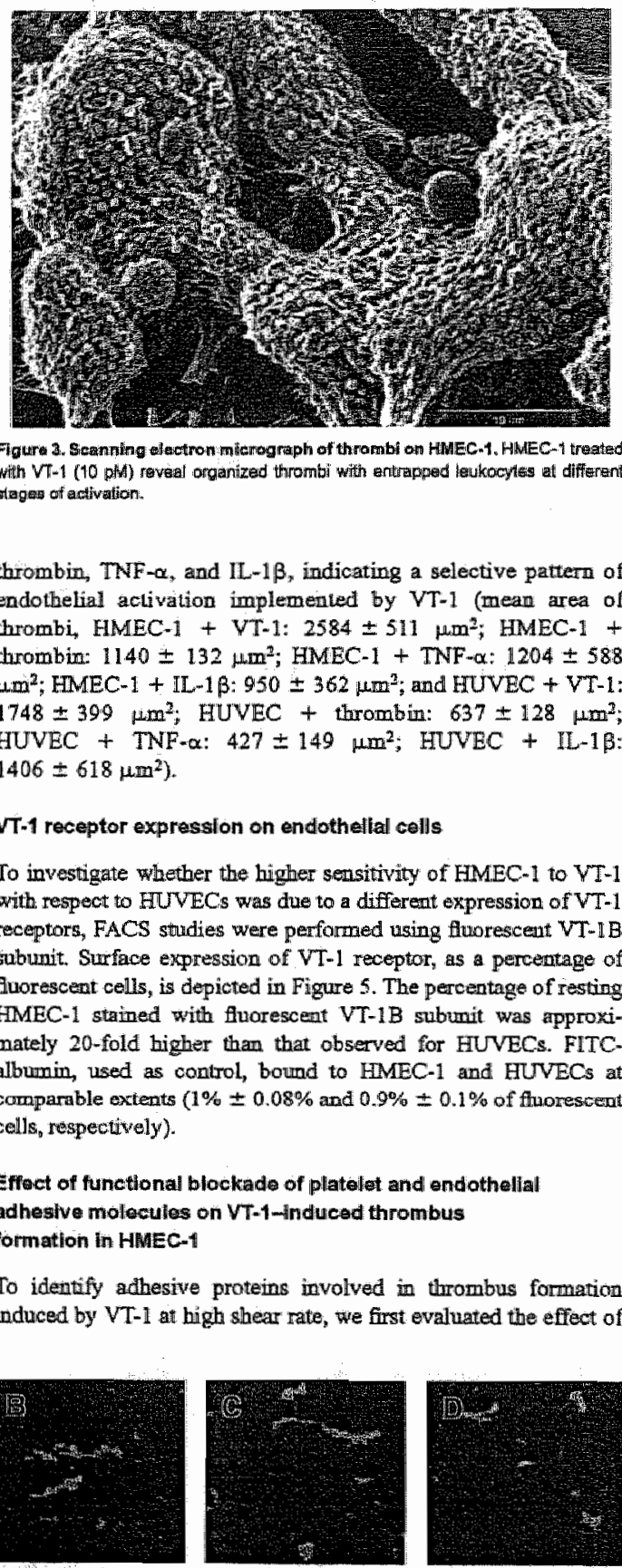

Figure 3. Scanning ollectron miterograph of thwombi on HMEC-1, HALEC-1 treated

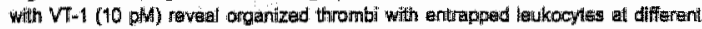
alage of activation:

thrombin, TNF $-\alpha$, and $\mathrm{LL}-1 \beta_{n}$ indicating a selective pattern of endothelial activation implemented by VT-1 (mean area of trombi, HMEC-1 + VT-1: $2584 \pm 511 \mu^{2} ; \mathrm{HMEC}^{2}-1+$ thrombin: $1140=132, \mathrm{Hm}^{2}$; HMEC-1 + TNF-a: $1204 \pm 588$ $\mu \mathrm{m}^{2}$; HMEC-1 + IL-1 $3: 950 \pm 362 \mathrm{\mu m}^{2}$; and HUVEC + VT-I: $1748 \pm 399 \mathrm{Hm}^{2} ;$ HUVEC + thrombin: $637 \pm 128 \mathrm{H}^{2}$; HUVEC + TNP- $\alpha: 427 \pm 149 \mu \mathrm{m}^{2} ;$ HUVEC + IL-1B: $\left.1406 \pm 618 \mathrm{\mu m}^{2}\right)$.

\section{VT-1 receptor expression on endothellal cells}

To investigate whether the higher sensitivity of HMEC-1 to VT-1 with respect to EUVVECs was due to a different expression of VT-1 receptors, FACS studies were performed using fiworescent VT-IB subunit. Surface expression of VT-1 receptor, as a percertage of fivorescent cells, is depicted in Figure 5. The percentage of resting HMEC-1 stained with fluorescemt VT-1B subumit was approximately 20-fold higher than that observed for HUVECs. FITC albumin, used as control, bound to HMEC-1 and HUNECis at comparable extents $(1 \% \pm 0.08 \%$ and $0.9 \% \pm 0.1 \%$ of fhorescent cells, respectively).

Effect of functional blockadie of pllatellet andi endiothellial: ad hesive mollesules on VT-1-inuduiced thrombus formation in HIMEC-1

To identify adhesive proteins involved in thrombus formation induced by VT-1 at high shear rate, we first evaluated the effect of
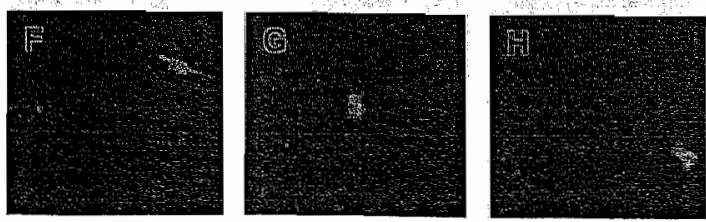


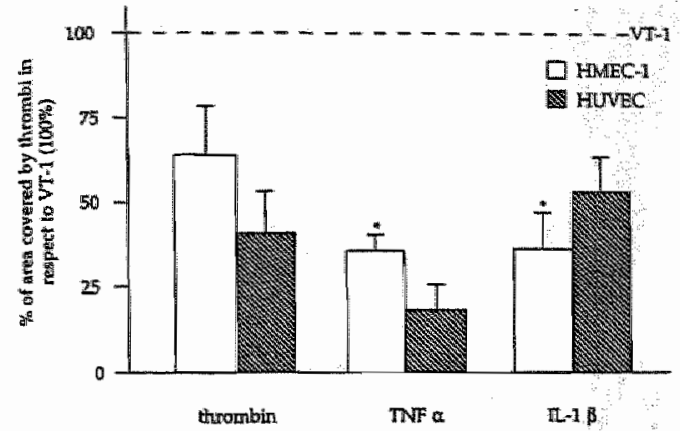

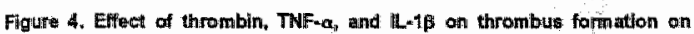

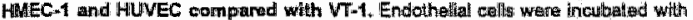

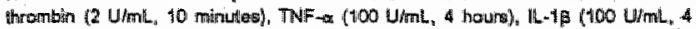

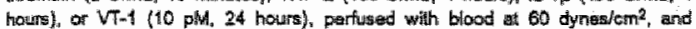
examinind under confocal microscopy. Data are expressed as mean \pm SE of percent

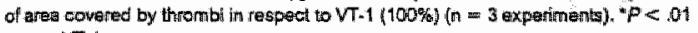
versus vi-1.

blocking the interaction between vW and platelet receptors GPIb and $\alpha_{\mathrm{Im}} \beta_{3 \mathrm{i}}$ As shown in. Figure 6, ATA, which inhibits vWF-GPIb interaction, conpletely prevented platelet deposition and thrombus formation induced by VT-1 (10 pM) on HMEC-1 surface (VT-1 + ATA: $919 \pm 256 \mu \mathrm{m}^{2}$ ver:us VT-1:9502 $\left.\pm 1475 \mu \mathrm{m}^{2} \mathrm{P}<.01\right) \ldots$ similar significant $(P<.01)$ reduction in the area occopied by trombi was observed by blocking the platelet receptor $\alpha_{\text {mb }} \beta_{3}$ with the chimeric $7 \mathrm{E} 3$ Fab (VT-1 + 7E3:952 $\left.\pm 278 \mu \mathrm{m}^{2}\right)$.

Considering that GPIb is also expressed on endothelial cells, we. invastigated the rolle of this receptor on VT-1-induced thrombus. formation in HMEC-1. Functional blocking of GPIb with LJ-Ib1 $\mathrm{mAb}$ did not affect thrombus formation in response to VT-1 (VT-1 + anti-GPIb: $12096 \pm 2716 \mu \mathrm{m}^{2}$ versus VT-1: $12696 \pm$ $1677 \mu^{2}$ ), suggesting, that in this experimental setting endothelial GPTb was not involved in VWF-inchuced thrombi at high shear stress.

Because it is known that VWF, besides bincing extracellular matrix proteins, can interact with endothelial $\beta$-integrim subunit

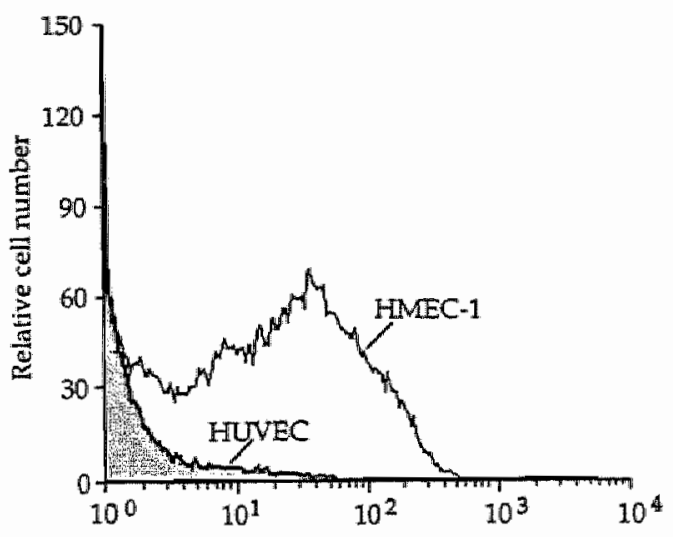

Fluorescence intensity (log scale)

Figure $\mathrm{S}_{\mathrm{n}}$ Flow cyntomatric anditysis of VT-1 receptor expression on unstimu-

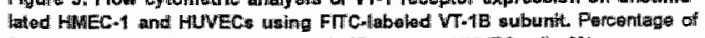

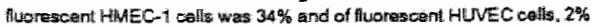

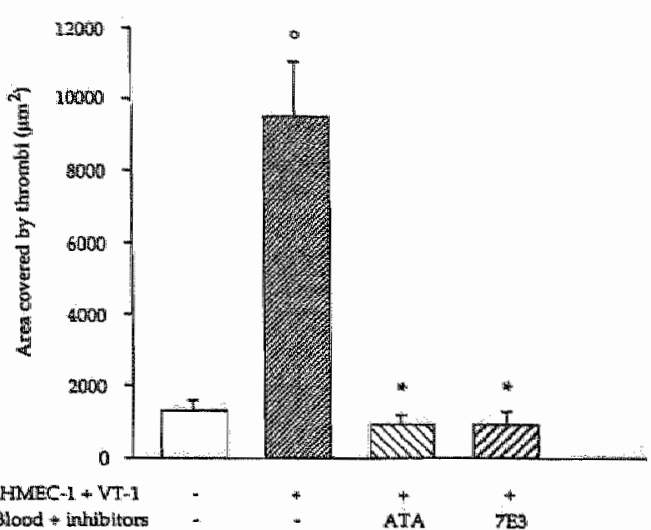

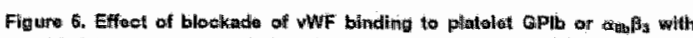

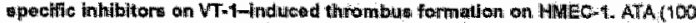

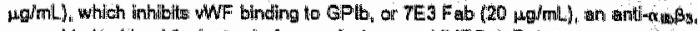

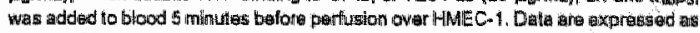

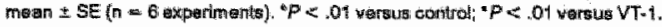

wia RGD sequence, whe assessed the role of 9 - 3 -integrin and more specificaly of $\alpha_{3} \beta_{3}$ in the thrombotic process mouced by VT-1 in HMVEC-1. As shown in Figure 7, blocking of $B$-integrio subunit by $7 \mathrm{E3}$ or intibition of $\alpha_{4} \mathrm{p}_{3}$-iotegrin complex by LM609 both resulted in a significand $(P<.01)$ reduction of the area covered by thrombi (VT-1 + 7E3: $2477=515 \mathrm{um}^{2}$; VT-1 + LM609: $3096 \pm 972 \mu \mathrm{m}^{3}$ versis VT-1: $11609 \pm 1961 \mu \mathrm{m}^{2}$ ).

To irvestigate endothelial adhesive proteins that can directly interact with plateil receptors, $\mathrm{HMEC}-1$ premoubated for 24 hours with VT-1 were exposed io enti-P-selectin and ant-PECAM-1 antibodies. Anti-P-selectin antibody allonst completely $(P<.01)$ prevented platelet adhesion (VT-1 + anti-P selectim: $2386 \pm 826$ $\left.\mu m^{2}\right)$. Bloclking of PECAM-1 had a less prononnced but still significant $(P<.05)$ inhibitory effect on VT-1-induced thrombus formution with the area covered by thrombi averaging $4.553 \pm 532$ $\mathrm{mm}^{2}$ (Figure 7). Irrelevant antibody did not significantly modify VT-1-induced platelet deposition (percent of reduction ton covered by thrombi compared with VT-1 alones $10 \mu \mathrm{w} / \mathrm{mil}, 2 \%$ $\mu \mathrm{g} / \mathrm{mL}, 9 \%$ and $50 \mathrm{\mu g} / \mathrm{mil}, 15 \%)$

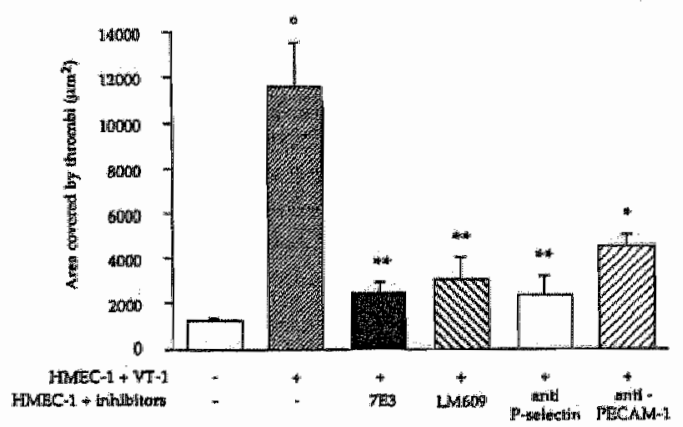

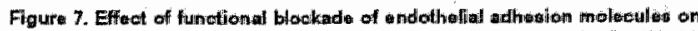

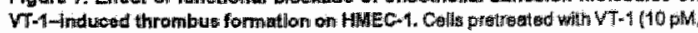

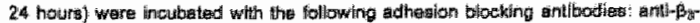

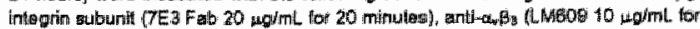

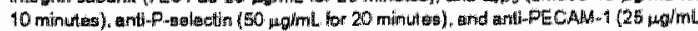

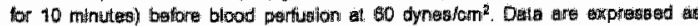

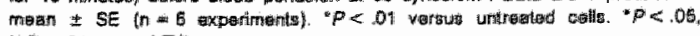
$\rightarrow P<$, OT weralu VT. 
The insolvernetat of P-selectin and PECAM-1 in platelen deposition elicited by VT.1 was also confimed on primary

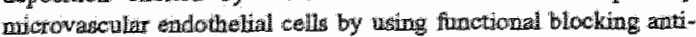
bodic that redued by $79 \%+7 \%$ and $86 \% \pm 4 \%$ respectrielly the area covered by thombi ( $<<.01$ wersuls VTw

\section{Endothellal adhesive protelns linolved in VI-1-induced thrombisus formation}

We characterized by confocal flucrescence microseopy the distribution on the ndothelial surface of the adhesive molecules found in the above experments to be implicated in the thrombotic process induced by VT-1. As shown in Figure 8A, B, FMEC-1 treated with VT-1 (10 pM, 24 hoursi) extibited an incteased expression of vitronectin receptor, as small diffuse granules on the lominal surfuce, in comparison to tusstimulated cells.

The HMEC-1 cell line in a resting condinon did not stain for Pselection the apical surface (Figure $8 C$ ). In contrast, on VT-1 challenge a strong fluorescence was observed with the P-selectin staining paltern of granules distributed on the apical side (1)

PECAM-1 localized to the cell-cell border of adjacent unstimulated HMEC - 1 as a linear staining (Figure 8E). After treatment with VT-1 PECAM-1 redistributed axay from intercellular junctions and fomed irregular patches of staining along the periphery of the
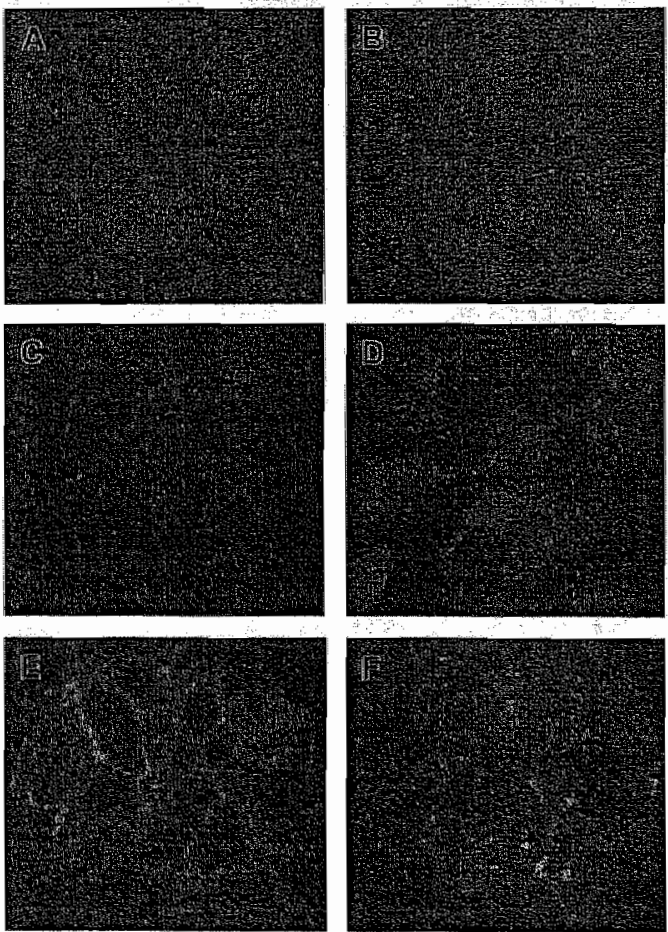

Figure

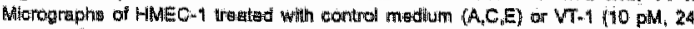

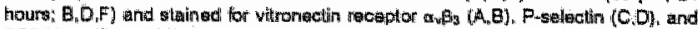

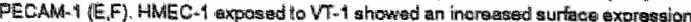

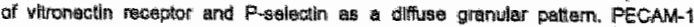

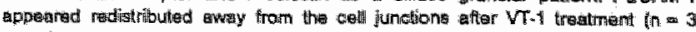

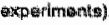
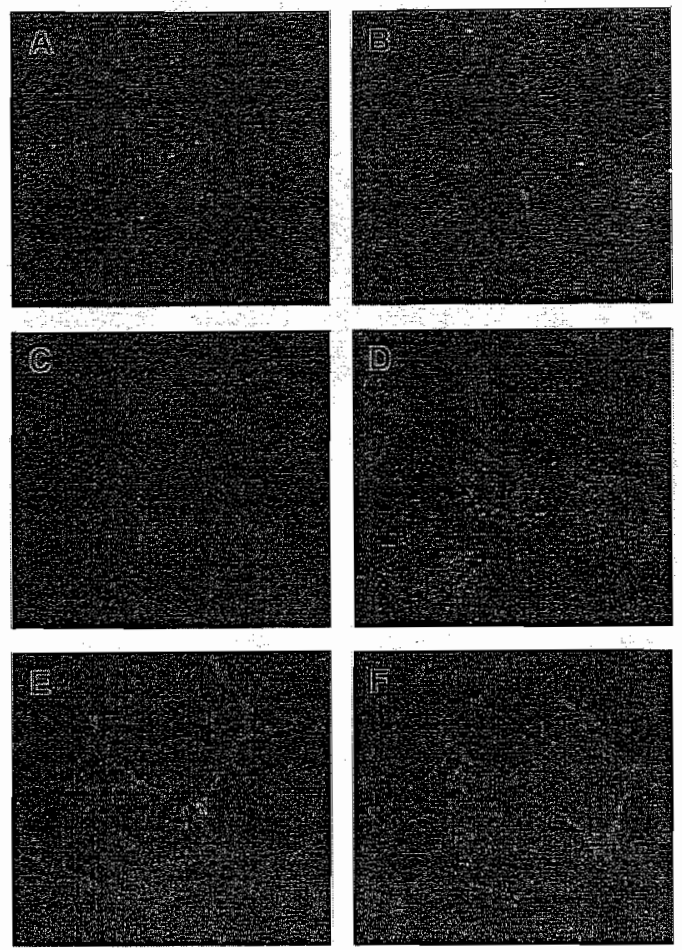

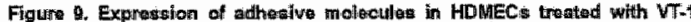

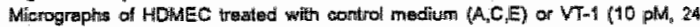

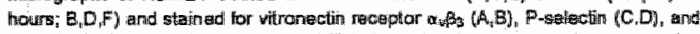
PECAN-1 IE

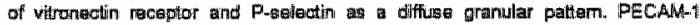
apperared redistrtbuted away from the ceallmcel bordis and irregular patchesi of

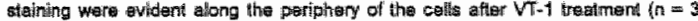
exporimantsy.

cell or diffuse granules on the luminal surface and/or at the intratcellular level ifigure 8F

By studying the effect of VT-1 on the expression of these achesive proteins in primiary HDMECs wie observed a distribution similar to that of the HMBC-1 lime (Frgure $9 \mathrm{~A}-\mathbb{F}$ ).

\section{Discussion}

Verotoxin-producing $E$ coll, the calasative agent of D+HUS, activates endothelial cells to acquire a prothrombotic phenotype with corresponding lesions confined to microvessels mostly of renal glomeruli. th

In this report we show for the first time that VT-1 directly induces platelet adhesion and thrombus formation on cultured ondothellial colls perfised with whole blood in a flow chamber system under shear stress levels high nough to mimic the ones encoumtered in the mierocinculation. The effect of VI-I was superior to that of other known thrombogenie agonisis such as thrombin and cytokines.

The area occupied by thrombi was more pronounced on W-1-treated endothelial cells of microvascular (FMEC-1) in comparison with large-wessel (HUVEC) ongin. The HMEC-1 line 
bat a sindilar sensitivity to the thrombogeaic effect of VTa as HDMECs.

That microwascular endothelinm is indeed more suscoptible to the prothrombotic actiwity of VT-1 is consistent with previons findings. Thus, renal microvascular endothelial cell viability as well as their protein sym thesis capacity, were rafuced by VT concentrations that were instead not cytotoxic for HUNECs. Basal Go3 levells in remal wicrovascular evetothelial cells were 50-fold higher than in HUVEC, which suggested a relationship between the degree of VT sensitit $\mathrm{w}$ ity and the amount of Gb3 receptor expressed by these cellis. Similar to renall microwascular endothelial cells, we found that HMEC-1 expressed about 20-fold more VT-1 receptors than HUVECs, which might account for the different sensitivity of different vascular beds to VI-mediated diseaste.

In the attempt to identify the adhesive proteins involved in platelat-endothelial cell interactions elicited by VT-1, which eventually resulted in thrombus formation on $\mathrm{KMEC}$-1, fue first focused on WWF, which is the indispensable adbesive substrate to promote platelet thrombus formation in high shear stress environments. ${ }^{1.5}$ We found that ATA, an imbibitor of WWF-platelet GPlb interaction, completely prevented the deposition of thrombi. Furthermore, blockade of $\alpha_{0 b} \beta_{3}$ on activated platelets by chimeric $7 E_{3}$ Fab also abrogated platelet adhesion and thrombus formation. These observations extend to our experimental condition what has been dowmented in other settings, 15,35 that is at bigh shear stress the mechanism supporting platelet adhesion and thrombus formation requires binding of platelet GPIb to VWF. The engagement of this receptor then promotes activation of platcilet receptor $\alpha_{\text {mot }} \beta_{3}$ that mediates inteversible adhesion by interacting with the RGD sequence of vWF. Therefore, the inhibition of cone of these sieps with ATA or 7E3 wovild result in a complete blocking of thrombus formation.

It has been widely described that interaction of vWF with platelet $G P T b / \alpha_{m b} \beta_{3}$ is instrumental in mediating platelet adbesion to subendothelial matrix at high shear rates. ${ }^{15}$ Here, we provide a series of obserwations indicating that VWF-mediated platelet achesion on VT-1 challenge occurred mainly on the endothellal surface rather than in the subendothelinm. First, whe have verified by light microscopy that the integrity of the endothelial layer was still preserved after blood perfusion at high shear stress. Moreover, based on. the vidence that wWF vin the RGD sequence." binds vitronectin receptor $\left(\alpha_{1} \beta_{3}\right)$, the major integrin expressed on endiothelial cells; ${ }^{16}$ we have documented by confocal fluorescence microscopy that vitronestin receptors were up-regulated andlor redistributed on the apical aspect of HMEC-1 after VT-1 exposure. Finally, fumctional blocking of endothelial vitronectin receptior $\alpha_{y} \beta_{3}$, with LM609 almost completely abrogat thrombus formantion. Altogether these data indicate that VT-1 alters endothelial thromboresistance by inducing changes in the surface expression of vitronectiti receptor that leacis to platelet deposition wia a WWFdependent bridging mechanism. These findings are in line with recent studies showing that prothrombotic mediators such as $\alpha$-tharmbin and IL-1 9 induced on the luminal surface of endothelial cellls wp-regulation of vitronectin receptors that in turn promoted platelet adhesion through an RGD-dependent pattway. ${ }^{36}$

Our finding that treatment of endothelial cells with anti-GPIb antibody did not inhibit thrombus formation inducer by VT-1 suggested that GPIb expressed on endotbelium is not engaged in the interaction with soluble WWF in a high shear stress environenent.

The endothelial adhesive moleciles P-selectin 20 and PECAM-123 bave been involved in the process of plateler deposition on activated or damaged endothehiun by their direct binding to platelets, ${ }^{2 i, 24,37}$ Thus, it has been simown by intravital finorescence microseopy thai ischemia/reperfurion injury caused owerexpession of $\mathbb{D}-$ selectin on investinal mieroxascular endothelial cells, in

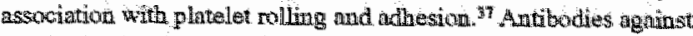
P-selectim sigaificontly reduced anicrowascular thrombosis, which implied a tirect role of this endathelial adhesive molecula in piatelet deposition under flow conditions. We have foviad that mbibition of P-selectin with a specific anvibody caused a significant decresse in VT-induced thrombus formation on WMEC-1. These datr, along with aur obseryation of a stong expression of P-selectir on the apical surface of HMEC-1 after VT-1 challenge. provide evidence for the involventent of P-selection in the thrombotic process elicited by VT-1 at high shenr stress.

As for endothelial PECAM-1, its contribution to platiolet deposition was proved in a model of laser-induced endothelial injury in mouse brain arterioles by the observation that antiPECAM-11 aratibody reduced microvased lar unombosis over damaget but not denuded endothelium. ${ }^{34}$ Our present study showed that functional blocking of PECAM-1 resulted in a siguriffoant reduction of the area coverad by thrombi in $\mathrm{HM}$ IEC 1 exposed to VT-1. In ardotion, confocal microscopy experiments reveraled lav VT-I induced a redistribution of this protein a way from oeli junctions, a paltern similar to that deseribed in human endothelial cells after oytokine stimulation. ${ }^{38}$ We speculate that PECAM-1 once redistribut ed on the endotheliad sur face may undergo phosplor ylation, ${ }^{23}$ which would render this adtesive receptor svailsble for platelet interaction.

In prinary microvascular endothelial cells treated with VT-1, expression of vitronection receptor, P-selection, and PECAM-I Was similar to that observed in the HMEC-1 line. Moreover, as in HMEC-1, blockade of P-selectia and PECAM-1 by spacific antibodies markedly limited VT-1-induced thrombus formation, thus suggestimg that thrombotic response elicited by VT. 1 involved activation of the same endothelinl adhesive protens in both line and primary microvascular endothelial cells.

In conclusion, our results fidicate for the first time that (1) VT-1 is a potent promoter of plateliet adhesion and thrombus formation on endothelial cellis under bigh shear stress; (2) microvascular endothelial cells damonstrate a remarkably mreater sensitivity to the thrombogenis effect of VT-1, then endothelium derived from large vessells, possibly due to the liather expression of VT-1 receptori, (3)

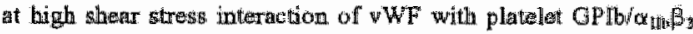
supports VT-1-iraduced platelet deposition througl the biugh to vitronection receptor on the endothelial luminal surface; and (4) up-regulation andor redistribution of andotholial vitronatin recap-

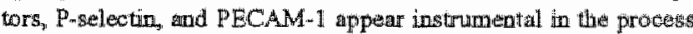
of thrombus formation induced by $\mathrm{VT}-1$

These findings anight belp to elarify why thrombi in HUS preferentidly lowalize in microvessels and prowide insights on the determinants possibly inwolved in process of microwaseular thrombosis associaned with D HUS

\section{Acknowledgments}

We are indebted to Prof Giuseppe Sillwa and Piero Pellini for hel pful cooperation during scanning ellectron macroscopy evaluations (Po Litecnico di Milano, llaly). We thank Dr Anoa Falanga (Unit of Hematology, Azjencla Ospedal jera, Ospedaij Rimiti di Bergamo, litaly) for kind cooperation, and Stefania Angioletti, Chiara Rossi, and Federica Casiraghi for technical assistance 


\section{References}

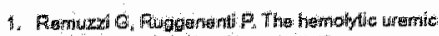

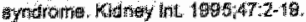

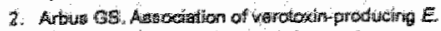

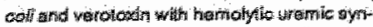

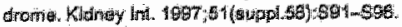

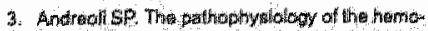

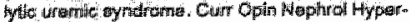

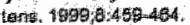

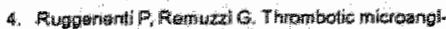

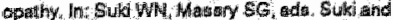

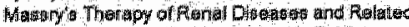

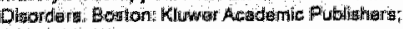

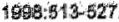

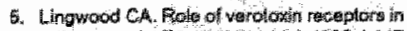

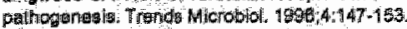

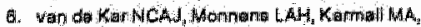

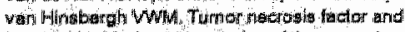

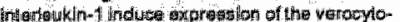

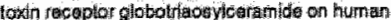

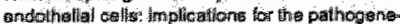

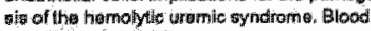
$1992760.2755-2784$

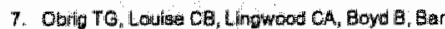

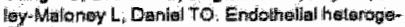

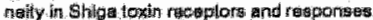

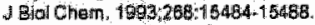

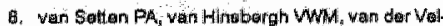

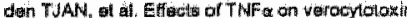

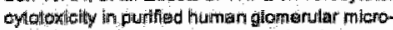

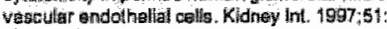
$1248 \div 256$.

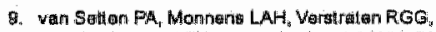

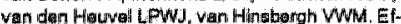

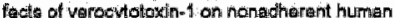

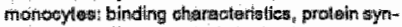

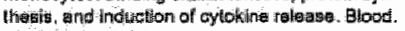

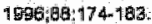

10. Forsyli KO, Simpsion $A C_{1}$, Fitzpiatrick MMA, Barrah

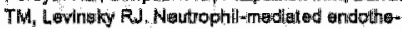
liall injury tri hae miclytic urame syndiome. Lan. cel. $1909901 ; 111-414$.

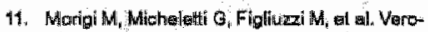

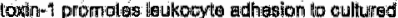

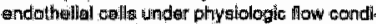
tions: Blood. 19:5; 86:4553-45:58.

12. Androoli SP, Groen DF, Warctoxin 1 promalos witrit: oxide (HO) ganeration in glomerular endotheila! crelts: (GEC) and acolarates PMN mediatod

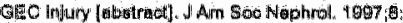

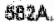

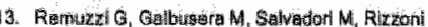

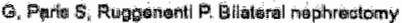

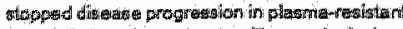

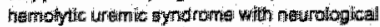

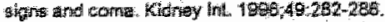

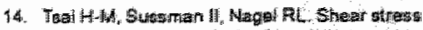

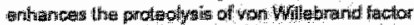

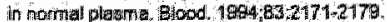

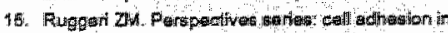

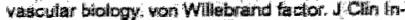

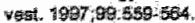

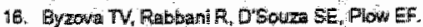

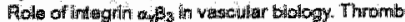

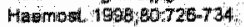

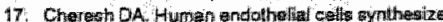
and axperes an Arg-Gly Aap-directed achesion

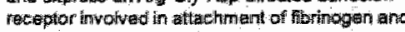

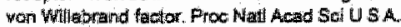
1097 ; $34.647-6475$

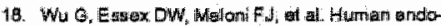

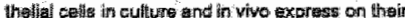

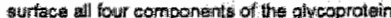
HAN complox Elood. 1997,90:2650-2609.

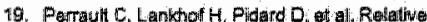

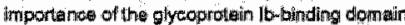

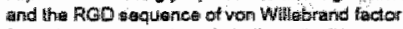

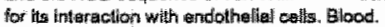
$1997,90,2335-2344$

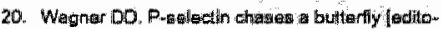

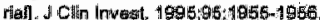

21. Fronette PS, Jahrusion RC, whenes RO, Hagner DO. Platelats roll on, stimulated endothedilum in wiva an interiaction mediated by ordotialial P.

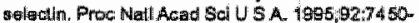
7.454

22. Chong BH, Munray B. Bemdi WC, Durilog LC, Brighton T, Chesteman CW Plasme P seleatin is increased in thrombot consumptive platiolat of orders. Blood. 1994,85:4 1535-1541.

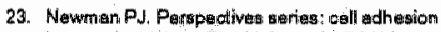
in vascular biology. The biology of PECAM-1 J Clin Invest 1997\%9a:3-8.

24. Rosemblum WI, Nelsom GH, Worntey B, Werner

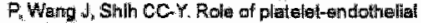
coill arthesion molsicule (PECAM) in piatellat adhet sibniagregration owar hinjured but nol dertudad andothellitum in wivo and ex who, Stroke, 1895;27 7001711 .

25. Ades EW, Ciandal FJ, Swartimk RA, at al HMEC-1: establishment of wn immortallized hu-

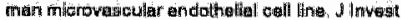

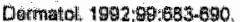

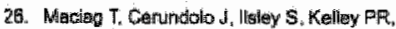

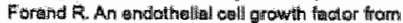

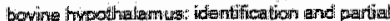

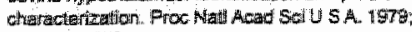
$70.5674-5378$

27. Igfre E

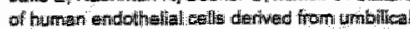

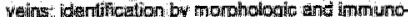

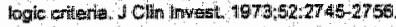

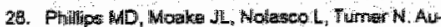

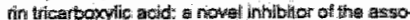

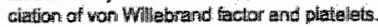
Bloos. $1988.72-17992-1903$.

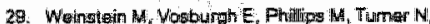

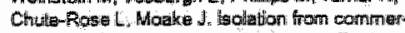

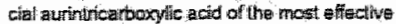

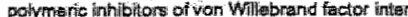

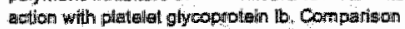
With other polyanion ic and pahrarondtic poly-

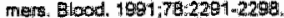

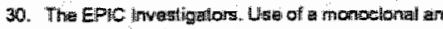

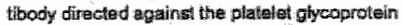

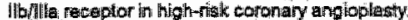
N Engl w Hod 1904-330.956-981

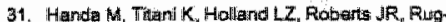
gar ZW. The von Willabrand tactor-birnding to

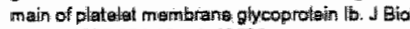
Ghem, $1906 ; 284 ; 12579-12585$

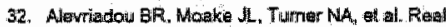

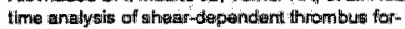
mation and its blockede by intribltors of wom Wrilie

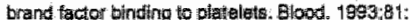
1263.1276.

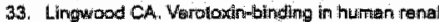
sections Nepitron, 1594;60:2!-28.

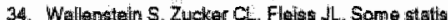

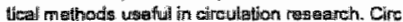
Res: $1900 \mathrm{~d}$ - $7: 1-9$

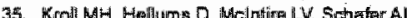
Moake AL. Platelete and ahear wtrasio. Bllood $1996,88+15.25-1541$

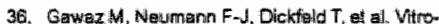
neetin raceptor ( $\left.\alpha_{4} \beta_{3}\right)$ meditates plateles, adhession to the lumiral aspect of end ot hellal cellis limpliesthons for repartusion in acuke myocardlel infarc tion. Chevilation. 1997;90:1200-4818

37. Masstrem $s$, Enders $G$, Leiderer $R$ of al Platel andothelizal cell interactions durng: ischomial reperfusion: the rale of P-sellectin. Elood. 1998: 92.507-5:15.

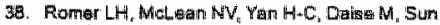

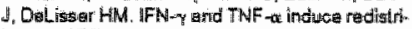

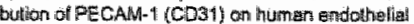
cot? 
CHAPTER 6

\section{IN RESPONSE TO PROTEIN LOAD PODOCYTES REORGANIZE CYTOSKELETON AND MODULATE ET-1 GENE: IMPLICATION FOR PERMSELECTIVE DYSFUNCTION OF CHRONIC NEPHROPATHIES}

M. Morigi, S. Buelli, S. Angioletti, C. Zanchi, L. Longaretti, C. Zoja, M. Galbusera,

S. Gastoldi, P. Mundel, G. Remuzzi and A. Benigni

Am J Pathol 2005; 166: 1309-1320 
$\therefore \quad \vdots$

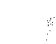




\title{
In Response to Protein Load Podocytes Reorganize Cytoskeleton and Modulate Endothelin-1 Gene
}

\author{
implication for Permselective Dysfunction of Chronic \\ Nephropathies
}

\author{
Marina Morigi," Simona Buelli," \\ Stefania Angioletti, ${ }^{*}$ Cristina Zanchi, ${ }^{*}$ \\ Lorena Longaretti," Carla Zoja," \\ Miriam Galbusera, "Sara Gastoldi, " Peter Mundel, ${ }^{\dagger}$ \\ Giuseppe Remuzzi, ${ }^{\star \ddagger}$ and Ariela Benigni" \\ Prow the Mario Negri" Institule for Pliarnacological Restarch,

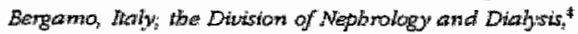 \\ Arienda Ospedaliera, Oppedall Rumiti di Bengama, Bergano, \\ Italy; and the Department of Heditine" Abert Etrstein Callege of \\ Haticing New Tork New York
}

Effacement of podocyte foot processes occurs in many proteinuric nephropathies and is accompanied by rearrangement of the actin cytoskeleton. Here, we studied whether protein operload affects intracellular pathways, leading to cytoskeletal archuttecture changes and ultimutely to podocyte dysfunction. Mouse podocytes bound and endocytosed broth albumin and IgG pia receptor-specific mechanisms. Protein orerload caused redistribution of F-actin fibers instrumental to up-regulation of the prepro-endothelin (ET) 1 gene and producthon of the correspoinding peptide. Increased DNA-binding activity for nuclear fictor (NF)-kB and Ap-1 nuclear proteins was measured in nuclear extracts of podocytes exposed to excess proteins. Botth Y27632, which inihibits Rho kinase-dependent stress fiber formation, and jasplakinolide, an F-actin stabllizer, decreased NF-kB and Ap-1 activity and reduced ET-1 expression. This suggested a role for the cytoskeleton, through activated Rho, in the regulation of the ET-1 peptide Focal adhesion kinase (FAK), an integria-assoctated nonreceptor tyrosine kinase, was phosphorylated bry albumin treatment via Rho kinase-triggered actin reorganitzation. FAK activation led to NF-kB- and Ap-1-depentient ET-1 expression. These data suggest that reorgamiation of the actin cytoskeletal network in response to protein load is implicated in modulation of the ET-1 gene via Rho latnase-dependent FAK activation of $\mathrm{NF}-\mathrm{KB}$ and $\mathrm{Ap}-1$ in differentiated podocytes. Increased ET-1 generation might alter glomernilar permselectivicy and amplify the noxious effect of protein operload on dysfunctional podacytes. (Am J Patbol 2005, 166:1309-1320)

Glomerulosclerosis, key lesion of progressive renal disease, consists of extracellular matrix accumulation and progressive obliteration of glomerular capillaries with loss of glomerular filtration capacity. Permissive factors include high intraglomentar capillary pressure, hypertrophy, and the filtration of excess amounts of plasma proteins across the capillary barrier." "- A crucial component of the glomerular filter is the podocyte, a highly specialized epithelial cell endowed with foot processes. Podocytes possess a contractile structure, composed of actin and associated proteins and connected to the glomerular basement membirane at focal contacts via $\alpha_{3} \beta_{1}$ integrim, that stabilizes glomerular architectur by ouniteracting the distension of the glomerular besement membrane. The contractile apparatus of the foot processes responds to vasoactive hormones to control glomerular capillary surface area and in turn ultrafiltration coefficient

Recent experimental and clinical ewidence seemis to imply an important role of podocytes in the pathophys. ology of glomerular damage and progressive renal dys. function. $^{9-74} \| \mathrm{n}$ this context, repeated irjections of albuj min in rats are followed by glomerular epithelial coll swelling, cytoplasmic protein dioplats in podocytes, and extensive foot process effacement. Such events culmi nate in podocyte detachment from the basement mem-

Aceopled por publication dantuary $20,2005$.

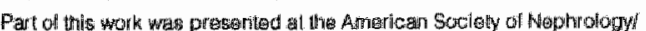

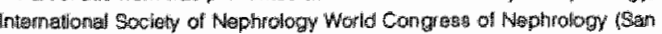
Francisco. CA Oelober 10 to 17 , 2001$)$

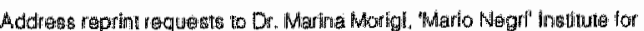

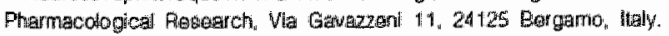
E-matr: morlgionationegilit 
brane. Evidence of a catisal link between podocyte protein deposition and progressive damage rests on the demonstration that in rats wth renal mas reduction profein accumulation in podacytes preceded dedifferentitavon aridinjury, occurmented as loss of synapiopodin and incirease in desmin expression. "Podocyte abnomalties were acompanied by unstoming growth factor $\beta$ mifin up regulation. Concomilarily, in witro experiments indicated that albumin overtoad in cultured podocytes: caused loes of the synaptopodin differentation marker, and enhanced transforming growth factor- $\beta 11 \mathrm{MPNA}$ and proten. Whether protein overload also affects the generation of other mediators of renal damage in podocytes is Ill defiried.

Endothelin-(ET) i, a highly potent vasocongtrictor peptide, ${ }^{17}$ has been implicated in the pathogenesis of glomerulosclenosis by virtue of its action on cell proliferation, chemotaxis, and extracellular matrix accumulation. ${ }^{10}$ Among renal colls; glomerular epithelial colls constitutively express preproET-1 MPNA and synthesize the mature peptide 2ait whose generation is markedly up-regulated by transfoming growth factor $\beta, C 5 b-9$, and thrombin. ${ }^{2}$ Stringent control of ET-y gene expression is achieved through a highly regulated promoter containing consensus sequences for the binding sites of the nuclear factor -1 , the activating protein-1 (Ap-1), dimers Jun-Fos, GATA-2, and nuclear factor (MF)-kB. ${ }^{22-24}$ Activating protein-1 transcriptional activation is regulated by Rho-related small GTPases ${ }^{25}$ involved in the remodeling of actin cytoskele. ton. ${ }^{20.27}$ Finding that overexpression of dominant-inegative mutants of RhoA and RhoB led to a significant reduction in pre-pro-ET. I promoter activity indicates that Pho proteins modulate basal expression of ET-1 gene in endothelial cells: 28 No vidence is available as for the regulation of ET-1 gene transcription and related intracelular mechanisms in podocytes.

Here wa test the hypothesis that protein overload alters the F-actin based contractile padocyte apparatus resulting ith modulation of ET-1 gane expression and produc. tion of the vasasctive peptide. We also provice widence for relevant intracellular signaling evoked by oytoskeletal changes ultirately leading to ET-1 gene expression.

\section{Materials and Methods}

\section{Cell Culture and incubation}

Immortalized mouse podocytes were grown according to the method described by Mundel and colleagues. Briefly, cells were cultured under growth-permissive conditions on rat tail collagen type l-coated plastic dishes (BD Bioscience. Bedford. MA), at $33^{\circ} \mathrm{C}$ ir RPMI 1640 medium (Invizogen, Gaithersburg. MD) supplemented with 10\% fetal bovine serum (Inwitrogen), $10 \mathrm{U} / \mathrm{m}$ mouse recombinant y-interferon (Sigma Chemical Co. Saint Louis, MO), and 100 U/mi penicillin plus $0.1 \mathrm{mg} / \mathrm{m} / \mathrm{strep}$ tomycin (Sigma). To induce differentiation, podocytes were maintained in nonpermissive conditions at $37^{\circ} \mathrm{C}$ whout $y$-interferon for 14 days and used for the experiments. In this culture condition, cells stopped proliferating and were identifed as differentiated podocytes by their aborized morphology and the presence of high levels of synaptopodim, using indirect immundfuorescence microscopy. Cells were routinely mantained for 24 hours in serumtree medium before all of the experiments.

\section{Experimental Design}

We inst addressed whether albumin and $\mathrm{gG}$ bind to podocytes through a receptor-mediated mechanism. Binding and uptake studies were performed as previously described ${ }^{30}$ using human serum albumin (HSA, low endotoxin; Sigmall labeled with 5(6) -carboxyluorescein. N-hydroxysurcinimide ester (FLUOS) of fluorescein isothiocyanate (FITC)-conjugated human lgG (IgG. Sigma). To investigate the efflect of protein overload on F-actin cytoskeletal rearrangement, confluent differentiated podocytes were exposed for 30 minutes, and $1,2,6,24$, and 48 hours to medium alone or in the presence of 10 $\mathrm{mg} / \mathrm{ml}$ of HSA or IgG ( 6 and 24 hours) (Sigma). Then cells were fixed and processed for immunofulorescence stud. ies. Synaptopodin expipssion was evaluated by immunofluorescence experiments in podocytes challenged for 6 and 24 hours with HSA ar IgG. The concentration of HSA and IgG was selected on the basis of previous exper:ments of ours and other investigators on podocytes ${ }^{\text {it }}$ and tubular cells ${ }^{31-33}$ Because phenotypic changes induced by protein load have been found duration-dependent, $^{34}$ the relatively high concentration of plasma proteins in our short-term culture system would simulate the actual total amount of proteins handled by the cells in a chronic pathological condition.

The expression of ET-1 gene was evaluated in differentiated podocytes exposed to $10 \mathrm{mg} / \mathrm{ml}$ of albumin for different time intervals by Northem blot analysis and realtime polymerase chain reaction (PCR). Podocytes challenged with $\lg G$ (10 $\mathrm{mg} / \mathrm{ml})$ ) for 24 hours were also stud. led (real-time PCR). The time course of ET-1 protein synthesis was assessed by radiommunoassay (RIA) in supernatants of podocytes exposed to HSA.

To study the possible role of cytoskeleton in the regulation of ET-1 gene in podocytes laden with proteins, cells were treated with Y27632 110 $\mu$ mol L: Calbiochem. La Jolla, CA), a specific inhibitor of Rho kinase pathway involved in stress fiber formation, ${ }^{35}$ or jasplakinolide (200 nmol/L; Molecular Probes, Cambridge, UK), ar F-actin stabilizer ${ }^{36} 30$ minutes prior and during $3,6,15$, and 24 hours of incubation with albumin, taken as representative protein. Then ET-1 mRNA transcript and protein lewels were measured.

The activation of the transcription factors $N F-k B$ and Ap- 1 was inwesitigated in podocytes exposed to medium alone, HSA, or IgG ( $10 \mathrm{mg} / \mathrm{ml}$, 30 minutes). The eftect of the cytoskeleton inhibitors, Y27632 and jasplakinolide, on DNA-binding activity of these transcription factors was also assessed. To eluciclate the role of focal adhesion kinase (FAK), an integrin-associated nonreceptor tyrosine kinase, in HSA-induced ET-1 expression, we first investigated the phosphorylation of FAK by Westerm blot in podacytes treated for 5 minutes, 30 minutes, and 1, 2, 
3 and 6 hours with HSA (10 $\mathrm{mg} / \mathrm{mm}$. We then assossed the impact of cytoskeleton rearrangement on FAK activa* thon by studying the effect of Ya7G32 or jasplakinolide in podocytes exposed for 30 minutes to HSA. Next tuncwonal blockade of FAK whth genistein " $25 \mu \mathrm{mol} /$, Calbiochem $)^{37}$ on NF- $k 8$ and AP-Y activation was inwestigated. Finally, the effect of FAK inhibition on ET-1 expression was evaluated by studying the effect of genistein, an inthibitor of tyrosine kinases, or the transfection with a recombinant adenovirus encoding FAK-rolated nonkinase $(A d-F R N K)^{38}$ in podocytes challenged with HSA for 3 hours. To understand the functional significance of increased ET-1 production we evaluated the efioct of exogenous ET- $1100 \mathrm{nmol} / \mathrm{L}$, Sigma) ${ }^{39}$ added to podocytes for 2,6 , and 15 hours, on F-actin distribution.

\section{Albumin Labeling}

Ten mg of human albumin (Sigma) were dissolved in $1 \mathrm{ml}$ of butfer carbonate, pH 8.5 , added to a solution of $1 \mathrm{mg}$ of FLUOS in dimethylsulfoxide (Sigma). Labeled HSA was separated from unbound material by gel chromatography using Sephadex G50 column (Pharmacia Fine Chemicals, Uppsala swederi, pre-equilibrated and eluted with carbonate buffer. The eluted fraction was analyzed with a spectrometer, UNNis at the wavelengths of 280 and $486 \mathrm{~nm}$, and final concentration of albumin was determined by Coomassie blue $G$ dye-binding method.

\section{Binding and Uptake Studies}

\section{HSA Binding and Uptake}

For binding experiments, podocytes were grown on collagen-coated plastic Petri dishes and used 14 days after seeding. The cells were maintained for 24 hours in serummer condition and then washed with Ringer's solution, pH 6.0 , at $4^{\circ} \mathrm{C}$ to remove proteins or amino acids. Binding inhibition studies were performed incubating podocytes with Ringer's solution, pH 6.0, containing 50 $\mu \mathrm{g} / \mathrm{m}$ of RUOS-HSA on $10 \mathrm{C}$ for 15 minutes in the $\mathrm{ab}$ sence of piesence of increasing concentrations of cold HSA $(0$ to $10 \mathrm{mg} / \mathrm{ml}$ ). Unbound FLUOS-HSA was re. moved by washing with Ringer's solution, $\mathrm{pH} \mathrm{7.4}$. Cells were lysed in 10 mmol/L MOPS solution (morpholinopropanesulfonic acid, Sigma) containing $0.1 \%$ Triton $x-100$ and the cell-associatad fluorescence was measured by spectrofluorometer. Protein content was determined using the BCA Protein Assay Reagent kit (Plerce, Rockford. 1h) with bovine serum albumin as standard. Binding was expressed as mg/g protein.

For uptake studies, podocytes were grown on collagen-coated glass cowerslips for 14 days. The monolayers were maintained for 24 hours in serumufree condition and then washed with Finger's solution at pH 6.0. Podocytes were incubated in Ringer's solution. $\mathrm{pH} 6.0$, containing $50 \mu \mathrm{g} / \mathrm{ml}$ of FLUOS-HSA with or withaut $5 \mathrm{mg} / \mathrm{mll}$ of unlabeled HSA at $37^{\circ} \mathrm{C}$ for 3 hours. At the end of incubation the cells were washed with Ainger's solution, 0.47 .4 , and fixed with $2 \%$ paralomaldehyde and $4 \%$ sucrose for 10 mitrutes at $37^{\circ} \mathrm{C}$. The fixed monolayers were mounted in $1 \%$ Npropylgallate in $50 \%$ glyoerol ard 0.1 moll TrisHCH. $\mathrm{pH} 8$, and photographs wers taken using hmmothurescence microscopy.

\section{lgG Binding and Uplake}

Podocytes were grown on collagenmooted coverslips for 14 days and maintained for 24 hours in sorum conditions. For binding studies the cells were washed with Ringer's solution at pH 6.0 and incubated with hu. man FITC-I GG (Sigma), $50 \mu \mathrm{g} / \mathrm{m} /$, with or without $5 \mathrm{mg} / \mathrm{ml}$ of unlabelled human lgG (Sigma), at $4 \mathrm{C}$ for 1 hour. Uptake was performed by incubating the monolayers for 3 hours al $37^{\circ} \mathrm{C}$ with the concentration of FITChuman $1 \mathrm{gG}$ and unliabeled $\lg \mathrm{G}$ used for binding. At the end of the incubation the cells were washed and processed as doscribed for HSA uptake.

\section{Flurescence Confocal Microscopy}

Padocytes plated on collagen type 1-couated glass coverslips were maintained in nonpermissiwe conditions for 14 days and incubated with medium alone. HSA, IgG, or ET-1 for different time intervals. At the end of incubation, cells were fixed in $2 \%$ paraformalchehyde plus $4 \%$ su. orose in phosphate-buffered saline (PBS), pH 7.4, for 10 minutes at $37^{\circ} \mathrm{C}$, and then permeabilized with $0.3 \%$ Triton $X-100$ (Sigma) in PBS for 4 minutes at room temperature. After three washings with PBS, nonspecific binding sites were saturated in blocking solution (2\% fetal bovine se rum, $2 \%$ bovine serum albumin, $0.2 \%$ bovine gelatin in PBS) for 30 minutes all room temporature. Podocytes were incubated with mouse monoclonal antibody antisynaptopodin (undiluted: Progen Immunodiagnostica, Heidelberg, Germany) for 1 hour at room temperature. washed, and then incubated with FITC.conlugated goat

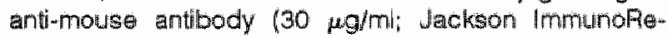
search Laboratories, West Grove. PA). Negative conturol experiments with secondery arntibody alone were per. formed. For F-actin staining, fixed and permeabilized cells wer incubiated with rhodamine phalloidin, 20 U/m. for 45 minutes (Molecular Probes Inc., Eugene, OR): negative control experiments without thodamine-pheallot din were performed. For double labeling of Fwactin and ZO-1, cells were preincubated overnight with polyclonal rabbit anti-ZO 4 antibady $(10 \mu \mathrm{g} / \mathrm{ml}$; Zymed Laboratores, San Francisco, CA) followed by thodamine phellaidin. Coverslips were washed and mounted in $1 \% \mathrm{~N}$. propyl-gallate in $50 \%$ glycerol 0.9 mol/L Tris $4 \mathrm{Cl}$, pH 8 , and examined using inverted confocal laser microscopy (LSM 510 meta: Zeiss, Jena, Germariy). Repesentative fileids were digitalized with millions of colors and printed.

\section{Northern Blot Analysis}

Total RINA was isolated from podocytes by the guanidim isothiocyanatelcesium chloride procedure. Fiflegen wo of total RNA was then fractionated on $1.2 \%$ agarose gel and 
Whotied onto synthetc membranes (Zeta piobe; Bio-Rad. Filnmond. CA). ET-1 mand was deteded by using a 319 bp fragment of rat ET-1 CDNA. The probes were labeled wh $\mathrm{a}^{32 P}$ dCTP by randomprimed nethod. Hybridzation was performed overnight at $60^{\circ} \mathrm{C}$ in $0.25 \mathrm{mo} / \mathrm{L}$ $\mathrm{Na}_{2} \mathrm{HPO}_{4}, \mathrm{PH} 7.2$ and $7 \mathrm{w}$ sodium dodecyl sulfate. Filters were washed twice for 30 minuthes with 20 mmolh $\mathrm{Na}_{2}, \mathrm{PO}_{4}, \mathrm{pH} 7.2$, and $5 \%$ sodium dodecyl sulfate and twice for 10 minute with 20 mmoll $\mathrm{Na}_{2} \mathrm{HPO}$, $\mathrm{pH} 7.2$ and $1 \%$ sodum dodecyl sultate at $60^{\circ} \mathrm{C}$. Membranes wer subsequently probed with $\beta$-actin cDNA, taken as internal standard of equal loading of the samples on the nembrane. Expression of ET-1 miNA was corrected for Buctir expression and quantified densitometrically

\section{Quantitative Real-Time PCR}

Total RNA was extracted from podocytes by the guanidium isothicicyanete/cesium chloride procedure. Contaminating genomic DNA was removed by ANase-free DNase (Promega, Ingelheim, Germany) for 1 hour at $37^{\circ} \mathrm{C}$. The purified ANA $(1 \mu \mathrm{g})$ was reverse-transcribed using random hexamers (50 ng) and $200 \mathrm{U}$ of SuperScript II RT (Life Technologies, San Giuliano Milanese. Italy) for 1 hour at $42^{\circ} \mathrm{C}$. No enzyme was added for reverse transcriptase-negative controis.

Peal-time PCA was performed with the ABI Prism 5700 sequence detection system (PE Biosystems, Wartington. UK) using heat-activated TaqDNA polymerase (Amplitaq Gold, PE Biosystems). The TaqMan PCR reagents kit was used according to the manufacturer"s protocol. After an initjal hold of 2 minutes all $50^{\circ} \mathrm{C}$ and 10 minutes at $95^{\circ} \mathrm{C}$, the samples were cycled 40 times at $95^{\circ} \mathrm{C}$ for 15 seconds and $60^{\circ} \mathrm{C}$ for 60 seconds. $C t$, or threshold cycle, is used for relative quantification of the input target number. The comparative Ct method normalizes the number of target gene copies to a housekeeping gene such as glyceraldehyde-3 phosphate detyydrogenase (GAPDH) ( $\triangle C H$ ). Gene expression was then waluated by the quantification of CDNA corresponding with the target gene relative to callbrator samplo surving as a physiological refor. vnce (eg, untreated cells, $\Delta \Delta \mathrm{Ct}$ ). On the basis of expomential amplification of tirget gene as well as calibrator, the amount of amplified molecules the threshold cycle fiven by: $2^{-} \Delta \Delta C$. The following speciflo primers $(300$ nmol/L) were used: mouse ET-1: sens, 5*AACTACGAAGGT GGAGGCOA; anti-sense, 5"-CACGAAAAGAHCOCTGATGC, GAPLH senSe, 5'TCATCICGTGCATCCACTGGT; anti-sense 5'-GTGGGATGACCTIGCCCAC. Al primers were obtained from Sigma Genosys (Cambridgeshire, UKY.

\section{Radioimmunoassay}

ET-1 production was assayed in podocyte supernatants by redioimmunoassay (RIA). Either stendard compounds or unkrown samples $(100 \mu l)$ were mixed with $100 \mu$ ll of antisarum (Peninsula Laboratories Inc. Belmont. CA) di. luted in phosphate buffer "PH 7.2 (RIA buffer), at a final dilution of 1:72,000. The reaction mixture was incubated tor 24 hours at $4^{\circ} \mathrm{C}$, then 15,000 cpm of $(25)$ ET-1 in 100 H was added and the incubation prolonged for 24 hours at $4 \mathrm{C}$. Separation of free from antibody-bound ( $\left.2 x_{1}\right)$ ET-1 was acheved by addition of a second antibody $\{500$ $\mu$ of immunoprecipitating mixture consisting of a sheep antiraboit lga and polyethylene glycol) for 30 minutes at room temperature. Finally, 500 wl of PIA buffer was added to stop the reaction, and the immunoprecipitates were centrifuged at $5000 \times g$ for 30 minutes. Supernatents were discar ded and pellet radioactivity delected by gamma counier (Beckman, Irvine, CA. . Resuls were expressed as pgiro cells. The minimum detectable concentration was 0.4 pg/tube. Nonspecific binding diud not exceed $2 \%$ of total radioactivity. The cross-reactivity of the antibody with other endothelins is as follows: endothelin-2, 46.9\%; endothelin-3, $17 \%$; and big endothelin-1, $9.4 \%$. Intra-assay and interassay variability averaged $10 \%$ and $12 \%$, respectively, throughout a range beween 0.4 and $100 \mathrm{pg} / \mathrm{tube}$.

\section{Preparation of Nuclear Extracts and Electrophoretic Mobility Shift Assay (EMSA)}

Nuclear extracts were prepared from podocytes with the NE.PER nuclear and cytoplasmic extraction reagents kit (PlercelCelbio, Pero, taly) according to the manufacturer's instructions. To minimize proteolysils, all buffers contained protease intibitor cocktail (Boehringer Mannhe:m, Mannheim, Germany). The protein concentration was determined by the Bradford assay using the Bio-Fiad protein assay reagent.

EMSAS were performed as previously described wo with the kb DNA sequence of the immunoglobulin gene $\left(5^{*}\right.$. CCGGTCAGAGGGGACTICCGAGACT) and consent sus binding site for Ap-1 (5'-CGCTTGATGACTCAGCCGGAA). Nuclear extracts $(3 \mu g)$ were incubated with 50 kcpm of ${ }^{2}$ P-labeled ollgonucleotide in a binding teaction mixture $[10 \mathrm{mmol}$ L Tris-HCl, pH 7.5, $80 \mathrm{mmol} / \mathrm{MaCl}, 1$ mmoln ethylenediamine tetraacetio acid, $1 \mathrm{mmol} / \mathrm{L}$ dithiotheitol, $5 \%$ glycerol, $1.5 \mu$ of poly (di-dC)] tor 30 minutes on lce. In competition studies, a top-fold molar excess of unlabeled oligonucleotide was added to the binding reaction mixture belore the addition of the labeled NF-kB or Ap-1 probes. For densitometric analysis the wolume density for each band was determined in arbitrary units. The sum of the volume density of bands for a single sample was used as an indifect measure of NF.*kB or Ap-1 activation and expressed as a fold in. crease of the mean densitometry of respective control (represented as 1).

\section{Westem Blot Analysis}

Podocytes were lysed in the lysis buffer: $20 \mathrm{mmol} / \mathrm{L}$. Tris$\mathrm{HCl}, \mathrm{pH} 7.5,150 \mathrm{mmol} / \mathrm{NaCl}, 2 \mathrm{mmol} / \mathrm{L}$ ethylenediamine tetraacetic acid. $1 \%$ Triton $X-100,2.5$ mmol $/$ som diun pyrophosphate, $1 \mathrm{mmol} / \mathrm{L}$ B-glycerophosphate. plus phosphatase inhibitors $1 \mathrm{mmol} / \mathrm{Na}_{3} \mathrm{VO}_{4} .50$ mmol/ NaF, and protease inhibitors 1 mmoln phenylmethyl sultonyl fluoride and $1 \mu \mathrm{g} / \mathrm{ml}$ leupeptin. Protein 
a
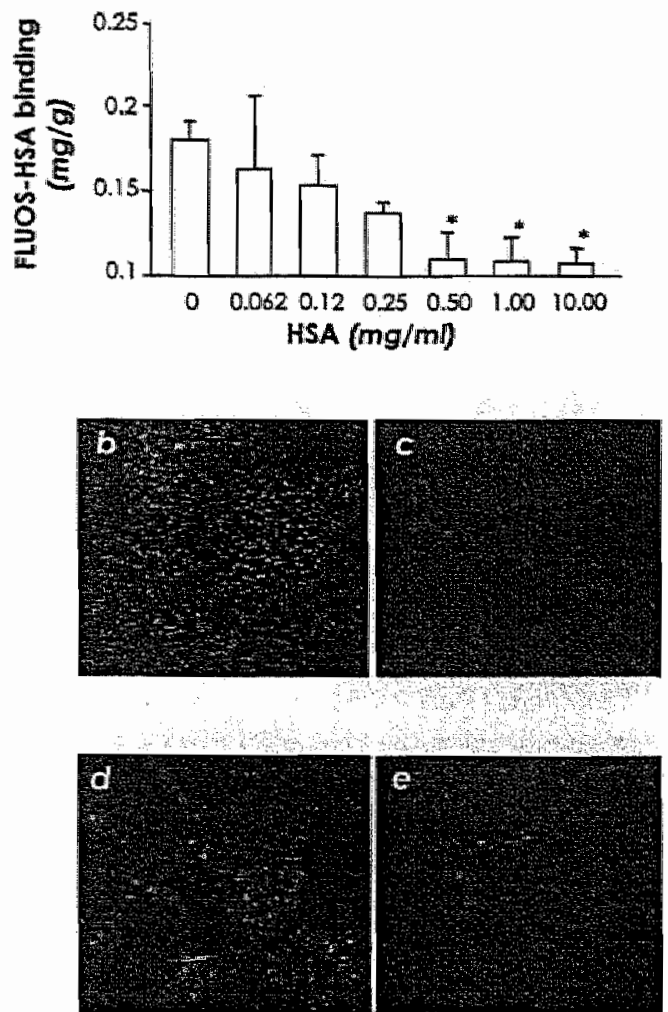

8

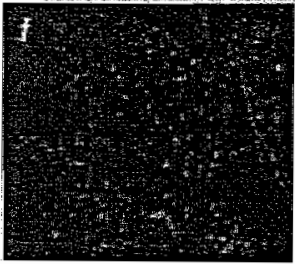

9

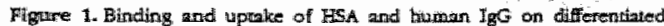

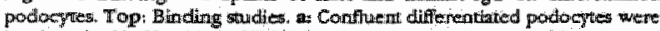

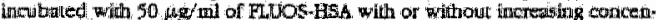

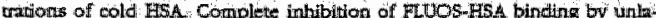

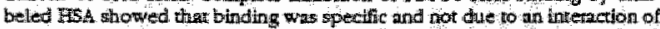

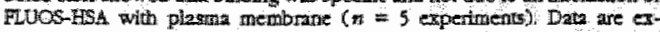

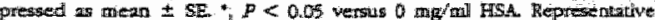

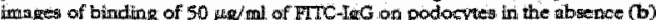
or presence of 5 arg

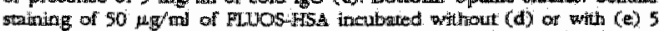

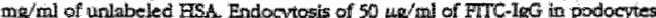
in the absence (f) of presence $(\mathrm{g})$ of $5 \mathrm{mg} / \mathrm{thl}$ of uniabeled Ioci. Original muspegrifications: $\times 600$

concentration was determined by protein assay based on bicinchoninic acid color formation (Pierce, Milan, Italy). Proteins $(30 \mu g)$ were separated on $7.5 \%$ polyacrylamide gels by sodium dodecyl sulfate-polyacrylamide gel electrophoresis and transferred to nitrocellulose membranes. Membranes were blocked for 1 hour at room temperature
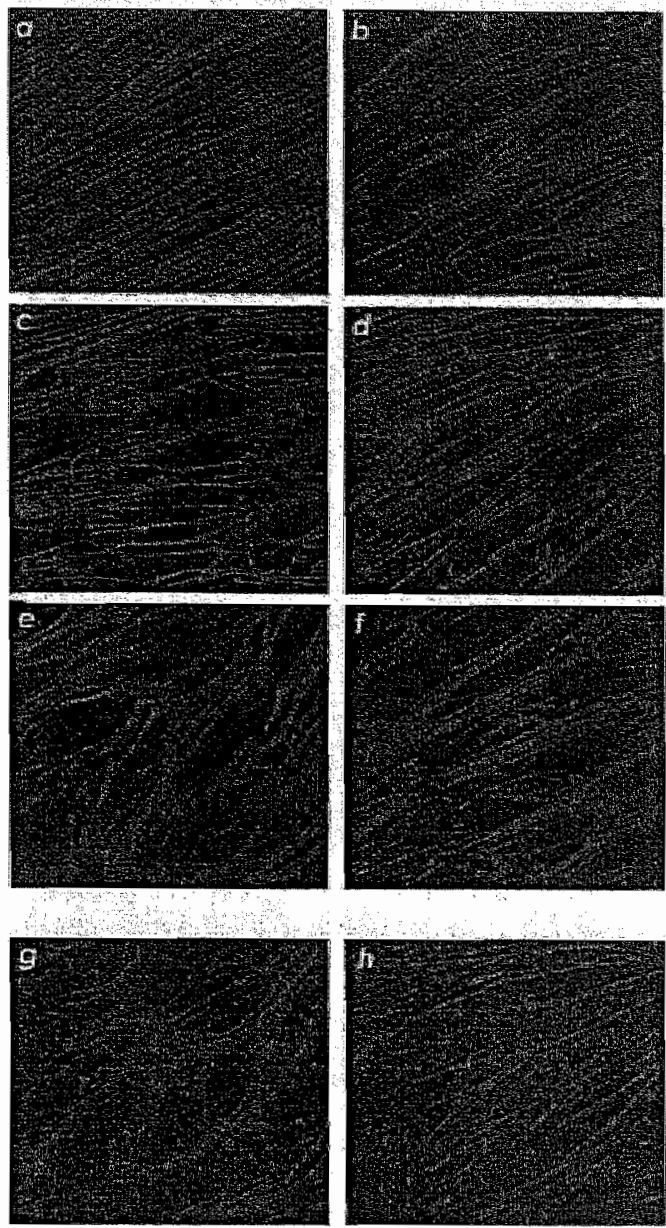

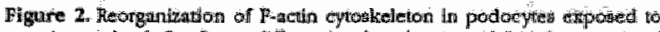

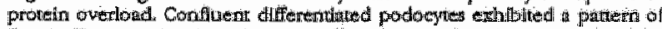

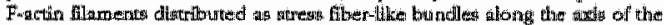

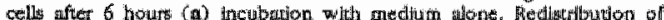

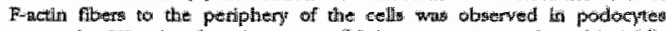

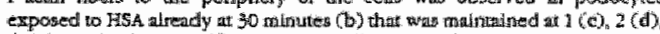

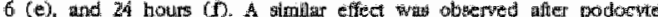

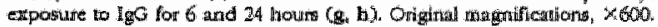

With PBS containing $5 \%$ bovine serum albumin (for P-FAK detection) ol $5 \%$ nonfat dry milk (for FAK detection) and $0.1 \%$ Tween 20 , and then incubated overnight al $4 \% \mathrm{C}$ with the following primary antibodies (Blosource Europe, Nivelles, Belgium): rabbit polyclonal ant-FAK (PY397) (1 1000) raboit polyclonal anti-FK (1:1000). After incubation with the secondary antibodies, horseradish peroxidase-coniugated goat aniflgG rabbit (Sigma) diluted 1:10,000, for 1 hour at room temperature in PBS with $1 \%$ bovine serum albumin or $1 \%$ nonfat dry milk and $0.1 \%$ Tween 20, proteins bands were detected by Supersignal chemiluminescent substrate (Pierce). 

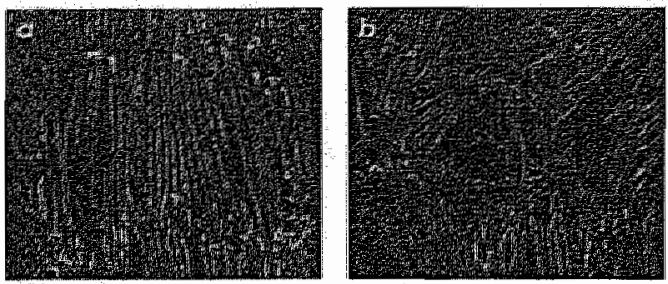

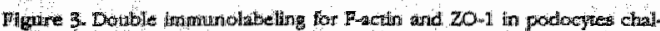

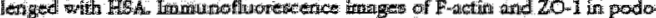

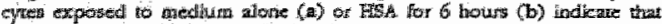

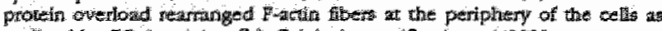

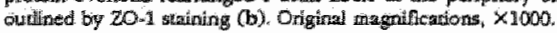

\section{Adenoviral Constructs and Transfection Exporiments}

A replication-defective adenovirus encoding FAK-related nonkinase (Ad-FRNK) was constructed using a $1.2-\mathrm{kb}$ wild-type chick FRNNK cDNVA the gift of Dr. J.T. Parsons, Department of Microbiology, Health Sciences Center. Univarsity of Virginia, Charlottesville, VA). ${ }^{38}$ For adenovirall infection, podocytes were incubated with Ad-FRNK or Ad-null at a multiplicity of infection of 50 in RPMI 1640 without serum for 3 hours at $37^{\circ} \mathrm{C}$. The adenoviruses were washed off and cells maintained in serum-free medium for 24 hours. Then, podocytes were exposed to HSA ( 10 $\mathrm{mg} / \mathrm{mll}$ for 3 hours and processed for ET-1 mRNA expression. Transfection did not affect cell viability.

\section{Statistical Analysis}

Results are expressed as mean \pm SE. Statistical analysis was performed using Student's t-test, one-way analysis of variance, followed by Tukey test for multiple comparisons, and Kruskal Wellis test, es appropriate. Statistical significance was defined as $P<0.05$.

\section{Results}

\section{Binoing and Uptake of Abumin and lgG in Differentiated Mouse Podocytes}

We investigated binding and uptake of MSA and IgG in differentated mouse podocytes. FLUOS-HSA was displaced by cold HSA in a concentration-dependent manner at $4^{\circ} \mathrm{C}$, indicating the presence of saturable binding sites for albumin on the podocyte surtace (Figure 1a). Similarly, podocytes exposed to FITC-IgG showed (Figure 1b) a specific binding of the protein, with a granular pattern on the apical surface of podocytes that was completely displaced by cold lgG (Figure 1c). HSA and lgG endocytosis into podooytes was detected after 3 hours of exposure at $37^{\circ} \mathrm{C}$ to FLUOS-HSA or FITC-igG (Figure 1, d and f, respectively). Uptake was markedly inhibited by an excess of both unlabeled proteins (Figure $1, \theta$ and $g$ ), suggesting a receptor mediated endocytosis of HSA and IgG in poolocytes.

\section{Effect of Protein Overload on F-Actin Cytoskeleton and Synaptopodin Distribution in Differentiated Podocytes}

Differentialted podocytes maintained for 14 days in monpermissive culture conditions exjibited, when contluent, a pattern of Fuatin filements distributed as stress fiberlike bundles along the axis of the cells or into the process of arborized cells, as wisualized by confocal microscopy (Figure 2a). Albumin induced a marked redistribution of F-actin fibers toward the periphery of the cells already after 30 minutes (Figure 2b), which was maintainied thereafter (Figure 2 ; o to f) until 48 hours (data not shown). A similar effect was observed after podocyte challenge with IgG (Figure 2, g and h). To demonstrate the peripheral distribution of F-actin fibers induced by excess proteins, double immunostaining of actin and $\mathrm{ZO}-1$, a cell membrane markar that defines podocyte outine, was performed. Figure 3 shows that HSA Unduces actin rea:rangement at the cell periphery in the vicinity of $\mathbb{Z O}-1$ a
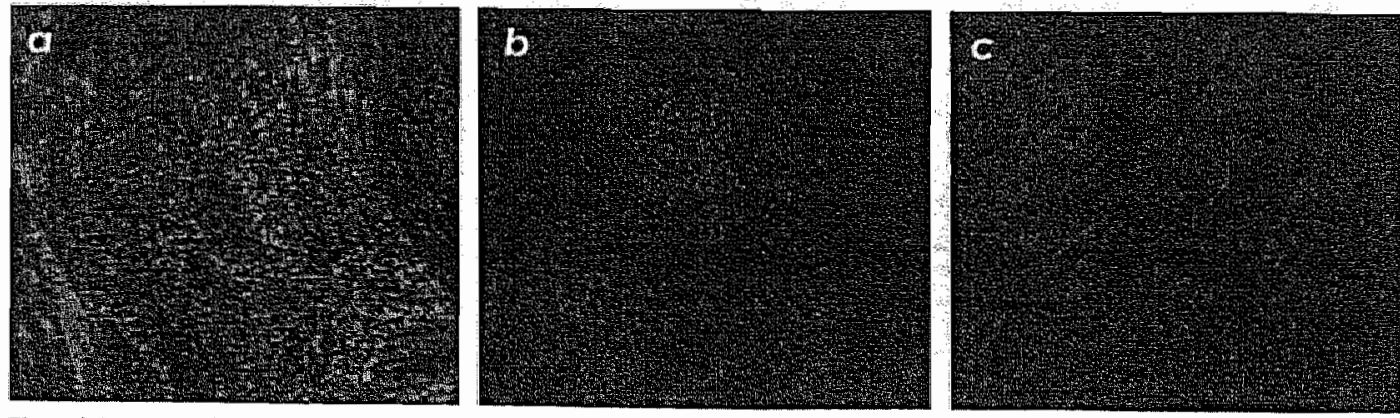

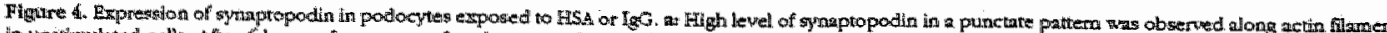

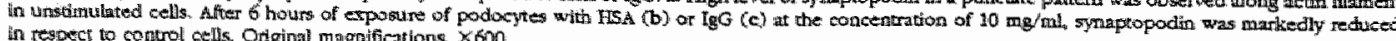



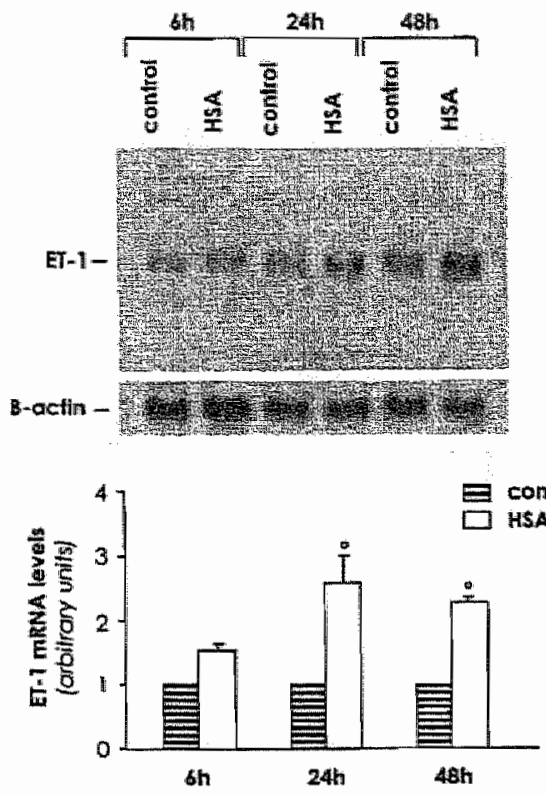

Figure 5. ET-I DRNA expression in podonytes exposed ro ponelin ovierlond. Top: Miorthem blot experioments were performed using total RNA isolared frow podocytes exposed to medum alone (control) or albumin ( $10 \mathrm{mg} / \mathrm{mil}$ )

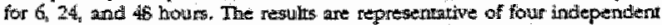
cmoeriments. Botuorm: Densirometric ansilysis of avromeliograph signals for

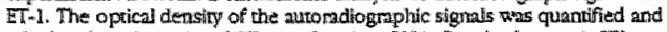

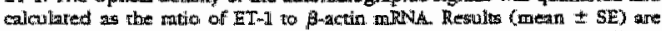
expresed a fold increase grewner than conrol (consdemed as bi) in denst-

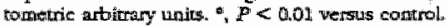

the expense of transcytoplasmic filaments (Figure $3 b$ ). Cytoskeletal changes were accompanied by loss of staining for symaptopodin, an F-actin-associated protein, considered a sperific marker of podochte differentiaion. ${ }^{41}$ As shown in Figure 4, unstimulated ceils revealed high levels of synaptopodin in a punctate pattern along the actin filaments and at focal contact. Exposure of podocytes to HSA or lgG lor 6 or 24 hours resulted in a similar marked reduction of synaptopodin staining.

\section{Protein Overioad induces ET-1 Gene \\ Expression and Protein via Cytoskeleton Rearrangement}

Because reorganization of cytoskeletal network is functionally linked to modification of transcriptional events that regulate inflammetory and wasoactive genes, including ET-1, ${ }^{4-4}$ we studied the ability of a high concentration of plasma proteins to modulate the expression of ET-1 gene and protein in differentiated podocytes, end the potential role of cytoskeleion in such induction. By Northern bilot, a 1.3-kb mPNA transcript specific for ET-1 was observed in unstimulated control podocytes (Figure 5). Albumin promoted after 6 hours of incubation a 1.5 fold increase in ET-1 transcript level as compared to control cells, which wes further enhanced at 24 and 48

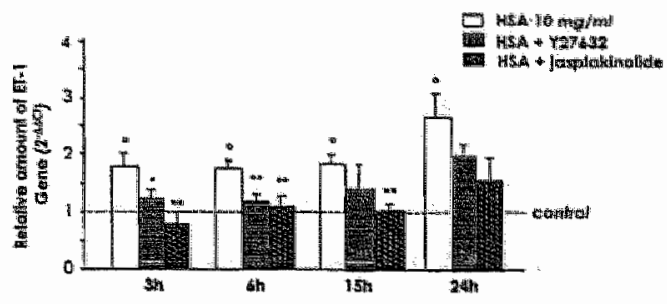

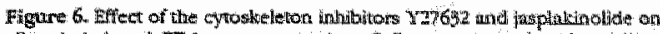

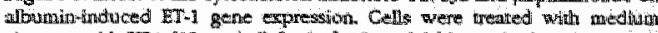

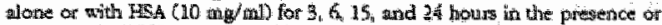

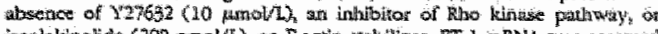

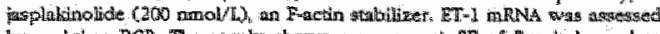

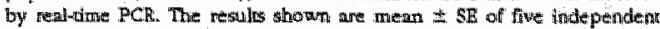

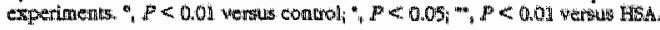

thours (2.5- and 2.2-fold, respectively) (Figure 5). The effect of abumin on ET-1 gene expression was consistent with data of real-time PCR experiments (figure 6). Actually, ET-I message levels increased within 3 mours of albumin exposure and was elevated at 6 and 15 hours with a peak at 24 hours ( $P<0.01$ versus unetimulated cells at all of the times considered). ET-y MRNA overexpression was also observed when podocytes wer chat. lenged with lgG for 24 hours (1.5 fold increase greater than control $p<0.05$ ). As shown in Figure 6, exposure of podocytes to $Y 27632$, a specific Rho kinase inhibitor inwolved in stress fiber formation, resulted in a significant inhilbition of ET-1 gene expression at 3 and 6 hours. The effect was mo more significant at 24 hours. Treatment with jasplakinolide, an F-actin stabillizer, normalized ET-H mPNA expression until 15 hours. Thereafter, a less inhibitory effect was observed. The up-reguliation of ET-1 MRNA was associated with a time-dependent ncrease of the native peptide secreted into cell supernatants (Figure 7). Unstimulated cells syrthesized constitutively low levels of ET-1 protein. After HSA exposure, a significant increase in peptide secretion was found at 3 hours, which was more pronounced at 15 and 24 hours Y27632 had an early inhibitory affect resulting in the normiatization of ET-1 secretion at: 3 hours. This efeot was lass pro

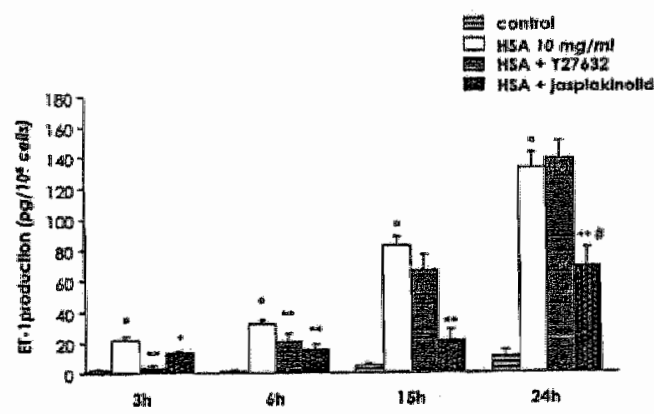

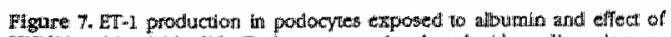

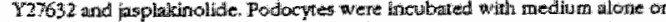

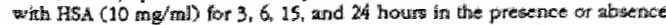

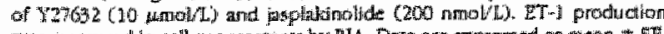

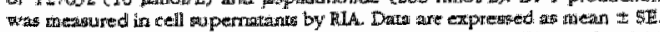

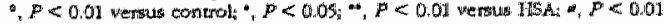
veras HAS + Y T2763? 

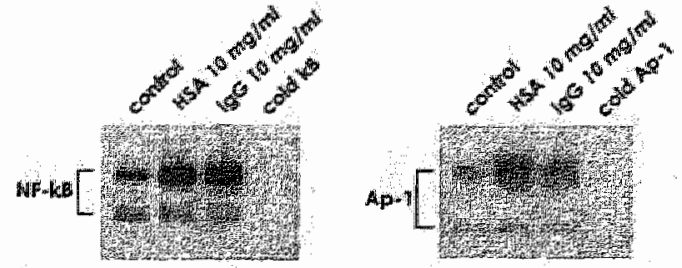

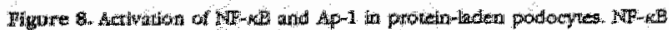

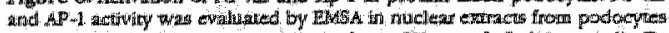

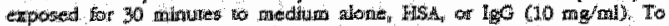

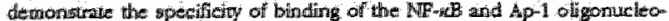

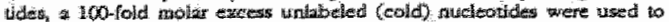

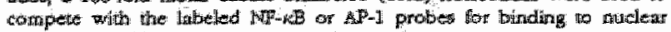

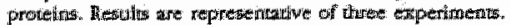

nounced, although still significant until 6 hours. Podom cytes exposed to jasplakinolide showed instead a long lasting inhibitory effect on ET-1 production, to the extent that a significant reduction over HSA still persisted at 24 hours (Figure 7 ).

\section{Albumin and IgG Activate NF-kB and $A p-1$ in Podocytes via Cytoskeloton}

The effect of HSA and $\lg G$ on NF-kB and Ap-1 activation in podocytes is depicted in Figure B. Nuclear extracts were assayed for NF-kB and AP-1 DNA binding activity using radiolabeled specific oligon:toleotide probes. Unsuimulated ceils displayed two constitutive bends of MF. $\ltimes$ B: an upper complex and a faster migrating lower complex. Thiry minutes of incubation of podocytes either with albumin or $\lg G$ led to a substantial rise in NF-kB-binding activity of the two complexes. A remarkable increase of the Ap-1-binding activity greater than control was delected after podocyte challenge with either protein. The specificity of binding reactians was confirmed in compefition experiments by the ability of excess unlabeled (cold) NF-k of Ap-1 ollgonucleotides to inhibit binding.

Next, we investiglated whether the activation of $N F{ }_{-k} B$ and Ap- induced by protein overload could be regulated by intracelluar signals ewoked by cytoskeleton re. arrangement. To this purpose, experiments were performed in podomytes exposed to albumin, taken as representative protein. As shown in Figure 9 , densitomet. ric andysis of five independent experiments reveeled a 5.3. fold increase of $\mathrm{NF}-k \mathrm{~B}$ activity greater than contio Treatment with Ya7632 reduced by nearly $70 \%$ NF-kB activation induced by abumin. A $58 \%$ inhibition was obsarved after jasplaknolide. Apr I DNA binding activity was stgnificantly anhanced by albumin (2.2-fold greater than controly (Figure 9). In the presence of $\gamma 27632$ and jasplakinolide, AP-1 activation was reduced by $30 \%$ and 4.\%, ropectivily.

\section{Role of FAK in Protein Overload-Induced ET-1}

Integrin-mediated activation of the noneceptor yrosine kinase FAK results in the propagation of intracellular sig. nals that turn on transcriptional events. First, we studied
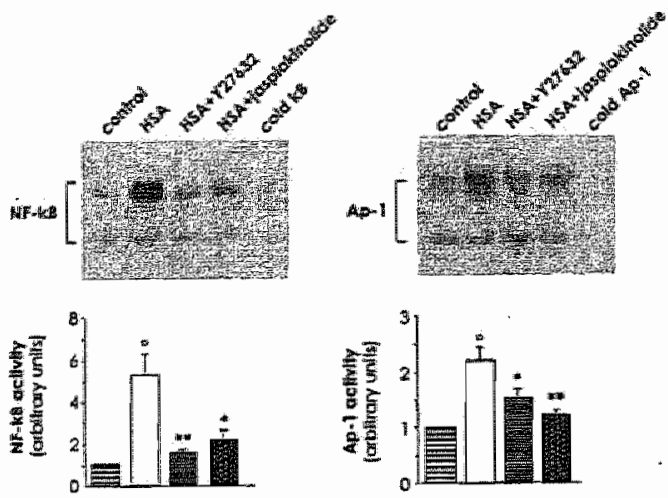

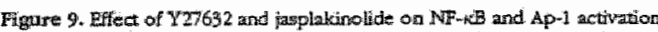

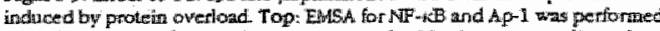

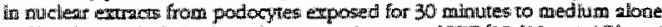

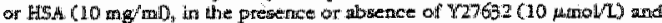

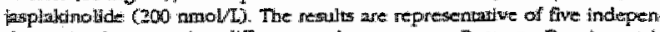

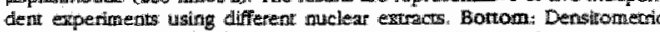

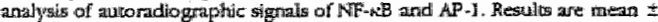

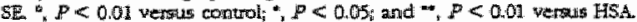

the contribution of FAK in the regulation of ET-1 gene expression induced by HSA overload. By Western blot experiments, albuminmloaded podocytes exhibited a marked FAK phosphorlation at 5 minutes, that remained sustained unth 6 hours (figure 10a, lett).

Next, to assess a possible involvement of cytoskeleton changes in FAK activation "we evaluated the effect of Y27632 or jasplakinolide in albumin-treated podocytes. As shown in Figure 10a (right), both compounds reduced FAK phosphorylation after 30 minutes of exposure with HSA, suggesting a downstream regulation of FAK by Rho kinase-triggered actin redistribution. We also observed that the tyrosine kinase inthibitor genistein markedly reduced $N F-F_{B}$ - and Ap- 1 -binding activity (Figure 10b) in HSA-laden podocytes. As a consequence. ET-1 mRNA levels were significantly decreased by genistein in is spect to HSA alone, as documented by realtime PGR assessment (Figure 10c). Transient overexpression of FAK-related nonkinase, an endogenous inthibitor of FAK actiwity, by adenoviral gane transfer interfered with ET-1 gene expression to the extent that ET-1 mFNA transcript levels were reduced by $50 \%$ compared to cells trans. fected with null gene.

\section{Effect of Exogenous ET-1 on Podocyte Cytoskeleton}

We then evaluated the functional effect of ET-1 on the distribution of Factin. Figure 11 shows that in contro cells actin stress fibers were arranged in parallel whereas on exposure to ET. 1 ( $100 \mathrm{nmol} / \mathrm{L}$ ) for 2 and 6 hours, this patterm changed, leading to F-actin redistributhon at the cell periphery, at the expense of transcytoplas. mic microfilaments. The effect was transient and partially recovered at 15 hours. These data provide the first evidence that ET-1 may alter podocyte F-astin contractile 
a

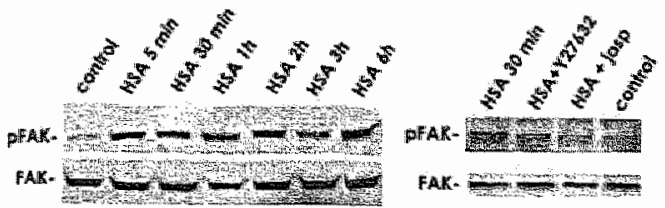

b
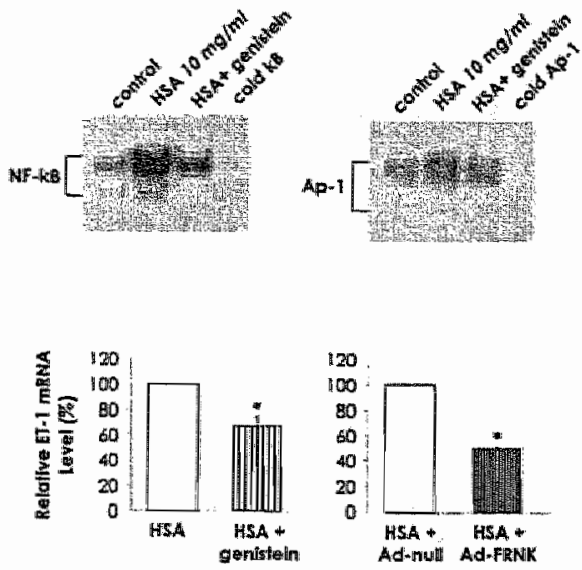

Figure 10. Hole of FAK on ET-1 gene arcivation/exprestion in HSA-treated podocyres Left Activalion of FAB in podocyres exposed to HISA (10

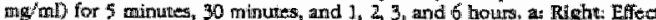

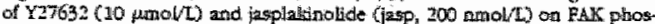
phorytation in portocyces treated for 30 minutes with HSA Ceil lysares we the analyzed by western blot using antibody against the plasphorylated form. The bloss were stripped and reprobed with an antibuty antimonphosphorylated FAK to confirm equal lording of the proteins on the gel The blot is

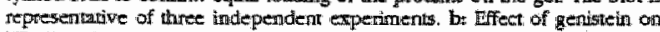

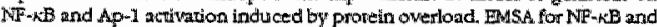
Ap-1 was performed in muclear extracts from podocytes exposed for 30 minutes to medium alone or HSA to the pritsence on absence of genistein (25

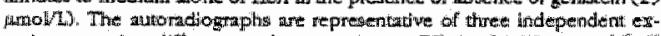

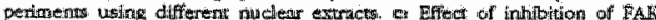

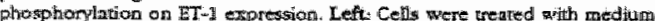

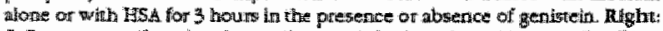

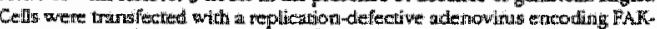
related nondinase (AdPRI

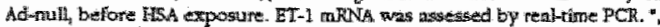

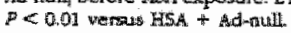

apparatus relevant for the maintenance of glomerular permselectivity.

\section{Discussion}

Far from being a simple prognostic clinical parameter. proteinuria has been considered a piwotal causative tacfor for progressive tubular iniury that precedes the relentless deterioration of renal function in progressive nephropathies. ${ }^{6}$ Proteins filtered in exuberant amounts as a consequence of the alteration of the size-selective function of the glomerular barrier in proteinuric conditions, have an intrinsic renal toxicity because of overwabsorpton by proximal tubular cells, which causes activation of tubular-dependent pathways of interstitial inflammation.
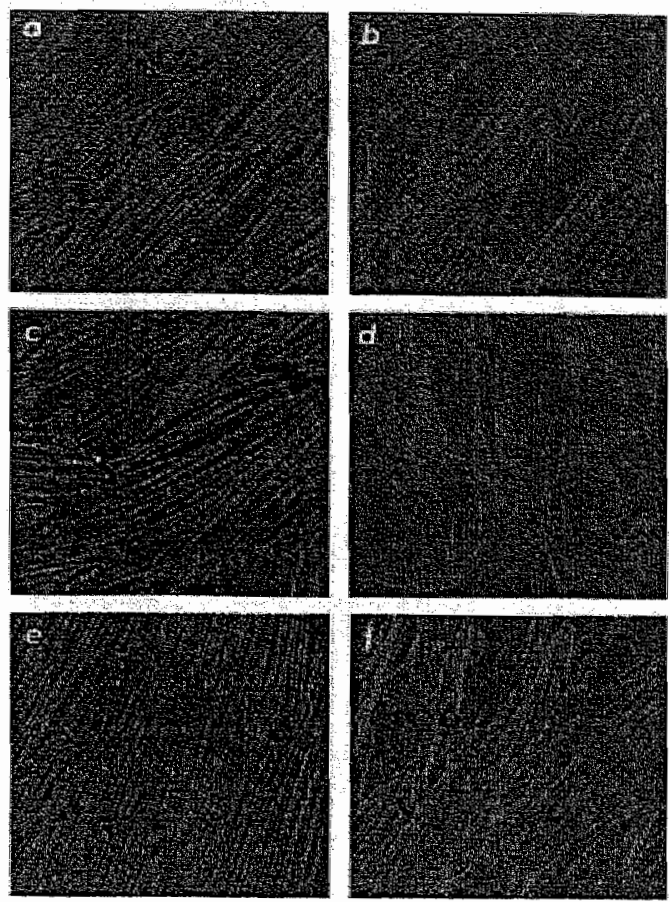

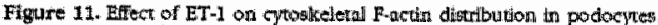

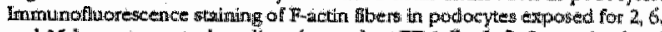

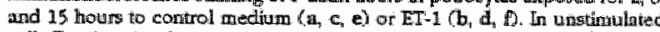

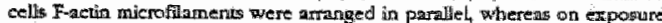
to ET-1 $1100 \mathrm{mmol} / \mathrm{L})$ for 1 and 6 hours, this pattem chariged leading to

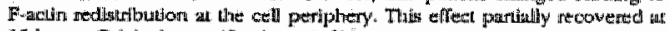
15 hours, Orightnl magnificationts, $\times 600$

and fibrosis. ${ }^{6.45}$ Ultrafiltered plasma proteins al so induce morphological changes in podocytes, ${ }^{5}$ which include re. versibie retraction and flattening of the epithelial loot

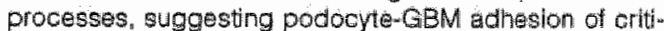
cal relevance for a functional filter. "4t4 Mechanims and mediators underlying phenotypic changes in glomerular epithellum induced by protein overload ars poorly defined.

In the present study, we found that abumin and ige bind to oultured murine podocytes in receptor-specific manner. Because of the recent demonstration of the presence of megalin, ${ }^{47}$ which acts as a receotor for allbumin and 19 light chain, on this very cell line, it is possible that in our setting albumin and $1 \mathrm{gG}$ binding to the murine podocyte is mediated by megalin. the fact that megalin possesses endocytotic function in differentiated podocytes ${ }^{47}$ would also suggest that albumin and IgG uptake, here documented, may occur through their binding to this receptor. Downstream pathway transituc. ing signals after protein binding to the receptors are currently poorly understood. It has beer recently sown that the cytoplasmic carboxy-terminal NPXZ domain of megalin interacts with Disable protein (Dab) 2, an intra cellular adaptor protein that is potentially involved in transmembrane signal transduction and reguates cellu- 


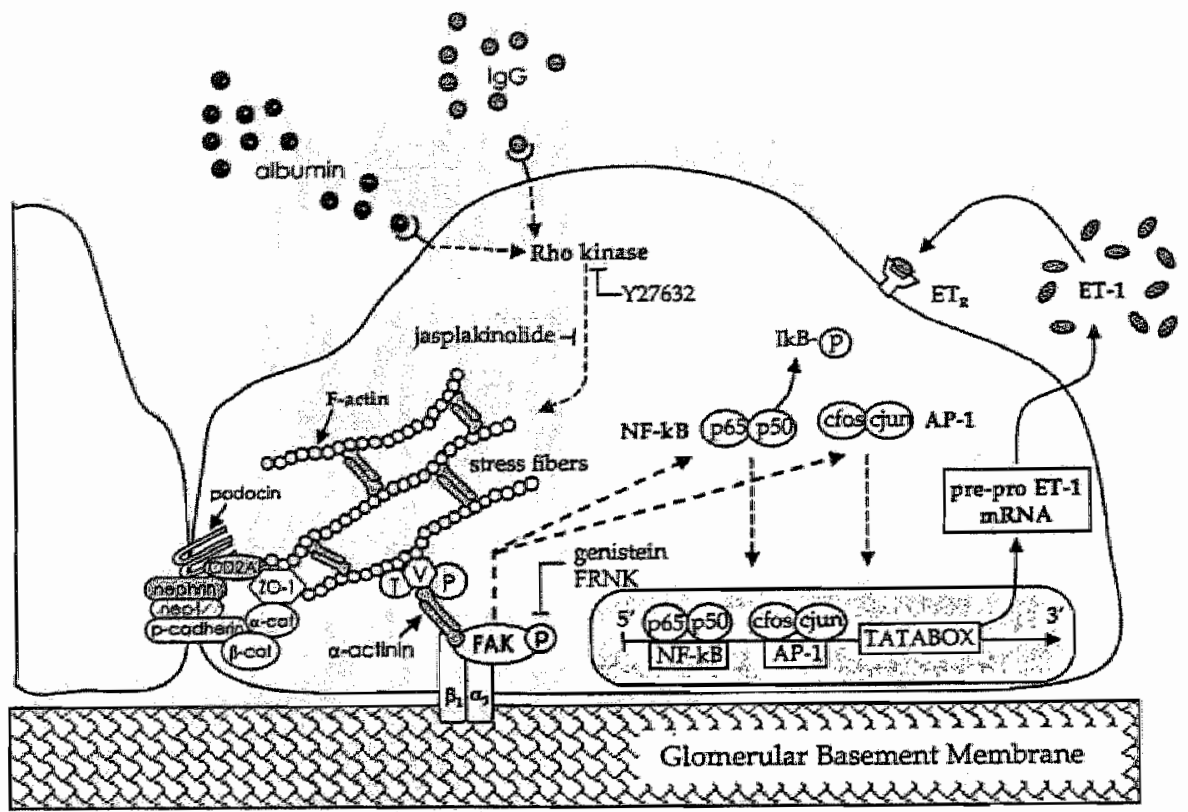

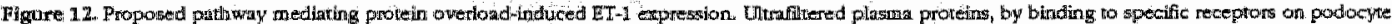

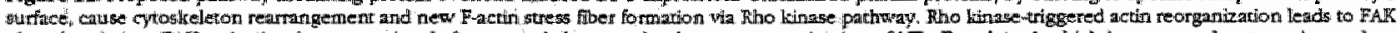

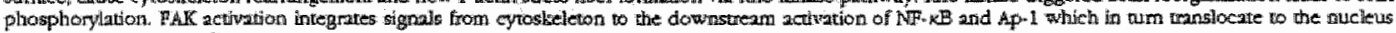
and promole pre-pro EI-1 gene transeription.

lar growth and differentiation. Whether Dab 2 could transduce the signal after protein binding to megalin on podocytes is worth investigating

Exposure of podocytes to albumin and IgG induces early phenotypic changes consisting of cytoskeleton F. actin rearrangement with marked decrease of synaptopodin staining. The uitimate effect of proteins on actinassociatwo synaptopodin would be taken as to indicate protein accumblation as a trigger of pococyte dedifferantiation, a phenomenon already described in vivo in areas of segmental sclerosis to podocytes are highly differentiented wells that possess a complex contractile structure composed of Factin microflaments, most abundart in the foot process, exhibiting a high degree of organizetion. ${ }^{7}, 35,5$ is2 F-actin is connected with adaptor molectules thet anchor the slit diaphragm proteins and $\alpha 3 \beta 1$ integins, transmembrane proteins that forn focal adhesion complexes and mediate podocyte-GBM matrix interacton. ${ }^{7}$.A16,52 Cytoskeleton F-actin rearrangement is closely associated with podocyte shape changas and dystunction in disease? "14.46 In wtro, actin filament disorganization affects cell achesion to the extracellular matrix through a 3 Bt integrin that functions as receptor-transducing signals. The consequent outside in signals irigger specific celluiar responses that lead to activation of gene expression of adhesive molecules, cyiokines, and vasoactive mediators. ${ }^{2}$.5s.54 Based on this evidence, we asked whether rearrangement of the cytoskeleton induced by protein overload was associated with up-regWation of the ET-1 gene. Our results indicate that ET-1 gene expression is efficiently enhanced by albumin and IgC load, in parallel with the generation of the protein, in a time-dependent manner, suggesting that glomerular epithellal cells in the proteinuric setting are an important sotrice of ET-1. These data are in line with in wo evidence in a murine model of protein oweribad that renal ET-1 transctipt levels increased together with the renal symthesis of the peptide in concomitance with the devel. opment of podocyte structural damage ss $^{\text {s. }}$

Endothelin-1 secreted by podocytes may function in a paracrine manner on glomerular cietls affecting the tone of the glomerular capillary, enthancing the vascular permeabilly, and stimulating mesangial cell contraction by wirue of its wasoconstrictor effects. Finding that the cyloskeleton stabilizer jasplakinolide significantly reduced expression and production of ET-1 would support the notion that protein-induced rearrangement of the actin cytoskeleton contributes to regulate ET-1. Furthermore, the addition of $Y 27632$ an inhibitor of Rho kinases crucial for the formation of stress fibers and focal adhesions, 26,27 also markedly decreased ET-1 expression indicating that ET-11 gene transcription is regulated by Rho-dependent pathway. in agreement with our findings are data that the Fho GTPase family modulates basal expression of preproET-A transcript levels in vascular endothelial cells in culture. ${ }^{28}$ Regulation of the preproET-1 gene is complex and has been attributed to multiple pegulatory elements. It is well-known that human preproET-1 gene possesses in the promoter region consensus sequences for tran. scription factors induding $N F-k B$ and $A p-1{ }^{23.24}$ in the 
present study, electrophortic analysis of the nuclear extracts of podocytes oaded with albumin or lgc rewealed a rapld horease in NF-kB-and Ap-1 DNA-binding activities. Of interest intibition of cytoskeleton rearrange ment by jasplakinolide and by Rho knase inhbitor prewented $\mathrm{NF}$ \% $\mathrm{B}$ and $\mathrm{Ap}-1$ activation, indicating the presence of cytoskeleton-regulated signal transcluction pathway of gene activation. These data are in line with previous observations of the involvement of Pho GTPase family in regullating $N F-k B$ and $A p-1$ in genetically modfied cultured fibroblasts. 25.26 .56

We finally irvestigated the role of FAK, a cytoplasmic nomeceptor tyrosine kinase that localizes in integrin-extracellular matrix complexes, ${ }^{46}$ as the effector molecule linking actin reorganization with transcriptional events Evidence is avaliable as to indicate that FAK activation is dependent on actin cytoskeleton. ${ }^{57}$ Phosphorylation of FAK on Tyr397 is a docking site for activation of other tyrosine kinases such as the Src-family protein kinasas ${ }^{50}$ that transduice the signals from focal adhesions to intracellular largets resulting in gene activation. The present experiments showed that exposure of murine podocytes to albumin induced a rapid and sustained FAK phosphorylation that was substantially affected by the Rho kinase inhibitor and jasplakinolide. Inhibition of FAK activation with genistein, a tyrosine kinase inhibitor, markedly reduced NF-kB and Ap-1 DNA-binding activity and consequently inhibited ET-1 mRNA expression. Transfection experiments with an adenoviral construct encoding a replication-defective FAK-related nonkinase (FANK), ${ }^{\text {as: }}$ further confirmed that FAK signaling contributes to ET-1 gene regulation to the extent that overexpression of FRWK resulted in a partial but significant inhibition of ET-1 mRNA expression in albumin-laden podocytes.

We tinally addressed a possible effect of ET-1 on cultured podocytes that express on their surface-specific receptors for the peptide. ${ }^{59,60}$ Podocytes exposed to exogenous ET-1 exhibited rapid and consistent cytoskeletal changes, as revealed by the redistribution of F-actin fibers to the cell periphery. This result unravels a nowel clue of the effect of ET-1 on kidney cells. So far data are available to indicate the pivotal role of ET- 1 in the biology of mesangial cells, in that the peptide can elicit proliferatom, "hypertrophy, and contraction of the mesangium. ${ }^{19}$ In wiew of the fact that ET-1 acts as a local hormone whose effects are exerted in a paracrine as well as autocrine manner, it is possible that overproduction of $E T-1$ by podocytes may regulate the contractile status of either metsangial or glomerular epitholial cells.

In conclusion. we have demonstrated that in podocytes the abnormal uptake of plasma proteins induces Rho kinasewdependent F-actin cytoskeletal rearrangement leading to possible cell dedifferentiation. Such structural changes translate into the activation of FAK in turn responsible for $\mathrm{NF}-\mathrm{kB}$ - and Ap-1-dependent ET-1 gene up-regulation (Figure 12). Endothelin-1 overproduction may act on the podocyte contractile apparatus alter. ing the glomerular capillay surface area thus leading to protein permeability dystunction. These results indicate podocytes as a novel cellular target for the toxic eifiect of excess plasma ultrafitured proteins.

\section{Acknowledgments}

We thank Dr. U. T. Parsons (Department of Microbiology" Health Scitunces Center, Univer sity of Virgimia, Charlotteswhille, VA, for providing adenovirus enooding FAK-related nonkinase; Dr. Federica Valsecohi and Frabio sanganil for their precious contribution: and Manula Passera for help in prepering the manuscript. Dr. Buellis a recipient of fellowship of "Helsinn Healthcare SA" throught the cour. tesy of "Fondazione ainti per la Ricarca sulle malatti rare".

\section{References}

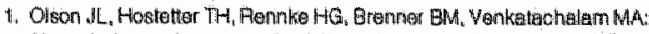

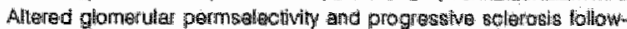

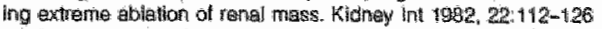

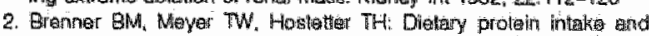
progressive nature of kidney diseass: the role of hemodynsmicully

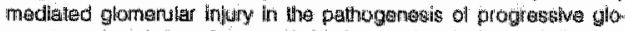

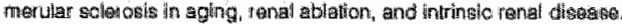

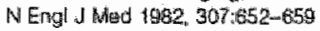

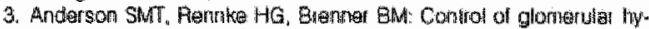
pertansion linits glomerular injury in rats with reducad rental mases. HClin Invert $1995,76,12 \mathrm{~m} 619$

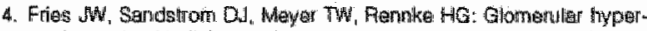

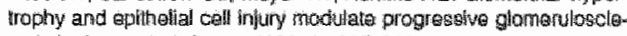

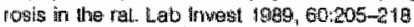

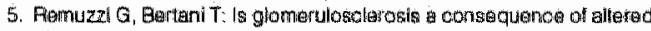
giomerular permeabllity to mecromolleculds? Kidney init 1900 $38.354-394$

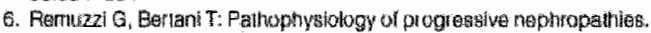
N Engl J Had 1998, 339:4:48-1450

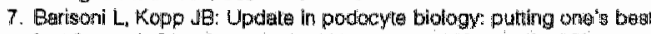

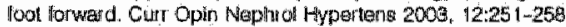

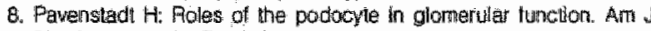
Physial $2000,278, F 173-5 \%$

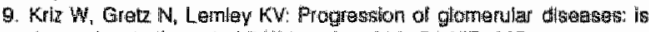
the podocylte the aulprit? Kadney lnt $1998,54: 687$-697

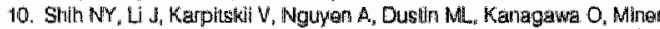
HH, Shaw AS: Congental nephrotic ayndrome tn micie lacking CD2 associallod protsir. Science 1999, 206:312-315

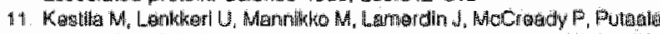

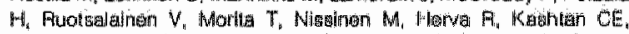

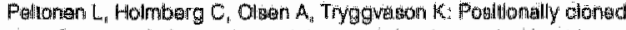

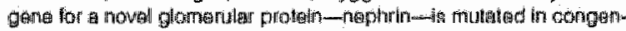
Hai nophrotic aydrome. Mol Call $1999,1,575-582$

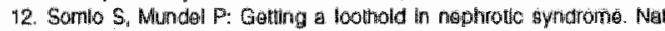
Gone: 2000, 24:333-335

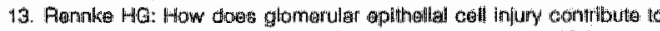

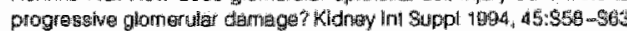

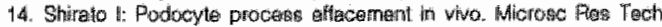
$2002,5724,246$

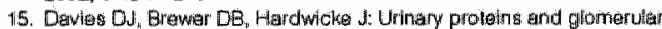

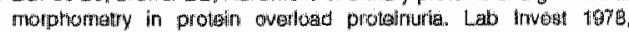
$39: 232-243$

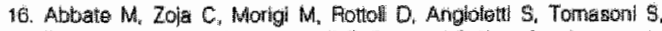

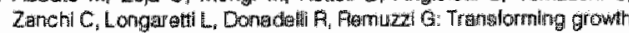

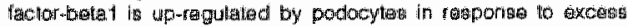

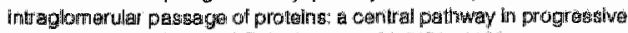

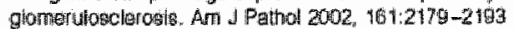

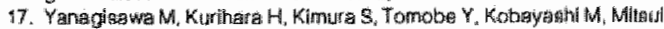

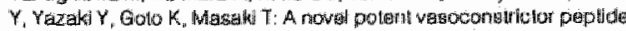

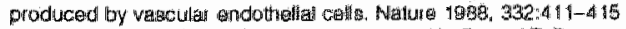

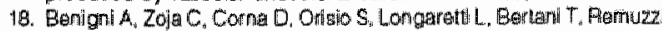

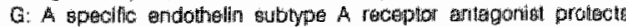

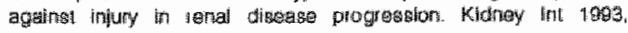
4.4: $440-444$

19. Sorokim A, Kotan DE: Physioboy and pethology of andothelith-1 in

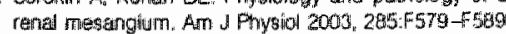




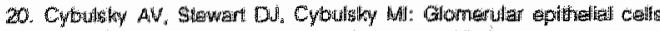

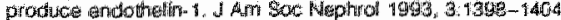

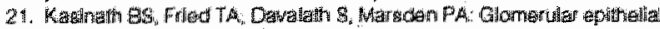

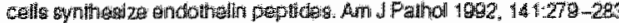

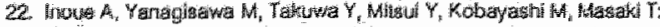

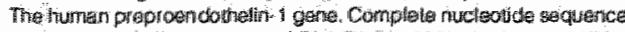

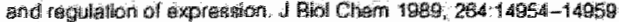

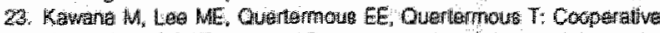

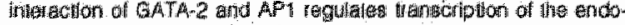

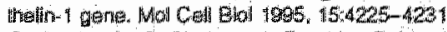

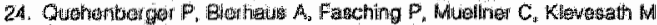

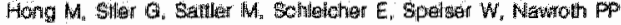

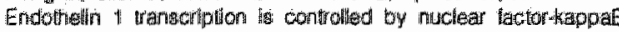

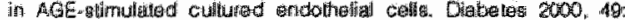
$1: 581-1570$

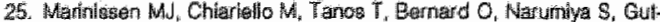

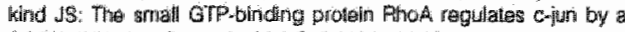

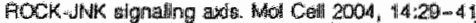

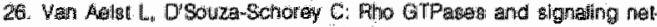
workis. Ganes Dev 1997, 11:2295-2322

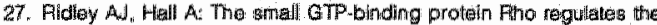

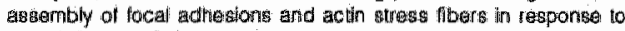

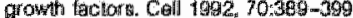

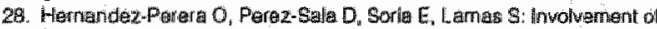
Fho GTPases in the transcelptionial inibilton of preptoendothein-1

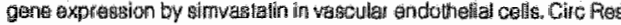
$2500,87: 616-622$

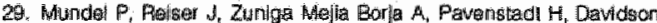
GP, Kriz W, Zeller P: Fearrangements of the cytoskeleton and call coniacts inducen proceses totmation during differentlation of conditonaly immortalized mouse podocyte cell inas. Exp Coll Fes 1997. $230: 240-259$

30. Gekle $M$, Mildenborgor $S$. Fraudinger $P$, Sillbernagl $S$; Long-term protein exposure reduces albumin bindirig and uplake in proximeat tubule-derived opossum kidmey cells. J. Am Soc Neptrol 1998, $9960-168$

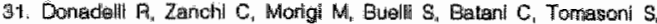
Corno D. Ronoll D, Benilgni A, Abbale M, Ferruzzi G, Zoja C: Frolein overtoad induces fractalkine upregulation in proximal tubular cells

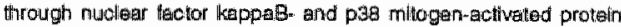
kirnese-dependant patthways, J Am Soc Nephnol 2003, 14:2436-2446

32. Tang $S$, Leang $\mathrm{J}$, Abe $K$, Chan KW, Chan LY, Chan TM, Lai KN: Albumin stimulates interleukn-8 axpression in proximal mbular epi. the liall calls in vitro and in vitwo. I Cllin Invest 2003, 114:515-527

33. Wang $Y$, Chen $\$$, Chen $L$, Try YC. Rangan GK, Harris DC: Induction of monocyte chemoaltractant prolein- 4 in proximal tubuite colls by

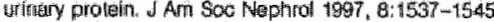

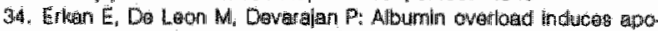

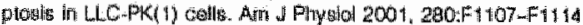

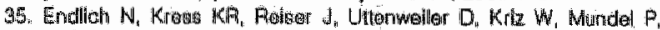
Endlich K: Padosyles respond to mochankel strese in vitra. J Am Soc

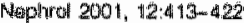

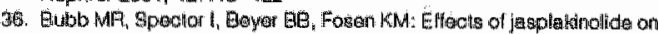
the kinelice of acth polymutizenton. An explanation for certain tm vivo

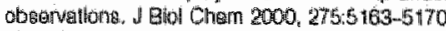

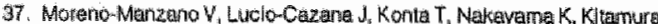
M: Enhancement of TWF-aiphatinduced apoptogas by inmobilized

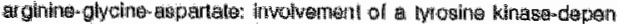
dant, MAF kingse-indepandent mechanism. Biochem Blophys Pas Comminum $2000,277: 298-299$

38. Pichardison A. Parsons. T: A mectianisin for regulation of the adhe-

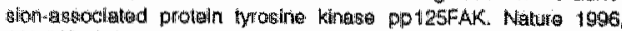
$380: 536-540$

39. Simonson MS, Dum MA: Entothelirin-1 stimulates contrecton of rat glomoru/ar mosisnglat colts and potwntates bela-aurenergic-nedialod oyclic adenosine monophosphate accumulathen. J Clin Irivest 1990. 85:790-797

40. Zola C, Donadalil H, Collaoni S, Figlizzil M, Bonazzola S, Morigi M, Remuzzi G. Protein owel loed stiatulates FANTES production by prox-. intal tubular cells depending on NF-keppa B activation. Kidney lat 1900, 53: $9008-1615$
41. Munded P, Heid HW, Munded TH, Kugar hat Reiser J, Kriz W Symaptopodin: an actin-associaled protein in lelencephalic dendrites and renal podowyes. J Cell Biol 1097, 139:193-204

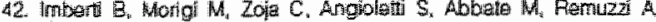

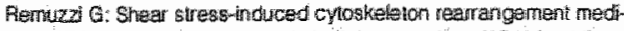

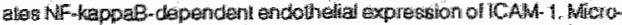
wasc Fis $2000,60: 122-128$

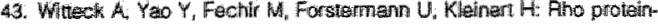

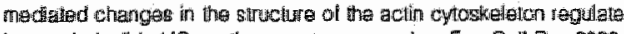
thuman inducitis kso synthase gene exprassion. Exp Cell Res 2003, $287: 106-115$

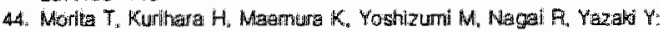

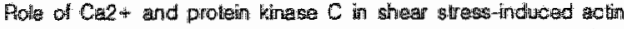
depolymerization and endothelini it gane expression. Circ Res 19g4, $75: 630-696$

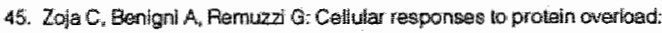
koy event in renal disease progressiton. Curr Opin Naphrol Hypertens 2004, 13:3-37?

46. Kretzlar M: Fegulation of adhesive hnteraction between padocytes and glonerular basement membrane. Hhorosc Ples Toch 2002. $57: 247-253$

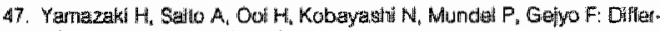
antiatton-induced cullured podocytas express endocytically active megalin, a Heymann nephritts antigen. Nephron Exp Nephrol $20044_{1}$ $96052-658$

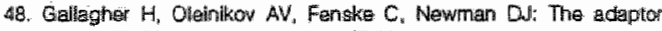
disabled 2 binds to the thin of Psi xNPX' sequence on the cyloplasmic tail of megallin. Biochimle 2004, 86:179-182

49. Barisonil L, Kriz W, Mthndel P, D'Agati V: The dysregulated podocyte phenotype a novel concopt tin the pathogenesis of colliepsing idiopattic focal segmental glomerulosclerosis: and HiV-assoclated nophropettry. I Arm Soc Naphral 1999, 10:51-61

50. Shwastava $T$, Garole FE, Whiting JM, Alon US: Synapiopodin expresston in idiopathic nephrotic syndiome of childhood. Kidrey lint 2001 , $59: 118=125$

51. Drenckhatha $D$, Franke RP: Uitrastructural organization of comtractile and cytoskatstal proteins in glomerular podocyes of chicken, rat, and man. Lab Invest 19188, 59:673-682

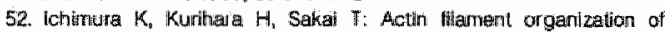

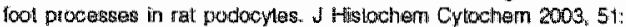
$1589-1600$

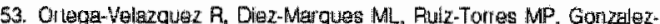
Plubio M, Rodriguez-Puyd M, Rodrilguez Fuyd D: Arg-Gily-Asp-Sor (RGDS) pepide stimulates transiorming growth factor betat tran. scription and secretion through intogrin activation. FASER I $20013_{2}$ $17: 1529-153.1$

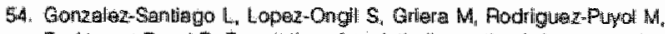
Rodriguez Puyol D: Regulation of endothelin symthasis by axtracellilas mats in hurnan endothelial cells. Kidney int 2002, 62:537-543

55. Benigni A Conta D, Zoja C. Langaratt L, Gaglierdini E. Parico M. Cofthian TM, Pernuzzl G: Targeted delation of angiotensin II type IA receptor does not protect mice firom progressive nephropatby of owerkad protelnurie. I Am Soc Nephrol 2004, 45:2666-2674

56. Porona $R$, Montanar S. Saniger $L$, Sanchez-Perez I, Bravo $A$, Lacal JC: Actwation of the nuclear factor kappas by flvo, COCAL2, and Ficic-1 proteins. Genes Dev 1997, 11:463-475

57. Chem HC, Appoddu PA, Parsoris JT. HAldebraind JO, Schallor MD,

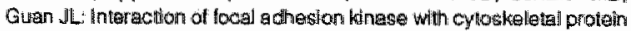
talln. d Bicl Chern 1995, 270:16995-16999.

58. Schllaspher DO, Hanks: SK, Hunter T, van der Gor P: Integrin-mediated bignal transduction linked to Ras pathway by GRB2 binding to fockal adhestion kinase. Niature 1994, 372;786-791

59. Spath M, Pavensigdt H, Muller C, Fietersen J, Wammer C, Schollimeyer Pu. Regulation of phosphoinositide hydrolysis and eytosolke troe cak. clum induced by endothellin in human glomenular eplthellal cetlls. Nephred Dial Transptant 1995, 10:1299-1304

60. Yamamoto $T$, Hifohama $T_{\text {, Lanuta }} H$ : Endotholin 8 receptlos flike immuncreactivty in podocytes of the rat kidney. Arch Histol Cynol $2002,65: 245-250$ 


\title{
SHIGA TOXIN-2 UP-REGULATES ENDOTHELIN-1 GENE IN GLOMERULAR PODOCYTES AND PROMOTES CYTOSKELETAL DYSFUNCTION: IMPLICATIONS FOR GLOMERULAR ISCHEMIIA AND HEMODYNAMIC CHANGES OF HUS
}

\author{
M. Morigi, S. Buelli, C. Zanchi, L. Longaretti, D. Macconi, A. Benigni, \\ G. Remuzzi and C. Zoja
}

Am J Pathol 2006; manuscript in submission 

Podocyte derived endothelin-1 induces actin remodeling and mediates Shigatoxin renal toxicity

Marina Morigi ${ }^{*}$, Simona Buelli*, Cristina Zanchi*, Lorena Longaretti", Daniela Macconi*, Ariela Benigni*, Giuseppe Remuzzi*\# and Carla Zoja *

* Mario Negri Institute for Phamacological Research, Via Gavazzeni 11, 24125 Bergamo, Italy;

\# Unit of Nephrology and Dialysis, Azienda Ospedaliera, Ospedali Riuniti di Bergama, Largo Barozzi 1, 24128 Bergamo, Italy;

Running Title: Stx-2 induces podocyte dysfunction via ET-1

Correspondence to:

Marina Morigi, Biol.Sci.D.

'Mario Negri' Institute for Pharmacological Research

Via Gavazzeni 11, 24125 Bergamo, Italy

Phone: +39-035-319 888;

Fax: +39-035-319 331

E-mail: morigi@marionegri.it 


\section{ABSTRACT}

Shigatoxin (Stx) is the offending agent of post-diarrheal HUS, characterized by glomerular ischemic changes preceeding microvascular thrombosis. Since podocytes are highly sensitive to Stx cytotoxicity and represent a source of vasoactive molecules, we studied whether Stx-2 modulated the production of endothelin (ET)-1, taken as candidate mediator of podocyte dysfunction. Stx-2 enhanced ET-1 mRNA and protein via activation of NF-kB and Ap-1, to the extent that transfection with dominant negative mutant of $\mathrm{IkB}$ kinase2 or with Ap-1 decoy oligodeoxynucleotides reduced ET1 mRNA. A role for $\mathrm{p} 38$ and p42/44 MAPK in mediating NF-kB-dependent gene transcription induced by Stx-2 has been proposed based on data that Stx-2 phosphorylated p38 and p42/44 MAPK and that inhibitors of both MAPK reduced transcription of NF-kB promoter/luciferase reporter gene construct induced by Stx-2. Stx-2 caused F-actin redistribution and intercellular gaps via ET-1 induction since cytoskeleton changes were prevented by $\mathrm{ET}_{\mathrm{A}}$ receptor blockade. As Stx-2, exogenous ET-1 induced cytoskeleton rearrangement and gaps, and increased protein permeability. These data suggest that podocyte is a target of Stx, novel stimulus for the synthesis of ET-1 that may control in autocrine and paracrine fashion glomerular remodeling and hemodynamic derangement in HUS. 


\section{INTRODUCTION}

Shigatoxin (Stx)-producing E. coli has been strongly indicated as the offending agent of typical post-diarrheal hemolytic uremic syndrome (D+HUS), a disorder of thrombocytopenia, microangiopathic hemolytic anemia and acute renal failure that mainly affects infants and small children (1-3). The kidney is the privileged organ of Stx toxicity, because it expresses high levels of the specific receptor glycosphingolipid globotriaosyl ceramide $(\mathrm{Gb} 3)(4,5)$. The characteristic lesion consists of swelling and detachment of glomerular endothelial cells that have been extensively recognized as the main target of Stx (6). Retraction and collapse of the capillary tuft in the glomerulus are prominent and tipically occur in association with fusion of foot processes and swelling of podocytes $(6,7)$. While ischemic lesion in the glomerular microcirculation can significantly contribute to renal dysfunction, the precise role of podocyte injury in the toxic response to Stx and the underlying cellular and molecular mechanisms have not been established yet.

Recent studies have indicated that glomerular visceral epithelial cells (podocytes) are sensitive to the toxic effects of Stx-1 and 2 isoforms because they express high levels of $\mathrm{Gb3}$ and bind $\mathrm{Stx}$, as documented either in cultured cells ( 8 ) or in human renal biopsies (9). In vitro, Stx-1 activated podocytes to release inflammatory cytokines like IL-1 and TNF, which remarkably increased the cellular content of Gb3 receptor, thereby enhancing renal toxin responsiveness $(8,10)$. In an experimental model of HUS in baboons, swelling of podocytes with asmophillic inclusions was found in 
association with the typical glomerular endothelial lesions after intravenous infusion of Stx-1 (11).

Podocytes represent a crucial component of the glomerular filter barrier. They are highly specialized cells endowed with foot processes that through a contractile structure, composed of actin and associated proteins connected to the glomerular basement membrane, stabilize glomerular architecture by counteracting the distension of the basement membrane $(12,13)$. The contractile apparatus of the foot processes responds to vasoactive hormones, thus controlling the glomerular capillary surface area and the ultrafiltration coefficient. Podocytes are an important source of the vasoconstrictor peptide endothelin-1 (ET-1), recognized to play a key role in the control of glomerular hemodynamics $(14,15)$. They constitutively express preproET1 mRNA and synthesize the mature peptide, whose generation is markedly upregulated by TGFB, MAC and thrombin (14). Stadies have shown that podocytes are target of ET-1 because they express $\mathrm{ET}_{\mathrm{A}}$ and $\mathrm{ET}_{\mathrm{B}}$ receptors $(16,17)$.

With the attempt to identify possible mechanisms evoked by Stx that could contribute to podocyte dysfunction and renal function impairment in HUS, we tested whether Stx-2 induced in cultured podocytes the expression and synthesis of ET-1, instrumental for cytoskeletal remodeling and cellular retraction. Intracellular signals involved in ET-1 gene regulation were also investigated. 


\section{METHODS}

\section{Cell culture and incubation}

Immortalized mouse podocytes were grown according to the method described by Mundel et al (18). Briefly, cells were cultured under growth-permissive conditions on rat tail collagene type I coated plastic dishes (BD Bioscience Bedfird, $\mathrm{MA}$ ), at $33^{\circ} \mathrm{C}$ in RPMI 1640 medium (Invitrogen, Gaithesburg, MA) supplemented with 10\% fetal bovine serum (FBS, Invitrogen), $10 \mathrm{U} / \mathrm{ml}$ mouse recombinant $\gamma$-interferon (Sigma Chemical Co, Saint Louis, MI, USA) and $100 \mathrm{U} / \mathrm{ml}$ penicillin plus $0.1 \mathrm{mg} / \mathrm{ml}$ streptomycin (Sigma). To induce differentiation, podocytes were maintained in nonpermissive conditions at $37^{\circ} \mathrm{C}$ without $\gamma$-interferon for 14 days and used for the experiments. In this culture conditions, cells stopped proliferating and were identified as differentiated podocytes by their arborized morphology and the presence of high levels of synaptopodin, using indirect immunofluorescence microscopy. Cells were routinely maintained for $24 \mathrm{~h}$ in serum free medium before all the experiments.

To investigate the effect of Stx-2 on the expression of ET-1 gene, differentiated podocytes were exposed for 3,6 and $24 \mathrm{~h}$ to medium alone or to Stx-2,50pM and 1nM (Toxin Technology Inc., Sarasota, FL, USA); preliminary experiments showed that these concentrations did not affect podocyte wiability as evaluated by viable cell count by Trypan blue dye exclusion (Sigma). ET-1 mRNA transcript levels were measured by Northern blot analysis and real time PCR. To exclude any possible effect of lipopolysaccharide (LPS) contamination of Stx-2 preparation on ET-1 mRNA 
expression, in some cases podocytes were incubated with Stx-2 in the presence of the LPS inhibitor polymyxin B (10 $\mathrm{g} / \mathrm{ml}$, Sigma) (19).

The time-course of ET-1 protein synthesis was assessed by radioimmunoassay (RIA) in supernatants of podocytes exposed to both concentrations of Stx-2.

To study intracellular signaling pathways that regulate ET-1 gene transcription in Stx-2 loaded podocytes, we first assessed the potential role of NF-kB and Ap-1 by determining the activity of both transcription factors in nuclear extracts from podocytes exposed for $30 \mathrm{~min}$ to Stx-2 (50pM and $1 \mathrm{nM})$ and by evaluating the effect of NF-kB and AP-1 inhibition on ET-1 gene expression. Podocytes were transfected for $3 h$ with a dominant negative mutant of the $\mathrm{KkB}$ kinase2 (IKK2) (20), a kinase that acts as an upstream activator of NF-kB, and then exposed to Stx-2 (50pM) for $24 \mathrm{~h}$. In other experiments, podocytes were transfected for $2 \mathrm{~h}$ with double-stranded oligodeoxynucleotides (ODN) (21) that scavenge Ap-1 activity by competitive reaction, or mutated control ODN, and then exposed to the toxin for $6 \mathrm{~h}$. Then, we studied whether Stx-2 induced activation/phosphorylation of p38 MAPK and p42/44 MAPK -known activators of NF-kB and Ap-1- in podocytes treated with $50 \mathrm{pM} \mathrm{Stx}-2$ for $15,30,60,180 \mathrm{~min}$. To elucidate whether MAPK were involved in NF$\mathrm{kB}$ regulation, podocytes were transfected with NF- $\mathrm{kB}$ luciferase reporter gene and incubated with Stx-2 $(50 \mathrm{pM}, 6 \mathrm{~h})$ in the presence or absence of the p38 inhibitor SB$202190(20 \mu \mathrm{M})(22)$ or the p42-44 inhibitor PD-98059 $(10 \mu \mathrm{M})(23)$.

The effect of Stx-2 on F-actin cytoskeletal rearrangement and gap formation was assessed in differentiated podocytes exposed for $15 \mathrm{~h}$ to Stx-2 $(50 \mathrm{pM})$. The involvement of ET-1 in the process of F-actin changes and gap formation was 
investigated by using a specific $\mathrm{ET}_{\mathrm{A}} / \mathrm{ET}_{\mathrm{B}}$ receptor antagonist J-104132 (1nM, Banyu Pharmaceutical co., Ibaraki, Japan) (24) or an ETA receptor antagonist, LU-302146 $(1 \mu \mathrm{M}$, Knoll AG, Ludwighafen, Germany) (25), added $1 \mathrm{~h}$ prior and during $15 \mathrm{~h}$ of Stx-2 incubation.

\section{Northerm blot analysis}

Total RNA was isolated from podocytes by the guanidium isothyocianate/cesium chloride procedure. Fifteen $\mu$ g of total RNA was then fractionated on $1.2 \%$ agarose gel and blotted onto synthetic membranes (Zeta-probe; Bio-Rad, Richmond, CA, USA). ET-1 mRNA was detected by using a 319 bp fragment of rat ET-1 cDNA. The probe was labeled with $\alpha-32 \mathrm{P}$ dCTP by random-primed method. Hybridization was performed overnight at $60^{\circ}$ in $0.25 \mathrm{M} \mathrm{Na}_{2} \mathrm{HPO}_{4}, \mathrm{pH} 7.2,7 \%$ SDS. Filters were washed twice for $30 \mathrm{~min}$ with $20 \mathrm{mM} \mathrm{Na}_{2} \mathrm{HPO}_{4}, \mathrm{pH} 7.2,5 \%$ SDS and twice for $10 \mathrm{~min}$ with 20 $\mathrm{mM} \mathrm{Na} 2 \mathrm{HPO}_{4}, \mathrm{pH} 7.2,1 \% \mathrm{SDS}$ at $60^{\circ}$. Membranes were subsequently probed with $\beta$ actin CDNA, taken as internal standard of equal loading of the samples on the membrane. Expression of ET-1 mRNA was corrected for $\beta$-actin expression and quantited densitometrically.

\section{Quantitative Real Time PCR}

Total RNA was extracted from podocytes by the guanidium isothiocyanate/cesium chloride procedure. Contaminating genomic DNA was removed by RNase-free DNase (Promega, Ingelheim, Germany) for $1 \mathrm{~h}$ at $37^{\circ} \mathrm{C}$. The purified RNA $(1 \mu \mathrm{g})$ was reverse transcribed using random examers $(50 \mathrm{ng})$ and $200 \mathrm{U}$ of SuperScript II RT 
(Life Technologies, San Giuliano Milanese; Italy) for $1 \mathrm{~h}$ at $42^{\circ} \mathrm{C}$. No enzyme was added for reverse transcriptase-negative controls ( $\mathrm{RT}^{-}$).

Real-time PCR was performed with ABI PRISM 5700 Sequence Detection System (PE Biosystems, Warrington, UK) using heat-activated TaqDNA polymerase (Amplitaq Gold, PE Biosystems) (26). The SYBR Green I PCR Reagents kit was used according to the manufacturer's protocol. After an initial hold of $2 \mathrm{~min}$ at $50^{\circ} \mathrm{C}$ and $10 \mathrm{~min}$ at $95^{\circ} \mathrm{C}$, the samples were cycled 40 times at $95^{\circ} \mathrm{C}$ for $15 \mathrm{~s}$ and $60^{\circ} \mathrm{C}$ for $60 \mathrm{~s}$. Fluorescence detection, defined as threshold cycle ( $\mathrm{Ct})$, is picked in the exponential phase of the PCR and used for relative quantification of the target gene. The comparative Ct method normalizes the number of target gene copies to an housekeeping gene as Glyceraldehyde-3-phosphate dehydrogenase (GAPDH) ( $\triangle \mathrm{Ct}$ ). Gene expression was then evaluated by the quantification of cDNA corresponding with the target gene relative to a calibrator sample serving as a physiologic reference (e.g.r untreated cells, $\Delta \Delta \mathrm{Ct})$. On the basis of exponential amplification of target gene as well as calibrator, the amount of amplified molecules at the Ct is given by:

$2^{\Delta \Delta \mathrm{Ct}}$. The following specific primers $(300 \mathrm{nM})$ were used:

mouse ET-1: sense 5'-AACTACGAAGGTTGGAGGCCA, antisense 5'CACGAAAAGATGCCTTGATGC; GAPDH sense $5^{\prime}$ TCATCCCTGCATCCACTGGT, antisense $5^{s}$-CTGGGATGACCTTGCCCAC. All primers were obtained from Sigma Genosys (Cambridgeshire, UK). True identity of the amplification products was ensured by primer specificity for ET-1 mouse 
sequence, the presence of a single dissociation curve at a constant I melting, and the lack of genomic DNA contamination or primer dimers in RT - sample.

\section{Radioimmunoassay}

ET-1 production was assayed in podocyte supernatants by radioimmunoassay (RIA).

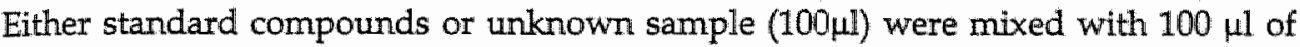
antiserum (Peninsula Laboratories Inc. Belmont, $\mathrm{CA}$ ) diluted in phosphate buffer $\mathrm{pH}$ 7,2 (RIA buffer) at final dilution 1:72000. The reaction mixture was incubated for $24 \mathrm{~h}$ at $4^{\circ} \mathrm{C}$; then $15000 \mathrm{cpm}$ of $(125 \mathrm{I}) \mathrm{ET}-1$ in $100 \mu \mathrm{l}$ was added and the incubation prolonged for $24 \mathrm{~h}$ at $4^{\circ} \mathrm{C}$. Separation of free from antibody-bound (125I) ET-1 was achieved by addition of a second antibody $(500 \mu l$ of immunoprecipitating mixture consisting of a sheep anti-rabbit IgG and polyethylene glycol) for 30 minutes at room temperature. Finally, $500 \mu I$ RIA buffer was added to stop the reaction, and the immunoprecipitates were centrifuged at $5000 \mathrm{~g}$ for $30 \mathrm{~min}$. Supernatants were discarded and pellet radioactivity detected by gamma counter (Beckman, Irvine, CA). Results were expressed as $\mathrm{pg} / 10^{6}$ cells. The minimum detectable concentration was $0.4 \mathrm{pg} /$ tube. Nonspecific binding did not exceed $2 \%$ of total radioactivity. The cross-reactivity of the antibody with other endothelins is as follows: endothelin$2,46.9 \%$; endothelin-3, $17 \%$; and big endothelin- $1,9.4 \%$. Intra-assay and inter-assay variability averaged $10 \%$ and $12 \%$ respectively, over a range between 0.4 and 100 $\mathrm{Pg} /$ tube. 
Nuclear extracts were prepared from podocytes with the NE-PER ${ }^{T M}$ Nuclear and Cytoplasmic Extraction Reagents Kit (Pierce/Celbio, Pero, Itally) according to the manufacturer's instructions. To minimize proteolysis, all buffers contained protease inhibitor cocktail (Boehringer Manneheim, Germany). The protein concentration was determined by the Bradford assay using the Bio-Rad protein assay reagent.

Electrophoretic mobility shift assays (EMSAs) were performed as previously described (22) with the kB DNA sequence of the immunoglobulin gene (5'CCGGTCAGAGGGGACTTTCCGAGACT) and consensus binding site for Ap-1 (5'CGCTTGATGACTCAGCCGGAA). Nuclear extracts $(3 \mu \mathrm{g})$ were incubated with 50 $\mathrm{kcpm}$ of ${ }^{32} \mathrm{P}$ labeled oligonucleotide in a binding reaction mixture $[10 \mathrm{mM}$ Tris- $\mathrm{HCl}$ pH 7.5, $80 \mathrm{mM} \mathrm{NaCl}, 1 \mathrm{mM}$ EDTA, $1 \mathrm{mM}$ dithiothreitol, $5 \%$ glycerol, $1.5 \mu \mathrm{g}$ of poly (dI-dC)] for $30 \mathrm{~min}$ on ice. In competition studies, a 100-fold molar excess of unlabeled oligonucleotide was added to the binding reaction mixture before the addition of the labeled $\mathrm{kB}$ or Ap-1 probes. For densitometric analysis the volume density for each band was determined in arbitrary units. The sum of the volume density of bands for a single sample was used as an indirect measure of NF-kB or Ap1 activation and expressed as a fold increase of the mean densitometry of respective control (represented as 1).

\section{Adenoviral vector-mediated gene transfer in podocytes}

Replication-deficient adenovirus encoding for kinase-defective dominant negative form of human IKK2 (AdV-dnIKK2) was a kind gift of Dr.R. de Martin (University of 
Vienna, Austria) (20). Replication-deficient adenoviral vector having no insert (AdV0) was from Novartis Pharma (Basel, Swiss). All viruses used belong to Ad5 serotype. For transfection experiments, podocytes were incubated with adenoviruses at a multiplicity of infection of 50 in RPMI 1640 without serum for $3 \mathrm{~h}$ at $37^{\circ} \mathrm{C}$. The adenovirus was washed off and cells were maintained in serum-free medium for 24 $\mathrm{h}$. Then cells were exposed to $50 \mathrm{pM}$ Stx-2 for additional $24 \mathrm{~h}$ and processed for endothelin-1 mRNA expression (real time PCR analysis). Transfection did not affect cell viability.

\section{Ap-1 decoy oligodeoxynucleotide (ODN) technique}

The sequences of the phosphorothioate double stranded ODN against the Ap-1 binding site and the mutated control ODN were as follows:

Ap-1 decoy ODN (consensus sequences are underlined), 5'CGCTTGATGACTCAGCCGGAA-3', 3'-GCGAACTACTGAGTCGGCCTT-5',

mutated control ODN, 5'-CGCTTGATGACTTGGCCGGAA-3', $\quad 3^{\prime}-$ TTCCGGCCAAGTCATCAAGCG-5:

Double stranded ODN (21) were prepared from complementary single stranded phosphorotioate oligonucleotides, by melting at $80^{\circ} \mathrm{C}$ for 5 minutes followed by $3-4 \mathrm{~h}$ reconstitution period at room temperature. To study the effect of Ap-1 decoy, podocytes were transfected with $200 \mathrm{nM}$ Ap-1 decoy ODN or mutated control ODN in serum free medium, using Oligofectamine ${ }^{\mathrm{TM}}$ Reagent according to the manufacturer's instructions (Invitrogen, San Giuliano Milanese, Italy). Two hours after transfection, Stx-2 at the final concentration of $50 \mathrm{pM}$ was added to the cells for 
$6 \mathrm{~h}$ without removing transfection mixture. Then, cells were processed for ET-1 mRNA expression (real time PCR analysis).

\section{Western blot analyses}

Podocytes were lysed with lysis buffer (Tris- $\mathrm{HCl} 20 \mathrm{mM} \mathrm{pH} \mathrm{7.5,} \mathrm{NaCl} 150 \mathrm{mM}$, EDTA $2 \mathrm{mM}$, Triton-X100 1\%, sodium pyrophosphate $2.5 \mathrm{mM}, \beta$-glycerophosphate 1 $\mathrm{mM})$ plus phosphatase inhibitors $\left(\mathrm{Na}_{3} \mathrm{VO}_{4} 1 \mathrm{mM}, \mathrm{NaF} 50 \mathrm{mM}\right)$ and protease inhibitors (PMSF $1 \mathrm{mM}$, leupeptin $1 \mu \mathrm{g} / \mathrm{ml}$ ). Protein concentration was determined by protein assay based on bicinchoninic acid color formation (Pierce, Millan, Italy). Proteins $(30 \mu \mathrm{g})$ were separated on $10 \%$ polyacrylamide gels by SDS-PAGE and transferred to nitrocellulose membranes. Membranes were blocked for $1 \mathrm{~h}$ at room temperature with PBS containing 0.1\% Tween-20 and 5\% BSA (for phosphorylated protein detection) or $5 \%$ non-fat dry milk (for un-phosphorylated protein detection), and then incubated overnight at $4^{\circ} \mathrm{C}$ with the following primary antibodies: mouse monoclonal IgM anti phospho-p38 (1:300) or mouse monoclonal IgG phosphop42/44 [Thr202/Tyr204] (1:1000) in PBS plus 1\% BSA; mouse monoclonal IgG antip38 (Santa Cruz Biatechnology, Santa Cruz, CA) 1:200 or mouse monoclonal IgG anti-p42/44 (Cell Signaling Technology Inc., Beverly, MA) 1:2000 in PBS plus 1\% non-fat dry milk. After incubation with the secondary antibodies, horseradish peroxidase-conjugated rabbit anti-IgG mouse or goat anti-IgM mouse (Sigma), for $1 \mathrm{~h}$ at room temperature in PBS with $0.1 \%$ Tween-20 and 1\% BSA or $1 \%$ non-fat dry millk, proteins bands were detected by Supersignal chemiluminescent substrate (Pierce). 


\section{Reporter luciferase gene assay}

Podocytes were transfected with $1 \mu \mathrm{g}$ NF-kB luciferase reporter gene (Stratagene; M= Medical, Florence, Italy) by the Superfect transfection reagent following manufacturer's protocol (Qiagen, Milan, Italy). Three hours after transfection, the reporter gene was washed off and cells were maintained overnight in fresh medium without serum (22). Then cells were exposed to $S \mathrm{tx}-2(50 \mathrm{pM})$ for additional $6 \mathrm{~h}$. The p38 inhibitor SB-202190 $(20 \mu \mathrm{M})$ or the p42/44 inhibitor PD-98059 $(10 \mu \mathrm{M})$ were added $1 \mathrm{~h}$ before and during stimulation with Stx-2. Podocytes were subsequently lysed in $1 \mathrm{X}$ reporter lysis buffer for $15 \mathrm{~min}$ at room temperature. The lysates were cleaned by centrifugation. The luciferase activity was measured according to standard protocols (Stratagene; M-Medical), with a Lumat LB9507 luminometer (EG\&G Berthold, Bad Wildbad, Germany). Induced luciferase activities were normalized on the basis of protein contents and expressed as fold stimulation compared with unstimulated controls.

\section{Immunofluorescence staining for F-actin}

Podocytes plated on type I collagen-coated glass coverslips were maintained in nonpermissive conditions for 14 days and incubated with medium alone, Stx-2 at 50pM $15 \mathrm{~h}$ and in additional experiments with ET-1 (100 nM) for $6 \mathrm{~h}$. At the end of incubation, cells were fixed in $2 \%$ paraformaldehyde plus $4 \%$ sucrose in PBS pH 7.4 for $10 \mathrm{~min}$ at $37^{\circ} \mathrm{C}$. After three washings with PBS, non-specific binding sites were saturated in blocking solution ( $2 \% \mathrm{FBS}, 2 \%$ bovine serum albumin, $0.2 \%$ bovine gelatin in PBS) for $30 \mathrm{~min}$ at room temperature. Then podocytes were incubated with 
rhodamine-phalloidin $20 \mathrm{U} / \mathrm{ml}$ for $45 \mathrm{~min}$ (Molecular Probes Inc., Eugene, OR, USA); negative control experiments without rhodamine-phalloidin were performed. Coverslips were washed and mounted in 1\% N-propyl-gallate in $50 \%$ glycerol, $0.1 \mathrm{M}$ Tris- $\mathrm{HCl}, \mathrm{pH} 8$ and examined using fluorescence microscopy Olympus $\mathbb{1} \times 70$ (Olympus Italia srl, Segrate-Milano, Italy) at the original magnification $\times 600$. To evaluate gap formation, we counted the number of gaps of 15 fields taken randomly for each sample.

\section{Permeability studies}

Permeability was determined by measuring the transepithelial passage of FITC-BSA from apical to basolaterall compartment of transwell bicameral chambers $(0.4 \mu \mathrm{m}$ pore Corning Costar Corporation, Cambridge, MA) as previously described with slight modifications (27). Podocytes were exposed to test medium or ET-1 (100 nM, Sigma) for $6 \mathrm{~h}$, then FITC-BSA $100 \mu \mathrm{g} / \mathrm{ml}$ (Sigma) was loaded into the apical compartment for $1 \mathrm{~h}$ at $37^{\circ} \mathrm{C}$. Fluorescence in the basolateral compartment was measured using fluorescence spectroscopy (ex $=490$; em $=525)$. Permeability index (PI) was calculated as follows:

Permeability index $\%=\frac{\text { (experimental clearance-spontaneous clearance) }}{\text { (clearance of filter alone-spontaneous clearance) }} \times 100$

where experimental clearance was fluorescence from the basolateral compartment upon ET-1, spontaneous clearance was average fluorescence in unstimulated control, and clearance of filter alone fluorescence without cells. 
Statistical analysis

Results are expressed as mean \pm SE. Statistical analysis was performed using

Student's $t$ test, ANOVA followed by Tukey test for multiple comparisons, and Kruskall Wallis test, as appropriate. Statistical significance was defined as $P<0.05$. 


\section{RESULTS}

\section{Stx-2 increases ET-1 expression and protein in cultured podocytes}

We assessed the capability of St $x-2$ to modulate EI- 1 mRNA expression and protein synthesis in differentiated mouse podocytes maintained for 14 days in non permissive culture condition. By Northern blot, a $1.3 \mathrm{~kb}$ mRNA transcript specific for ET-1 was observed in unstimulated control podocytes (Figure 1A). Stx-2 at the subtoxic concentrations of $50 \mathrm{pM}$ and $1 \mathrm{nM}$ induced a significant increase of ET-1 transcript levels over control at 3 and $6 \mathrm{~h}$, which further enhanced after $24 \mathrm{~h}$ incubation (2.9- and 3.2 -fold increase). The upregulation of ET-1 gene was also confirmed by real time PCR studies (Figure 3). The stimulatory effect of Stx-2 on ET-1 mRNA expression ( $24 \mathrm{~h}$ ) was not due to LPS contamination as indicated by experiments using LPS inhibitor polymyxin B (Stx-2: 3.1, Stx-2+polymyxin B: 3.6-fold increase of ET-1 mRNA over control).

Overexpression of ET-1 gene was paralleled by a significant time-dependent increase of the native peptide released into the supernatants of Stx-treated podocytes. ET-1 production, already detected at 6 hours, was more pronounced starting from 15 hour exposure to both Stx-2 concentrations (Figure 1B).

\section{Upregulation of ET-1 mRNA in response to Stx-2 is dependent on NF- $k B$ and $A p-1$}

Since the promoter region of ET-1 has consensus sequences for NF-kB and Ap-1 (28, 29), we studied the DNA binding activity of these transcription factors in podocytes challenged with Stx-2. As shown in Figure 2A, nuclear extracts from unstimulated 
cells displayed two constitutive bands of NF-kB: an upper complex and a faster migrating lower complex. Thirty min incubation of podocytes with Stx-2 $(50 \mathrm{pM}$ and $1 \mathrm{nM}$ ) elicited a substantial rise in NF-kB binding activity of the two complexes. Densitometric analysis of three independent experiments revealed a 6 - and 10-fold increase of NF-kB activity induced by $S t x-2$ over control $(P<0.05)$. Similarly, Ap-1 activation was detected in podocytes exposed to both concentrations of $S t x-2(P<0.05$ vs control) (Figure 2B). The specificity of binding reaction was confirmed by the ability of excess cold NF-kB and Ap-1 oligonucleotides to inhibit binding.

To establish whether upregulation of ET-1 mRNA in response to Stx-2 was dependent on NF-kB, podocytes were infected with a recombinant adenovirus encoding the dominant negative mutant of the IkB kinase 2 (AdV-dnIKK2), which fails in promoting the dissociation of $\mathrm{IkB} \propto$ from $\mathrm{NF}-\mathrm{kB}$, and then treated for 24 hours with Stx-2 $(50 \mathrm{pM})$. Real time PCR experiments indicated that overexpression of dnIKK2 resulted in a significant $(\mathrm{P}<0.01)$ reduction of ET-1 mRNA in respect to Stxtreated cells infected with the control adenovirus (AdV-0) (Figure 3A). Notably, dnIKK2 almost completely normalized ET-1 mRNA levels. No difference in ET-1 mRNA levels was observed between Stx-treated podocytes infected or not infected with AdV-0.

The role of Ap-1 was assessed by transfection of podocytes with double stranded (decoy) ODN that scavenge active Ap-1, thereby blocking its binding to the promoter regions of target genes. A partial, although significant reduction (26\%) of ET-1 expression was found in cells transfected with decoy ODN against Ap-1 in respect to mutated control ODN podocytes treated with Stx-2 (Figure 3B). 
Stx-2 activates p38 and p $42 / 44$ MAPK, instrumental for NF- $k B$ transcriptional activity

Given that in other cellular systems p38 and p42/44 MAPK modulate the transcriptional activity of NF-kB and Ap-1 (22, 30-34), we investigated whether Stx-2 induced activation/phosphorylation of both MAPK. By Western blot analysis, podocytes challenged with Stx-2 (50 pM) exhibited a rapid p38 MAPK phosphorylation within $15 \mathrm{~min}$ that further increased at 30 and $60 \mathrm{~min}$ in respect to control (Figure 4A). As shown in Figure 4B, Stx-2 induced a marked increase in the level of $\mathrm{p} 42 / 44$ MAPK phosphorylation starting at $30 \mathrm{~min}$, then declining to the basal level by $180 \mathrm{~min}$.

Next, we assessed whether $\mathrm{p} 38$ and p42/44 MAPK activated by Stx-2 were involved in NF-kB transcriptional activity, responsible for ET-1 gene regulation. The effect of p38 and p42/44 MAPK inhibitors, SB-202190 and PD-98059, was assessed in Stx-2 treated podocytes transfected with a vector encoding the luciferase reporter gene driven by a promoter containing consensus sequence for NF-kB. Results showed that Stx-2 increased luciferase activity by 2.7 -fold in respect to control, which was reduced by $37 \%$ by the p38 MAPK inhibitor and almost completely abrogated after p4.2/44 MAPK functional blockade (Figure 4C).

\section{Stx-2 promotes cytoskeleton rearrangement and gap formation via ET-1}

Differentiated podocytes possess a contractile structure composed of F-actin fibers extended across the entire cell body (Figure 5A) that after Stx-2 (50 pM) were greatly 
redistributed to the cell periphery (Figure 5B-C). Alterations in actin-based cytoskeleton were associated with the formation of intercellular gaps (Figure 5B-C). Quantitation of gaps revealed a higher frequency in podocytes exposed to Stx-2 compared to unstimulated cells (Figure 5F). To document that ET-1 is a major mediator of Stx-induced podocyte structural changes, we tested the effect of the $\mathrm{ET}_{\mathrm{A}} / \mathrm{ET}_{\mathrm{B}}$ and $\mathrm{ET}_{\mathrm{A}}$ receptor antagonists $\mathrm{J}-104132$ and LU-302146. Both agents, similarly prevented F-actin redistribution induced by Stx-2 (Figure 5D,E), and reduced gap formation (Figure 5F), thus suggesting a role of $\mathrm{ET}-1$ via $\mathrm{ET}_{\mathrm{A}}$ receptor.

\section{ET-1 induces F-actin redistribution and alters protein permeability in podocytes}

That ET-1 modifies podocyte cytoskeleton was further confirmed by another series of experiments where the peptide was exogenously added to cultured podocytes (Figure 6A,B). Following exposure to ET-1 (100 nM, $6 \mathrm{~h})$, podocytes underwent cytoskeleton alterations, as visualized by the redistribution of F-actin fibers to the cell periphery, and intercellular gap formation (Figure 6B). This effect was remarkably comparable to that seen after Stx-2 treatment.

Evaluation of transepithelial passage of fluorescent albumin to the basolateral compartment of bicameral chambers showed unequivocal increase in albumin permeability across podocyte monolayer upon ET-1 challenge (Figure 6C). 


\section{DISCUSSION}

The kidney is the privileged target of Shigatoxin, the causative agent of D+HUS. The role of podocyte in the toxic response to Stx, and the underlying cellular and molecular mechanisms have been explored in the present study. We focused on the vasoconstrictor peptide ET-1 found to be elevated in plasma and urine of children during the acute phase of HUS $(35,36)$. In the kidney ET-1 is produced by all glomerular cell types and by tubules (37), and when bound to $\mathrm{ET}_{\mathrm{A}}$ receptor it elicits different biological activities including contraction, proliferation, and inflammatory cell recruitment (38). The present results indicate that Stx-2, at subtoxic concentrations, enhanced gene expression of ET-1 in cultured murine podocytes, which was followed by increased synthesis of the mature peptide. In vivo, the increased production of vasoactive ET-1 by podocytes might have an impact on glomerular microcirculation, and possibly account for renal dysfunction in HUS, considering the podocyte location in the glomerulus at close proximity with the endothelium.

A pivotal aspect of this study was the identification of the intracellular signals involved in Stx-induced ET-1 overexpression in podocytes. Regulation of the pre-pro ET-1 gene is complex and has been attributed to multiple regulatory elements. Evidence is available showing that pre-proET-1 gene possesses in the promoter region specific consensus sequences for the transcription factors NF-kB and Ap-1 (28, 29). Podocytes exposed to Stx-2 exhibited a rapid and massive activation of NF-kB. Ap-1 was also significantly activated by the toxin, although to a lesser extent. In 
other cellular systems, as monocytes (39) and endothelial cells (40), previous reports showed that Stx increased either NF-kB or AP-1 binding activity, responsible for cytokine and chemokine gene expression. The direct demonstration that NF-kB modulates ET-1 mRNA expression derives from experiments where transfected podocytes that overexpressed a dominant negative mutant of the IKK2 $(20,22)$ - a specific kinase that acts as upstream activator of NF-kB (41)-failed to increase ET-1 gene expression in response to $\mathrm{Stx}-2$. In addition, finding that $\mathrm{Stx}$-treated podocytes transfected with the Ap-1 decoy ODN showed a significant decrease of ET-1 mRNA indicates that ET-1 gene expression is at least in part dependent on Ap-1 activation.

It has been consistently documented that $\mathrm{p} 38$ and $\mathrm{p} 42 / 44$ MAPK pathways are fundamental for initiating the transcriptional activity of NF-kB and Ap-1 (22, 30-34). The involvement of $\mathrm{p} 38$ and $\mathrm{p} 42 / 44$ MAPK in mediating NF-kB-dependent gene transcription rests on data that Stx-2 phosphorylated p38 and p42/44 MAPK and that inhibitors of both MAPK decreased the transcription of NF-kB promoter/luciferase reporter gene construct induced by the toxin. Consistently with our results, other studies have implicated MAPK activation in Stx-induced gene transcription in various target cells. In human adenocarcinoma-derived renal tubular cell line (ACHN), Stx-2 induced p38 and p42/44 MAPK activation instrumental for NF-kB-induced TNF $\alpha$ transcription (30). In addition, Stx-1-induced TNF $\alpha$ gene expression in a mononuclear cell line was decreased by blockade of p38 pathway (42). 
Another major finding that arises from this study is that Stx-2 caused a marked rearrangement of the contractile $\mathrm{F}$-actin apparatus of podocytes, associated with the formation of intercellular gaps reflecting effective podocyte process retraction. In vivo, podocyte cytoskeletal derangement, consisting of marked disaggregation and redistribution of actin filaments, results in foot process effacement and cell retraction, structural alterations common to both human and experimental glomerulopathies associated with proteinuria and renal function impairment (43-45). Foot process effacement, which possibly develops in association with increased mechanical stress, can be considered as an adaptive change in the podocyte phenotype to counteract glomerular capillary expansion, at the price of reducing the actual filtration area (43). As for possible mechanisms by which Stx may influence cytoskeleton remodeling, a study (46) performed in ACHN cells derived from renal tubular epithelial carcinoma showed that binding of Stx-1 B subunit to Gb3 receptor caused the phosphorylation of ezrin, a linker protein that connects the plasma membrane with actin filaments. Ezrin phosphorylation occurred via activation of Src PTK, crucial determinant of cell contraction and cytoskeleton remodeling (47), and was followed by redistribution of cytoskeletal organizing proteins including actin, vimentin, cytokeratin, paxillin and FAK (46). In our experimental setting we tested the hypothesis that cytoskeletal changes induced by Stx-2 in podocytes could be related to the production of ET-1, on account of its ability to induce stress-fiber formation (48) and to activate Src PTK family (49). Finding that treatment of podocytes with $E T_{A} / E T_{B}$ or $E T_{A}$ receptor antagonists prevented F-actin redistribution and decreased gap formation induced by Stx-2, does suggest a role for ET-1 in the dysfunction of the contractile apparatus 
eventuating into cell retraction. Moreover, the observation that both agents protected podocytes against Stx-2 toxicity to a similar extent would indicate that the effects of ET-1 are transduced by ETA $_{\mathrm{A}}$ receptor. Notably, morphological alterations similar to those caused by Stx-2 were observed when exogenous ET-1 was added to cultured podocytes, causing F-actin redistribution and gap formation. In addition, ET-1 significantly increased transepithelial passage of fluorescent albumin to the basolateral compartment of podocytes grown on a bicameral chamber, which probably reflected an alteration of podocyte-podocyte contact. Altogether these data point to ET-1 as a key mediator of toxin-induced podocyte alterations.

In conclusion, our results document that the podocyte is a functionally relevant target of Stx-2 that via upregulation of ET-1 gene induces podocyte activation and cytoskeletal derangement. These changes might contribute to glomerular dysfunction in D+HUS. 


\section{ACKNOWLEDGMENTS}

Part of this work was presented at the annual meeting of the American Society of Nephrology (San Diego, CA, November 12-17, 2003). The Authors thank Dr. Peter Mundel (Department of Medicine, Albert Einstein College of Medicine, New York, USA) for providing the conditionally immortalized murine cell line and Dr. Rainer de Martin (Department of Vascular Biology and Thrombosis Research, University of Vienna, Vienna, Austria) for providing recombinant adenovirus expressing dnIKK2. The Authors are indebted to Dr. Mauro Abbate and Dr. Susanna Tomasoni for their precious contribution. Dr. Simona Buelli is a recipient of a fellowship "Helsinn Healthcare SA" through the courtesy of "Fondazione Aiuti per la Ricerca sulle Malattie Rare". Manuela Passera helped preparing the manuscript. 


\section{REFERENCES}

1. Ruggenenti $P$, Noris M, Remuzzi G: Thrombotic microangiopathy, hemolytic uremic syndrome, and thrombotic thrombocytopenic purpura. Kidney International 60:831-846, 2001

2. Andreoli SP: The pathophysiology of the hemolytic uremic syndrome. Curr Opin Nephrol Hypertens 8:459-464, 1999

3. Karmali MA: Infection by Shiga toxin-producing Escherichia colñ: an overview. Mol Biotechnol 26:117-122, 2004

4. Lingwood CA: Role of verotoxin receptors in pathogenesis. Trends Microbiol 4:147-153, 1996

5. Lingwood CA: Verotoxin-binding in human renal sections. Nephron 66:21-28, 1994

6. Habib R: Pathology of the Hemolytic Uremic Syndrome. In Hemolytic Uremic Syndrome and Thrombotyc Thrombocytopenic Purpura, B.S. Kaplan, R.S. Trompeter, and J.L. Moake, editors, New York, Dekker, M. Inc., 1992, 315-353.

7. Striker GE, Striker LJ, D'Agati V: Renal Lesions in Hypertension. In The Renal Biopsy Major Problems in Pathology. V.A. Livolsi, editor, Philadelphia, Saunders, W.B. Company, 1997, 258-268.

8. Hughes AK, Stricklett PK, Schmid D, Kohan DE: Cytotoxic effect of Shiga toxin-1 on human glomerular epithelial cells. Kidney International 57:23502359,2000 
9. Ergonul Z, Clayton $\mathbb{F}$, Fogo $A B$, Kohan $D E$ : Shigatoxin-1 binding and receptor expression in human kidneys do not change with age. Pediatr Nephrol 18:246253,2003

10. Hughes AK, Stricklett PK, Kohan DE: Shiga toxin-1 regulation of cytokine production by human glomerular epithelial cells. Nephron 88:14-23, 2001

11. Taylor FB, Jr., Tesh VL, DeBault L, Li A, Chang AC, Kosanke SD, Pysher TJ, Siegler RL: Characterization of the baboon responses to Shiga-like toxin: descriptive study of a new primate model of toxic responses to Stx-1. Am J Pathol 154:1285-1299, 1999

12. Barisoni $\mathrm{L}_{x}$ Kopp JB: Update in podocyte biology: putting one's best foot forward. Curr Opin Nephrol Hypertens 12:251-258, 2003

13. Pavenstadt $\mathrm{H}$ : Roles of the podocyte in glomerular function. Am J Physiol Renal Physiol 278:F173-179, 2000

14. Cybulsky AV, Stewart DJ, Cybulsky MI: Glomerular epithelial cells produce endothelin-1. Journal of American Society Nephrology 3:1398-1404, 1993

15. Kasinath $B S$, Fried $T A$, Davalath $S$, Marsden PA: Glomerular epithelial cells synthesize endothelin peptides. Am J Pathol 141:279-283, 1992

16. Yamamoto T, Hirohama T, Uemura $H$ : Endothelin B receptor-like immunoreactivity in podocytes of the rat kidney. Arch Histol Cytol 65:245250,2002

17. Ortmann J, Amann K, Brandes RP, Kretzler M, Munter K, Parekh N, Traupe T, Lange M, Lattmann T, Barton M: Role of podocytes for reversal of 
glomerulosclerosis and proteinuria in the aging kidney after endothelin inhibition. Hypertension 44:974-981, 2004

18. Mundel P, Reiser J, Zuniga Mejia Borja A, Pavenstadt H, Davidson GR, Kriz W, Zeller R: Rearrangements of the cytoskeleton and cell contacts induce process formation during differentiation of conditionally immortalized mouse podocyte cell lines. Exp Cell Res 236:248-258, 1997

19. Giambartolomei GH, Zwerdling A, Cassataro J, Bruno L, Fossati CA, Phillipp MT: Lipoproteins, not lipopolysaccharide, are the key mediators of the proinflammatory response elicited by heat-killed Brucella abortus. Journal Immunology 173:4635-4642, 2004

20. Oitzinger $W$, Hofer-Warbinek R, Schmid JA, Koshelnick $Y$, Binder BR, de Martin R: Adenovirus-mediated expression of a mutant IkappaB kinase 2 inhibits the response of endothelial cells to inflammatory stimuli. Blood $97: 1611-1617,2001$

21. Viedt $C$, Dechend $R$, Fei J, Hansch GM, Kreuzer J, Orth SR: MCP-1 induces inflammatory activation of human tubular epithelial cells: involvement of the transcription factors, nuclear factor-kappaB and activating protein-1. Journal of American Society Nephrology 13:1534-1547, 2002

22. Donadelli R, Zanchi C, Morigi M, Buelli S, Batani C, Tomasoni S, Corna D, Rottoli D, Benigni A, Abbate M, Remuzzi G, Zoja C: Protein overload induces fractalkine upregulation in proximal tubular cells through nuclear factor kappaB- and p38 mitogen-activated protein kinase-dependent pathways. Journal of American Society Nephrology 14:2436-2446, 2003 
23. Hannken $T$, Schroeder $\mathbb{R}$, Zahner $G$, Stahl $R A$, Wolf $G$ : Reactive oxygen species stimulate $\mathrm{p} 44$ / 42 mitogen-activated protein kinase and induce p27(Kip1): rolle in angiotensin II-mediated hypertrophy of proximal tubular cells. Joumal of American Society Nephrology 11:1387-1397, 2000

24. Nishikibe $M$, Ohta $H$, Okada $M$, Ishikawa $K$, Hayama $T$, Fukuroda $T$, Noguchi K, Saito M, Kanoh T, Ozaki S, Kamei T, Hara K, William D, Kivlighn S, Krause S, Gabel R, Zingaro G, Nolan N, O'Brien J, Clayton F, Lynch J, Pettibone D, Siegl P: Pharmacological properties of J-104132 (L-753,037), a potent, orally active, mixed ETA/ETB endothelin receptor antagonist. J Pharmacol Exp Ther 289:1262-1270, 1999

25. Brehm BR, Klaussner M, Wolf SC: Chronic elevated endothelin-1 concentrations regulate mitogen-activated protein kinases ERK 1 and ERK 2 in vascular smooth muscle cells. Clin Sci (Lond) 103 Suppl 48:137S-140S, 2002

26. Morigi M, Buelli S, Angioletti S, Zanchi C, Longaretti L, Zoja C, Galbusera M, Gastoldi S, Mundel P, Remuzzi G, Benigni A: In response to protein load podocytes reorganize cytoskeleton and modulate ET-1 gene: implication for permselective dysfunction of chronic nephropathies. Am J Pathol:In press, 2005

27. Oshima T, Laroux FS, Coe LL, Morise Z, Kawachi S, Bauer P, Grisham MB, Specian RD, Carter P, Jennings S, Granger DN, Joh T, Alexander JS: Interferongamma and interleukin-10 reciprocally regulate endothelial junction integrity and barrier function. Microvasc Res 61:130-143, 2001 
28. Quehenberger $P$, Bierhaus $A$, Fasching $P$, Muellner $C_{i}$ Klevesath $M$, Hong $M$, Stier G, Sattler M, Schleicher E, Speiser W, Nawroth PP: Endothelin 1 transcription is controlled by nuclear factor-kappaB in AGE-stimulated cultured endothelial cells. Diabetes 49:1561-1570, 2000

29. Kawana M, Lee ME, Quertermous EE, Quertermous T: Cooperative interaction of GATA-2 and AP1 regulates transcription of the endothelin-1 gene. Mol Cell Biol 15:4225-4231, 1995

30. Nakamura A, Johns E]. Imaizumi A, Yanagawa Y, Kohsaka T: Activation of beta(2)-adrenoceptor prevents shiga toxin 2-induced TNF-alpha gene transcription. Journal of American Society Nephrology 12:2288-2299, 2001

31. Ryoo SW, Kim DU, Won M, Chung KS, Jang YJ, Oh GT, Park SK, Maeng PJ, Yoo HS, Hoe KL: Native LDL induces interleukin-8 expression via $\mathrm{H} 2 \mathrm{O} 2$, p38 Kinase, and activator protein-1 in human aortic smooth muscle cells. Cardiovasc Res 62:185-193, 2004

32. Wang $T, H u$ YC, Dong $S$, Fan M, Tamae D, Ozeki M, Gao Q Gius D, Li J): Coactivation of ERK, NF-kappa B and GADD45beta in response to ionizing radiation. Journal Biological Chemistry, 2005

33. Carter $\mathrm{AB}$, Knudtson $\mathrm{KL}$, Monick MM, Hunninghake GW: The p38 mitogenactivated protein kinase is required for NF-kappaB-dependent gene expression. The role of TATA-binding protein (TBP). Journal Biological Chemistry 274:30858-30863, 1999

34. Goebeler M, Gillitzer R, Killian K, Utzel K, Brocker EB, Rapp UR, Ludwig S: Multiple signaling pathways regulate NF-kappaB-dependent transcription of 
the monocyte chemoattractant protein-1 gene in primary endothelial cells. Blood 97:46-55, 2001

35. Yamamoto $T$, Nagayama $K$, Satomura $\mathbb{K}$, Honda $T$, Okada S: Increased serum IL-10 and endothelin levels in hemolytic uremic syndrome caused by Escherichia coli O157. Nephron 84:326-332, 2000

36. Siegler RL, Edwin SS, Christofferson RD, Mitchell MD: Endothelin in the urine of children with the hemolytic uremic syndrome. Pediatrics 88:1063-1066, 1991

37. Wilkes BM, Susin M, Mento PF, Macica CM, Girardi EP, Boss E, Nord EP: Localization of endothelin-like immunoreactivity in rat kidneys. Am J Physiol 260:F913-920, 1991

38. Sorokin A, Kohan DE: Physiology and pathology of endothelin-1 in renal mesangium. Am J Physiol Renal Physiol 285:F579-589, 2003

39. Sakiri R, Ramegowda B, Tesh VL: Shiga toxin type 1 activates tumor necrosis factor-alpha gene transcription and nuclear translocation of the transcriptional activators nuclear factor-kappaB and activator protein-1. Blood 92:558-566, 1998

40. Zoja C, Angioletti S, Donadelli R, Zanchi C, Tomasoni S, Binda E, Imberti B, te Loo M, Monnens L, Remuzzi G, Morigi M: Shiga toxin-2 triggers endothelial leukocyte adhesion and transmigration via NF-kappaB dependent upregulation of IL-8 and MCP-1. Kidney International 62:846-856, 2002

41. Mercurio F, Zhu H, Murray BW, Shevchenko A, Bennett BL, Li J, Young DB, Barbosa M, Mann M, Manning A, Rao A: IKK-1 and IKK-2: cytokine-activated IkappaB kinases essential for NF-kappaB activation. Science 278:860-866, 1997 
42. Foster GH, Armstrong CS, Sakiri R, Tesh VL: Shiga toxin-induced tumor necrosis factor alpha expression: requirement for toxin enzymatic activity and monocyte protein kinase $C$ and protein tyrosine kinases. Infection and Immunity 68:5183-5189, 2000

43. Shirato I: Podocyte process effacement in vivo. Microsc Res Tech 57:241-246, 2002

44. Ito K, Ger YC, Kawamura S: Actin filament alterations in glomerular epithelial cells of adriamycin-induced nephrotic rats. Acta Pathol Jpn 36:253-260, 1986

45. Lachapelle $\mathrm{M}$, Bendayan M: Contractile proteins in podocytes: immunocytochemical localization of actin and alpha-actinin in normal and nephrotic rat kidneys. Virchows Arch B Cell Pathol Incl Mol Pathol 60:105-111, 1991

46. Takenouchi H, Kiyokawa N, Taguchi T, Matsui J, Katagiri YU, Okita H, Okuda K, Fujimoto J: Shiga toxin binding to globotriaosyl ceramide induces intracellular signals that mediate cytoskeleton remodeling in human renal carcinoma-derived cells. J Cell Sci 117:3911-3922, 2004

47. Platek A, Mettlen M, Camby I, Kiss R, Amyere M, Courtoy PJ: v-Src accelerates spontaneous motility via phosphoinositide 3-kinase, phospholipase $C$ and phospholipase $D$, but abrogates chemotaxis in Rat-1 and MDCK cells. J Cell Sci 117:4849-4861, 2004

48. Kawanabe $Y$, Okamoto $Y$, Nozaki K, Hashimoto $N_{s}$ Miwa S, Masaki T: Molecular mecharism for endothelin-1-induced stress-fiber formation: 
analysis of $G$ proteins using a mutant endothelin(A) receptor. Mol Pharmacol $61: 277-284,2002$

49. Imamura $\mathrm{T}$, Huang J, Dalle $\mathrm{S}$, Ugi S, Usui I, Luttrell LM, Miller WE, Lefkowitz RJ, Olefsky JM: beta -Arrestin-mediated recruitment of the Src family kinase Yes mediates endothelin-1-stimulated glucose transport. Journal Biological Chemistry $276: 43663-43667,2001$ 


\section{LEGEND TO FIGURES}

Figure 1. ET-1 mRNA expression and protein synthesis in podocytes exposed to Stx-2.

(A) Northern blot experiments were performed using total RNA isolated from podocytes exposed to medium alone (control), $S t x-2(50 \mathrm{pM}, 1 \mathrm{nM})$ for 3,6 and $24 \mathrm{~h}$. The results are representative of 5 independent experiments. The optical density of the autoradiographic signals was quantified and calculated as the ratio of ET-1 to $\beta$-actin mRNA. Results (mean \pm SE) are expressed as fold increase over control (considered as 1) in densitometric arbitrary units. ${ }^{*} \mathrm{p}<0.05^{* *} \mathrm{p}<0.01$ vs control.

(B) Stx-2 stimulates ET-1 production by podocytes. Podocytes were incubated with medium alone, Stx-2 $(50 \mathrm{pM}, 1 \mathrm{nM})$ for $6,15,24$ and $48 \mathrm{~h}$. ET-1 production was measured in cell supernatants by RIA. The results are representative of 3 independent experiments. Data are expressed as mean \pm SE. * $\mathrm{p}<0.01$ vs control.

Figure 2. Activation of NF-kB and Ap-1 in podocytes exposed to Stx-2.

(Top) Electrophoretic mobility shift assay (EMSA) for NF-kB (A) and Ap-1 (B) was performed in nuclear extracts of podocytes exposed for $30 \mathrm{~min}$ to medium alone, Stx-2 (50 pM, $1 \mathrm{nM})$. To confirm the specificity of the binding reaction, a 100-fold molar excess unlabeled (cold) nucleotide was used to compete with the labeled NF-kB or AP-1 probes for binding to nuclear proteins. The results are representative of 3 independent experiments employing different nuclear extracts. (Bottom) Densitometric analysis of 
autoradiographic signals of NF-kB (A) and AP-1 (B). Results are mean \pm SE. p $\mathrm{p}<0.05$ vs control.

Figure 3. ET-1 mRNA upregulation induced by Stx-2 is inhibited by adenovirus-mediated dominant negative mutant of IKK 2 or by Ap-1 decoy ODN.

(A) Cells were left untreated or infected for $3 \mathrm{~h}$ with a recombinant adenovirus coding for a dominant kinase-negative mutant of IKK2 (AdVdnIKK2) or with a control adenovirus (AdV-0) and then were maintained in serum free medium for $24 \mathrm{~h}$ before incubation with medium alone or Stx-2 $(50 \mathrm{pM})$ for $24 \mathrm{~h}$. Cells were processed for ET- $1 \mathrm{mRNA}$ expression by real time PCR. The results shown are mean \pm SE of 3 independent experiments. ${ }^{*} \mathrm{p}<0.05,{ }^{* *} \mathrm{p}<0.01$ vs control; ${ }^{\circ 0} \mathrm{p}<0.01$ vs AdV $-0+5 \mathrm{tx}-2$

(B) Ap-1 decoy ODN or mutated control ODN were added to podocytes $2 \mathrm{~h}$ before incubation with medium alone or Stx-2 (50 pM) for $6 \mathrm{~h}$. ET-1 mRNA was assessed by real time PCR. The results shown are mean \pm SE of 3 independent experiments. ${ }^{* *} \mathrm{p}<0.01$ vs control; ${ }^{\circ} \mathrm{p}<0.05$ vs control ODN $+S t x-$ 2.

Figure 4. Stx-2 activates $p 38$ and $p 42 / 44$ MAPK instrumental for NF- $k B$ activation. Activation of $\mathrm{p} 38$ (A) and $\mathrm{p} 42 / 44$ (B) in podocytes exposed to Stx-2 (50 pM) for 15, 30, 60 and $180 \mathrm{~min}$. Cell lysates were analyzed by Western blot using antibodies against the phosphorylated form of each MAPK. The blots were 
stripped and reprobed with anti-nonphosphorylated p38 or p42/44 antibodies to confirm equal loading of the proteins on the gel.

(C) Effect of pharmacological inhibition of $\mathrm{p} 38$ and $\mathrm{p} 42 / 44$ MAPK on Stx-2induced NF-kB-dependent promoter activity. Podocytes were transfected for $3 \mathrm{~h}$ with NF- $\mathrm{kB}$ luciferase reporter gene. Then cells were maintained in serum free medium for $15 \mathrm{~h}$ before exposure to $S t x-2(50 \mathrm{pM})$ for additional $6 \mathrm{~h}$. The p38 inhibitor SB-202190 (20 $\mu \mathrm{M})$ and the p42/44 inhibitor PD-98059 $(10 \mu \mathrm{M})$ were added $1 \mathrm{~h}$ before and during stimulation with Stx-2. Relative luciferase activity is expressed as fold stimulation by assuming control as 1. Data are mean $\pm \mathrm{SE}$ (three experiments). ${ }^{*} \mathrm{p}<0.01$ vs control; ${ }^{\circ} \mathrm{p}<0.01$ vs Stx2.

Figure 5. Stx-2 induces cytoskeletal F-actin redistribution and gap formation via $\mathrm{ET}_{\mathrm{A}}$ receptor. Immunofluorescence staining of F-actin fibers in podocytes stimulated for $15 \mathrm{~h}$ with medium alone (A), Stx-2 (50 pM) (B-C), Stx-2 in the presence of J$104132(1 \mathrm{nM})$, an $\mathrm{ET}_{\mathrm{A}} / \mathrm{ET}_{\mathrm{B}}$ receptor antagonist $(\mathrm{D})$, or LU-302146 $(1 \mu \mathrm{M})$, an $\mathrm{ET}_{\mathrm{A}}$ receptor antagonist $(\mathrm{E})$. Each $\mathrm{ET}-1$ receptor antagonist was added 1 $h$ before and during the incubation with Stx-2. In unstimulated cells F-actin microfilaments are arranged in parallel, whereas Stx-2 leads to F-actin redistribution at the cell periphery in association with gap formation. Both agents prevent cytoskeletal redistribution and gaps. Magnification $600 \mathrm{X}$. 
The number of gaps was counted in fifteen random fields for each sample and the results are expressed as mean $\pm \mathrm{SE}$ (seven experiments) (F). ${ }^{*} \mathrm{p}<0.01$ vs control; " ${ }^{\circ}<0.01$ vs Stx-2.

Figure 6. Effect of exogenous ET-1 on cytoskeletal F-actin distribution and albumin permeability in podocytes.

Immunofluorescence staining of F-actin fibers in podocytes exposed for $6 \mathrm{~h}$ to control medium (A) or ET-1 (100 nM) (B). ET-1 promotes changes in cytoskeleton distribution leading to F-actin rearrangement at the cell periphery and intercellular gap formation. Magnification X600.

(C) The permeability index reflecting transepithelial passage of fluorescent albumin to the basolateral compartment of the bicameral chamber is increased in cells exposed to ET-1 (100 nM) for $6 \mathrm{~h}$ ( $\mathrm{n}=3$ experiments). ${ }^{*} \mathrm{p}<0.01$ vs control. 


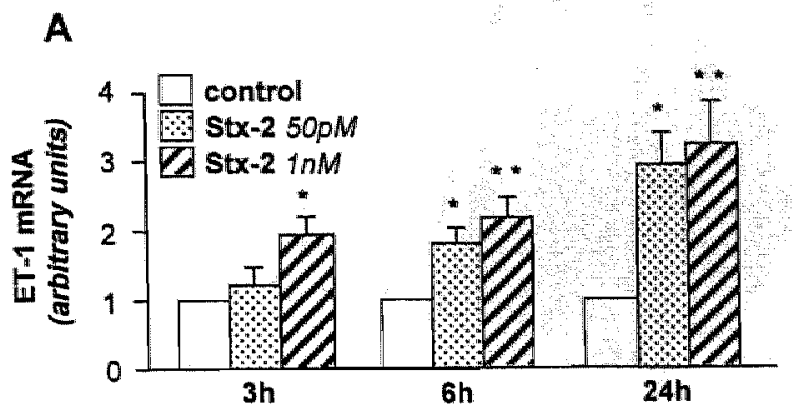

B

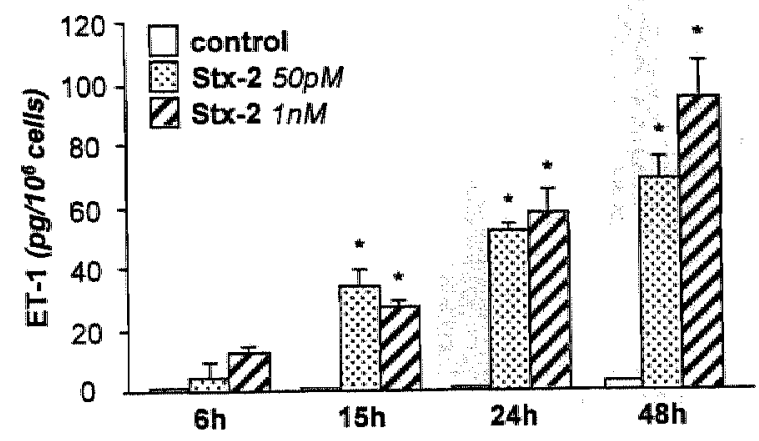

Figure 1 

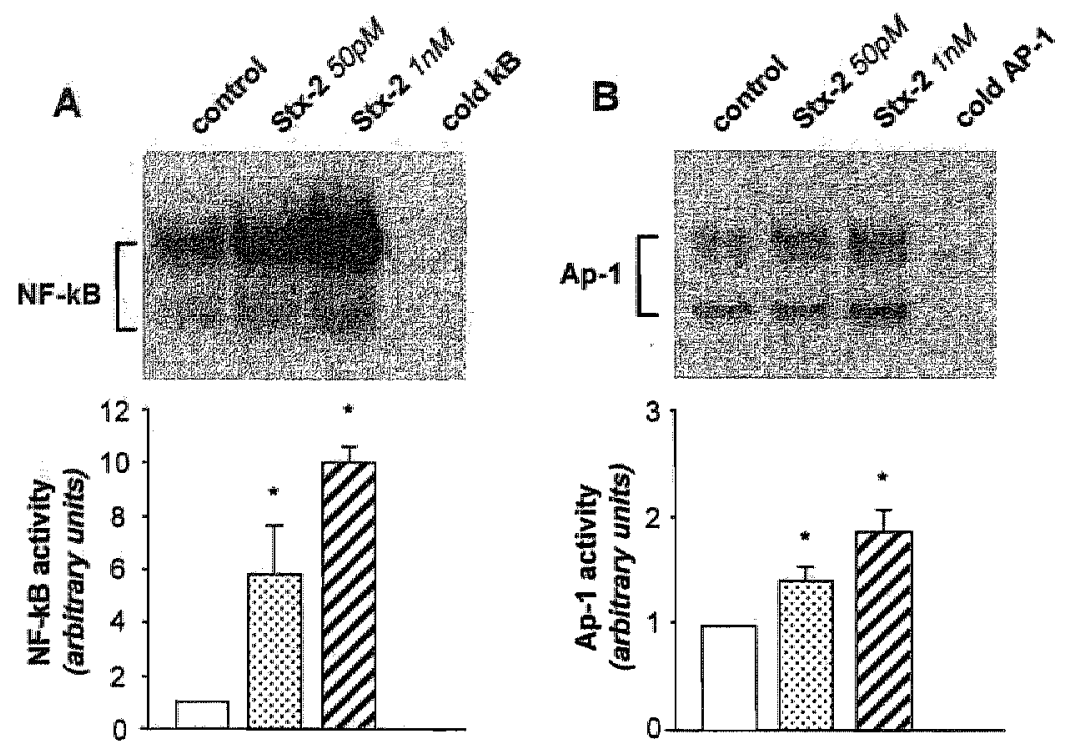

Figure 2 
A
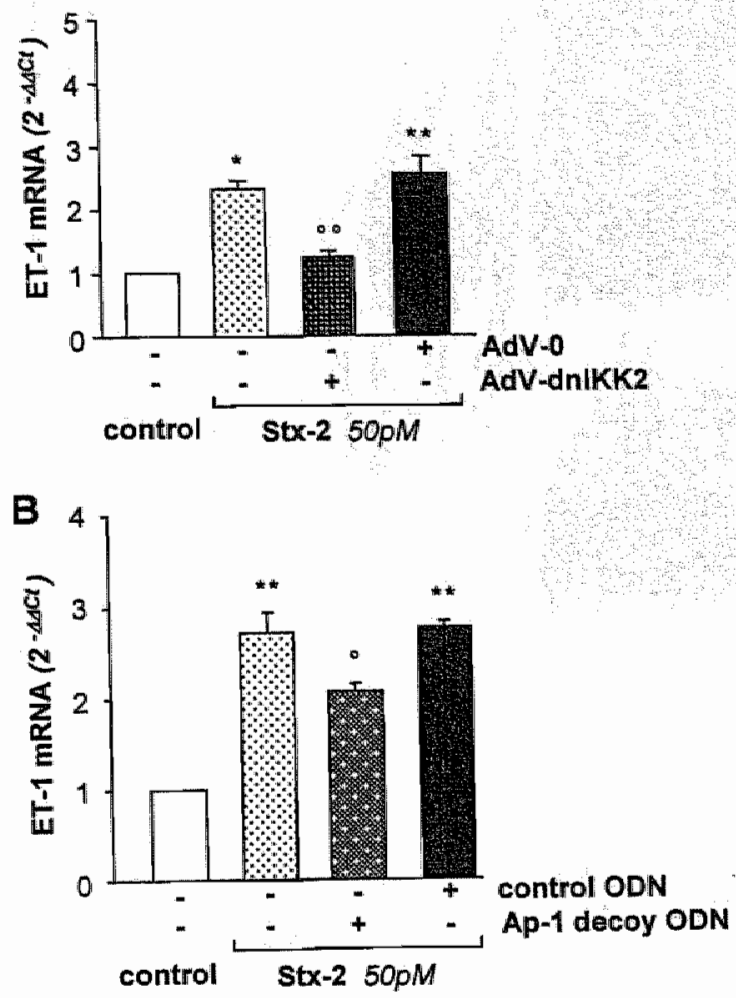

Figure 3 

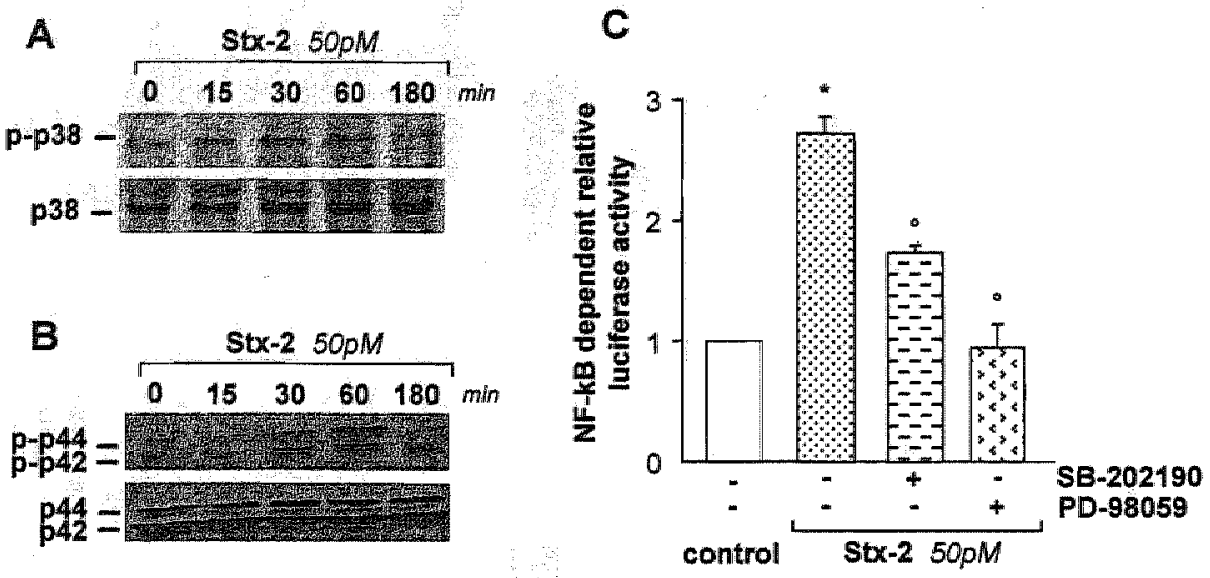

Figure 4 

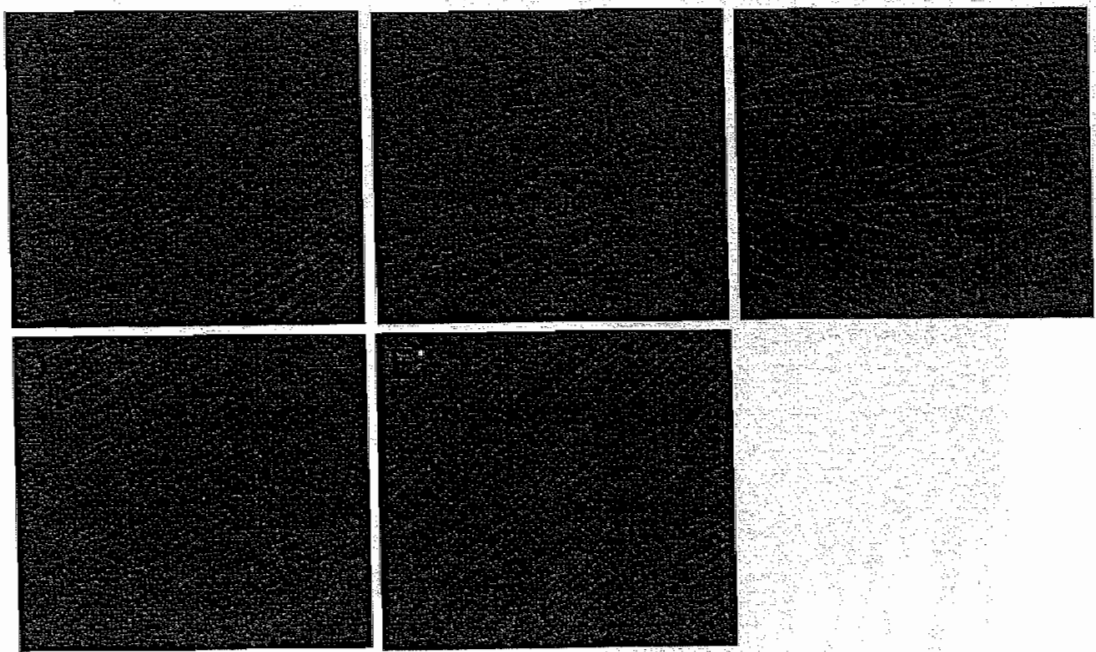

F

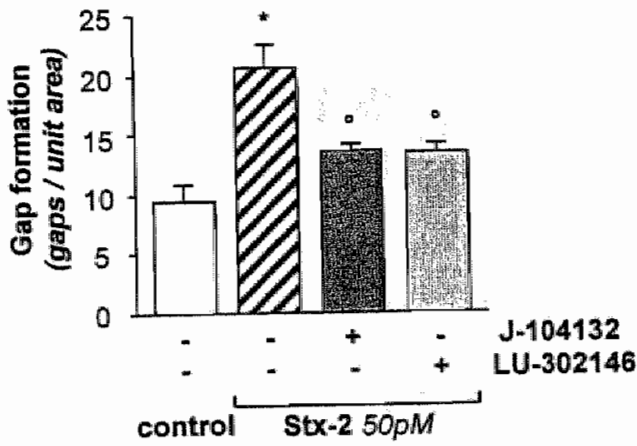

Figure 5 


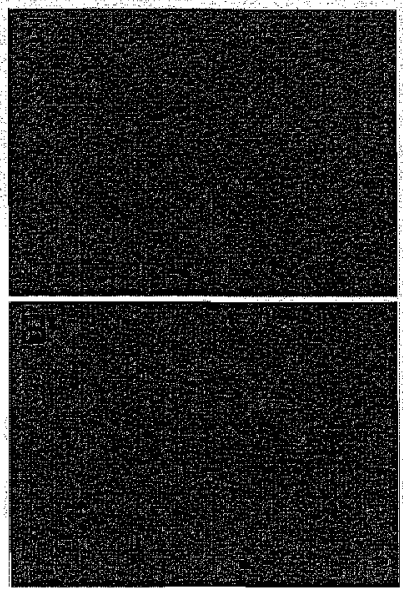

$\mathrm{e}$

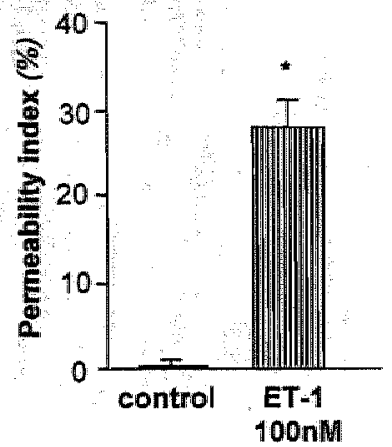

Figure 6 
CHAPTER 8

GENERAL DISCUSSION 


\section{GENERAL DISCUSSION}

In D+HUS, the pathological hallmark of Stx-mediated tissue injury is the development of vascular lesions in renal and other target organs in which endothelial cells are swollen and detached from the underlying basement membranes. Several evidence indicate that leukocyte as well as platelet activation participate in endothelial damage (Chapter 2).

In Chapter 3 of the present thesis it has been documented that exposure of human umbilical vein endothelial cells (HUVEC) to VT-1 induced a dose-dependent increase in the number of leukocytes that stable adhered to endothelium under flow conditions that mimic post-capillary venule circulation. The adhesion response by VT-1 was quite comparable to that of IL-1 $\beta$, one of the most potent inducers of leukocyte/endothelium interaction. The events that modulate the adhesion and infiltration of leukocytes into the endothelium are critically dependent on the adhesive molecules and chemokines possibly expressed on the surface of the endothelium/leukocytes, or induced by circulating cytokines and flow condition [1]. Early molecules involved in the process of leukocyte rolling belong to the selectin family [2, 3]. Firm leukocyte adhesion and consequent transmigration implies the involvement of leukocyte $\beta 2$ and $\beta 1$ integrin receptors with specific endothelial ligand, i.e., Intercellular adhesion molecule-1 (ICAM-1) and vascular adhesion molecule-1 (VCAM-1), belonging to the Immunoglobulin $G$ (IgG) gene superfamily [4]. Experiments with functional blocking antibody have demonstrated that the adhesive response elicited by VT-1 was dependent on the upregulation on endothelial surface of the adhesive molecules E-selectin, ICAM-1 and VCAM-1. The concept that leukocytes have a key role in the pathogenesis of microvascular lesions of D+HUS rests on the evidence that the degree of leukocytosis may be predictive for the outcome of the disease [5]. Neutrophils isolated from patients during the acute phase of the disease, are 
activated [6], adhere to endothelium more avidly than neutrophils from healthy subjects, and damage the endothelium by producing elastase [7] and superoxide [8]. In addition, ultrastructural examination of renal biopsies from HUS patients with evidence of VTproducing E.coli infection, revealed the presence of polymorphonuclear and mononuclear cell infiltration at glomerular level [9], along with microvascular injury.

In the present study, giving TNF $\alpha$ before challenge with VT-1 significantly increased the number of adherent leukocytes under flow in respect to cells challenged with the toxin alone. These data may be explained by the observation that TNF $\alpha$-a cytokine mainly produced by VT-activated monocytes/macrophages- upregulated the endothelial expression of $\mathrm{Gb} 3$, the specific endothelial receptor of $\mathrm{VT}-1$, and increased $\mathrm{VT}-1$ binding [10]. An important role of TNF in toxin-mediated microvascular injury derives from the finding that mice genetically defective in TNF $\alpha$ production were less sensitive to the lethal effect of $\mathrm{VT}-1$ [11] and have a longer time to death in respect to control mice. Thus damage to blood vessels in VT-producing E.coli infections might be caused in part by the action of leukocytes secondary to the role of $V T$ in upregulating vascular adhesion proteins.

Relevant to better understanding the nature of the adhesive phenomena triggered by Stx2. may be the data presented in Chapter 4 that described the effect of the toxin on endothelial expression of the chemoattractant proteins IL-8 and MCP-1, and their functional role on leukocyte adhesion and transmigration across the endothelium. We observed that subtoxic concentrations of Stx significantly increase the number of leukocytes, mainly polymorphonuclear cells, that adhered and then transmigrated through HUVEC monolayer under flow. Challenge of glomerular endothelial cells with Stx-2 induced massive adhesion and transmigration to a similar extent than that observed on 
HUVEC, thus suggesting that both cell types exhibited a similar sensitivity to the toxin, which possibly stimulated identical intracellular signals involved in the adhesive phenomena.

Evidence is available that in HUS patients, urinary levels of $\mathrm{KL}-8$ and MCP-1 were significantly increased during the acute phase of the disease and decreased until recovery, implying a role of these chemokines in the recruitment of inflammatory cells at glomerular levels $[12,13]$. In this respect, we focused our attention on these chemokines and we found a strong expression of $L L-8$ and MCP-1 MRNA after a short exposure of HUVEC to Stx-2. The functional role of both chemokines in the adhesive process evoked by Stx-2 rests on data that blocking antibodies against $\mathrm{LL}-8$ and MCP-1 -that drive recruitment and activation of neutrophils and monocytes, respectively- significantly reduced the adhesion and subendothelial transmigration of distinct leukocyte subsets in HUVEC, as well as in glomerular endothelial cells treated with the toxin. It is known that these chemokines may trigger leukocyte adhesive process either as soluble proteins or as immobilized molecules bound to heparan sulfate proteoglycans of the endothelial surface of post- capillary venules and small veins $[14,15]$. Reports have clearly demonstrated that in a model of monocytes rolling on adenovirally mediated E-selectin transduced endothelial cells under flow condition, IL-8 and MCP-1 caused stable adhesion of monocytes to the endothelium through the activation of leukocyte integrins [16].

Since molecular studies have identified NF-kB binding sites within the promoter region of both IL-8 and MCP-1 $[17,18]$ we investigated whether Stx-2 induced chemokine expression through a transcriptional activation mechanism mediated by NF-kB. This transcription factor belongs to Rel family and exists in an inactive form in the cell cytoplasm bound to the inhibitory protein IkB. Upon activation by different stimuli, NF-kB translocates into the nucleus for binding to DNA motifs in gene promoters [19]. We found that challenge 
of endothelial cells with Stx-2 elicited a substantial rise in NF-kB binding activity and that the subunits involved were p65/p50 heterodimer and p50/p50 homodimer. These findings are consistent with a previous study showing that Stx-1 treatment of human monocytes resulted in activation and subsequent nuclear translocation of NF-kB, an event that preceded cytokine gene induction [20]. That upregulation of IL-8 and MCP-1 in Stx-treated endothelium is dependent on NF-kB activation was proven by our data that overexpression of $\mathrm{IKB} \alpha$, the specific inhibitor of NF-kB, produced by transfecting endothelial cells with adhenovirus encoding $I K B \alpha$, fully suppressed the property of the toxin of inducing the expression of both chemokines by endothelial cells. As expected, delivery of $\mathrm{lkB} \alpha$ also inhibited the adhesion and transmigration of leukocytes in Stx-treated HUVEC. Altogether these data might be relevant to understand the role of adhesive molecules and chemokines in promoting leukocyte-endothelium interaction which favors microvascular lesions in D+HUS and could help to identify novel molecular targets for therapeutic intervention.

Thrombocytopenia and formation of renal thrombi in the microcirculation are characteristic lesions of D+HUS. The mechanism by which these thrombi are formed is unclear, and several conflicting reports have investigated the potential interactions of VT with platelets $[21,22]$. In Chapter 5 we addressed the possibility that VT-1 could directly modulate antithrombogenic properties of the endothelium under high shear stress typically present in the microcirculation. We have demonstrated that VT-1 was a potent promoter of platelet adhesion and thrombus formation on cultured endothelial cells perfused with whole blood in a flow chamber system under high shear stress levels. The effect of VT-1 was higher than that of thrombogenic agonists such as thrombin and cytokines. Microvascular endothelial cells -of dermal origin- demonstrated a remarkably greater sensitivity to the 
thrombogenic effect of VT-1 than endothelum derived from large vessels (HUVEC), possibly because they expressed higher levels of Stx receptors (20-fold more). Similar expression of Gb3 receptor was described on renal microvascular endothelial cells [23]. which may account for the different sensitivity of different vascular districts to VT-induced iniury.

In order to identify the adhesive proteins involved in thrombus formation ellcited by StX on microvascular endothelial cells, we first focused on von Willebrand factor (WWF) an indispensable adhesive substrate to promote thrombus formation in high shear stress environments [24]. We observed that polymeric aurin tricarboxylic acid, an inhibitor of WWF-platelet GPIb interaction, and chimeric 7E3 Fab which blocks $\alpha_{116}-\beta_{3}$ on activated platelets, completely prevented platelet deposition and thrombus formation, suggesting the involvement of WWF-platelet interaction at high shear stress in this phenomenon. These findings are consistent with the evidence, in a different experimental setting, that the mechanism supporting platelet adhesion and thrombus formation requires binding of GPIb to WWF at high shear stress [24]. The engagement of this receptor determines activation of the $\alpha_{41}-\beta_{3}$ receptor that in turn promotes irreversible platelet adhesion by interacting with the RGD sequence of WWF. We also provided the observation that upon endothelial exposure to VT-1, WWF-mediated platelet deposition occurred mainly on endothelial surface rather than in the subendothelium. Based on the evidence that WWF can interact with endothelial $\beta_{3}$ integrin subunit, the vitronectin receptor [25], via RGD sequence, we have documented that VT-1 induced on the luminal endothelial surface upregulation and/or redistribution of the vitronectin receptor. Functional blocking of this endothelial ligand almost completely prevented platelet deposition, thus suggesting that the toxin possibly alters endothelial thromboresistance by inducing changes in the surface expression of 
vitronectin receptor that in turn leads to platelet adhesion via a vWF-dependent bridging mechanism. On the other hand, functional blockade of endothelial P-selectin and PECAM1 with specific antibodies was associated with a marked reduction of the endothelial area covered by thrombi under flow condition. As for the prothrombotic role of both adhesive proteins, previous studies documented their involvement in the process of platelet adhesion on activated or damaged endothelium by their direct binding to platelets $[26,27]$. Thus, in a model of ischemia/reperfusion injury endothelial overexpression of P-selectin was instrumental for the process of platelet rolling and deposition [28]. The proof of a direct contribution of endothelial PECAM-1 to platelet adhesion derives from data that in a model of laser-induced endothelial injury in brain arterioles, anti-PECAM-1 antibody reduced microvascular thrombosis over damaged but not denuded endothelium [27]. In our experimental condition, the thrombogenic effect of P-selectin and PECAM-1 was associated with an increased expression of P-selectin, and redistributed PECAM-1 away from cell-cell border of VT-1-treated endothelial cells, thus indicating that alteration of endothelial adhesion molecule expression induced by $V T-1$ is a critical step in enhancing platelet adhesion and thrombus formation in microvascular endothelium. In conclusion, our results might be relevant to understand why thrombi in HUS localize in microvessels rather than in larger ones and could help to formulate therapeutic strategies to prevent endothelial injury without the need to suppress platelet function.

In D+HUS renal susceptibility has been ascribed to the relatively high levels of $G b 3$ receptor expressed by this tissue. Ischemic lesions in the glomerular microcirculation typically occur in association with fusion of foot process and swelling of podocytes [29]. Studies directed at understanding the role of podocytes in the toxic response of Stx-2 are discussed in Chapter 7. We reasoned that podocytes in virtue of their susceptibility to the toxic effect of the toxin and the capability to produce vasoactive mediators could have an 
impact in glomerular microcirculation and account for renal functional derangement in Stxassociated HUS.

Propedeutic to this study was a previous paper - described in Chapter 6 - focused on the mechanisms underlying podocyte phenotypic changes induced by protein overload, and ultimately leading to cell dysfunction. In many proteinuric nephropathies, proteins filtered in exuberant amounts through the glomerular capillary barrier may have an intrinsic renal toxicity and serve as an early trigger of tubular interstitial inflammation [30]. Ultrafiltered plasma proteins also induced morphological changes in podocytes, which include reversible retraction and flattening of the epithelial foot processes suggesting podocyte/glomerular basement membrane (GBM) interaction to be of critical relevance to functional filter. We documented that in murine podocytes in culture, the abnormal uptake of plasma proteins, albumin and Immunoglobulin $\mathrm{G}(\mathrm{lgG})$, induced a marked redistribution of F-actin fibers accompanied by loss of synaptopodin, an F-actin-associated protein considered a specific marker of podocyte differentiation [31]. This effect would be taken to suggest that protein accumulation at glomerular level triggers podocyte dedifferentiation, a phenomenon already described in vivo in areas of segmental sclerosis [32]. F-actin is connected with adaptor molecules that anchor the slit diaphragm proteins and $\alpha 3 \beta 1$ integrins, transmembrane proteins that form focal adhesion complexes and mediate podocyte/GBM matrix interaction [33]. Cytoskeletal rearrangement affects cell adhesion to matrix with consequent activation of out-side in signals that trigger specific cellular responses and lead to activation of gene expression of inflammatory and vasoactive mediators [34]. Consistently, we found that the F-actin redistribution induced by protein load was instrumental to the upregulation of the vasoactive peptide Endothelin -1 (ET-1) in parallel with the generation of the protein. Increased DNA-binding activity of the transcription factors NF-kB and Ap-1, known to regulate ET-1 gene expression, were also 
measured in nuclear extracts of podocytes exposed to excess proteins. Furthermore, treatment of podocytes with an inhibitor of Rho kinases - crucial in the formation of stress fibers and focal adhesion complex [35] - markedly decreased NF-kB and Ap-1-dependent ET-1 gene upregulation, thus suggesting that podocytes in proteinuric setting are an important source of ET-1 regulated via Rho dependent-cytoskeleton signal transduction pathway of gene activation. These data are in line with previous reports in vitro of the involvement of Rho-GTPase family in modulating basal expression of ET-1 transcript levels in vascular endothelial cells and also in regulating NF-kB and Ap-1 in genetically modified cultured fibroblasts $[36,37]$. Finally, we assessed the role of focal adhesion kinase (FAK) a cytoplasmic non receptor tyrosine kinase localized in integrin-extracellular matrix complexes [33] - that acts as an effector molecule linking actin reorganization with transcriptional events. Results showed that FAK is phosphorylated by protein treatment and that FAK signaling contributes to ET-1 gene regulation to the extent that transient overexpression by adenoviral gene transfer of FAK-related non kinase, an endogenous inhibitor of FAK activity, resulted in a partial but significant inhibition of ET-1. These data suggest that reorganization of cytoskeletal network in response to protein load plays a central role in the cascade of intracellular events that lead to podocyte dysfunction and ET-1 gene regulation.

On the basis of this study, and once verified that murine podocytes effectively represent an important source of ET-1, as also described by other groups for rat podocytes [38], we moved to investigate (Chapter 7) possible mechanisms evoked by Stx that could contribute to podocyte phenotipic alteration and ET-1 gene expression. We focused on the vasoconstrictor peptide ET-1 found to be elevated in plasma and urine of children during the acute phase of D+HUS [39]. Our results indicate that Stx-2 at subtoxic concentrations, increased mRNA transcript levels of ET-1 which was followed by the enhanced synthesis 
of the mature peptide. The relevance of this finding rests on the evidence that $E T-1$, if produced at glomerular level, may induce cell proliferation, chemotaxis, extracellular matrix accumulation and may stimulate the contraction of mesangial cells, regulating glomerular capillary surface area and filtration rate [40] .

An important aspect of this study has been the identification of intracellular pathways activated by $S t x-2$ and involved in ET-1 overexpression in podocytes. Our data showed that Stx-2 induced a rapid and massive activation of the transcription factor NF-kB and to lesser extent of Ap-1. The direct demonstration that NF-kB and Ap-1 modulates ET-1 gene expression derives from experiments where transfection of podocytes with dominant negative mutant of IKB kinase2 or with Ap-1 decoy oligodeoxynucleotide failed to increase ET-1 mRNA transcript levels in response to the toxin. The present results indicate that the Stx-2, besides the capability to activate NF-kB-dependent inflammatory genes in glomerular endothelial cells, responsible of leukocyte recruitment and endothelial injury, is also able to activate glomerular podocytes to express NF-kB dependent vasoactive genes that might contribute to renal function impairment in HUS patients.

Furthermore, the involvement of p38 and p42/44 MAPK in mediating NF-kB dependent gene transcription rests on data that Stx-2 phosphorylated/activated p38 and p42/44 MAPK and that inhibitors of both kinases decreased the transcription of NF-kB promoter/luciferase reporter gene construct induced by Stx-2. In line with our results, other studies have implicated p38 and p42/44 MAPK activation in Stx-induced NFkB-dependent gene expression of TNF in human adenocarcinoma-derived renal tubular cell line [41]. Another important finding that arises from this study is that the toxin caused a marked redistribution of the contractile F-actin apparatus accompanied by intercellular gap formation, reflecting podocyte process retraction. In wivo, podocyte cytoskeletal derangement results in foot process effacement and cell retraction, characteristic adaptive 
changes in a wide variety of human and experimental glomerulopathies with heavy proteinuria and renal function impairment [42]. Data that an $E T_{A}$ receptor antagonist prevented Stx-2 induced structural changes does suggest a role of ET-1 in the dysfunction of podocyte contractile apparatus. Of interest, ET-1 added exogenously to cultured podocytes determined morphological alterations similar to those of Stx-2 and increased protein permeability, thus implicating a modification of podocyte-podocyte contact.

In conclusion, our finding point to podocytes as critical targets of Stx-2, a novel stimulus for the synthesis of ET-1 that besides its autocrine action might exerts toxic effects in paracrine fashion by stimulating mesangial cell contraction and affecting the glomerular capillary surface area and filtration rate, thus contributing to glomerular ischemic changes and hemodynamic derangement in HUS. 


\section{REFERENCES}

1. Morigi $M$, Zoja $C$, Figliuzzi $M$, Foppolo $M$, Micheletti $G$, Bontempelli $M_{1}$ Saronni $M_{1}$ Remuzzi G, Remuzzi A: Fluid shear stress modulates surface expression of adhesion molecules by endothelial cells. Blood 85:1696-1703, 1995

2. Lawrence $M B$, Springer TA: Neutrophils roll on E-selectin J Immunol 151:63386346,1993

3. Alon $R$, Rossiter $H$, Wang $X$, Springer TA, Kupper TS: Distinct cell surface ligands mediate $T$ lymphocyte attachment and rolling on $P$ and $E$ selectin under physiological flow. J Cell Biol 127:1485-1495, 1994

4. Wuthrich RP: Intercellular adhesion molecules and vascular cell adhesion molecule1 and the kidney. J Am Soc Nephrol 3:1201-1211, 1992

5. Milford DV, Staten J, MacGreggor I, Dawes J, Taylor CM, Hill FG: Prognostic markers in diarrhoea-associated haemolytic-uraemic syndrome: initial neutrophil count, human neutrophil elastase and von Willebrand factor antigen. Nephrol Dial Transplant 6:232-237, 1991

6. Fitzpatrick MM, Shah V, Trompeter RS, Dillon MJ, Barratt TM: Interleukin-8 and polymorphoneutrophil leucocyte activation in hernolytic uremic syndrome of childhood. Kidney Int 42:951-956, 1992

7. Forsyth KD, Simpson AC, Fitzpatrick MM, Barratt TM, Levinsky RJ: Neutrophilmediated endothelial injury in haemolytic uraemic syndrome. Lancet $\|: 411-414$, 1989

8. King AJ, Sundaram $S$, Cendoroglo M, Acheson DW, Keusch GT: Shiga toxin induces superoxide production in polymorphonuclear cells with subsequent impairment of phagocytosis and responsiveness to phorbol esters. $J$ Infect Dis $179: 503-507,1999$ 
9. Inward CD, Howie AJ, Fitzpatrick MM, Rafaat F, Milford DV, Taylor CM: Renal histopathology in fatal cases of diamhoea-associated haemolytic uraemic syndrome. British Association for Paediatric Nephrology. Pediatr Nephrol 11:556-559, 1997

10. van de Kar NCAJ, Monnens LAH, Karmali MA, van Hinsbergh WWM: Tumor necrosis factor and interleukin-1 induce expression of the verocytotoxin receptor globotriaosylceramide on human endothelial cells: implications for the pathogenesis of the hemolytic uremic syndrome. Blood 80:2755-2764, 1992

11. Barrett TJ, Potter ME, Strockbine NA: Evidence for participation of the macrophage in Shiga like toxin-II induced lethality in mice. Microbial Pathogenesis 9:95-103, 1990

12. van Setten PA, van Hinsbergh $W W$, van den Heuvel LP, Preyers $F$, Dijkman $H B$, Assmann KJ, van der Velden TJ, Monnens LA: Monocyte chemoattractant protein-1 and interleukin-8 levels in urine and serum of patents with hemolytic uremic syndrome. Pediatr Res 43:759-767, 1998

13. Inward $C D$, Varagunam $M$, Adu $D$, Milford $D V$, Taylor $C M$ : Cytokines in haemolytic uraemic syndrome associated with verocytotoxin-producing Escherichia coli infection. Arch Dis Child 77:145-147, 1997

14. Luster AD: Chemokines--chemotactic cytokines that mediate inflammation. N Engl J Med 338:436-445, 1998

15. Webb LM, Ehrengruber MU, Clark-Lewis I, Baggiolini M, Rot A: Binding to heparan sulfate or heparin enhances neutrophil responses to interleukin 8. Proc Natl Acad Sci U S A 90:7158-7162, 1993

16. Gerszten RE, Garcia-Zepeda EA, Lim YC, Yoshida M, Ding HA, Gimbrone MA, Jr., Luster AD, Luscinskas FW, Rosenzweig A: MCP-1 and IL-8 trigger firm adhesion of monocytes to vascular endothelium under flow conditions. Nature 398:718-723, 1999

17. Kunsch C, Rosen CA: NF-kB subunit-specific regulation of the interleukin-8 promoter. Mol Cell Biol 13:6137-6146, 1993 
18. Ueda $A$, Okuda $K$, Ohno $S$, Shirai $A$, Igarashi $T$, Matsunaga $K$, Fukushima $J_{\text {, }}$ Kawamoto $S$, Ishigatsubo $Y$, Okubo T: NF-kappa $B$ and $S p 1$ regulate transcription of the human monocyte chemoattractant protein-1 gene. J Immunol 153:2052-2063, 1994

19. Tak PP, Firestein GS: NF-kappaB: a key role in inflammatory diseases. J Clin Invest $107: 7-11,2001$

20. Sakiri R, Ramegowda $B$, Tesh VL: Shiga toxin type 1 activates tumor necrosis factor-alpha gene transcription and nuclear translocation of the transcriptional activators nuclear factor-kappaB and activator protein-1. Blood 92:558-566, 1998

21. Karpman D, Papadopoulou D, Nilsson $K$, Sjogren AC, Mikaelsson $C$, Lethagen S: Platelet activation by Shiga toxin and circulatory factors as a pathogenetic. mechanism in the hemolytic uremic syndrome. Blood 97:3100-3108, 2001

22. Thorpe CM, Flaumenhaft R, Hurley B, Jacewicz M, Acheson DW, Keusch GT: Shiga toxins do not directly stimulate alpha-granule secretion or enhance aggregation of human platelets. Acta Haematol 102:51-55, 1999

23. Obrig TG, Moran TP, Brown JE: The mode of action of Shiga toxin on peptide elongation of eukaryotic protein synthesis. Biochemical Journal 244:287-294, 1987

24. Ruggeri ZM: von Willebrand factor. J Clin Invest 99:559-564, 1997

25. Cheresh DA: Human endothelial cells synthesize and express an Arg-Gly-Aspdirected adhesion receptor involved in attachment to fibrinogen and von Willebrand factor. Proc Natl Acad Sci U S A 84:6471-6475, 1987

26. Frenette PS, Johnson RC, Hynes RO, Wagner DD: Platelets roll on stimulated endothelium in vivo: an interaction mediated by endothelial P-selectin. Proc Natl Acad Sci U S A 92:7450-7454, 1995

27. Rosenblum WI, Nelson GH, Wormley B, Werner P, Wang J, Shih CC: Role of platelet-endothelial cell adhesion molecule (PECAM) in platelet adhesion/aggregation over injured but not denuded endothelium in vivo and ex vivo. Stroke 27:709-711, 1996 
28. Massberg $S$, Enders $G$, Leiderer $R$, Eisenmenger $S$, Vestweber $D$, Krombach $F$, Messmer K: Platelet-endothelial cell interactions during ischemia/reperfusion: the role of P-selectin. Blood 92:507-515, 1998

29. Striker GE, Striker LJ, D'Agati V: Renal Lesions in Hypertension, in The Renal Biopsy Major Problems in Pathology, edited by Livolsi VA, Third ed, Philadelphia, Saunders, W.B. Company, 1997, pp 258-268

30. Remuzzi G, Bertani T: Pathophysiology of progressive nephropathies. N Engl J Med $339: 1448-1456,1998$

31. Mundel P, Reiser J Zuniga Mejia Borja A, Pavenstadt $H$, Davidson GR, Kriz W, Zeller R: Rearrangements of the cytoskeleton and cell contacts induce process formation during differentiation of conditionally immortalized mouse podocyte cell lines. Exp Cell Res 236:248-258, 1997

32. Srivastava T, Garola RE, Whiting JM, Alon US: Synaptopodin expression in idiopathic nephrotic syndrome of childhood. Kidney Int 59:118-125, 2001

33. Kretzler $\mathrm{M}$ : Regulation of adhesive interaction between podocytes and glomerular basement membrane. Microsc Res Tech 57:247-253, 2002

34. Gonzalez-Santiago L, Lopez-Ongil $S$, Griera $M_{n}$ Rodriguez-Puyol $M$, RodriguezPuyol D: Regulation of endothelin synthesis by extracellular matrix in human endothelial cells. Kidney Int 62:537-543, 2002

35. Ridley AJ; Hall A: The small GTP-binding protein tho regulates the assembly of focal adhesions and actin stress fibers in response to growth factors. Ceil 70:389399,1992

36. Hernandez-Perera O, Perez-Sala D, Soria E, Lamas S: Involvement of Rho GTPases in the transcriptional inhibition of preproendothelin-1 gene expression by simvastatin in vascular endothelial cells. Circ Res 87:616-622, 2000

37. Van Aelst L, D'Souza-Schorey C: Rho GTPases and signaling networks. Genes Dev $11: 2295-2322,1997$ 
38. Cybulsky AV, Stewart DJ, Cybulsky MI: Glomerular epithelial cells produce endothelin-1. J Am Soc Nephrol 3:1398-1404, 1993

39. Siegler RL, Edwin SS, Christofferson RD, Mitchell MD: Endothelin in the urine of children with the hemolytic uremic syndrome. Pediatrics 88:1063-1066, 1991

40. Sorokin A, Kohan DE: Physiology and pathology of endothelin-1 in renal mesangium. Am J Physiol Renal Physiol 285:F579-589, 2003

41. Nakamura A, Johns EJ, Imaizumi A, Yanagawa $Y$, Kohsaka T: Activation of beta(2)adrenoceptor prevents shiga toxin 2-induced TNF-alpha gene transcription. J Am Soc Nephrol 12:2288-2299, 2001

42. Shirato I: Podocyte process effacement in vivo. Microsc Res Tech 57:241-246, 2002 
$\cdots$ 
CHAPTER 9

SUMMARY 


\section{SUMMARY}

Shiga toxins (Stx) has been strongly indicated as the causative agent for typical childhood $\mathrm{D}+$ HUS. The kidney is the privileged target of the toxin, with glomerular ischemic changes including tuft retraction and capillary wall thickening, both preceding microvascular thrombosis. Endothelial dysfunction is crucial to the development of microvascular lesions and increasing evidence suggests that StxNT by favoring interaction of endothelial cells with leukocytes and platelets, serve to amplify and extend the injury at renal level. Local thrombosis amplifies the inflammatory injury by promoting complement activation -in particular the alternative pathway- and deposition within capillary vessels (Chapter 2).

In this thesis further investigations where performed to address the renal toxicity of Stx with the aims of providing insights on the molecular events involved in microvascular lesions in HUS.

In Chapter 3 we investigated in vitro the effect of VT-1 on leukocyte adhesion to vascular endothelium under physiologic flow condition using a parallell plate flow chamber. Incubation of human umbilical vein endothelial cells (HUVEC) with increasing concentrations of VT-1 resulted in a dose-dependent increase in the number of adhering leukocytes to HUVEC. The adhesive response induced by the toxin was quite comparable to the effect of $1 \mathrm{~L}-1 \beta$, one of the most potent inducer of endothelial cell adhesiveness. Rolling phenomenon was not affected by VT-1. We then explored the role of adhesive molecules in VT-induced leukocyte adhesion. Functional blocking of E-selectin, ICAM-1 and VCAM-1 on endothelial cells with respective antibodies, significantly reduced VTinduced increase in leukocyte adhesion. Pre-exposure of endothelium with TNF $\alpha$ before challenge with VT-1, significantly increased the number of adherent leukocytes under flow. 
This observation is consistent with the finding that this cytokine does promote upregulation of endothelial Gb3 receptor and supports toxin-binding. These data identify a novel mechanism by which $V T$ directly modulates leukocyte-endothelium interaction, thus increasing leukocyte adhesion and upregulating adhesive proteins on endothelial surface membrane.

Kidney specimens from HUS children with evidence of Stx-producing $E$ coli infection revealed a massive infiltration of polymorphonuclear and mononuclear cells within the glomeruli, along with microvascular injury. Urinary levels of IL-8 and monocyte chemoattractant protein-1 (MCP-1), potent attractants of neutrophils, monocytes/macrophages and T lymphocytes, were elevated during the acute phase of the disease in these patients, suggesting the involvement of these chemokines in the recruitment of inflammatory cells at glomerular level. In Chapter 4, we tested the hypothesis that Stx-2 could modulate the endothelial expression of MCP-1 and IL-8 and their functional role on leukocyte adhesion and transmigration. We found that subtoxic concentrations of Stx-2 induced a significant increase in the number of leukocytes adhering to HUVEC, followed by a massive transmigration through the endothelium. MCP1 and IL-8 mRNA expression was increased after exposure to Stx-2. Blocking of endothelial MCP-1 and IL-8 with the corresponding antibodies significantly reduced Stxinduced leukocyte adhesion and migration either on HUVEC or glomerular endothelial cells. Adenovirus-mediated gene transfer of $1 \mathrm{kB} \alpha$ down-regulated chemokine expression and also inhibited the adhesion and transmigration of leukocytes in Stx-treated HUVEC. These data suggest that Stx-2 via a transcriptional activation mechanism mediated by NFKB upregulates MCP-1 and IL-8, key mediators of leukocyte adhesion and transmigration. 
In D+HUS, thrombotic microangiopathy, defines a lesion of vessell wall thickening and intraluminal platelet thrombosis that occlude the microcirculation of the kidney and other organs. The reason why thrombi form only on arterioles and capillaries is not known. In Chapter 5 we studied whether Stx-1 directly affected endothelial antithrombogenic properties promoting thrombus formation on human microvascular endothelial cells (HMEC-1) under high shear stress. HUVEC were used for comparison, as large vessel endothelium. VT-1 directly induced platelet adhesion on cultured endothelial cells perfused with whole blood in a flow chamber system under shear stress levels high enough to mimic the ones encountered in the microcirculation. This effect was more pronounced on VTtreated endothelial cells of microvascular (HMEC-1) in respect to large vessel (HUVEC) origin, since basal expression of Gb3 receptor in HMEC-1 was 50-fold higher than in HUVEC. In the attempt to identify the adhesive proteins involved in platelet-endothelium interactions elicited by VT-1, we first focused on von Willebrand factor (WWf), which is indispensable substrate to promote thrombus formation. Blocking the binding of WWf to platelet glycoprotein $1 \mathrm{~b}$ by aurintricarboxylic acid and the glycoprotein $\alpha_{\mathrm{lib}} \beta_{3}$ integrin by chimeric 7E3 Fab resulted in a significant reduction of VT-induced platelet deposition, indicating a role of WWf-platelet interaction at high shear stress in this phenomenon. Inhibition of endothelial vitronectin receptor, P-selectin and PECAM-1 with specific antibodies markedly reduced the endothelial surface area covered by thrombi. These data along with the observation of a strong expression of these adhesive proteins due to upregulation/redistribution, on the endothelial surface of HMEC-1 after VT challenge, provide insights on the determinants possibly involved in the process of microvascular thrombosis associated with D+HUS. 
Podocytes are sensitive to the toxic effects of Stx-1 and 2 isoforms; as documented either in cultured cells or in human renal biopsies. Podocytes, a crucial component of the glomerular filter, are highly specialized epithelial cells endowed with foot processes. They possess a contractile structure that respond to vasoactive hormones to control glomerular capillary surface area and in turn ultrafiltration coefficient. Effacement of foot processes occurs in many proteinuric nephropathies and is accompanied by rearrangement of the actin cytoskeleton. Instrumental in studying the effect of Stx on podocytes, in Chapter 6 we first set up the technique to maintain in culture immortalized mouse podocytes and to induce differentiation of podocytes which in this conditions stop to proliferate and express high levels of synaptopodin. Then, we assessed whether protein overload -reproducing the condition of exaggerated plasma protein traffic through the glomerular capillary barrieraffects intracellular pathways, leading to cytoskeletal architecture changes and ultimately to podocyte dysfunction. We have found that in podocytes the abnormal uptake of plasma proteins induces Rho kinase-dependent F-actin cytoskeletal rearrangement leading to cell dedifferentiation. Such structural changes translate into the activation of FAK in turn responsible for NF-kB- and Ap-1 dependent ET-1 gene upregulation. ET-1 overproduction may act on the podocyte contractile apparatus altering the glomerular capillary surface area thus leading to protein permeability dysfunction. These results indicate podocyte as a novel cellular target for the toxic effect of excess plasma ultrafiltered protein.

Since podocytes express Stx specific receptor, are susceptible to Stx citotoxicity and represent an important source of vasoactive molecules, we investigated in Chapter 7 whether Stx-2 modulates the expression and production of the vasoconstrictor peptide, Endothelin-1 (ET-1), taken as candidate mediator of podocyte dysfunction. Stx-2 enhanced ET-1 mRNA and protein through the activation of NF-kB and Ap-1 to the extent that 
transfection with dominant negative mutant of $1 \mathrm{~KB}$ kinase2 or with $\mathrm{Ap}-1$ decoy oligodeoxynucleotide reduced ET-1 mRNA. We further investigated the intracellular signals activated by Stx-2 possibly involved in the upregulation of ET-1 gene. A role for p38 and p42/44 MAPK in mediating NF-kB-dependent gene transcription induced by Stx-2 has been proposed based on data that Stx-2 phosphorylated p38 and p42/44 MAPK and that inhibitors of both MAPK reduced transcription of NF-kB promoter luciferase reporter gene construct induced by Stx-2. Additionally, Stx-2 induced F-actin redistribution and intercellular gap formation via ET-1 induction since cytoskeletal changes were prevented by $E T_{A}$ receptor blockade. Findings that podocyte challenge with $E T-1$ induced podocyte F-actin redistribution and in parallel increased protein permeability, unravel ET-1 as a major mediator of the toxin-induced effect. In summary, our data are the first to document that podocyte is a functionally relevant target of Stx, a novel stimulus for the synthesis of ET-1 synthesis that controls in autocrine and paracrine fashion glomerular remodeling and hemodynamic derangement in HUS. 


$$
2
$$




\section{CURRICULUM VITAE}

Marina Morigi was born in Ravenna, Italy, on August $30^{\text {th }}$ 1961. She took the upper-school leaving the certificate at "Liceo Scientifico Collegio Vescovile S. Alessandro" of Bergamo on 1980. She graduated in Biological Sciences at the University of Milano on December $17^{\text {th }}$ 1987. From January 1988 she had a fellowship from Mario Negri Institute of Pharmacological Research of Bergamo in the Laboratory of Kidney Disease coordinated by Dr. Giuseppe Remuzzi, obtaining a position as Scientist on October 1995 . She had the opportunity to spend some month at Women's Hospital of Boston, working in the laboratory of Prof. Barry Brenner with his collaborator Dr. Philip Marsden, during 1991. On 1996 she became head of the Unit of Renal and Endothelial Cell Biology and since 2000 she is head of the Laboratory of Cell Biology and Xenotransplantation. In these years she has contributed to define the mechanisms underlying endothelial cell dysfunction in thrombotic microangiopathies and hyperacute vascular rejection of xenograft. Moreover, she put her research effort in the identification of inflammatory mediators and mechanisms triggered by exaggerated protein traffic, characteristic of proteinuric progressive nephropathy, using in vitro systems of proximal tubular cells and podocytes exposed to protein overload. Another major research topic has related to the regenerative potential of adult bone marrow-derived stem cells in renal damage by acute and chronic insult in experimental mouse models. She is also involved in stem cell therapy with embryonic stem cells to correct genetic defect characteristic of Fabry disease in experimental K/O mouse model.

Dr. Marina Morigi has authored and co-authored 49 scientific articles and reviews. 



\section{ACKNOWLEDGMENTS}

I wish to express my deep gratitude to Prof. Giuseppe Remuzzi who always supported and encouraged me and my work during these years.

I am indebted to Prof. Karel Leunissen for the opportunity he gave me to discuss my PhD thesis in the prestigious Universiteit Maastricht.

I thank my colleagues and friends, Carla Zoja, Ariela Benigni, Simona Buelli, Manuela Passera, Antoinette van Engelen and Antonella Piccinelli for their continued and helpful collaboration. 